\title{
SUCCESS OF ECOTOURISM SITES AND \\ LOCAL COMMUNITY PARTICIPATION IN \\ SABAH
}

by

Awangku Hassanal Bahar Pengiran Bagul

\author{
A thesis submitted to \\ Victoria University of Wellington \\ in fulfilment of the requirements for the degree of \\ Doctor of Philosophy in Tourism Management
}

Victoria University of Wellington 2009 


\section{TABLE OF CONTENTS}

LIST OF FIGURES.......................................................................... VI

LIST OF TABLES .......................................................................VIII

LIST OF ACRONYMS AND ABBREVIATIONS.....................................IX

ACKNOWLEDGEMENTS.............................................................XI

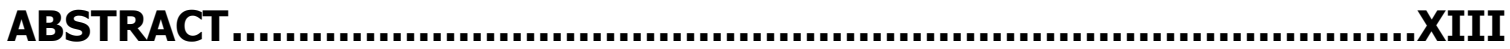

CHAPTER 1. INTRODUCTION .................................................... 1

1.1 IntRoduction to the ReSEARCh Problem ..................................................

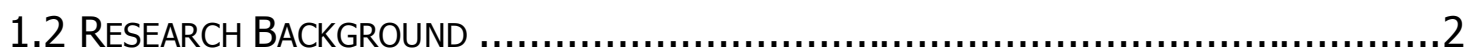

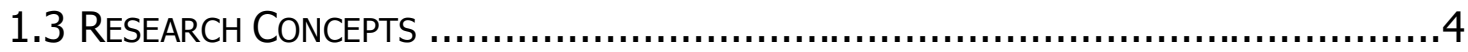

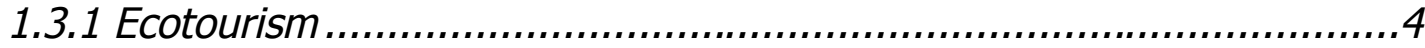

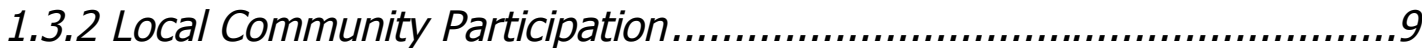

1.4 RESEARCH ISSUES, TASKS AND JUSTIFICATION ...........................................

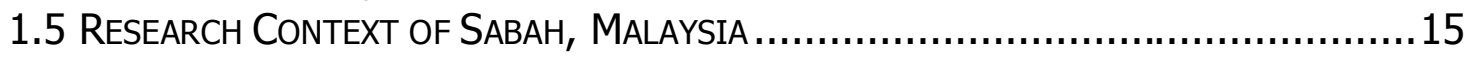

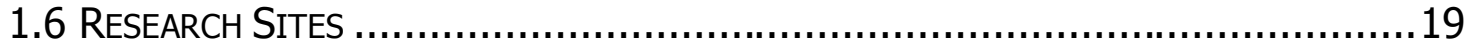

1.6.1 Selection and General Criteria of Research Sites ...........................19

1.6.2 Kampung Bavanggazo............................................................21

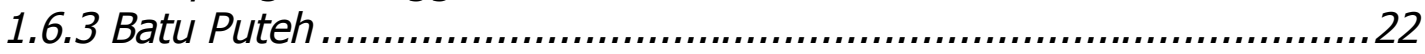

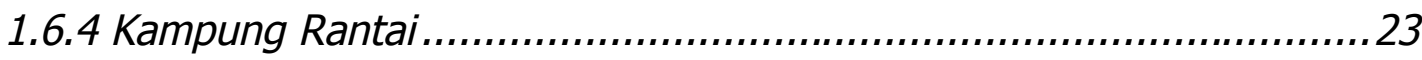

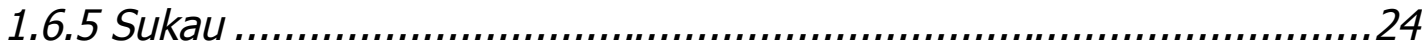

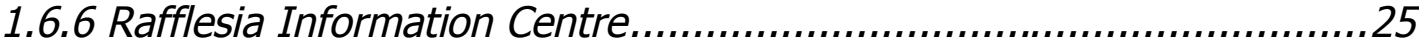

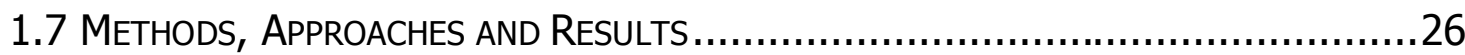

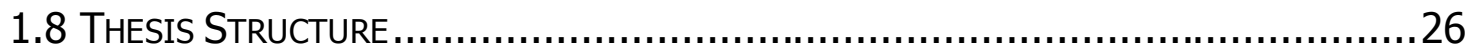

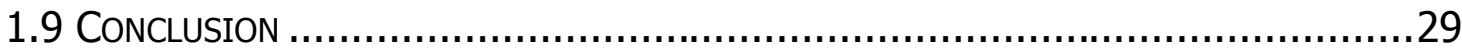

CHAPTER 2. ECOTOURISM AND LOCAL COMMUNITY PARTICIPATION30

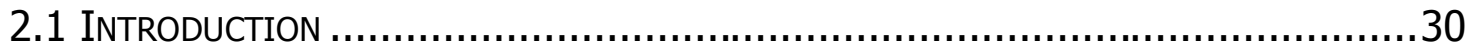

2.1.1 The History of Ecotourism .........................................................

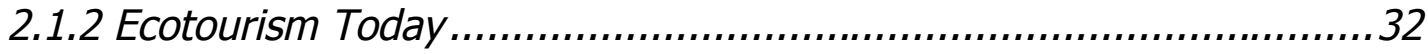

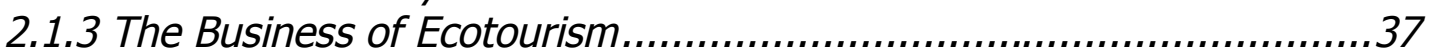

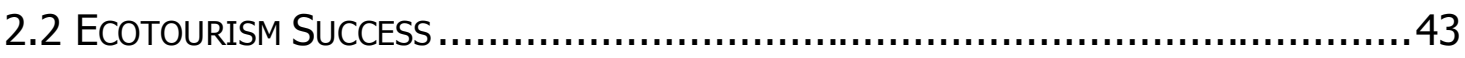

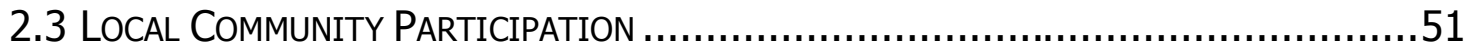

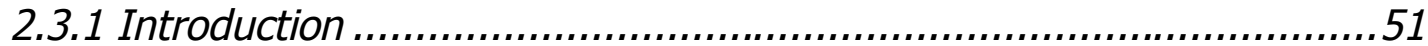

2.3.2 Criticism of Local Community Participation......................................60

2.3.3 Local Community Participation in Ecotourism ................................63 63

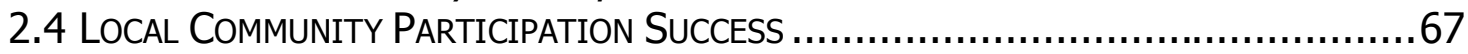

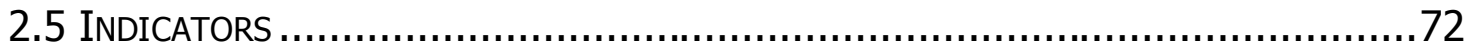




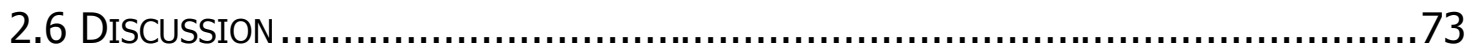

CHAPTER 3. RESEARCH METHODOLOGY ...................................... 75

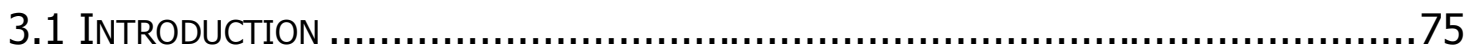

3.2 SELECTION AND JUSTIFICATION OF METHODOLOGY ...................................... 76

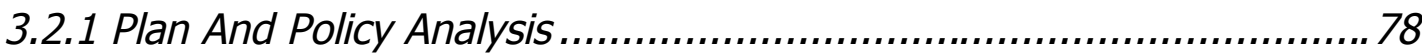

3.2.2 Comparative Case Studies Method ..............................................79

3.2.3 Concept Clarifications, Operational Definitions and Site Selection......81

3.3 DATA COLLECTION METHOD ................................................................ 91

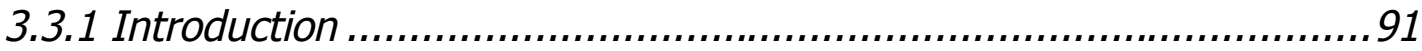

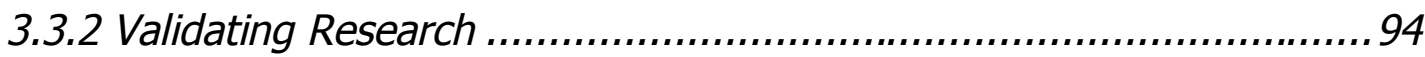

3.3.3 Secondary Data Research......................................................95

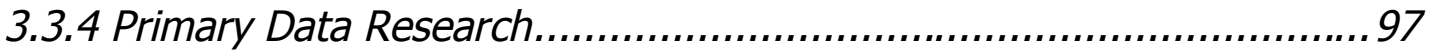

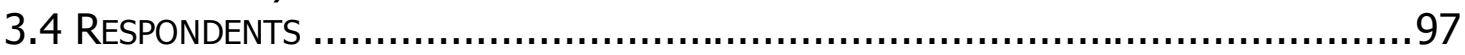

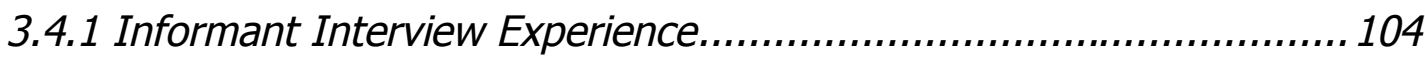

3.4.2 Questionnaire Survey Experience............................................... 106

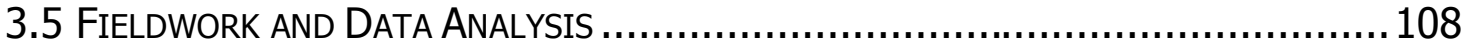

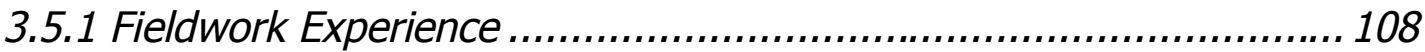

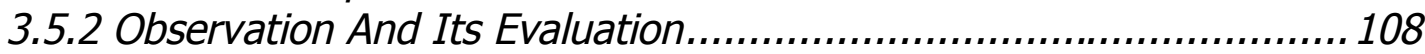

3.5.3 Data Analysis and Indicator Development...................................108

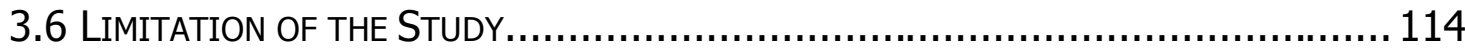

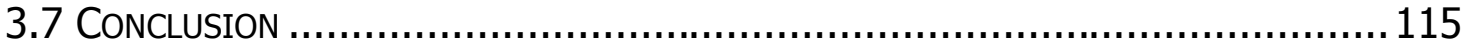

CHAPTER 4. PLANS AND POLICIES ANALYSIS .............................. 117

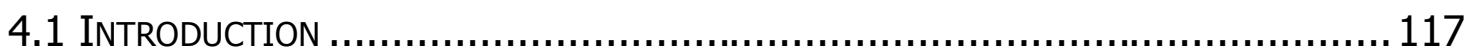

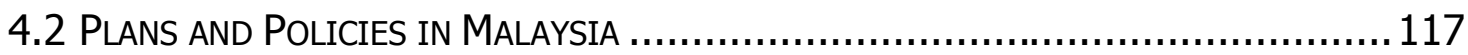

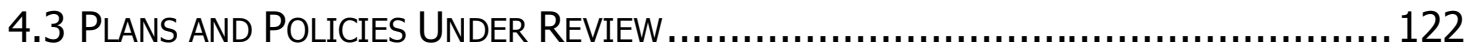

4.4 Review of National LeVel Plans and Policies .................................... 125

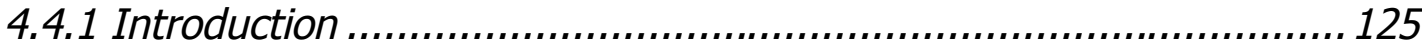

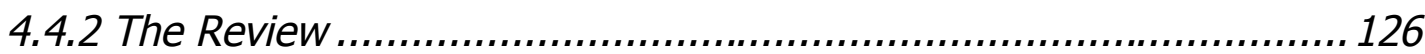

4.5 ReVIeW of State LeVel PlanS And Policies ......................................... 140

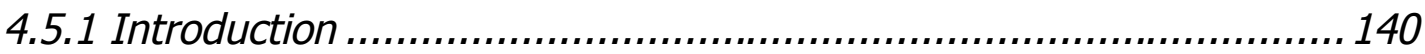

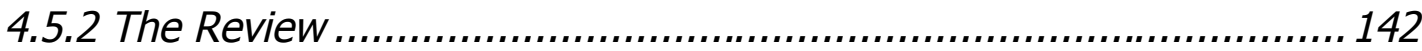

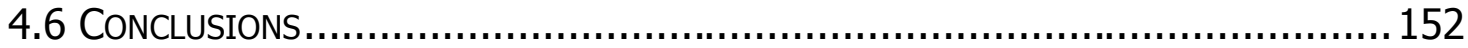

CHAPTER 5 - CASE STUDIES........................................................ 156

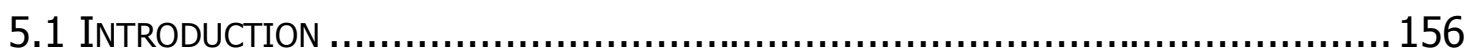

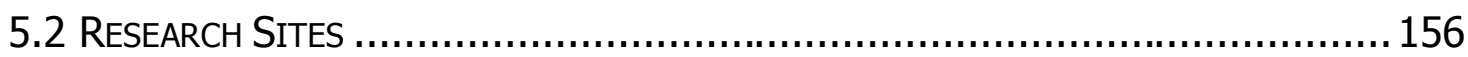

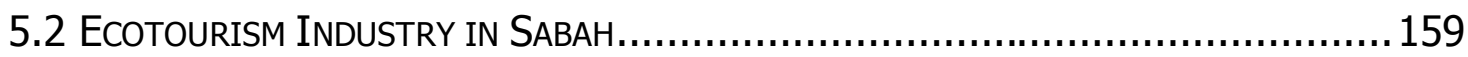

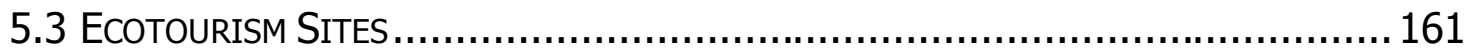

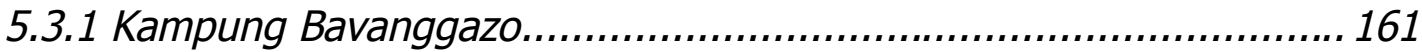

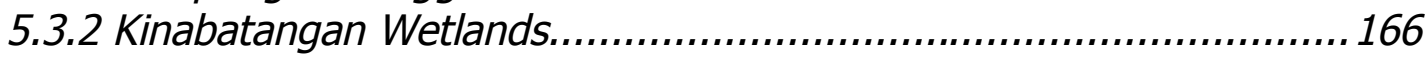

5.3.2.1 Batu Puteh......................................................................... 171

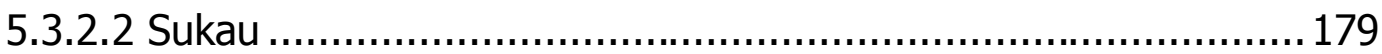


5.3.3 Rafflesia Information Centre................................................... 183

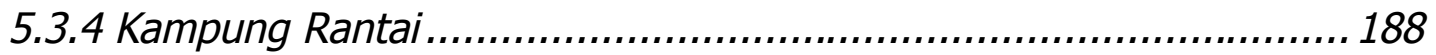

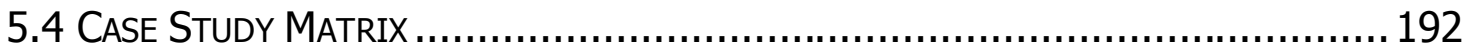

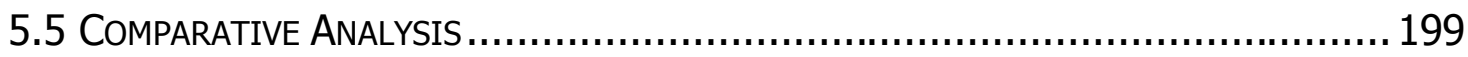

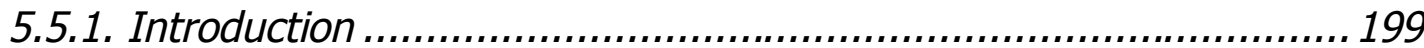

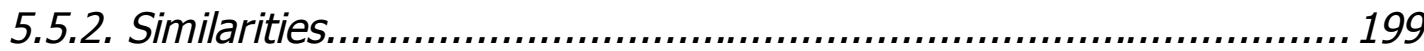

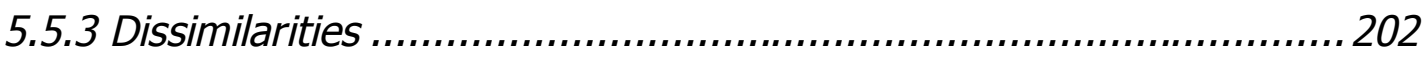

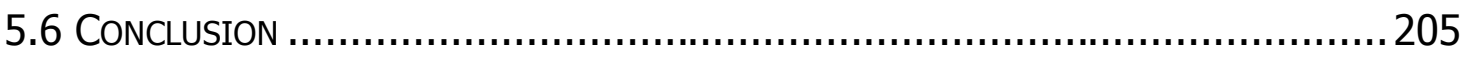

CHAPTER 6. LOCAL COMMUNITY PARTICIPATION SUCCESS ............ 207

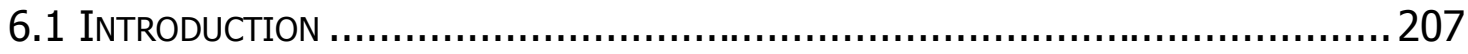

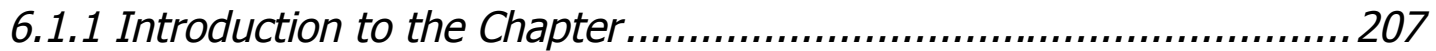

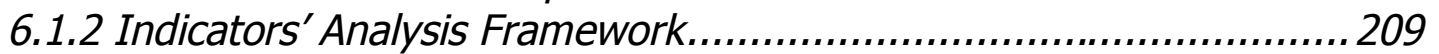

6.2 RESEARCH FINDINGS - GENERAL INDICATORS ........................................ 212

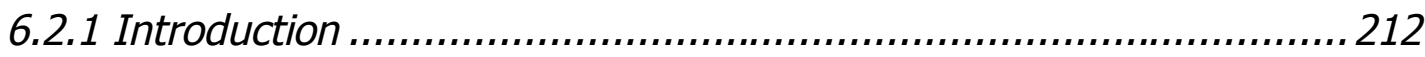

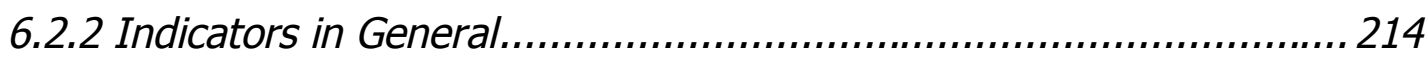

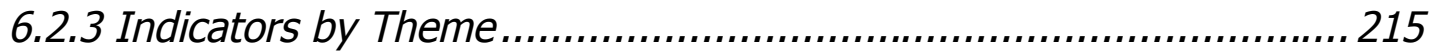

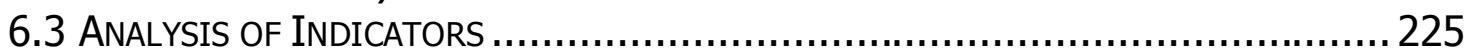

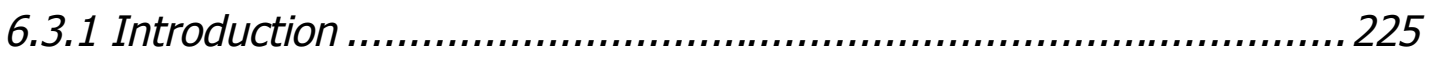

6.3.2 Indicators by Stakeholder....................................................226

6.3.2.1 Analysis of Indicators by Stakeholders ................................ 238

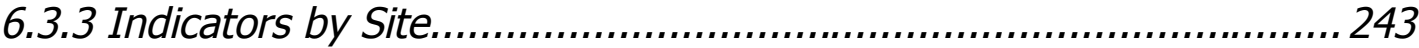

6.3.3.1 Kampung Bavanggazo .................................................... 243

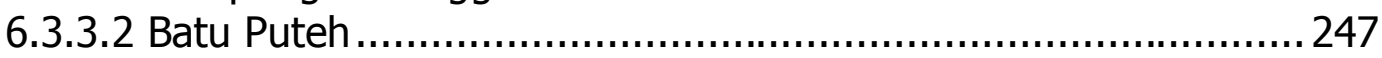

6.3.3.3 Kampung Rantai......................................................... 250

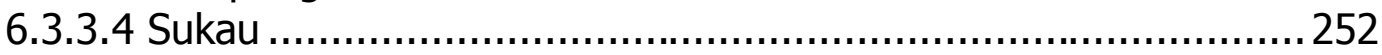

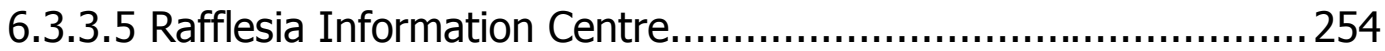

6.3.3.6 Analysis of Indicators by Site.............................................255

6.4. SUCCESS INDICATORS: RESEARCH VS. LITERATURE REVIEW..........................261

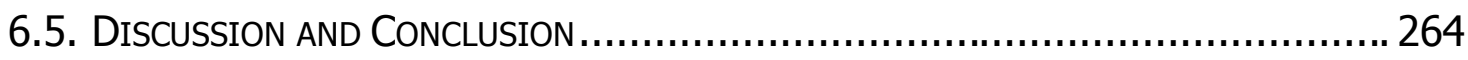

CHAPTER 7. ECOTOURISM SITE SUCCESS.................................... 269

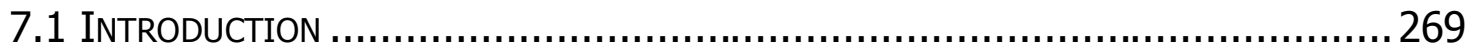

7.1.1 Introduction to the Chapter......................................................269

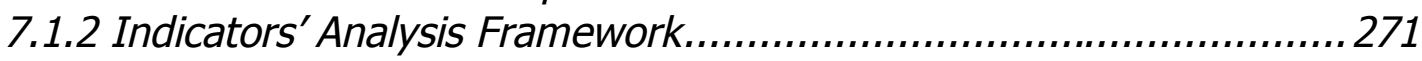

7.2 RESEARCH FinDINGS - GENERAL INDICATORS ..........................................22

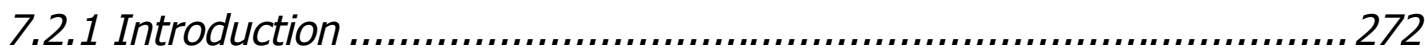

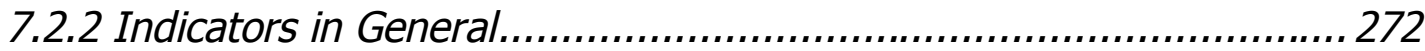

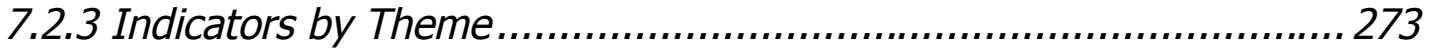

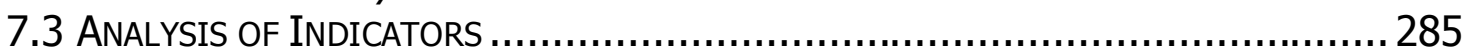

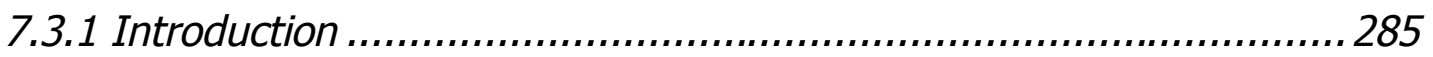

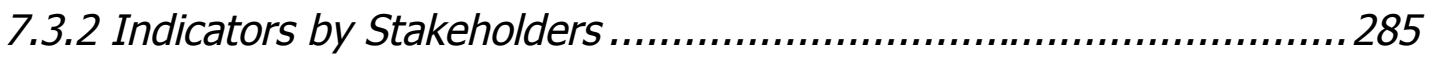

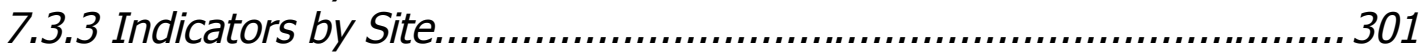

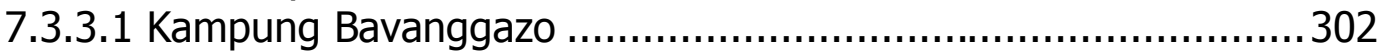




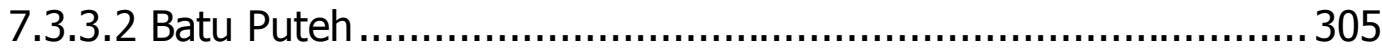

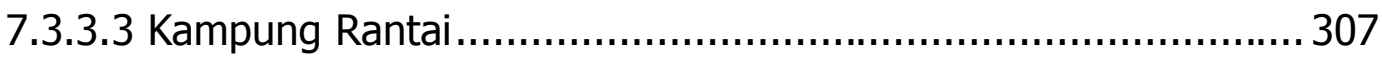

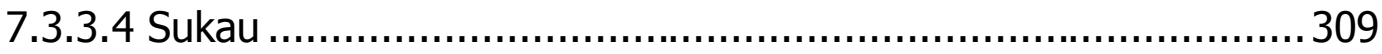

7.3.3.5 Rafflesia Information Centre............................................. 312

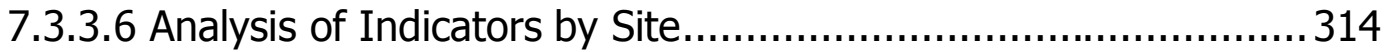

7.4 SUCCESS INDICATORS: RESEARCH VS. LITERATURE REVIEW............................318

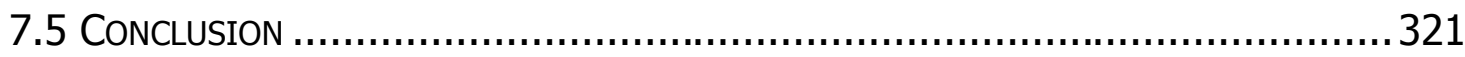

CHAPTER 8. DISCUSSION AND CONCLUSIONS .............................. 326

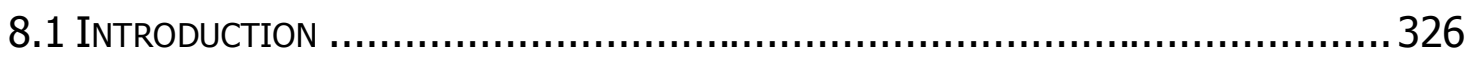

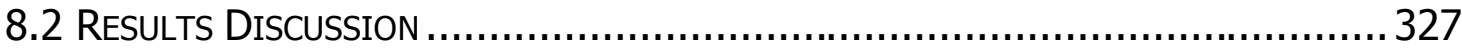

8.2.1 Local Community Participation Success vs. Ecotourism Site Success 332

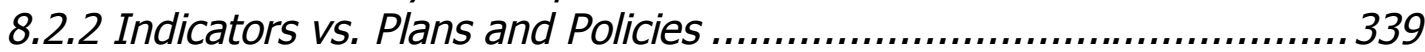

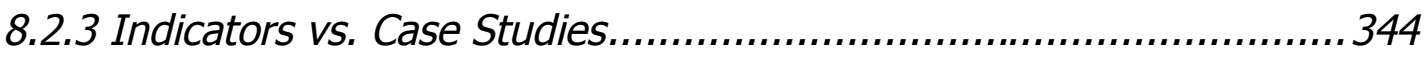

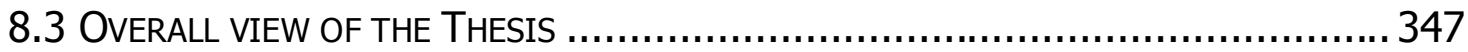

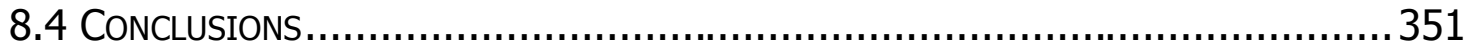

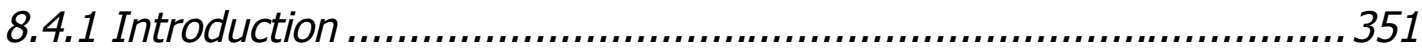

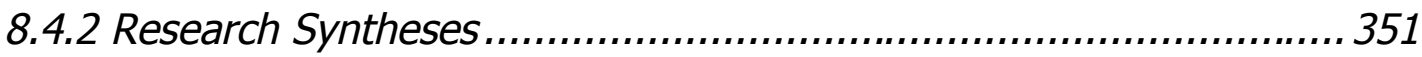

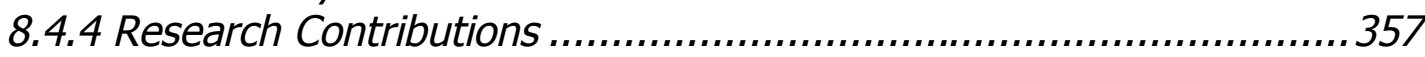

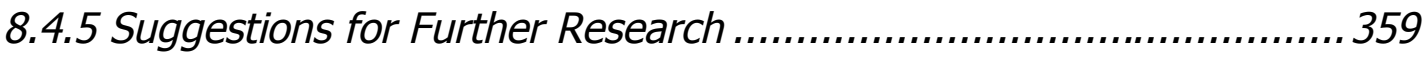

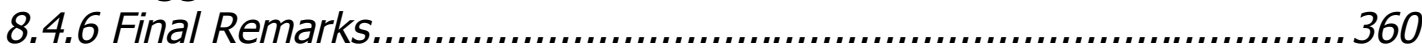

BIBLIOGRAPHY......................................................................... 361

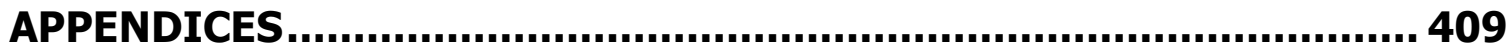




\section{LIST OF FIGURES}

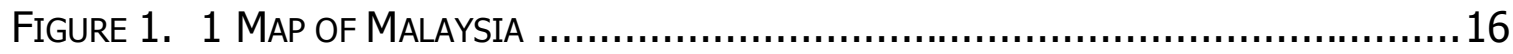

FIGURE 1. 2 MAP OF SABAH ................................................................. 17

FigURE 1. 3 MAP OF ReSEARCH SitES .................................................... 21

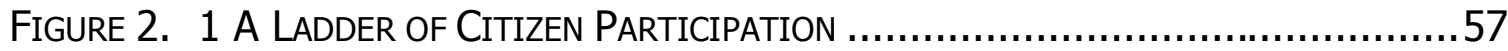

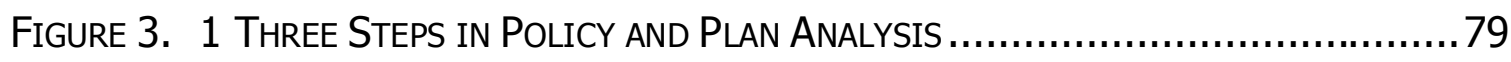

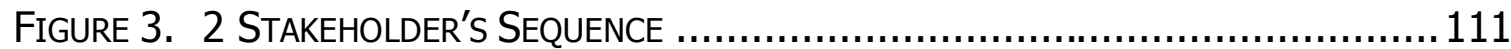

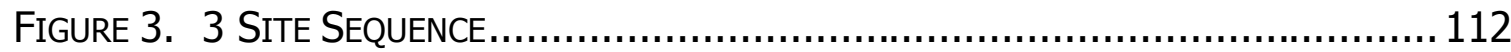

Figure 4. 1 Structure of Plans and Policies Under ReView ........................ 121

Figure 4. 2 Map of Existing, Potential, ANd High Priority Areas As Suggested by National Ecotourism Plan And ReSEARCh AREAS In SABAH......................... 134

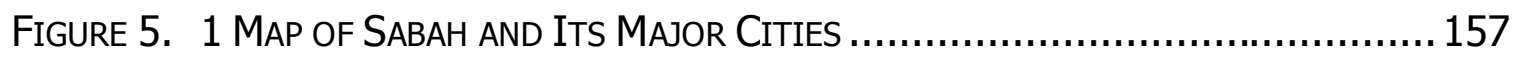

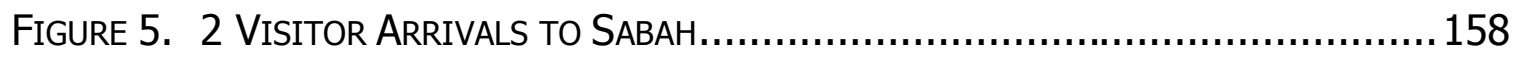

FigURE 5. 3 MAP OF BAVANGGAZO RUNGUS LONGHOUSE.................................. 162

FigURE 5. 4 Visitor ARRIVALS TO BAVANGgAZO RUNGUS LONGHOUSE IN $2003 . . . . . . . . .166$

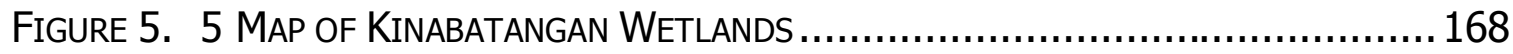

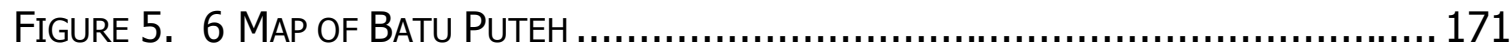

Figure 5. 7 Visitor ArRivals to Batu Puteh, Kinabatangan ............................. 177

FIGURE 5. 8 MAP OF SUKAU.................................................................. 179

FigURE 5. 9 VisitoR ARRIVALS TO SUKAU, KinABATANGAN ................................ 182

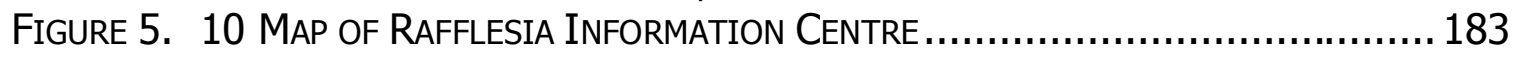

FiguRE 5. 11 Visitor to RafFlesia Information Centre, TAMBUnAN.................... 186

FigURE 5. 12 MAP OF KAMPUNG RANTAI .............................................. 188

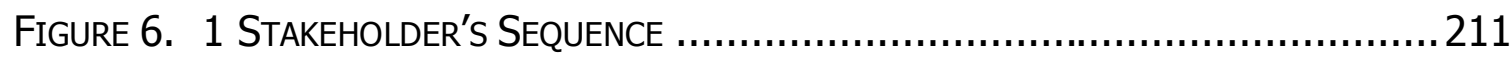

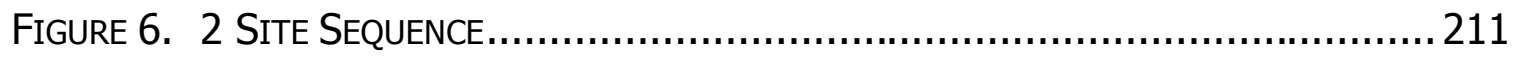

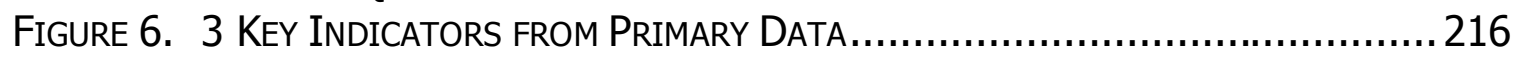

Figure 6. 4 Three Sub-Clusters of Local Community Participation SucCesS

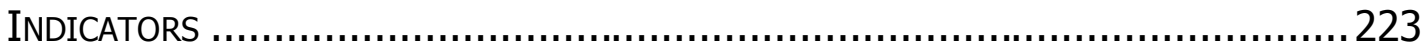

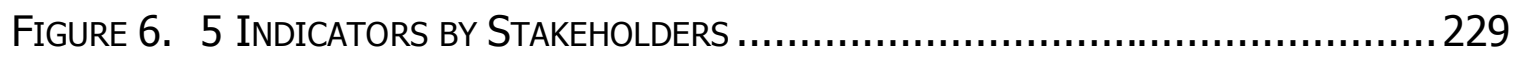

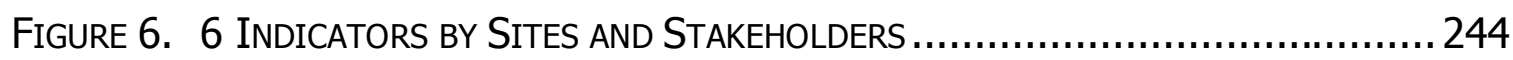

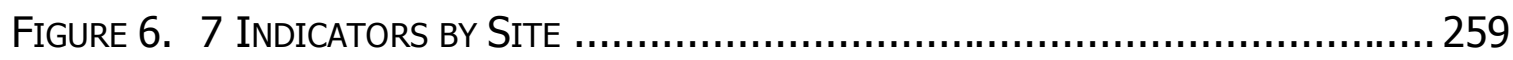

FiguRE 7. 1 ECOTOURISM Site SuCCESS INDICATORS ................................... 275 
Figure 7. 2 Three Sub-Clusters of Local Community Participation Success

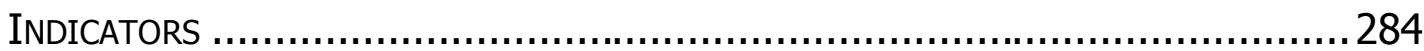

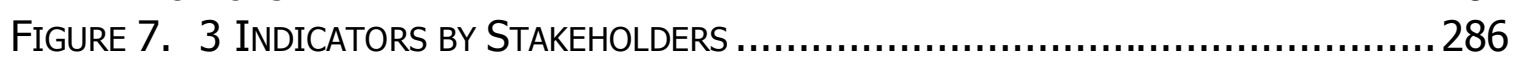

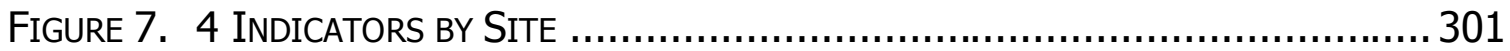

FigURE 8. 1 LOCAL COMMUNITY PARTICIPATION SUCCESS INDICATORS.........................329

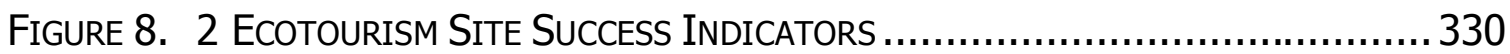




\section{LIST OF TABLES}

Table 2. 1 Other Type Of Tourism With Similar Concept to ECOtOURISM...............36

TABLE 2. 2. ECOTOURIST MARKET PROFILE ....................................................42

TABLE 2. 3 ECOTOURISM SUCCESS INDICATIORS FROM LITERATURE REVIEW....................50

Table 2. 4 A Typology of Participation: How People Participate in DeVelopment

PROGRAMS AND PROJECTS....................................................................54

TABLE 2. 5 FACTORS FOR LoCAL COMMUNITY PARTICIPATION IN ECOTOURISM.................66

TABle 2. 6 LoCAL COMmUNity PARTICIPATION SUCCESS FROM LiteratURE REVIEW .........71

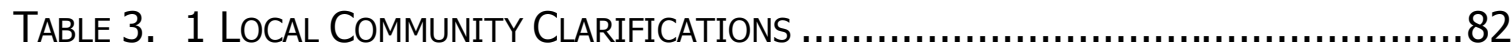

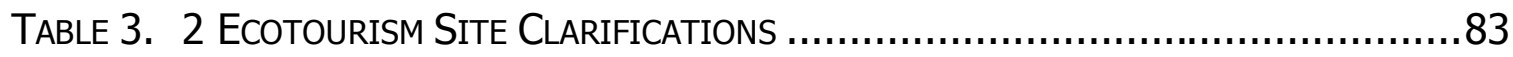

TABLE 3. 3 LOCAL COMMUNITY PARTICIPATION CLARIFICATIONS .................................. 84

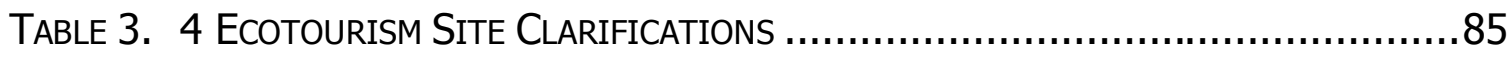

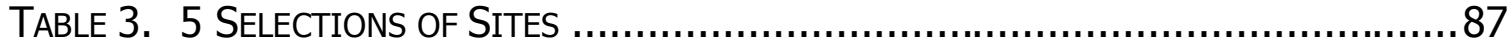

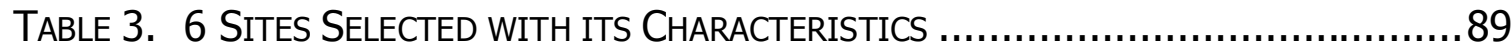

TABle 3. 7 Six SOURCES OF EVIDENCE: StRENGTHS AND WEAKNESSES ........................99

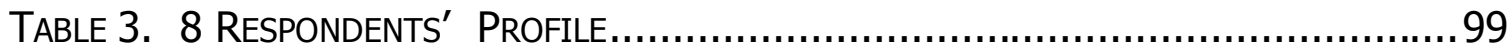

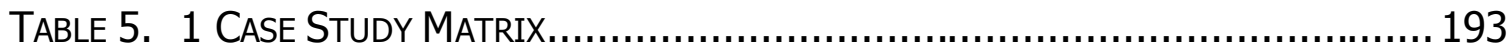

Table 6. 1 Local Community Participation SucCess from the Literature ReView 262

TABLE 7. 1 ECOTOURISM SuCCESS IndicATORS FROM THE LITERATURE REVIEW ..............319

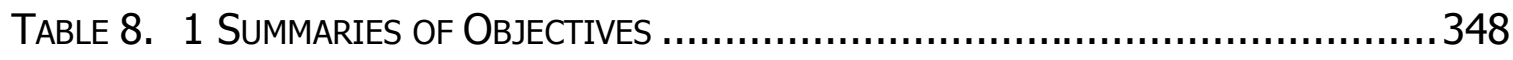




\section{LIST OF ACRONYMS AND ABBREVIATIONS}

ASEAN

BIMP-EAGA

COMMACT

DANCED

EAC

GTZ

IDS

ITBC

IUCN

JICA

JKKK

$\mathrm{Kg}$.

KPD

Corporation)

MAMAKAT

MESCOT

MICE

MNS

MOCAT

MOCET

MTCE
Association of Southeast Asian Nations

Brunei Darussalam-Indonesia-Malaysia-Philippines-East ASEAN Growth Area

Common Wealth Network for People-Centred Development

Danish Cooperation for Environment and Development

Environmental Action Committee (Sabah)

Deutsche Gesellschaft für Technische Zusammenarbeit

Institute for Development Studies

Institute for Tropical Biology and Conservation

International Union for Conservation of Nature

Japan International Cooperation Agency

Jawatankuasa Kemajuan dan Keselamatan Kampung (Village

Development and Security Committee)

Kampung (Village)

Koperasi Pembangunan Desa (Rural Development

Koisaan Misompuru Manampasi Koburuon om Koubasanan Tulun Tokou/Persatuan Kerjasama Memulihara Kemajuan dan Kebudayaan Masyarakat Desa (Rural Community Conservation, Development and Culture Cooperative Society) Model Ecologically Sustainable Community Based Conservation and Tourism

Meetings, Incentives, Conventions and Exhibitions

Malaysian Nature Society

Ministry of Culture, Arts and Tourism (Malaysia)

Ministry of Culture, Environment and Tourism (Sabah)

Ministry of Tourism, Culture and Environment 
MTEST

(Sabah)

NDP

NVP

NGO

OPP2

OPP3

PACOS

PRA

RRJP2

RM

RRA

SBE

SEA

SEPA

SPE

TIES

UKM

UMS

UN

UNEP

VDSC

VMS

VUW

WTO

WWF
Ministry of Tourism, Environment, Science and Technology

National Development Plan

National Vision Policy

Non-Governmental Organisation

Second Outline Perspective Plan

Third Outline Perspective Plan

Partners of Community Organisations

Participatory Rural Appraisal

Rangka Rancangan Jangka Panjang Kedua (RRJP2) or Second Outline Perspective Plan (OPP2)

Rancangan Malaysia (Malaysia Plan)

Rapid Rural Appraisal

School of Business and Economics (UMS)

South East Asia

Sabah Environmental Protection Association

Sekolah Perniagaan dan Ekonomi (School of Business and Economics)

The International Ecotourism Society

Universiti Kebangsaan Malaysia (The National University of Malaysia)

Universiti Malaysia Sabah

United Nations

United Nations Environment Programme

Village Development and Security Committee

Victoria Management School

Victoria University of Wellington

World Tourism Organisation

World Wide Fund for Nature 


\section{ACKNOWLEDGEMENTS}

First and foremost, I would like to thank my supervisor, Prof. Doug Pearce, who has been working with me on this thesis. His support and detailed comments have helped me shape my ideas, realise my aims and complete this thesis. I owe him a depth of gratitude that cannot be measured. The support of the Public Service Department of Malaysia, Universiti Malaysia Sabah and Victoria University of Wellington has been essential to the development and completion of this thesis.

I would also like to thank the Tourism Group at Victoria Management School, especially Mrs. Linda Walker, whose constant patience made working at the school more bearable. To my PhD colleagues and friends, Dr. Davina Stanford, Dr. Guilherme Palhares-Lohmann, Chris Botrill, Dr. Wayne Pihema, Chootima Longjit, Jorge Ivan Vélez-Castiblanco, Dr. Jovo Atelvajic, Joan Enric Capellà i Cervera and Neil Plimmer, thank you so much for being there for me. You have all been wonderful to me. My special thanks go to the Tourism Masters and Honours students, who were my constant source of inspiration. I would also like to thank the wonderful people at Victoria Management School, Prof. John Davies, Dr. Mondher Sahli, Dr. Brad Jackson, Prof. George Lafferty and Dr. Sally Davenport, for their support.

My particular thanks are due to my peers in Malaysia especially to Pauline Chin of Sabah Tourism Board, Fauziahton Awang Samad of Kota Kinabalu City Council, Zawawi Tiyunin and Wan Shawaluddin Wan Hassan of Universiti Malaysia Sabah for their assistance in providing materials for my thesis. Not forgetting the wonderful people that I met during my fieldwork who have given me so much help and comfort while doing my thesis. Thank you to John Arnold Sienna and Brenda Ann Lajingah for the editing work. 
To my wonderful close and true friends, Zahrin Adabi, Yusuf Ibrahim, Emil Johan Dato' Ismail, Mohamad Hafizan Ahmad Zaini, Yang Mulia Raja Intan Mahtera Raja Kamaluddin, Nazrul Syafnizah Dato' Abdul Raman, Norsita Sa'at-Adabi, Mohamad Hazwan Dato' Abdullah, Wan Mohamad Zahuri Yahaya, Soudalayphone Paseuth and Martin Leng Fu, you have all made my life in Wellington enjoyable and more meaningful. A special thanks to my sister, Dayangku Hassanah Irdawati, for managing my PhD finance. To Tim and Suriah Burns, thank you for taking care of me and giving me a lot of support while I was in Wellington. Deep appreciation for Liu who supports me in doing my amendments.

Lastly, to all the members of my family, I sincerely thank each and every one of you from the bottom of my heart for your continuous love and support, and for moulding me into the person I am today. 


\section{ABSTRACT}

Sabah, Malaysian Borneo, is an ecotourism destination that is well known in the international tourism scene, where nature and culture has been positioned as the two main products. With high biodiversity and more than 30 distinctive cultures, ecotourism has been embraced by all stakeholders in the state since the 1990s. After a decade or so, many stakeholders are very eager to judge and give judgments of what success entails. The complexity of the stakeholders' characteristics usually results in various perceptions of success. The thesis sets out to interpret and develop the indicators for success of local community participation and ecotourism sites in Sabah. Both, local community participation and ecotourism site were chosen due to the nature of the ecotourism industry where business and community development is very closely tied together. This thesis employs plans and policy analysis and comparative case study as its methodology. The data were then analysed to get the results, which are success indicators for local community participation and ecotourism sites based on the perception of stakeholders. The indicators emerged from the analysis are put into perspective by analysing the results with the analysis of plans and policies and case studies. Two sets of indicators are proposed, both for local community participation success and ecotourism site's success, which is valuable to the industry in reviewing their current plans and policies. It is also useful in monitoring and evaluating current local community participation activities. The indicators are quite consistent with those others drawn from the literature review. The analysis also shows that there are issues that need to be addressed with regards to these indicators. These indicators are output-based, therefore there is a need to establish the measurement or the parameters of these indicators to make it more quantifiable and more meaningful. Another aspect that the thesis identified is that the strongest indicators are those that were agreed by all stakeholders and the recipients that benefits are both the site and 
the local community. While this is emphasising the importance of local community in the ecotourism set up, it is also suggested that a set up of an integrated development and management among stakeholders, of local community and ecotourism with the common objective and common operational process, are seen as successful. This will contribute to tourism literature by enhancing the knowledge of ecotourism, and to the ecotourism industry by providing a means of evaluating local community participation activities and ecotourism sites. 


\section{CHAPTER 1. INTRODUCTION}

\subsection{Introduction to the Research Problem}

Tourism is a global industry with a bearing on the lives of millions of people. Its potential as a tool for development is enormous. With a growing interest to spend leisure time in nature and increasing awareness of environmentalism, ecotourism has become one of the fastest-growing segments of the tourism industry (United Nations, 2001). Compared with mass or 'old' tourism, ecotourism is touted as providing better sectoral linkages, reducing leakage of benefits out of the country, creating local employment, and fostering sustainable development (Belsky, 1999; Khan, 1997). Thus, it has been popularly promoted as a means of reconciling wildlife conservation with economic development, particularly in developing countries (Campbell, 2002). Ecotourism is characterised by its natural attractions, wildlife and wilderness habitats. Many countries favour ecotourism as a form of economic development as it is perceived as a low impact form of tourism. Ecotourism operations are generally small-scale, so are relatively easy to set up. Carefully planned and operated ecotourism sites, especially if it is village-based and includes local participation, is able to provide direct benefits that might offset pressure from other less sustainable activities that make use of natural and cultural resources. Duffy (2002) suggested that the development of ecotourism is also a response to criticism of the socially and economically divisive effects of mass tourism.

Ecotourism has presented opportunities for spreading and maximising economic benefits in a sustainable manner to villages, remote areas and national parks. However, this is only possible when government policies aim to have more tourism in these areas and the local people have the opportunity to participate in 
the process. Local community participation in ecotourism is naturally political as it relates to how groups and individuals are empowered and have control over their lives. It is advocated for various noble reasons. More importantly, the community will be affected by a project or a decision, so naturally they should have an active role and influence in every level of decision-making and planning. Local communities may benefit in economic terms as well as create a commitment to conservation and sustainable development. However, the reality of local community participation is somewhat more complicated as it is seldom straightforward. Since local community participation plays a vital role in ecotourism, the success of an ecotourism project depends to some extent on the success of local community participation. There is always the question of the effectiveness of community participation. This thesis intends to explore the perception of success of ecotourism sites and local community participation with reference to five ecotourism sites in Sabah, Malaysia.

\subsection{Research Background}

This research is largely influenced by considerable personal and professional experience in research and by a number of consultations in the area of rural tourism development. Frequent visits to the rural communities on a professional and personal capacity over the years in Sabah have left a large impression that there are varieties of participation in ecotourism ranging from handicraft making to eco-lodge ownership. Many locals who were interviewed were eager to be included, at varying levels of participation, in ecotourism projects. Most of them have the notion that ecotourism will improve their current economic conditions and thus improve their living conditions. There are many levels of participation ranging from decision-making to manipulative participation. The existence of participation in an ecotourism project sometimes does not reflect the true meaning of local community participation especially if it is a manipulative 
participation and the locals do not benefit or are bearing the costs of ecotourism development. This thesis' primary intent is to explore the issues and context of the success of local community participation. This will relate to the success of the ecotourism site, where local community participation is an integral part of success in ecotourism. 


\subsection{Research Concepts}

The essential concepts employed in this thesis are presented here. The two fundamental concepts clarified here are ecotourism and local community participation. They provide the fundamental understanding of the thesis. The main concepts that surround this thesis are further elaborated in the literature review chapter.

\subsubsection{Ecotourism}

Within one of the world's fastest growing industry of travel and tourism today, there are growing niche markets, one of which is ecotourism. Many developed and developing countries now have some sort of tourism policy. Most developing countries recognize tourism at the ministerial level and there are a host of agencies addressing policy issues such as promotion and marketing, infrastructure and training. Virtually every country has an association catering to private sector tourism interests, and many also have joint government-private consultative bodies (Ceballos-Lascuráin, 1996).

Ecotourism is always linked to the essential, distinctive nature of its location. It is also hailed as a potential sustainable development tool resulting from the growing threat to cultural and biological diversity posed by the growth of global tourism. The declaration of the year 2002 as International Year of Ecotourism by World Tourism Organisation (WTO) reflects the importance of ecotourism in a global tourism industry. Ecotourism is generally defined by its sustainable results: conserving natural areas, educating visitors about sustainability, and benefiting local people (Epler Wood, 2002). True ecotourism can in fact be one of the most powerful tools for protecting the environment. 
The International Ecotourism Society (TIES) produced one of the earlier definitions in 1991:

"Ecotourism is responsible travel to natural areas that conserve the environment and sustain the well being of local people"

Ecotourism is a sub-component of the field of sustainable tourism. The ecotourism components as summarised below offer a reflection of where ecotourism can be placed within the process of developing more sustainable forms of tourism (Epler Wood, 2002):

I. Contributes to the conservation of biodiversity.

II. Sustains the well-being of local people.

III. Includes an interpretation/learning experience.

IV. Involves responsible action on the part of tourists and the tourism industry.

V. Delivered primarily to small groups by small-scale businesses.

VI. Requires lowest possible consumption of non-renewable resources.

VII. Stresses local participation, ownership and business opportunities, particularly for rural people.

The last component suggests the need and importance of local community participation in ecotourism projects that can result in providing benefits to them. Ecotourism advocates the relationship between ecotourism development and the local community to its ability to provide development alongside environmental care. It is promoted as a means of ensuring that conservation is financially viable through the development of revenue-generating schemes for the locals. 
Butler (1992) has come up with nine characteristics that qualify an activity as an ecotourism activity: -

I. It promotes positive environmental ethics and fosters 'preferred' behaviour in its participants.

II. It does not degrade the resource. In other words, it does not involve consumptive erosion of the natural environment.

III. It concentrates on intrinsic rather than extrinsic values. Facilities and services may facilitate the encounter with the intrinsic resource, but never become attractions in their own right, and do not detract from the natural resource.

IV. It is oriented around the environment in question and not around man. Ecotourists accept the environment as it is, neither expecting it to change or to be modified for their convenience.

V. It must benefit the wildlife and environment. The question of whether or not the environment (not just people) has received 'benefits' can be measured socially, economically, scientifically, managerially and politically. At the very least, the environment must attain a net benefit, contributing to its sustainability and ecological integrity.

VI. It provides a first-hand encounter with the natural environment.

VII. It actively involves the local communities in the tourism process so that they may benefit from it, thereby contributing to a better valuation of the natural resources in that locality.

VIII. Its level of gratification is measured in terms of education and/or appreciation rather than in thrill-seeking or physical 
achievement; the latter is more characteristics of adventure tourism.

IX. It involves considerable preparation and demands in-depth knowledge on the part of both leaders and participants. The satisfaction derived from the experience is felt and expressed strongly in emotional and inspirational ways.

It is true that ecotourism must be sustainable but it has to be a viable business too. Ecotourism industry players have to develop their products and offerings to meet the demands of the tourism market and attract travelers. Operators have to make money to survive. The key is to develop a financially successful ecotourism business while protecting or even enhancing the natural environment. Involvement from other interests or stakeholders such as the government are crucial in terms of funding, knowledge and concern.

The future growth and direction of the tourism sector has been further influenced by the 'Earth Summit' (United Nations Conference on Environment and Development), held in June 1992, in Rio de Janeiro, Brazil. It sought agreement amongst world leaders on the concept of 'sustainable' use of resources.

This extended articulation of the definition of ecotourism was adopted by the 2002 World Ecotourism Summit. It distinguishes ecotourism from sustainable tourism by the addition of specific principles in relation to

"...conservation of the natural and cultural heritage, inclusion of local and indigenous communities in the planning, development and operation of ventures, thus contributing to their well-being; interpretation of the natural and cultural heritage of the destination 
to visitors; and preferring independent travelers and small groups" (World Ecotourism Summit 2002)."

The Summit declaration (The Quebec Declaration):

"...affirm that different forms of tourism, especially ecotourism, if managed in a sustainable manner can represent a valuable economic opportunity for local and indigenous populations and their cultures and for the conservation and sustainable use of nature for future generations and can be a leading source of revenue for protected areas,

...emphasise that at the same time, wherever and whenever tourism in natural and rural areas is not properly planned, developed and managed, it contributes to the deterioration of natural landscapes, threats to wildlife and biodiversity, marine and coastal pollution, poor water quality, poverty, displacement of indigenous and local communities, and the erosion of cultural traditions,

...acknowledge that ecotourism development must consider and respect the land and property rights, and, where recognized, the right to self-determination and cultural sovereignty of indigenous and local communities, including their protected, sensitive and sacred sites as well as their traditional knowledge,

...stress that to achieve equitable social, economic and environmental benefits from ecotourism and other forms of tourism in natural areas, and to minimise or avoid potential negative 
impacts, participative planning mechanisms are needed that allow local and indigenous communities, in a transparent way, to define and regulate the use of their areas at the local level, including the right to opt out of tourism development."

In summary, ecotourism is currently held to sit within four parameters, which are 1) it involves interaction with the natural environment; 2 ) it has an educational component (i.e. is designed to increase understanding of the environment and how it works); 3) it is done with a light ecological footprint; and 4) it is managed by businesses that are developed and run by local communities. The fourth parameter will become a large and important part of this thesis.

\subsubsection{Local Community Participation}

Human communities represent primary resources upon which tourism depends. Their existence in a particular place at a particular time may be used to justify the development of tourism itself. The basic reason for tourists to travel is to experience the way of life and material products of different communities. Communities also shape the 'natural' landscapes, which many tourists consume. Communities are, of course, also the source of tourists; tourists are drawn from particular places and social contexts, which in them will help shape the context of the tourists' experience in the host community (Richards and Hall, 2000).

'Community' is a subject often talked about and discussed, but it is not easy to pinpoint its exact meaning as the term is usually more complicated than one expects. The word 'community' implies a common interest, possession or enjoyment. It contains both physical and emotional elements, starting with the point it occupies in a particular area, which can be bounded physically by geographic landmarks such as rivers and mountains or simply by the proximity of 
the population, as in a small town. A community has a system of social organisation and activities as well as common ties ranging from family and heritage to making a living in similar ways. A community has a 'sense of place' within the landscape and/or historically, and usually possesses a range of traditions and values (Beeton, 1998). This can be applied to both indigenous and non-indigenous communities regardless of their sizes. The community is often treated as relatively homogeneous, with little internal conflict. Such assumptions of consensus themselves imbue 'community' with implicit ideological underpinnings.

Local community participation in any form of development is advocated for various noble reasons and is often rhetorical and permeated with lofty sentiments. According to Bachrach and Botwinick (1992), participation can lead to an enhanced sense of one's self-worth, and the self-exploration this involves also enables people to discover what their own real interests are. It is often argued that the community, who are affected by a project or a decision, should have an active role and influence in every level of decision-making and planning. Elements of a community approach to planning would appear to provide a basis for the formulation of tourism policies which would assist both local communities and visitors. In the long term, this would satisfy local desires to control the rate of change, if any, and meet visitors' interests in the maintenance of unique attributes of a destination (Hall, 2000). Community participation in the tourism planning process may generally be understood as the involvement of individuals within a tourism-oriented community in the decision-making and implementation process with regards to major manifestations of political and socio-economic activities. Nature-based tourism and ecotourism are particularly linked closely with the local community. 
Tourism development is generally the prerogative of entrepreneurs or special interest groups in communities, most of which treat tourism like other commercial forms. On the other hand, there is a growing support for communitybased approaches to tourism planning (Reid et. al, 2004). Ecotourism stresses that local business owners and communities must be involved. Opportunities to involve rural communities in tourism have attracted attention, and raised many expectations (Epler Wood, 2002). Without proper preparations, the risks in fostering local community participation in ecotourism ventures or projects are great. It is strongly advocated that the local community must be informed in advance of all the possible consequences of any tourism development. The local community involved must receive economic benefits and other tangible benefits (i.e. water, roads, health clinics) from the ecotourism project and its tourist facilities. Facilities such as eco-lodges, restaurants or campsites should be run by or in partnership with the local community. It is also recommended that the local community must formally consent to development in their area.

Local community participation at certain levels empowers the community to determine the direction of their development. Empowerment may thus be regarded as a developmental concept. Individual, family and community growth and potential are enhanced by empowerment and it may be viewed as either a process or an outcome (Sofield, 2003). Although empowerment is a concept which is implicit in most versions of 'sustainability', it is always assumed that a distributive form of empowerment to local communities is from the top, rather than generative empowerment from within.

The United Nations system in general, and the World Tourism Organisation in particular, have always encouraged national authorities to develop participative mechanisms in their activities. Participation of communities is considered not 
only necessary in ecotourism policy construction, but as its main justification as well.

\subsection{Research Issues, Tasks and Justification}

There are numerous studies on local community participation in ecotourism. Community participation is very much emphasised and encouraged, with many academics agreeing that it is a critical component for ecotourism success. It is therefore said that the success of ecotourism depends largely on the success of local community participation. However, comprehensive insights into both the success of local community participation and the success of ecotourism sites are still limited. The studies on the success indicators of local community participation in the ecotourism industry and ecotourism sites are even more limited. Some studies that focus on success indicators are not specific to the ecotourism field, but rather on general tourism areas or some other specialised field such as sustainable tourism (WTO, 1996). Therefore, the measures and indicators that are available in tourism literature do not capture the intention of this research, however they are useful in giving guidelines to the research.

As mentioned before, from previous professional and personal experiences, it is very enlightening to entertain various ideas and thoughts that came across from various people on the subject of success. Within a very short span of Sabah's ecotourism industry, many stakeholders are very eager to judge and give judgments of what success entails. This is due to the nature of ecotourism and its local participation where business and community development are very closely tied together and monitored by many for various reasons grounded in monetary and political factors. The complexity of the stakeholders' characteristics usually results in various perceptions of success. However, there are one or two notions that many of them agreed upon among themselves. This has become an 
interesting prospect for a thesis, where these thoughts and ideas can be analysed more systematically and be used in an academic manner. Based on academic reviews and experiences, two research issues were formulated that formed the main direction of this thesis.

The first research issue is interpreting and developing the indicators for success of local community participation in ecotourism sites in Sabah. The ecotourism concept states that local community participation is deemed a critical component in ecotourism operation. This view is supported by writers such as Epler Wood (2002), who suggested that the success of local community participation contributes to the success of ecotourism as a whole. A set of indicators for local community participation success based on this issue is valuable to the industry in reviewing their current plans and policies, and is useful in monitoring and evaluating current local community participation activities.

The second research issue is interpreting and developing the indicators for success of ecotourism sites in Sabah. Ecotourism success is generally indicated by the health of its business operations, since it is very much a business in nature. Other general success indicators are the positive impacts that it brought to the area and its community. A set of indicators for ecotourism site success that are based on this issue is valuable to the industry in reviewing their current plans and policies, and is useful in monitoring and evaluating current ecotourism projects.

Both issues are related to each other. The first research issue is a subset of the second research issue. In view of these research issues, it is expected that the success of both local community participation and ecotourism sites have considerable differences as different stakeholders (who are the respondents) also 
viewed and perceived success differently. The two sets of indicators developed at the end of the thesis will be useful in outlining the dimensions of indicators by looking into their characteristics. This will contribute to tourism literature by enhancing the knowledge of ecotourism, and to the ecotourism industry by providing a means of evaluating local community participation activities and ecotourism sites.

Based on the research issues, two key research questions emerged. They are:

I. What is success for local community participation?

II. What is success for ecotourism sites?

The research objectives that are derived from the research questions can be achieved in completing the research tasks. They are:

I. Determine what local community is in the context of Sabah.

II. Determine what makes a site an ecotourism site in the context of Sabah.

III. Analyse plans and policies that are relevant to local community participation and ecotourism sites in Sabah.

IV. Establish case studies for research sites.

V. Develop the indicators for local community participation success.

VI. Develop the indicators for ecotourism site success.

VII. Analyse the sets of indicators based on plans and policies, and case studies.

This thesis therefore contributes to a greater understanding of local community participation and ecotourism. It will give guidelines to the local community 
participation advocates to execute, evaluate and monitor local community participation more effectively through greater understanding. Ecotourism stakeholders may benefit from this thesis in terms of gaining knowledge in establishing, operating and evaluating a successful ecotourism site. The indicators that are developed in this thesis can be further used as a baseline standard to measure success. Last but not least, the thesis will also fill some of the gaps in tourism literature on the issues of success for local community participation and ecotourism.

\subsection{Research Context of Sabah, Malaysia}

Malaysia (Figure 1.1.) has one of the most vibrant and developed economies in South East Asia, enjoying political stability and industrial growth. A federation of 13 states and three federal territories, Malaysia is South East Asia's major tourist destination offering excellent ' $3 \mathrm{~S}$ ' (sun, sea and sand), bustling cities, and spectacular flora and fauna. Tourism has become Malaysia's second largest and most dynamic industry and also the second biggest contributor of foreign revenue. Malaysia received 17.3 billion in 2000, a 40\% jump from the RM12.3 billion in 1999; in addition, RM2 billion in corporate tax and RM500 million in service tax, putting real earnings from tourism at RM20 billion (Daily Express, 2003). 


\section{Eigure 1. 1 Map of Malaysia}

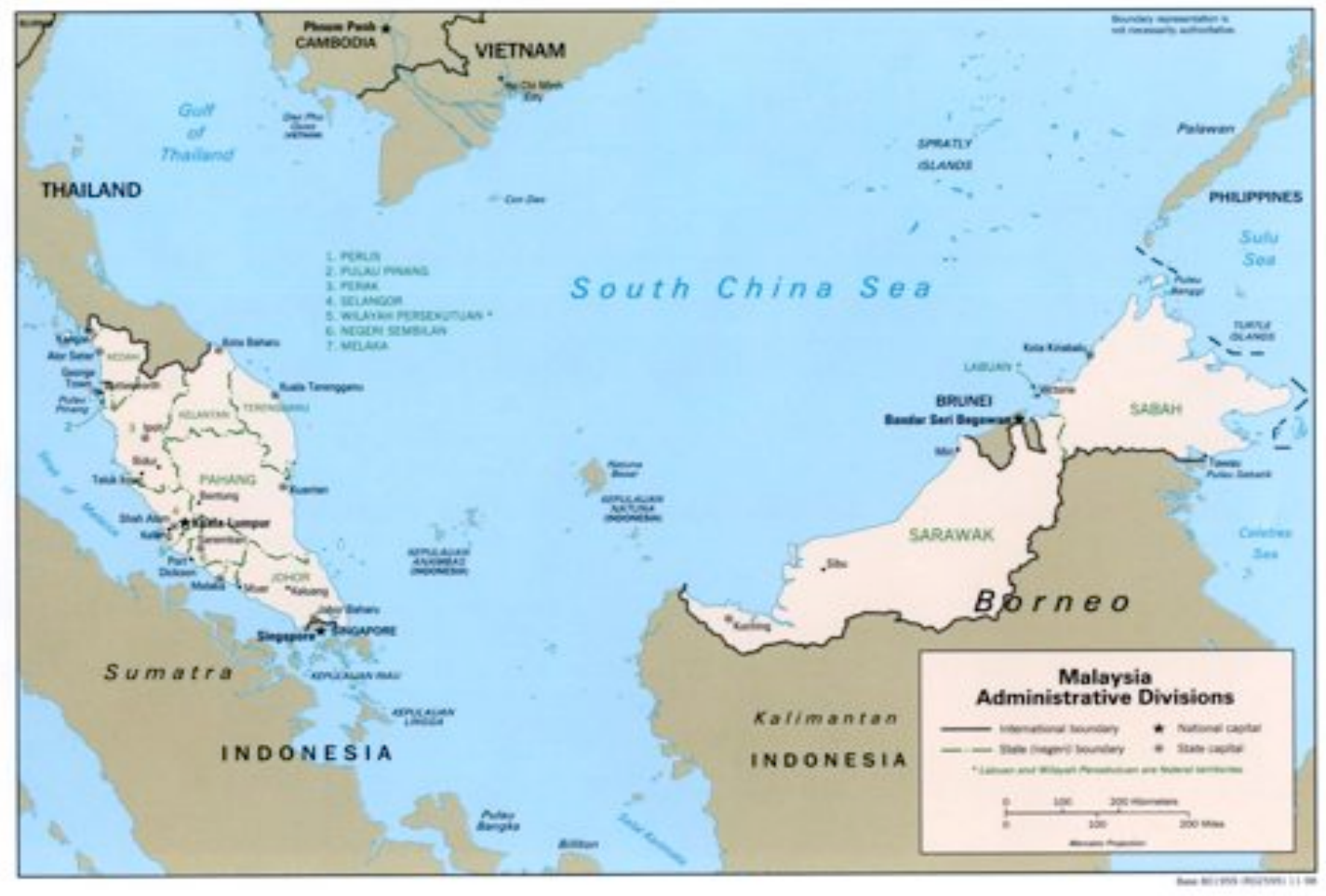

Source: Central Intelligence Agency (2004) 
Figure 1. 2 Map of Sabah

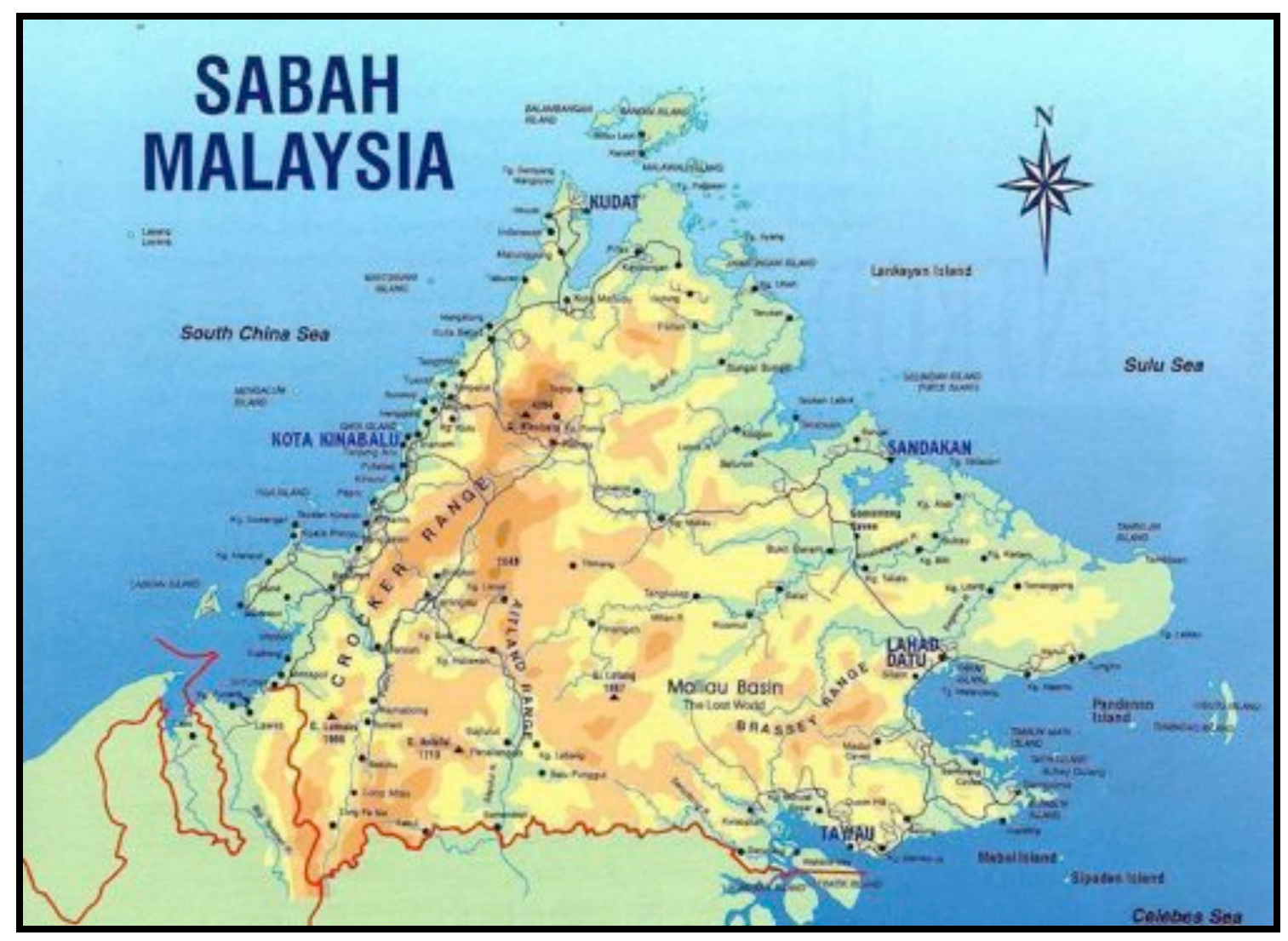

Source: Sabah Tourism Promotion Board (2004) 
Sabah, one of the thirteen Malaysian states, is located in the northern part of Malaysian Borneo (Figure 1.2), covering an area of 73,620 sq. km. It is a melting pot of many different cultures and traditions, being home to about 2.9 million people with more than 30 ethnic groups. It is also known as one of the twelve mega-diversity sites in the world with its rich living heritage, which makes it ideal for the ecotourism industry. It has world-class tourism products such as the highly pristine Sipadan Island, one of the top dive sites in the world, and Kinabalu Park, Malaysia's first World Heritage Site.

Since the 1980s, tourism has grown as an increasingly important industry in Sabah, reflected by the Federal Government through the doubling of its allocation for Sabah tourism projects from RM5.36 million under the Sixth Plan (1991-1995) to RM11.1 million under the Seventh Malaysia Plan (1996-2000). Tourism receipts amounted to RM1, 091 million in 2002, which is a significant contribution to Sabah's economy (Sabah Tourism Board, 2004). Approximately 9,000 people were employed in the industry by year 2000 and today it has over 255 hotels with more than 10,000 rooms.

Sabah enjoys a steady flow of ecotourists from domestic and international markets with a gradual increase in the number of visitor arrivals each year. These tourists are mainly from the United Kingdom, Germany, Sweden and other European countries such as Denmark, Italy, Switzerland and France. The rest of the ecotourists come from the Americas, Oceania, ASEAN ${ }^{1}$ countries with Singapore as a major contributor and Asian² countries (Sabah Tourism Board, 2004). Sabah, one of the states of Malaysia, is eager to develop ecotourism.

\footnotetext{
1 ASEAN comprises of Brunei Darussalam, Cambodia, Indonesia, Laos, Malaysia, Myanmar, Philippines, Singapore, Thailand and Vietnam.

2 The major markets from Asian countries are Japan, Taiwan and Hong Kong.
} 
The introduction of ecotourism in Malaysia and Sabah in the early 90s led to the development of Sabah Ecotourism Guidelines a few years later. Faced with an encouraging prospect, Sabah decided to position itself as a nature and culture destination and came up with a theme, 'Sabah Natur(e)ally' at the beginning of the millennium.

The recently published 'Sabah State Development and Progress Direction' in year 2004 by the Chief Minister of Sabah indicates that the Sabah tourism sector is set to expand to achieve a bigger contribution to its Gross Domestic Product. It envisions attracting a higher number of tourists through more intensive strategic marketing, infrastructure improvement and introduction of new products to new niche markets. It targets around 2.7 million tourists annually within 5 years where the tourists are mainly from the nature tourism segment.

\subsection{Research Sites}

There are generally 15 ecotourism sites throughout Sabah that fit into the definition of ecotourism. They are spread all over the state, with a high concentration on the east coast. These sites offer various ecotourism experiences ranging from passive activity such as wildlife watching to active activities such as mountain climbing. Out of the 15 sites in Sabah, only five were selected for this thesis due to their feasibility. The five selected are based on their characteristics that fit the concepts outlined in this thesis.

\subsubsection{Selection and General Criteria of Research Sites}

The selection of research sites is based on specific characteristics that are derived from the research operational ecotourism concepts and definitions. This is further elaborated in the methodology chapter. It is essential to do an 
independent selection, as there are ecotourism sites that may not comply with the recommended ecotourism guide. The ecotourism sites selected also conformed to the Sabah Ecotourism guidelines. The characteristics below have been useful in identifying research sites.

I. Type of activities - The activities at the selected ecotourism sites must have the prime motivation of observation and appreciation of natural features and related cultural assets.

II. Type of attractions - Selected ecotourism sites must have at least one flagship attraction. This refers to distinctive elements of natural and/or cultural heritage, which are found at the site.

III. Community involvement - Selected ecotourism sites must have a degree of local community participation at any level.

IV. Eco-practices - The area and facilities at the selected ecotourism sites should incorporate at least one eco-practice such as incorporating eco-design in its facilities, environmental zoning, nature trails management, refuse treatment practices, employing local communities and similar concepts.

V. Status of site protection - Selected ecotourism sites must be in or adjacent to an area with protection status such as World Heritage Site, Wildlife Sanctuary and Forest Reserve.

These characteristics were initially based on secondary research and the research sites were selected after an initial research on all the ecotourism sites including long-distant informant interview and discussion with thesis supervisor. Five ecotourism sites (Figure 1.3) were selected based on these criteria: 1) 
Kampung Bavanggazo; 2) Batu Puteh; 3) Kampung Rantai; 4) Sukau; and 5) Rafflesia Information Centre.

\section{Fiqure 1. 3 Map of Research Sites}

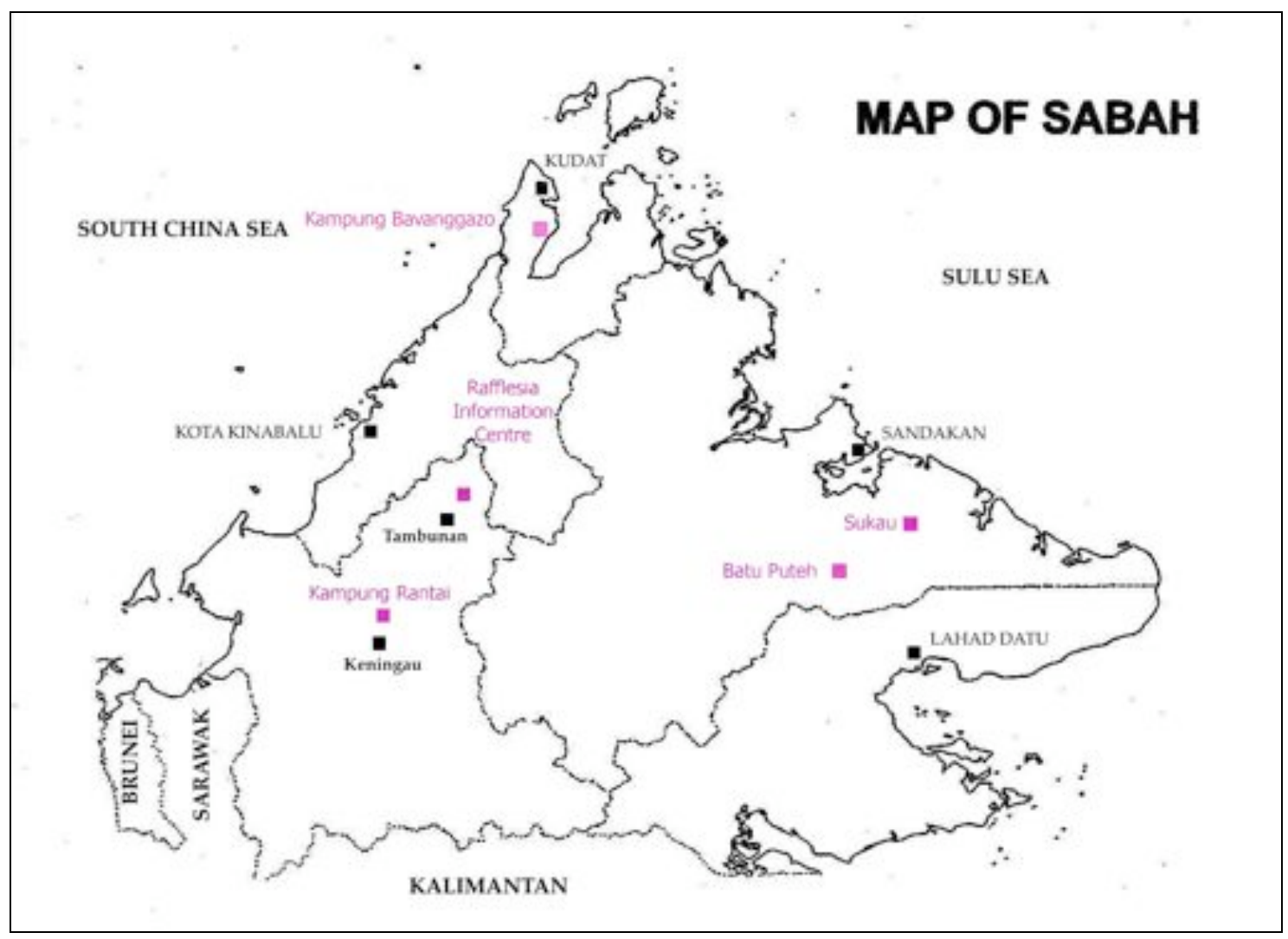

\subsubsection{Kampung Bavanggazo}

Kampung Bavanggazo is a village in the district of Kudat, in the northern part of Sabah. It is $130 \mathrm{~km}$ from the capital city, Kota Kinabalu, and inhabited by the Rungus ethnic group. There are only 40,000 Rungus people in Sabah, found only in the Kudat and Bengkoka Peninsula at the Northern Tip of Sabah, which makes them unique. Kampung Bavanggazo is famed for its Bavanggazo Rungus Longhouse, which is a living museum showcasing the culture and livelihood of 
the Rungus people including the nature surrounding the village. It is a family-run operation on a micro-scale, which was started in 1992. Only nine families were involved initially and these families lived in Bavanggazo Village, which is gazetted as a Village Reserve.

Sabah Tourism Board promotes the Rungus tribe as a very rare tribe, as its population is marginal in the context of world population. Almost all the villagers are farmers and the women are quite renowned for their handicraft-making skills. Bavanggazo Rungus Longhouse offers homestay experiences where tourists stay in a traditional longhouse and get involve in cultural activities and explore the natural surroundings. Locals use natural materials from the surrounding area to build the longhouses. Items such as food are either made or purchased locally. The staff are the villagers themselves. Income earned through the operations of the Bavanggazo Rungus Longhouse serves as their secondary income only. Handicrafts are sold at the village shop and sometimes taken to the capital city of Kota Kinabalu to be sold there. A big number of walk-in tourists, mostly foreigners, visit Bavanggazo Rungus Longhouse usually in groups using tour operators.

\subsubsection{Batu Puteh}

Batu Puteh is located in the Kinabatangan district located 6 hours away from Kota Kinabalu, on the East Coast of Sabah. The village itself is located within Malaysia's largest river flood plain and is partly gazetted as a Wildlife Sanctuary Area due to the high quality of nature all around it. The Orang Sungai ethnic group inhabits Batu Puteh where most of them are small-scale farmers and fishermen. Quite a number of the communities are involved in a group called MESCOT (Model Ecologically Sustainable Community Based Conservation and Tourism), which was established in 1998. WWF-Malaysia and Ministry of Tourism, 
Culture and Environment have been responsible in facilitating the establishment of MESCOT.

One of the major activities of MESCOT is the Miso Walai homestay. It is a wellknown program and the village has received an international award and a national award for the outstanding display of community participation in the ecotourism industry. Miso Walai homestay program offers an experience of the Sungai lifestyle and customs along with ecotourism activities involving appreciating the wildlife and pristine natural environment of Kinabatangan wetlands. Tourists have the chance to contribute back to the environment by joining the rainforest tree plantation program for rehabilitation of the surrounding natural environment. There are also campaigns for village landscaping, cleaning up litter and monitoring illegal logging activities. Miso Walai receives a great number of foreign tourists, usually brought by specialised tour operators. MESCOT has been working on aspects such as training guides and providing business fundamentals needed to operate homestay services, boat services and other ecotourism-related activities. Plans for the future of Miso Walai include development of the eco-resort, ongoing work to strengthen community capacity and continued sustainable growth.

\subsubsection{Kampung Rantai}

Kampung Rantai is 131 km away from the capital city, Kota Kinabalu and located near Keningau town, which is in the interior of Sabah. About 300 people populate the area and all of them are from the Dusun ethnic group.

Apart from a few government servants, most of the villagers are self-employed farmers with ginger as their main produce. Their livelihood is still very much dependent on subsistence farming. Selling of handicrafts made from rattan and 
bamboo from the surrounding forest, which is gazetted as a Virgin Forest Reserve, is another important source of income. The village has formed an association called MAMAKAT (Koisaan Misompuru Manampasi Koburuon om Koubasanan Tulun Tokou/Persatuan Kerjasama Memulihara Kemajuan dan Kebudayaan Masyarakat Desa/Rural Community Conservation, Development and Culture Cooperative Society), which involves all the villagers and is governed by elected committee members. MAMAKAT is responsible for tourism operations. Tourists live in a homestay, experiencing the Dusun lifestyle and customs, while enjoying the natural surroundings. There is also an agro-tourism farm nearby and visitors are able to go to the Bundu Apin-Apin Saturday market, which is a major weekly event for the villagers. Tourists to Kampung Rantai are usually local Sabahans. Ecotourism activities are done at the village and its surrounding area, whereby visitors can visit the pristine jungle and Rafflesia sites, while staying with the local community. The villagers opt for ecotourism since they feel that it can help to conserve the village area from the encroaching timber company, while trying not to change the landscape of the village.

\subsubsection{Sukau}

Sukau, which is situated on the East Coast of Sabah, has the highest ecotourism lodge concentration in Sabah. It is 8 hours away from the capital city, Kota Kinabalu, and is located at the Kinabatangan Wetlands, one of the richest ecosystems in the world. A large part of it has already been gazetted as a Wildlife Sanctuary Area.

Tourists started coming to the lower Kinabatangan area in the late 1980s, mainly to Kampung Sukau, Kampung Abai and Batu Puteh. However, the number of tourists was small and the visits were infrequent. Kampung Sukau has evolved into a prominent ecotourism destination because of its close proximity to the 
scenic Menanggul tributary where the world famous endemic monyet bangkatan or proboscis monkey can easily be spotted during a river cruise, and the historical Gomantong Caves where edible swallow nests, which are as valuable as gold, are collected. At present, Sukau receives a steady stream of visitors, mostly foreigners, from all over the world. The villagers are from the Sungai ethnic group and they are mainly government servants and self-sufficient farmers and fishermen. Some of the youth are hired to work at the lodge. One local owns a lodge, while urban-based tour operators own the others. Visitors usually follow a scheduled tour, which consists of river cruising for wildlife observation during sunrise and sunset, exploring the river and oxbow lakes nearby and wildlife watching at night in the jungle. There are usually optional activities such as exploring the nearby Gomantong Caves or having tea with the locals in their homes.

\subsubsection{Rafflesia Information Centre}

Rafflesia Information Centre is located at the Rafflesia Virgin Forest Reserve near Tambunan town, which is $58 \mathrm{~km}$ from Kota Kinabalu. The centre serves as the entrance to the Virgin Forest Reserves around it, which spans 365 hectares.

It is run by the Forestry Department of Tambunan and employs local villagers around Tambunan as Forest Rangers and guides. Many ethnic groups live in Tambunan although the Dusun ethnic group dominates. Visitors can go jungle trekking to see the biggest flower in the world, the Rafflesia, and learn more about the flower at the centre. Aside from the flower, visitors can enjoy the natural highland environment where the weather is temperate as it is located 1000-1500 above sea level. The Mahua Waterfall in the nearby national park is also an added attraction of the Rafflesia Information Centre. The Rafflesia Information Centre accommodates a high number of visitors from locals and 
overseas alike. Besides being a tourist attraction, the Rafflesia Information Centre is also involved in rehabilitation work of the Rafflesia flower.

\subsection{Methods, Approaches and Results}

This thesis employs plans and policy analysis and comparative case study as its methodology. It starts with an extensive literature review that helps clarify concepts and explore the issue of success in local community participation and ecotourism sites. The secondary research also assisted the development of plan and policy analysis, which is presented in Chapter Four. After a large part of the secondary research had been completed, primary research was conducted during the second year of the research. This involved informant interviews and a questionnaire survey of selected respondents. The data were then analysed to get the results as outlined in Chapter Three. The results are success indicators for local community participation and ecotourism sites based on the perception of stakeholders. The discussion in Chapter Eight will put the indicators into perspective by analysing the results with plans and policies and case studies. Details of the outlined methods, approaches and results are presented in Chapter Three.

\subsection{Thesis Structure}

This thesis consists of eight chapters altogether. Chapter One introduces the necessary background and concepts used in the thesis. This will provide the reader with the research needs, problems and issues. An initial introduction to all the five sites selected for the thesis research is provided here.

Chapter Two illustrates the need for and the importance of this thesis in the body of knowledge. It will provide an in-depth discussion and analysis of the 
theoretical background to the topic, concentrating on the core concepts of ecotourism and its role in development. The discussion will cross over the boundary of tourism to a broader discussion of local community participation as it has evolved through social theory. Both will focus on the success themes of local community participation and ecotourism sites. The discussion is concluded with the identification of issues and gaps of the theory and justifies the thesis position within the gap.

Chapter Three presents the methodology employed. It opens with methodological consideration and justification with a discussion on the selection of the methodologies and an in-depth exploration and application of plans and policies with comparative case study method. Concept clarification is also featured here. Data collection methods are also outlined focusing on the secondary research process and the primary research process, which revolves around the informant interview process and analysis, and questionnaire survey process and analysis. A comprehensive discussion on data analysis and indicators development will be presented at the end of the chapter.

The analysis and results are divided into four chapters. Chapter Four discusses the policy and plan for ecotourism set out by the federal and state governments. This chapter is useful as a setting for the research results where comparison and analysis can be made.

Chapter Five outlines the case studies selected for this research. It looks at the ecotourism and local community participation in Sabah in detail. It covers the evolution of the ecotourism industry in Sabah with its expectations and contributions. Comparative case studies analysis is done using a case study matrix. The analysis is outlined and also useful as a setting and further analysis for the research results. 
Chapter Six provides an analysis of local community participation success. It identifies themes, which emerged from the analytical part of the thesis research and expanded with further discussion. Success of local community participation is defined according to the research context and the success indicators that were brought into light from the analytical process are explored that can be put into perspective at the discussion chapter. Patterns of the indicators will be suggested in this chapter.

Chapter Seven provides the analysis of ecotourism site success. It also identifies themes emerging from the analytical part of the thesis research and is expanded with further discussion. Success of ecotourism sites will be defined according to the research context and local community participation indicators identified from the analysis are put forward in this chapter. Patterns of indicators will be suggested in this chapter. The result is further discussed in the discussion chapter. Chapter Six and Seven are similar as they use the same analytical framework but using different themes.

Chapter Eight focuses on analysis and the discussion of the results in chapters Four, Five, Six and Seven, and concludes the thesis. Insights on the relationship between success of ecotourism site and local community participation will also be discussed. The indicators that emerged from the results will be comparatively analysed based on three settings, which are 1) literature reviews, 2) plans and policies, and 3) case studies. This highlights the nature of the indicators in all settings. This chapter will conclude the thesis by revisiting the research objectives and questions and discussing how the research has met its expectations. It also reinforces the importance of this thesis with respect to its implications to the body of knowledge, policy and practice. Recommendations 
for essential aspects of ecotourism and local community participation will be outlined.

\subsection{Conclusion}

This thesis provides comprehensive insights into the success of local community participation and ecotourism sites with reference to Sabah. It provides an extended body of knowledge to the existing studies in the field and supplements extensions to the existing success indicators. In the next chapter, tourism literature focusing on ecotourism and local community participation are scrutinised and thoroughly analysed. The issues and gaps that are identified from the literature review process are presented thereby justifying the research issues. Based on the extensive literature review, there has not been an attempt to measure success of local community participation and ecotourism sites. There are works on sustainable tourism indicators that the World Tourism Organization or WTO was involved in, in the early 1990s (Weaver, 2006). These indicators provide a basic framework for sustainable tourism management in any destination. Specific indicators can be used for specific environments and sites such as coastal zones, mountains, urban areas and small islands. It is hoped that the indicators that has been developed could provide the fundamentals in indicators for local participation and ecotourism sites, while also adding knowledge to developing qualitative indicators, in general. 


\section{CHAPTER 2. ECOTOURISM AND LOCAL COMMUNITY PARTICIPATION}

\subsection{Introduction}

The literature review will span around ecotourism and local community participation. Within the topic of ecotourism, the history of ecotourism is studied to get the feel of the evolution of the field and why there is much emphasis on nature. The definition of ecotourism is also explored to draw out the important elements in the ecotourism concept. Here, local community participation is identified as one of the important elements. This is also the setting for developing an operational definition of ecotourism for this thesis that is set in Chapter Three. The business of ecotourism looks into the current trend and environment of the ecotourism industry. It puts the definition of ecotourism into the practice perspective which is also important in setting up the framework in Chapter Three. Ecotourism success is discussed extensively after the clarification of its history, definition and current trends. This is essential to set up the scene for this thesis.

The second topic of this literature review is local community participation. This topic is one of the important elements in the ecotourism concept. The concept of local community participation is explored while clarifying the definition of 'community' and 'participation'. The theory of local community participation is also critically reviewed to clarify the topic further before moving on to relate it to the ecotourism industry. Local community participation successes are explored later and these successes are linked to the success of ecotourism. 


\subsubsection{The History of Ecotourism}

The vague origin of ecotourism raises the questions of concept and variables in ecotourism. Ecotourism has been called by many names such as 'soft tourism', 'responsible tourism', 'green tourism', 'alternative tourism' and so on. The only consistency found within these names is the link to nature. Despite the variety of names, visitors have long been traveling to natural and pristine areas under the semblance of recreation and tourism. This has led some observers to question whether ecotourism is simply a new name for an old activity (Wall, 1994). The travel department of the American Museum of Natural History conducted natural history tours since 1953 (Blangy and Nielson, 1993). In the early twentieth century, African wildlife-based tourism visitors enjoyed trips to wilderness areas for the intrinsic nature of the experience.

The ecotourism stem can be traced back to the late 1980s (Orams, 1995; Hvenegaard, 1994), while others (Higgins, 1996) suggest that it can be traced to the late 1970's. Nelson (1994) illustrates that the idea of ecotourism is in fact an old one, which manifested itself during the late 60 s and early 70 s when inappropriate use of natural resources became a concern. Ecotourism at this time had been used as a tool for environmental conservation strategy.

Fennell (1998) found evidence that the Canadian government was operating 'eco-tours' in the mid 70s. These eco-tours centred on the Trans-Canada Highway and were developed on the basis of different ecological zones found along the course of the highway. The eco-tours were developed at a time when the Canadian government felt it important to allow Canadian and foreign travelers to appreciate human-land relationships through the interpretation of the natural environment (Fennell, 1999). Whatever names that ecotourism was known for or whatever origins it has, the present ecotourism now needs to reach lofty goals to simply exist. 


\subsubsection{Ecotourism Today}

\section{Ecotourism And Its Definition Today}

While ecotourism has been around for many years, the precise definition of ecotourism has remained vague. There are many difficulties in defining ecotourism without proper attention being paid to underlying philosophical and ethical principles. However, the most used definition of ecotourism today is the one coined by TIES as mentioned in chapter one. TIES defines ecotourism as a nature-based form of specialty travel, which involves:

"Responsible travel to natural areas, which conserves the environment and sustains the well-being of local people" (The International Ecotourism Society, 2000).

The World Conservation Union came up with a more comprehensive definition:

"Ecotourism is environmentally responsible travel and visitation to relatively undisturbed natural areas, in order to enjoy and appreciate nature (and any accompanying cultural features both past and present) that promotes conservation, has low negative visitor impact, and provides for beneficially active socioeconomic involvement of local populations" (The World Conservation Union, 1996).

In certain literatures, it was suggested that the term 'ecotourism' was coined by Hector Ceballos-Lascuráin, who was at the time (July 1983) Director General of Standards and Technology of SEDUE (the Mexican Ministry of Urban Development and Ecology) and founding president of PRONATURA (an influential Mexican conservationist NGO). He provided the first definition of the term later that year at a conference in Mexico City: 
"Ecotourism is that tourism that involves traveling to relatively undisturbed natural areas with the specific object of studying, admiring and enjoying the scenery and its wild plants and animals, as well as any existing cultural aspects (both past and present) found in these areas. Ecotourism implies a scientific, aesthetic or philosophical approach, although the 'ecotourist' is not required to be a professional scientist, artist or philosopher. The main point is that the person who practices ecotourism has the opportunity of immersing him or herself in nature in a way that most people cannot enjoy in their routine, urban existences. This person will eventually acquire a consciousness and knowledge of the natural environment, together with its cultural aspects, that will covert him into somebody keenly involved in conservation issues."

In general, ecotourism should satisfy conservation and development objectives (Lindberg, Enriquez and Sproule, 1996). However, even though the TIES definition has been widely accepted, it is not a functional definition for collecting statistics. Since no global initiative exists at present for gathering ecotourism data, ecotourism is considered a specialty segment of the larger nature tourism market. Ecotourism, however, should be viewed as a distinct from of nature tourism, as nature tourism is not defined by its benefits to both conservation and people in the host country.

It is generally agreed that ecotourism products and attractions are primarily nature-based, with the prefix 'eco' usually understood to stand for 'ecological' (Ceballos-Lascuráin, 1988). At one end of a nature-based product continuum, a product or destination may feature the entire ecosystem of the area, so that a 'montane rainforest' or 'coral reef' is experienced. This indicates a 'holistic' approach towards the product, since an ecosystem implies an integrated, interconnected entity. In contrast, an 'elemental' approach is evident at the other end of the continuum when a product focuses on specific, non-captive 
animals or plants that are deemed to be particularly attractive or interesting (Weaver, 2005). Examples of iconic charismatic mega fauna that are identified closely with particular destinations include the Orang Utan in Borneo. A smaller number of destinations feature charismatic mega flora, such as the Rafflesia flower in Borneo, which is distinguished by its beauty, size, age, rareness, and/or weirdness.

\section{Ecotourism And Cultural Attractions}

According to Weaver (2006), associated cultural influences are recognized as essential ecotourism attractions especially in the case of indigenous territories. This is based on the arguments that direct and indirect human influences critically affect the dynamics of any contemporary ecosystem and form a vital part of the ecosystem's interpretation and understanding.

Most definitions also recognise the importance of associated cultural attractions, both contemporary and relict. This is most evident in destinations that were or are occupied by indigenous people including Borneo. In such situations, the boundary between nature and culture is often blurred and natural ecosystems are subjected to the consequence of activities (e.g. firesetting, plant dispersal and hunting) undertaken by indigenous people over several millennia (Hinch, 2001). Here and elsewhere, the inclusion of a cultural component is a logical qualification to the 'nature-based' focus, given that few, if any, places are completely free from human influences. The cultural components may be omitted or downplayed to prevent distraction of attention to the target animal or plant.

\section{Debate On Ecotourism}

There is a considerable debate over what ecotourism really means. Ecotourism can be defined in terms of the 'product' or as an operating 'principle' (Cater, 1994). Buckley (1994), Orams (1995), and Stewart and Sekartjakrarini (1994) reviewed its definitions and concluded that preference for one over another reflects different priorities of stakeholders and analysts. Thus, while Orams 
(1995) favours a definition that focuses on encouraging better ecotourists who will help maintain a better environment, and Blangy and Nielsen (1993) focus on guidelines for operators (product-oriented definitions), proponents of local development find these types of definitions inadequate, or incomplete. While Stewart and Sekartjakrarini (1994) argue that the multifaceted nature of expanded, principle-based definitions lead to ambiguity in interpretation, a definition, which includes community development, is increasingly promoted (Boo, 1992; Budowski cited in Kutay, 1992; Cater 1994; Norris 1992; Whelan, 1991; Ziffer, 1989). This concept has grown and developed and ecotourism is now being promoted as a sustainable alternative to mass tourism.

Weaver (1991) emphasised that the development of ecotourism should be on a small-scale and have locally owned activities. The infrastructure and superstructure are simpler and less expensive compared to mass tourism requirements. There is also a higher input of local products, materials and labour, which has greater multiplier effect throughout the local economy with fewer leakages compared to large-scale and foreign-owned operations. The profits made should accrue locally which is a particularly attractive prospect for developing countries. This is further supported by the general consensus among speakers and delegates at the $7^{\text {th }}$ PATA Adventure Travel and Ecotourism Conference and Mart held in Balikpapan, where it was maintained that in order for ecotourism to remain environmentally and socially responsible, it has to remain small-scale and remain a 'niche' market.

Here, ecotourism literature broadly falls into two camps. First, the literature focuses on the demand-side: the characteristics and motives of ecotourists. Secondly, and of more relevance to this research, is the literature focused on the supply-side: much of which aims to evaluate these ventures against sets of principles, objectives or economic criteria (Doan, 2000; Lindberg, Enriquez and Sproule, 1996; Loon and Polakow, 2001; Ross and Wall, 1999; Wallace and Pierce, 1996) 
Table 2 1 Other Type of Tourism with Similar Concept to Ecotourism

\begin{tabular}{|c|c|c|}
\hline TYPES OF TOURISM & DEFINITION & ESSENCE \\
\hline Sustainable Tourism & $\begin{array}{l}\text { Tourism development that meets } \\
\text { the needs of the present without } \\
\text { compromising the ability of future } \\
\text { generations to meet their own } \\
\text { needs. }\end{array}$ & $\begin{array}{l}\text { Tourism that wisely uses and } \\
\text { conserves resources in order } \\
\text { to maintain long-term } \\
\text { viability (Budowski, 1976). }\end{array}$ \\
\hline Alternative Tourism & $\begin{array}{l}\text { Products and activities that were } \\
\text { thought to be more appropriate } \\
\text { than conventional mass tourism. }\end{array}$ & $\begin{array}{l}\text { Distinct contrast to the } \\
\text { unsustainable mass tourism } \\
\text { idea type in terms of } \\
\text { markets, attractions, } \\
\text { accommodation, economic } \\
\text { status and regulations, with } \\
\text { local control and small-scale } \\
\text { dynamics being core } \\
\text { principles (Weaver, 2006). }\end{array}$ \\
\hline \multicolumn{3}{|l|}{ Nature-Based Tourism } \\
\hline Ecotourism & $\begin{array}{l}\text { Travel to relatively undisturbed or } \\
\text { uncontaminated natural areas } \\
\text { with the specific object of } \\
\text { studying, admiring and enjoying } \\
\text { the scenery and its wild plants, } \\
\text { and animals, as well as any } \\
\text { existing cultural aspects } \\
\text { (Ceballos-Lascurin, 1988). }\end{array}$ & $\begin{array}{l}\text { Specialized product in the } \\
\text { natural setting where eco- } \\
\text { practices are present with } \\
\text { involvement of local people. }\end{array}$ \\
\hline
\end{tabular}

There has been a period of confusion especially amongst the practitioner and consumer on the different types of niche tourism that promotes conservation with nature as the main products. Table 2.1 above outlines other types of tourism that is similar to ecotourism and describes the relationship that they all have. 
Alternative tourism can be regarded as an early form of engagement using the idea of sustainability. In practice, destinations and business practices use ecotourism as a specialized part of their sustainable tourism development strategies.

\subsubsection{The Business of Ecotourism}

It is suggested that there are different types of ecotourism businesses. CruiseMalloy and Fennel (1997) argue that ecotourism businesses conform to one of three types of organisation cultures. 'Market ecotourism' refers to businesses that are characterised by ethical conduct and a commitment to sustainability. However, this is only as a means of avoiding external punishment or receiving awards. 'Socio-bureaucratic ecotourism' is equally concerned with financial viability, but the goals are pursued in different manners from conventional businesses like treating local customs as important elements in its business operations. 'Principled ecotourism' is the most advanced moral archetype, which values sustainable and unobtrusive ecotourism, and expands its notions of justice by operating with global ecology in mind.

Unfortunately, there are businesses taking advantage of the goodwill of ecotourism to promote remote destinations. The tour package offered might be a conventional trip, which has been rebranded to capture the growing ecotourism market. Businesses generally operate on the principle of maximising profits that they tend to emphasise short-term economic benefits, which may or may not conflict with long-term environmental interests (Forsyth, 1995). This 'environmental opportunism' has profound effects, as consumers did not know what they were getting, nor its impact on the environment, and did not know how the product differed from others. There is no question that 'green' sells and any term prefixed with 'eco' will increase interest and sales. There is no real indicator of the quality of the product on offer. In the last 10 years or so, there has been a proliferation of advertisements in the tourism industry, using terms as ecotour, ecotravel, ecovacation, ecologically sensitive 
adventures, eco(ad)ventures, ecocruise, ecosafari, ecoexpedition and ecotourism (Wight, 1994).

Ballantine and Eagles (1994) suggest that ecotourists can be defined on the basis of an intention to learn about nature, an intention to visit undisturbed areas, and a commitment of at least 33 per cent of their time to the first two criteria. However, the time factor advocated by Ballantine and Eagles may be applicable in the safari ecotourism settings of Africa, but could be more problematic in less structured ecotourism settings and situations (Blamey, 1995). Tourism literature defines 'tourism' under many different circumstances - time, space, economics, and whole system models - the same will likely occur for ecotourism. It depends on who operationalises the concept, and for what purpose (Buckley, 1994). There are earlier studies that attempt to classify ecotourist on the basis of setting, experience, and group dynamics. Kusler (1991) divided ecotourists to three main groups, which are:

I. Do-it-yourself ecotourists. Despite their relative anonymity, this group comprises the largest percentage of all ecotourists. These individuals stay in a variety of different types of accommodation, and have the mobility to visit any number of settings. Their experience, therefore, is marked by a high degree of flexibility.

II. Ecotourists on tours. This group expects a high degree of organisation within their tour, and travel to exotic destinations (e.g. Antarctica).

III. School groups or scientific groups. These groups often become involved in scientific research of an organisation or individual, often stay in the same region for an extensive period of time, and are willing to endure harsher site conditions than other ecotourists. 
Lindberg (1991), on the other hand, emphasises the importance of dedication and time, as a function of defining different types of ecotourists. This includes where they wish to travel, how they wish to travel and what they wish to experience. Lindberg has identified four basic types:

I. Hard-core nature tourists. Scientific researchers or members of tours specifically designed for education, removal of litter, or similar purposes.

II. Dedicated nature tourists. People who take trips specifically to see protected areas and who want to understand local natural and cultural history.

III. Mainstream nature tourists. People who visit the Amazon, the Rwandan gorilla park, or other destinations, primarily to take an unusual trip.

IV. Casual nature tourists. People who experience nature incidentally as part of a broader trip.

Panos (1995) came up with a classification of ecotourists based on demographic and behaviour. They are:

I. Whoopies (wealthy, healthy, older people) Professional people perhaps retired or on extended periods of leave, from rich, industrialised countries, aged between 44 and 64 years. They are bored with traditional mass tourism destinations and search out unique and pristine destinations.

II. Sensitive Souls - Members of the liberal middle class in the West. They donate to charities, are eco-friendly and perhaps, vegetarian. They prefer to book their travel with operators, which promise an appreciation of natural attractions in an exotic location, but in ways, which ensure local communities benefit from tourism. 
III. Ego-tourists - Young Western travelers who are financially less well endowed than the previous two categories, and who seek 'alternative' travel in the Third World as part of an extended vacation. They may travel independently or with an overland truck company, and are often more environmentally aware than other types of tourists. Interested in curriculum vitae building, they feel that as travelers (as opposed to tourists), they will gain certain personal attributes from their experience.

IV. Affluent southerners - Members of the growing middle class in Third World countries who may not be able to afford to travel abroad, especially to Western countries (unless they work for an aid organization which funds this), but who have an interest in the cultural and natural heritage of their own and neighbouring countries.

TIES has constructed an ecotourist market profile based on a 1994 survey of North American travel consumers (Table 2.2).

In 1989, ecotourism and the broader category of adventure travel had captured almost 10 per cent of the tourist market and were growing at a rate of 30 per cent a year (Whelan, 1991). Today, it is estimated that the ecotourism market is worth more than US $\$ 300$ billion dollars and much of this revenue is generated in developing countries, which perceive it as a lucrative, environmentally benign and sustainable alternative to mass tourism (Herbig and O'Hara, 1997). North America, Europe and Japan are the top three ecotourist-generated areas (Eagles, 1992). Developing countries have a comparative advantage in terms of the variety and extent of unspoiled natural environments. These include scenic attractions, secluded beaches with pristine coral reefs, and, flora and fauna in their original habitat. The economic needs of developing countries encourage the capitalisation on nature, and the development of ecotourism provides this opportunity. 
One of the major challenges that ecotourism is faced with at present is how to develop without destroying the environment. Uncontrolled mass tourism has heightened the awareness of adverse environmental and socio-cultural impacts. Many developing countries rely on their environment as a tourist attraction; therefore, lessening the impact of tourism on the environment is critical. Environmental and social problems, which are caused by conventional mass tourism development, are a clear example of how tourism can be destructive on its own. Ecotourism may also deprive indigenous people of access to the resource areas they traditionally used for their livelihood. This may drive them further into vulnerable ecosystems or into resource degrading employment (Herbig and O'Hara, 1997).

Ecotourism does not lack criticism on its theory and operations. Several researchers (Butler, 1990; Clarke, 1997; Wheeller, 1991) argued that this micro-solution to the macro problem of mass tourism, the inherent mis-match between size and scale, can only produce an unstable, and hence evolving, relationship. For Wheeller $(1991,1993)$, far from being a solution, ecotourism presents a possibly damaging state of affairs. It opens new locations to the tourist gaze, and the resultant destination lifecycle may only replicate the very problems that it was supposed to solve. As Wheeller (1993) postulated, this form has not replaced mass tourism, but has engendered its own packages which sit alongside those offered by major tour operators. 


\section{Table 2. 2. Ecotourist Market Profile}

\begin{tabular}{|c|c|}
\hline PROFILE & DETAILS \\
\hline Age & $\begin{array}{l}35-54 \text { years old, although age varied with activity and other factors such as } \\
\text { cost. }\end{array}$ \\
\hline Gender & $50 \%$ male and $50 \%$ female, although clear differences by activity were found. \\
\hline Education & $\begin{array}{l}82 \% \text { were college graduates; a shift in interest in ecotourism from those who } \\
\text { have high levels of education to those with less education was also found, } \\
\text { indicating an expansion into mainstream markets. }\end{array}$ \\
\hline Household Composition & $\begin{array}{l}\text { No major differences were found between general tourists and experienced } \\
\text { ecotourists. }\end{array}$ \\
\hline Party Composition** & $\begin{array}{l}\text { A majority }(60 \%) \text { of experienced ecotourism respondents stated they } \\
\text { preferred to travel as a couple, with only } 15 \% \text { stating they preferred to travel } \\
\text { with their families, and } 13 \% \text { preferring to travel alone. }\end{array}$ \\
\hline Trip Duration & $\begin{array}{l}\text { The largest group of experienced eco-tourists ( } 50 \%) \text { preferred trips lasting 8- } \\
14 \text { days. }\end{array}$ \\
\hline Expenditure & $\begin{array}{l}\text { Experienced ecotourists were willing to spend more than general tourists, the } \\
\text { largest group (26\%) stating they were prepared to spend } \$ 1,001-\$ 1,500 \text { per } \\
\text { trip. }\end{array}$ \\
\hline Important Elements of Trip & $\begin{array}{l}\text { Experienced ecotourists top three responses were 1) wilderness setting; 2) } \\
\text { wilderness viewing; and 3) hiking/trekking. }\end{array}$ \\
\hline Motivations for Taking Next Trip & $\begin{array}{l}\text { Experienced ecotourists top two responses were 1) enjoy scenery/nature; and } \\
\text { 2) new experiences/places. }\end{array}$ \\
\hline
\end{tabular}

**Experienced ecotourists - Tourists that had been on at least one 'ecotourism' oriented trip. Ecotourism was defined in this study as nature/adventure/culture oriented travel.

\section{Source: The International Ecotourism Society (2000)}

As ecotourism has grown in popularity, sometimes resembling traditional mass tourism, its definition has been expanded to incorporate ideas about ecotourists' responsibility, environmentally friendly destination management, profit linkages to conservation efforts, and the sustainable development of local human populations. Here, the literature emphasised that ecotourism is very much business in nature. It has recognized the profile of the ecotourist and knows how to target them. It commands a large amount of revenue worldwide every year. It is important to recognise that apart from achieving its ideal 
concepts of ecotourism, it also needs to be financially sustainable to be able to do that.

\subsection{Ecotourism Success}

Debates about success lie at the heart of much discussion in this thesis. What should ecotourism aim for? What constitutes success? What influences the industry is not just any objective measure of success or quality but also subjective measures of success. Success is often perceived as objective criteria subject to quantifiable analysis. Success in the ecotourism sense is mainly based on the desired outcomes and achievements. Many ecotourism writers deal with the outcomes of ecotourism, either positive or negative. The positive outcomes are usually viewed as successful scenarios or best practices. This gives some ideas on how success is viewed by writers in the tourism literature. Success, in this sense, is grounded in the perception of individuals.

Most tourism authorities agree that to be successful, ecotourism should promote conservation of natural resources and also provide financial gain for the host country and the local people (Ashton, 1991; Emmons, 1991; Cater; 1994). Developing countries have increasingly turned towards ecotourism to earn foreign exchange and at the same time, preserve the environmental resource base.

Like any other segments of tourism, the impacts of ecotourism can be divided into four: 1) economic, 2) cultural, 3) social and 4) environmental. Ecotourism can provide an economic rationale if an economic value is assigned to ecological resources that are to be conserved. It can be an important part of a more comprehensive development and conservation strategy by assisting in building a constituency necessary for effective policy and action. The positive outcomes are usually the desired outcomes of ecotourism stakeholders. The success of ecotourism is usually measured by the achievement of the 
outcomes. Since it is segmented into four main elements, the success of ecotourism can be divided by those four elements.

\section{Ecotourism Site Success}

Schevyns (1999) argues that ecotourism ventures should only be considered 'successful' if local communities have some measure of control and share equitably in the benefits. Schevyns also suggests that the term 'communitybased ecotourism' should be reserved for those ventures based on a highdegree of community control (and hence where communities command a large proportion of the benefits) rather than those almost wholly controlled by outside operators.

Some authors have clearly adopted a livelihood perspective embracing development and conservation when providing definitions of ecotourism. Lindberg et al. (1996), for example, examined ecotourism case studies in terms of the extent to which they generated economic benefits for the local community. However, this does not account for how the greater amount of money entering the community might be distributed, or how a community is being affected socially and culturally by ecotourism initiatives. Wight (cited in Thomlinson and Getz, 1996) provides a more holistic approach, stressing the need for social, environmental and economic goals to be considered in ecotourism initiatives.

McKercher (1998) identified six factors of failure in the nature-based tourism products including ecotourism. These are

I. Lack of Business Planning - Developing better business planning skills is essential. Planning includes accounting and bookkeeping, accessing finance, pricing, booking and reservation procedures, taxation, cost control and new business development. 
II. Poor marketing skills - A new sector such as ecotourism is typified by players who have no previous business skills with low level of marketing expertise. Overall the naturebased tourism sector has not been well served by the travel trade, which comprises retail travel agents, tour wholesalers and inbound tour operators.

III. Inadequate market research - Many successful tour operators carried out market research to determine whether a real business opportunity existed before they started out. Many assumed that there was an opportunity and invested in the business without looking further. Most tour operators appreciate the importance of market research, but few feel they have skills or the financial wherewithal to conduct it effectively.

IV. Operational issues - The need to develop and deliver tour products of a consistent quality is a key issue. Although many ecotourists are prepared to rough it, the facilities and services must still be of a suitable standard. A more strategic approach to planning the tour and a better understanding of client needs would ensure success.

V. Ethical and environmental issues - Nature-based tourism is confronted by the dual and conflicting task of both using natural areas and ensuring that the environmental integrity of those areas is maintained. Knowledge of local environment and the ability to effectively educate clients about the region is critical to the success of ecotourism operators.

VI. Personal issues - A range of personal issues can affect the individual's ability to deliver tourism product. The ability of many operators to deliver quality products is hampered by their own lack of previous tourism industry experience. 
Developing their own skills to a high enough level to operate a business can address these challenges.

Here, McKercher focused on the business side of tourism. The factors that he outlined showed that failure is contributed to the inexperience of the ecotourism business. His research focused on the business respondents of nature-based tourism including ecotourism. He found out that although the demand for nature-based tourism products is growing rapidly, the long-term viability of many businesses is not assured. This sector is found highly volatile. Literally hundreds of new operators enter the field each year and probably an equally large number leave. Even though McKercher focuses on the failure factors, he still explored a good deal of success factors in ecotourism.

Wearing and Neil (1999) state that the more obvious reason to employ ecotourism is to maximise the benefits of tourism, specifically:

I. Increased demand for accommodation venues (houses) and food and beverage outlets, therefore improving viability for new and established hotels, motels, guest houses, farm stays, etc.;

II. Additional revenue to local retail businesses and other services (e.g. medical, banking, car hire, cottage industries, souvenir shops, tourist attractions);

III. Increased market for local products (e.g. locally grown produce, artifacts, value-added goods), thereby sustaining traditional customs and practices;

IV. Employment of local labour and expertise (e.g. ecotour guides, retail sales assistants, restaurant table waiting staff);

V. Source of funding for the protection and enhancement/maintenance of natural attractions and symbols of cultural heritage; 
VI. Funding and/or volunteers for fieldwork associated with wildlife research and archaeological studies;

VII. Heightened community awareness of the value of local indigenous culture and the natural environment.

Benefits to the business, area and its community are the major reason for undertaking ecotourism. It is also one of the outcomes desired by all stakeholders. This is usually the measurement for success of ecotourism.

Ecotourism may have a profound effect on the culture at the destination area. Since culture is an area of interest to ecotourists, there has been a revival and rejuvenation of ancient festivals, cultural landmarks and so on. While this phenomenon may enrich the life of local communities and tourists alike, it also threatens the existence of some cultures in their original form. Commodification of culture also leads to negative perception of ecotourism. Even though there are arguments that culture will always evolve along with the process of modernisation, ecotourism has been criticised for accelerating this process. By focusing on the preservation of culture, it is quite clear that it is quite a positive outcome of ecotourism activities. These usually are seen as successful for a site.

Ecotourism helps to improve the standard of living, for example through increased disposable incomes of individuals. However, the collective effects of ecotourism may contribute towards the homogenisation of society (Mathieson and Wall, 1982). Contributing effects towards this homogenisation include:

I. Overcrowding of infrastructures, accommodations, services, and facilities, which tourists have to share with the local community.

II. The display of prosperity amid poverty.

III. The employment of non-locals in managerial and professional occupations carrying greater responsibilities 
and superior salaries compared to those occupations available to members of the host community.

IV. The increased activities deemed to be undesirable, such as prostitution, gambling and crime.

V. The gradual erosion of indigenous languages and cultures with the increasing number of visitors.

Rather than focusing on the desired outcome of ecotourism, these authors expressed the undesired outcome of ecotourism. This is a defensive view of development.

Despite all the examples or practices that show the benefits and costs of ecotourism, many third world countries choose ecotourism because the development of the local community is emphasised along with the benefits of conserving the natural surroundings (Scheyvens, 2002).

Since ecotourism has many examples where it has had a positive impact on the environment, it has been able to capitalise on this growing environmentally friendly sentiment. Positive impacts include the growth of certain species of animals and the conservation of natural areas. However, some negative environment fallout do occur such as over consumption of natural resources, disruption of wildlife and human congestion in natural areas (with the increase of ecotourists) which can cause erosion to pathways, increase in litter and waste, and damages to plants.

As new ecotourism activities are developed, their success depends not only on the attractiveness of the offerings and the efficiency of their provisions, but also on the legitimacy of the commercialisation itself. The issue here is that firms must be perceived as legitimate by key stakeholders in order to access critical resources. This is an especially difficult problem in ecotourism since, in bringing together environmental concerns and commercial tourism, it depends on the support of a particularly diverse group of stakeholders including private 
entrepreneurs, aboriginal groups, established tourism firms, industry associations, academic institutions, environmental groups, and regulatory bodies (Lawrence et. al, 1997).

The potential of ecotourism as a source of employment and economic growth worldwide is significant. The ecotourism industry is complex because of its nature and the dynamics between its stakeholders (Lawrence et. al, 1997). Each group brings to the industry its own set of interests, capabilities, strategies, and traditions that may, and often do, conflict. Despite all that, ecotourism is still seen as an avenue in supporting conservation and increasing people's appreciation of natural phenomena. Initiatives in the industry must provide opportunities for beneficial involvement of local communities and enhance local livelihoods. It could also be argued that ecotourism should be empowering for local participants. With empowerment, the local community has the freedom to decide on development issues and at the same time, maximize and ensuring benefits stay in the area. The empowerment of the local community also helps to build the local community's capacity and promote self-development to each individual.

Based on the literature review, several success indicators have been identified, as shown in the following Table 2.3. 


\section{Table 2. 3 Ecotourism Success Indicatiors from Literature Review}

\begin{tabular}{|c|c|c|c|}
\hline NO. & INDICATORS & PARAMETERS & SOURCE \\
\hline 1. & $\begin{array}{l}\text { Conservation of natural resources to } \\
\text { host country and local people }\end{array}$ & $\begin{array}{l}\text { Creation of } \\
\text { conservation } \\
\text { area/effort }\end{array}$ & $\begin{array}{l}\text { Ashton (1991), } \\
\text { Emmons (1991), } \\
\text { Cater (1994) }\end{array}$ \\
\hline 2. & $\begin{array}{l}\text { Financial gain to host country and } \\
\text { local people/economic benefits }\end{array}$ & $\begin{array}{l}\text { Amount of money } \\
\text { Increased disposable } \\
\text { incomes of } \\
\text { individuals } \\
\text { Holistic approach - } \\
\text { considering social, } \\
\text { environmental and } \\
\text { economic goals }\end{array}$ & $\begin{array}{l}\text { Ashton (1991), } \\
\text { Emmons (1991), } \\
\text { Cater (1994) } \\
\text { Wight (1994) } \\
\text { Mathieson and Wall } \\
\text { (1982) }\end{array}$ \\
\hline 3. & Control over development & $\begin{array}{l}\text { Some measure of } \\
\text { control (high degree) } \\
\text { Share equity in the } \\
\text { benefits }\end{array}$ & Schevyns (1999) \\
\hline 4. & Business success & $\begin{array}{l}\text { Finance } \\
\text { Sustainability in the } \\
\text { industry }\end{array}$ & Mc Kercher (1998) \\
\hline 5. & $\begin{array}{l}\text { Benefits of tourism maximized } \\
\text { - } \text { Increased demand for } \\
\text { tourism-related business } \\
\text { Additional revenue to local } \\
\text { retail businesses and other } \\
\text { services } \\
\text { - Increased market for local } \\
\text { products } \\
\text { - Employment of local laborers } \\
\text { and expertise } \\
\text { - Source of funding for the } \\
\text { protection and enhancement/ } \\
\text { maintenance of natural } \\
\text { attraction } \\
\text { Funding and/or volunteers for } \\
\text { fieldwork associated with } \\
\text { wildlife research and } \\
\text { archaeological studies } \\
\text { Heightened community } \\
\text { awareness of the value of } \\
\text { local indigenous culture and } \\
\text { natural environment }\end{array}$ & $\begin{array}{l}\text { Outcomes desired by } \\
\text { all stakeholders }\end{array}$ & $\begin{array}{l}\text { Wearing and Neil } \\
\text { (1999) } \\
\text { Lawrence et. al } \\
\text { (1997) }\end{array}$ \\
\hline 6. & $\begin{array}{l}\text { Profound effect on the culture in the } \\
\text { destination area }\end{array}$ & $\begin{array}{l}\text { Revival and } \\
\text { rejuvenation of } \\
\text { ancient festivals } \\
\text { and/or cultural } \\
\text { landmarks }\end{array}$ & $\begin{array}{l}\text { Wearing and Neil } \\
(1999)\end{array}$ \\
\hline 7. & Empowering local participants & $\begin{array}{l}\text { Level of } \\
\text { empowerment } \\
\text { should build local } \\
\text { community's capacity } \\
\text { and promote self- } \\
\text { development to } \\
\text { individuals }\end{array}$ & $\begin{array}{l}\text { Lawrence et. al } \\
\text { (1997) }\end{array}$ \\
\hline
\end{tabular}


The literature review suggested that the success of ecotourism is based on what it achieved in its operations. This is based on the initial aims and objectives of ecotourism and how to achieve them. The variety of success suggests that there are several factors that contribute to it. Furthermore, success is also based on individuals' perceptions, be it the government, tourist or local community. Many of the ecotourism operations, as discussed in the literature review, include local community as its main component.

\subsection{Local Community Participation}

\subsubsection{Introduction}

The key term i.e. community, used in this thesis needs to be clarified before the main discussion commences. Problems in defining the 'community' are as much about scale as diversity. Would the 'community' include only people from a village adjacent to a new tourism attraction, or villagers from the surrounding area who may also want to benefit from the attraction? Does it include just 'locals' or can it include migrant workers as well? Does it include only the poorer classes, or also the minority of elites (de Beer and Elliffe, 1997)? In a very broad sense, a community can be defined as 'a social network of interacting individuals, usually concentrated into a defined territory' (Johnston 2000). This definition could include many different types of communities including relatively self-sufficient villages with minimal engagement in the global economy. Milne (1998) takes Johnston's definition a step further, noting that communities can 'provide identity, meaning and a sense of self-worth to their members'. Neither of these definitions claims that communities are homogenous entities characterised by shared aims and the desire of all members for mutual well being. 
The term 'participation' is strongly associated with a neopopulist perspective. The neopopulist perspective focuses on people in local contexts and on smallscale, bottom up strategies for their development. Neopopulists are more likely to search for appropriate forms of tourism, which can enhance the well being of local communities. Such sentiments are expressed by Brohman (1996):

\begin{abstract}
Community-based tourism development would seek to strengthen institutions designed to enhance local participation and promote the economic, social and cultural well-being of the popular majority. It would also seek to strike a balanced and harmonious approach to development that would stress considerations such as the compatibility of various forms of tourism with other components of the local economy; the quality of development, both culturally and environmentally' and the divergent needs, interests, and potentials of the community and its inhabitants.
\end{abstract}

Thus, under neopopulism, tourism for development means tourism for development of the people, not tourism for the development of the industry itself. Local communities are central to tourism planning and management, and this encourages the voices of those most affected by tourism to be heard (Scheyvens, 1999).

Local community participation is not a new concept. The word participation implies how and to what extent people are able to share their views, take part in an activity, project, program, decision-making, policy-making and so on. The United Nations (UN) describes community development as a process, designed to create conditions of economic and social progress for the whole community with its active participation. Participation is naturally political as it relates to how groups and individuals are empowered and have control over their lives.

Naisbitt (1994) mentioned that there is a general trend from centralization to decentralization. Some political power has moved away from the central 
government to states, cities, towns and neighbourhoods. This trend has given opportunity to local people to deal with their own problems (Naisbitt, 1994). It can be argued that the community approach to planning is ushered in by the decentralization trend that is the result of a democratisation process and that community involvement encourages democratic government. Davidoff (1965) states that if democratic urban government is encouraged by the planning process, then community participation must be guided and supported in the planning process.

However, participation is seldom straightforward and somewhat complicated in real life. When there is some degree of participation occurring, it is very useful to determine the type of participation involved. Pretty's typology of participation is indispensable in explaining the different levels of participation (Table 2.4). He identifies seven levels of participation, with manipulative participation at one end of the spectrum and self-mobilisation at the other. A simplified dichotomy arising from Pretty's typology is passive versus active participation. When communities are passive participants in tourism, they may merely receive a few menial jobs at a tourist resort or have a percentage of gate takings from a national park disbursed to them, while exerting no control over the nature of tourism development or their involvement in it. Active participation, alternatively, means that communities have access to information on the pros and cons of tourism development, and are directly involved in planning for and managing tourism in line with their own interests and resources. 


\section{Table 2. 4 A Typology of Participation: How People Participate in Development Programs and Projects}

\begin{tabular}{|c|c|}
\hline TYPOLOGY & CHARACTERISTICS OF EACH TYPE \\
\hline Self-mobilisation & $\begin{array}{l}\text { People participate by taking initiatives independently of external institutions } \\
\text { for resources and technical advice they need, but retain control over how } \\
\text { resources are used. Self- mobilisation can spread if governments and NGOs } \\
\text { provide an enabling framework of support. Such self-initiated mobilisation } \\
\text { may or may not challenge existing distributions of wealth and power. }\end{array}$ \\
\hline Interactive participation & $\begin{array}{l}\text { People participate in joint analysis, development of action plans and } \\
\text { formation or strengthening of local institutions. Participation is seen as a } \\
\text { right, not just the means to achieve project goals. The process involves } \\
\text { interdisciplinary methodologies that seek multiple perspectives and make use } \\
\text { of systemic and structured learning processes. As groups take over local } \\
\text { decisions and determine how available resources are used, so they have a } \\
\text { stake in maintaining structures or practices. }\end{array}$ \\
\hline Functional participation & $\begin{array}{l}\text { Participation seen by external agencies as a means to achieve project goals, } \\
\text { especially reduced costs. People may participate by forming groups to meet } \\
\text { predetermined objectives related to the project. Such involvement may be } \\
\text { interactive and involve shared decision making, but tends to arise only after } \\
\text { external agents have already made major decisions. At worst, local people } \\
\text { may still be only co-opted to serve external goals. }\end{array}$ \\
\hline Participation for material incentives & $\begin{array}{l}\text { People participate by contributing resources, for example, labour in return for } \\
\text { food, cash or other material incentives. Farmers may provide the fields and } \\
\text { labour, but are involved in neither experimentation nor the process of } \\
\text { learning. It is very common to see this called participation, yet people have } \\
\text { no stake in prolonging technologies or practices when incentives end. }\end{array}$ \\
\hline Participation by consultation & $\begin{array}{l}\text { People participate by being consulted and by answering questions. External } \\
\text { agents define problems and information gathering processes, and so control } \\
\text { analysis. Such a consultative process does not concede any share in decision- } \\
\text { making, and professionals are under no obligation to take on board people's } \\
\text { views. }\end{array}$ \\
\hline Passive participation & $\begin{array}{l}\text { People participate by being told by what has been decided or has already } \\
\text { happened. It involves unilateral announcements by an administration or } \\
\text { project management without any listening to people's responses. The } \\
\text { information being shared belongs only to external professionals. }\end{array}$ \\
\hline Manipulative participation & $\begin{array}{l}\text { Participation is simply pretence, with "people's" representatives on official } \\
\text { boards but who are unelected and have no power. }\end{array}$ \\
\hline
\end{tabular}

Source: Pretty (1995) 
This does not mean that only the involvement that is initiated by local communities offers opportunities for active participation. Milne (1998) recognises a difference between sanctioned participation, in which governments establish and direct a process encouraging local involvement in decision-making, and independent political organisation, whereby separate groups attempt to exert control over tourism, sometimes through nonconfrontational means but other times through direct protest. Similarly, while there are greater opportunities for active participation in small-scale forms of tourism, active participation can also occur in more up-scale forms of tourism such as resorts if local people share ownership and management of the resort.

However Guijt and van Veldhuizen (1999), argue that such a typology can be over-simplistic for the following reasons:

- Wrong assumption of a static picture

By classifying a particular project as embodying a certain 'type' of participation, it ignores the changes that will occur as the intervention develops. Women and men can participate in different ways at different moments, as do the better off and the worse off, researchers and community members.

- Simplifying difference in terms of 'insider and outsider' Most typologies describe a sliding scale of shifting responsibility between insiders, and outsiders, or professionals. Viewing all community members as 'insiders', they ignore community-level differences, thus hiding the reality of high levels of participation by some individuals and none by others. Similar problems occur with stereotyping 'outsiders' in this way.

- Normative assumption of an ideal form of participation Implies that there is a pathway or continuum across which development interventions can and should move towards a state 
of absolute and enduring local participation. Yet the feasibility and desirability - for community members and professionals alike - of 100 per cent local participation is very questionable.

- Simplifying diversity and hindering innovation

By simplifying complex interaction processes, a prescriptive use of typology may be stimulated which can hinder innovation and change. While it is interesting to find one's place in typology, it is more important still to describe how community members and professionals wish to work together, why this is the case, and how it is evolving. It is important to ask which participatory approaches are useful for those aiming to build communities' and groups' capacities through participatory development.

Arnstein (1969) also comes up with a similar concept, which she calls 'The Ladder of Citizen Participation' (Figure 2.1).

The Ladder of Citizen Participation works as follows:

1 - Manipulation and $\mathbf{2}$ - Therapy. 1 and 2 are both non-participative. The aim is to cure or educate the participants. The proposed plan is best and the job of participation is to achieve public support through public relations efforts.

3 - Informing. This is the most important first step to legitimate participation. However, the emphasis is too frequently on a one-way flow of information. There is no channel for feedback. 


\section{Fiqure 2. 1 A Ladder of Citizen Participation}

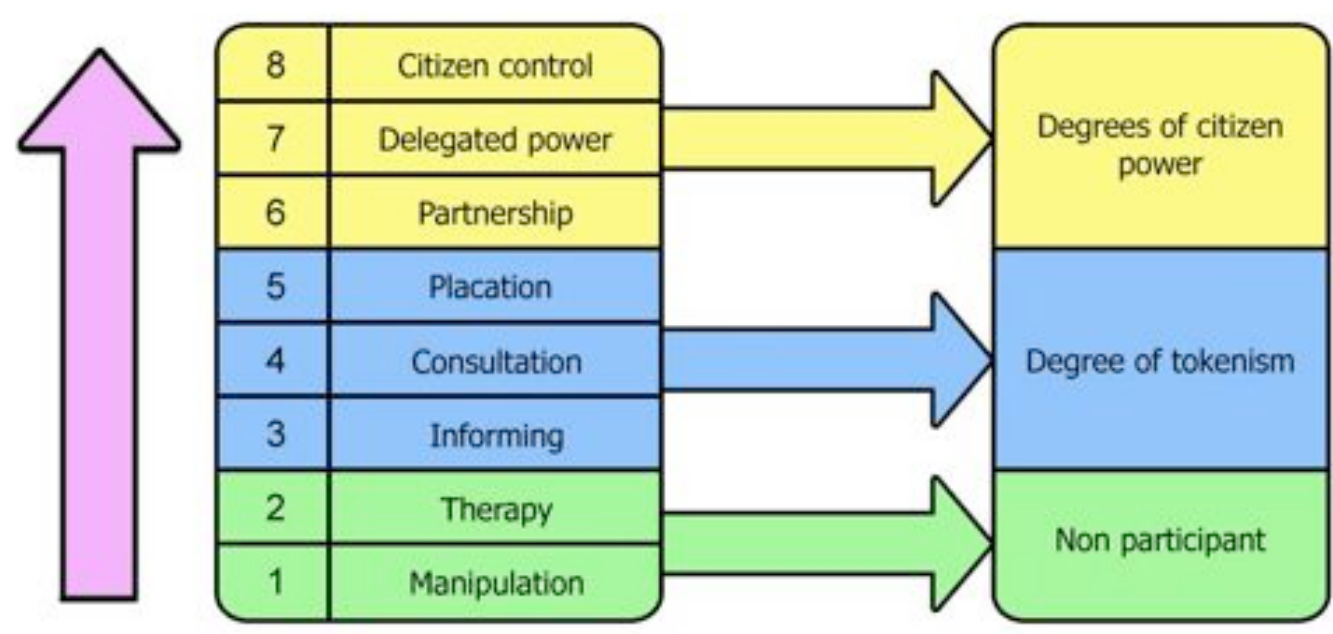

Source: Arnstein (1969)

4 - Consultation. These are legitimate attitude surveys, neighbourhood meetings and public enquiries. Arnstein, however, still feels this is just a window dressing act.

5 - Placation. It allows participants to advise or plan ad infinitum but retains for power holders the right to judge the legitimacy or feasibility of the advice, for example, co-option of handpicked 'worthies' into committees.

6 - Partnership. Power is in fact redistributed through negotiation between citizens and power holders. Planning and decision-making responsibilities are shared e.g. through joint committees.

7 - Delegated power. Participants are holding a clear majority of seats on committees with delegated powers to make decisions. The public now has the power to assure accountability of the program to them.

8 - Citizen Control. The citizens exercise full control over the planning, policy making and management of a program with no intermediaries between the citizen and the source of funds. 
It is perhaps too naïve to think that the whole community can be easily included in the planning and execution of development projects. The scale of such involvement is too massive and too complicated where the community in any case is made up of many different people with different interests, priorities and resources. In any case, only a handful of people have the time, resources and inclination to commit themselves to participate. Putting this into practice is by no means a simple process. Koch (1997) has identified a number of constraints to participation of local communities in tourism ventures and his points are applicable to a broad range of context. The constraints are:

I. Communities often lack proprietorship over land and natural resources, thus participation in tourism is limited to co-option in ventures controlled by outsiders.

II. Appropriate skills, knowledge and resources for developing tourism ventures are often lacking at the community level.

III. Poor communities find it difficult to accumulate or attract the capital necessary to develop tourism facilities or attractions.

IV. Communities are typically heterogeneous, comprising a range of different interest groups, which may come into competition regarding the development of a potentially lucrative tourism venture.

Despite the criticism, Pretty and Arnstein's works have become the basis of literature on community participation. The Typology of Participation and the Ladder of Citizen Participation are evidently useful in designing community participation programs. Since this thesis is dealing with many levels of community participation, the Typology of Participation and the Ladder of Citizen Participation have been helpful in determining the extent of the participation in the ecotourism sites. From there, further analysis can be made on the quality of the participation, which helps to formulate the success indicators for the ecotourism project and local community participation process. 
The vast literature on community participation has dealt mainly with questions having to do with the scope of participation - who participates, how many participate, how often people participate, the number of meetings held, and the different ways to involve community. Until very recently, the quality of participation and its contribution to the success of development projects has been largely ignored in the literature. Pretty points out that 'in recent years, there have been an increasing number of comparative studies of development projects showing that 'participation' is one of the critical components of success. As a result, the terms 'people participation' and 'popular participation' are now part of the normal language of many development agencies, including non-governmental organisations, government departments and banks'.

Arnstein (1969) argued that public participation implies that the local community will have a degree of control over the planning and decision-making process. Therefore, a community approach to tourism planning implies that there will be a need for partnership in, or community control of, the tourism development process. However, such a community approach has generally not been adopted by government authorities, often because of complaints from business interests of the economic impact of decision-making delays, which arise out of any statutory requirement for participation. Moreover, for many government officials, whether elected or otherwise, community control can also be interpreted as a loss of their power and their control over the planning process.

According to Freidmann (1992), community participation "permits the poor to reacquire power and control over their own lives and the natural and human resources that exist in their environment...if social and economic development means anything at all, it must mean a clear improvement in the conditions of the life and livelihood of ordinary people". There is no intrinsic reason, moral or otherwise, why large numbers of people should be systematically excluded from development in this sense or, even worse, should become the unwitting 
victim of other people's progress". Community participation also has been seen as one of the basic rights that 'people who must live with planning decisions should be involved in their formulation' (Rosenow and Pulsipher, 1979).

The highlight of the literature is that there are many dimensions of local community participation. As explained in the earlier part of this section, the spectrum of local community participation varies from total control at the top (or the most desired) to manipulation at the bottom (or the least desired). This is an important perspective to be noted when discussing local community participation and will be repeated throughout this thesis. The next section will see the literature critically reviewed to further clarify the topic of local community participation.

\subsubsection{Criticism of Local Community Participation}

As a concept, 'local community participation' is one of the most overused, but least understood concepts in developing countries without a serious attempt to analyse critically the different forms that participation could take (Nientied, 1990; Oakley, 1991; Gaigher, 1992). Jenkins (1993) identified seven impediments to public participation in tourism planning:

I. The public generally has difficulty in comprehending complex and technical planning issues.

II. The public is not always aware of or understands the decision-making process.

III. There is difficulty in attaining and maintaining representativeness in the decision-making process.

IV. The apathy of citizens

V. The increased costs in terms of staff and money.

VI. The prolonging of the decision-making process.

VII. Adverse effects on the efficiency of decision-making. 
Community participation in development projects often assumes the notion of 'common purpose and common good'. Involving people can be expensive in various ways and, in some instances, can paralyse decision-making, holding development investments hostage to unproductive activism and reinforce local power structures and power struggles. It also can use enormous amounts of time, cause endless delays and circularise decision-making, having to deal with a constantly changing cadre of decision-makers and every now and then evoke the new charge of lack of mandate.

Consultations within the community participation process can also be quite a flawed process, especially when residents are either not fully aware of the complexities of an issue or when they lack the emotional distance to make the wisest choice. Local governments must balance community wishes with responsible fiscal management. Local politicians are elected to make the hard decisions that are in the best interest of the community as a whole. Community consultations are important, especially when new developments are proposed that may lead to a change in the fundamental character of the community. (McKercher, 2001)

Tosun (2000) recognised that there are limitations to community involvement in the tourism development process. He identified that there are three categories of limitations, which are:

1. Operational limitation

a Centralised tourism administration

- Lack of co-ordination

a Lack of information

2. Structural limitation

- Lack of expertise

- Elite domination

- Lack of appropriate legal systems 
a High cost of community involvement

\section{Cultural Limitation}

a Any cultural beliefs and values that hinder progress

In addition to these limitations, he also identified that there is a general limited capacity of poor people, which can become major obstacles in the tourism development process. Tosun clearly stated that there is a variety of limitations that originated not just from internal factors, but external as well. Limitations such as cultural, for example superstition, will definitely slow the process of participation and should be seriously considered when pursuing any participation project.

It is also noted that the general assumption that the greater the degree of local control and participation, the greater the scheme's supposed sustainability and the wider the distribution of benefits within the community, does not always hold true. It has already been well established that sustainability differs according to the interests of those who are defining it, and the interests of the local community will not necessarily coincide with those of others; nor is it likely that the interests of the local community will be the same for all within the community. Another problem in utilising a community approach to tourism planning is the structure of the government. The system of governance may lead to difficulties in ensuring that tourism policies at different levels of government are adequately coordinated and that decisions and policies at one level are not at odds with decisions at another. Local power relationships within the community can be as factional as those which include players on a broader stage such as national governments, NGOs and supranational institutions. Thus, the emergence of local elites is likely to produce inequalities within the community, just as those other players produce disparities of benefits at a different level. 
In conclusion, local community participation is a visionary developmental tool that has been used for many years in the process of development both in developed and developing countries. It is used both in urban and rural areas but there are tendencies in developing countries that community participation is used heavily in the rural area as part of the development process. Ecotourism, being dependent on natural resources and located in rural areas, also incorporates community participation elements as it is regarded as ethical. However, community participation is usually not straight forward as it involves many stakeholders with various limitations. It is a good point to customize local community participation based on the surrounding environment and current times.

\subsubsection{Local Community Participation in Ecotourism}

Ecotourism has always stressed local participation, ownership and business opportunities, particularly for rural people (Epler Wood, 2002). She explains further that there must be a focused attention on local people, who must be given the right to prior informed consent, full participation and, if they so decide, given the means and training to take advantage of this sustainable development option. It also must be understood that if the community is not involved in initial decisions for the project - such as establishing the objectives for the project or defining its scope - then it is likely they will care less about its success. As ecotourism guidelines are being developed, it is important to consider some issues that may not be fully addressed by practitioners globally. One of them is the amount of control that traditional/indigenous communities retain when ecotourism is developed in natural areas that they manage or inhabit.

Cater (1994) indicates that the poorest countries are the least capable of withstanding the adverse impacts on their potential for sustainability; therefore, the need for sustainable ecotourism development is greater. The natural environment is essential to the attractiveness of a tourist destination as it 
provides the backdrop to commercial service areas and recreation (Farrell and Runyan, 1991). It is obvious that tourism consumes resources, creates waste and has specific infrastructure needs, and that as a consumer of resources, it has the potential to over-consume (Duffy, 2002). Since the cost of tourism is usually borne by the local community, it is always suggested that the local community must participate in the decision-making process that can have an impact in their lives.

There are several factors why local communities are interested in undertaking ecotourism (Wearing and Neil, 1999):

I) A desire to be part of the strong growth in tourism generally and see the potential of catering for special-interest tourism (niche markets);

II) An awareness of the high value of natural attractions in the locale;

III) Empathy for conservation ideals and the need for sustainable tourism;

IV) A desire to responsibly rejuvenate the local tourist industry.

Blank (1989) recognises that, 'communities' are the destination of most travellers. Therefore it is in communities that tourism happens. Because of this, tourism industry development and management must be brought effectively to 'bear in communities'. Under this approach, residents are regarded as the focal point of the tourism planning exercise, not the tourists, and the community, which is often equated with a region of local government, is regarded as the basic planning unit.

Hall (2000) advocates that a community approach to tourism planning is therefore a 'bottom up' form of planning, which emphasises development in the community rather than development of the community. Mowforth and Munt (1998) suggest that rather than looking for remedial action to counter the 
inequalities and unevenness of tourism developments, it might be more suitable for local communities to control developments from the start.

Many literatures stress the need for local community participation in ecotourism, which are linked more towards ethics. The ecotourism nature, which is ethical itself, fosters the needs for these ethical elements to be observed vigilantly. Many studies focus on examining the impacts of tourism and ecotourism on the environment in a larger sense (including the community) and suggest that community participation will minimise the adverse impact (Joppe, 1996; Lindberg and McKercher, 1997; Lash, 1998). Most researchers agree that some of these impacts can be prevented if the community gives its prior informed consent to any tourism and ecotourism projects in its area, participates in its development, and remains part of the planning process for tourism and ecotourism entering into the community. Despite the difficulties in implementing a community approach to tourism development, elements of the approach have proven to be attractive in tourism planning literature (e.g. Getz 1994; Ryan and Montgomery 1994; Simmons 1994).

The following Table 2.5 illustrates the summary of factors for local community participation in ecotourism based on the literature review. 


\section{Table 2. 5 Factors for Local Community Participation in Ecotourism}

\begin{tabular}{|c|c|c|c|}
\hline NO. & FACTORS & DETAILS & SOURCE \\
\hline 1. & Control over development & $\begin{array}{l}\text { Involvement and } \\
\text { presence of local } \\
\text { community } \\
\text { participation } \\
\text { structure }\end{array}$ & $\begin{array}{l}\text { Epler Wood (2002) } \\
\text { Blank (1989) }\end{array}$ \\
\hline 2. & $\begin{array}{l}\text { Counter inequalities and unevenness } \\
\text { of tourism development }\end{array}$ & $\begin{array}{l}\text { Control development } \\
\text { through participation }\end{array}$ & $\begin{array}{l}\text { Mowforth and Munt } \\
\text { (1998) }\end{array}$ \\
\hline 3. & Minimizing adverse impacts & $\begin{array}{l}\text { Community approach } \\
\text { development } \\
\text { Consent by local } \\
\text { community }\end{array}$ & $\begin{array}{l}\text { Cater (1994), Duffy } \\
\text { (2002) } \\
\text { Joppe (1996), } \\
\text { Lindberg and } \\
\text { McKercher (1997), } \\
\text { Lash (1998), Getz } \\
\text { (1994), Ryan and } \\
\text { Montgomery (1994), } \\
\text { Simmons (1994) }\end{array}$ \\
\hline 4. & Sustainable development & $\begin{array}{l}\text { Cost of development } \\
\text { borne by community }\end{array}$ & $\begin{array}{l}\text { Simmons (1994), } \\
\text { Tosun and Jenkins } \\
\text { (1998), Scheyvens } \\
\text { (1999) and } \\
\text { Scheyvens (1999), } \\
\text { Wearing and Neil } \\
\text { (1999) }\end{array}$ \\
\hline 5. & $\begin{array}{l}\text { A desire to be part of the strong } \\
\text { growth in tourism generally and see } \\
\text { the potential of catering to special- } \\
\text { interest tourism }\end{array}$ & $\begin{array}{l}\text { Realizing the } \\
\text { potentials for tourism } \\
\text { opportunities and } \\
\text { aspired by other sites } \\
\text { as examples }\end{array}$ & $\begin{array}{l}\text { Wearing and Neil } \\
\text { (1999) }\end{array}$ \\
\hline 6. & $\begin{array}{l}\text { An awareness of the high value of } \\
\text { natural attractions in the locale }\end{array}$ & $\begin{array}{l}\text { Realizing the } \\
\text { potentials for tourism } \\
\text { opportunities }\end{array}$ & $\begin{array}{l}\text { Wearing and Neil } \\
\text { (1999) }\end{array}$ \\
\hline 7. & $\begin{array}{l}\text { Desire to rejuvenate local tourist } \\
\text { industry }\end{array}$ & $\begin{array}{l}\text { Opportunities and } \\
\text { pride of the place }\end{array}$ & $\begin{array}{l}\text { Wearing and Neil } \\
\text { (1999) }\end{array}$ \\
\hline
\end{tabular}

There are many reasons why local community participation is undertaken or employed. It is simply more than developing the local community but also ensuring that the development, as a whole, is sustainable. Some authors suggested that the local community is the central focus of any form of tourism, including ecotourism, and their involvement is utmost important as they will bear the costs of development (Simmons, 1994; Tosun and Jenkins, 1998; Scheyvens, 1999; Scheyvens, 2002). There is the departure of the emphasis from 'nature' to 'nature where the community lives'. This shows that local communities are more prominent in ecotourism and its operation, making both 
entities closer. This suggests that there is definitely some kind of relationship in both topics when determining the success of both.

\subsection{Local Community Participation Success}

The discussion on 'success' in this section has a similar notion with what has been discussed in the earlier section. What should local community participation aspire to? What constitutes success? Success in a local community participation sense is mainly based on the desired outcomes and achievements. Success, in this context, is subjective to the perception of individuals.

Much of the ecotourism literature has dealt extensively with the impacts of the industry on the community (e.g. Stankey et. al., 1985; Ziffer, 1989; Whelan, 1991; Boo, 1992). Local community participation issues has received less attention. This notion is based on the assumption that local community participation is an essential objective that has to be achieved in order to fulfil the meaning and to conform to the concept of ecotourism. It is skewed to the idea of a workable concept of ecotourism.

The World Ecotourism Summit held in Québec, Canada in May 2002 recognises that there is a need for the empowerment of local communities. It also recognises that planning and policy development is not carried out with much stakeholder involvement and often their participation tends to be less meaningful. It is suggested that the communities should be able to take more control of the management of ecotourism and should be involved in managing resources and benefits (directly and indirectly). Many regional conferences felt that ecotourism projects could be used to complement intensively used destinations by reducing visitor pressures. This includes showing communities how they could be involved in planning and policy making processes, and the benefits that might accrue, as well as how to reap benefits; from ownership and control of ecotourism; from ecotourism planning and policy making 
initiatives; from galvanising local economies through a range of products; or from important conservation functions (Wight, 2002).

McIntosh and Goeldner (1986) highlighted the need for wider community involvement in tourism in their five goals of tourism development, in which they argued that tourism development should:

I. Provide a framework for raising the living standards of local people through the economic benefits of tourism;

II. Develop infrastructure and provide recreation facilities for both residents and visitors;

III. Ensure that the types of development within visitor centres and resorts are appropriate to the purposes of these areas;

IV. Establish a development program that is consistent with the cultural, social and economic philosophy of the government and the people of the host area; and

v. Optimise visitor satisfaction.

The goals of tourism development are quite similar to the goals of ecotourism, simply because ecotourism is a tourism business. Ecotourism is concerned with the local community and development must be in-line with sustainable and eco-friendly practices, while maximising visitors' experience at the ecotourism sites.

Since the destination community is seen as an important component of the tourism product (D'Amore, 1983; Murphy, 1983; Simmons, 1994), involvement of residents in the decision-making process is essential for sustainable tourism development. Ross (1991) observed that, if pleasant and satisfying experiences involving local residents are important in the destination images of tourists, and in their decision-making processes, then a consideration of the well being of local residents in the context of tourist development is critical. Should residents of tourism communities come to believe that continual tourist development is 
destroying their physical and social environment, and that tourists are the symbols of this process, then a degree of unpleasantness may eventually characterize many resident-visitor interactions, which would ultimately damage the image of friendliness in the locals, so prized by overseas tourists at present. Hall (2000) advocates that an examination of the social impacts of tourism has come to be regarded as essential not only from an ethical perspective of the need for community involvement in decision-making processes but also because without it, tourism growth and development may become increasingly difficult.

Community participation as described by Murphy (1985) is central to the alternative concept, with proponents arguing that participation in planning is necessary to ensure that benefits reach residents in destination areas (Simmons, 1994). Cater (1994) and Wild (1994) suggest that ecotourism will encourage local employment and small business development promotes higher economic multipliers, and that a community approach to decision-making helps to ensure traditional lifestyles and community values are respected. Kutay (1992) cites environmental benefits of community participation, arguing that a close working relationship between the local community and the industry will provide the means to support conservation efforts. Small scale, community-led tourism has been suggested as particularly appropriate for developing countries (Britton and Clark, 1987; Kangas, Shave and Shave, 1995; Oppermann, 1993).

In order to maximise the positive impacts of ecotourism, local communities must be included in the planning and development of ecotourism projects starting in the early stages. In order for them to participate fully in the planning process, they must be aware of the impacts and be supportive of the development. Furthermore, it is important that local communities 'have a basic level of awareness of the potential benefits and costs of tourism' to successfully participate in the planning process (Woodley, 1993). 
Murphy (1985) stressed that, if tourism is to become the successful and selfperpetuating industry as many have advocated, it needs to be planned and managed as a renewable resource industry, based on local resources and community decision-making processes. He also advocated the use of an ecological approach to tourism planning which emphasised the need for local control over the development process. One of the key components of the approach is the notion that in satisfying local needs it may also be possible to satisfy the needs of the tourist, a 'win-win' philosophy that is immensely attractive. Community development initiatives have a better chance of being accepted by the local community if the advocates acknowledge the fact that different groups within the community need different things, depending on their roles in, affinity within, and utilisation of the community.

The National Ecotourism Guidelines for Malaysia stated that local involvement and the generation of economic benefits are recognised as essential for the long-term success of ecotourism projects. This requires the creation and involvement of local stakeholders (individuals and communities), and an emphasis on local investment, control and decision-making. It suggested a few mechanisms for increasing local benefits, which includes:
I. Local ownership and management
II. Leasing to local individuals or concerns
III. Partial ownership
IV. Profit-sharing arrangements between tourism industry and local residents
V. Direct payments to communities from tourism revenues and local employment in tourism.

The guidelines emphasised the increasing local benefits through the process of local community participation. This shows that the benefits to the locals reflect the desired outcome from any activities that involve the local community. This desired outcome is an indication of success of community participation. This is 
extended to the business community, where suggestions are made to create linkages to the local community.

Based on the discussion above, there are several success indicators that can be identified based on the literature review. This is shown as in Table 2.6 below:

Iable 2. 6 Local Community Participation Success from Literature

Review

\begin{tabular}{|l|l|l|l|}
\hline NO. & INDICATORS & PARAMETERS & SOURCE \\
\hline 1. & Local employment & $\begin{array}{l}\text { Higher Economic } \\
\text { Multiplier }\end{array}$ & $\begin{array}{l}\text { Cater (1994) } \\
\text { National Ecotourism } \\
\text { Plan (1997) }\end{array}$ \\
\hline 2. & Small Business Development & $\begin{array}{l}\text { Higher Economic } \\
\text { Multiplier }\end{array}$ & Conservation effort \\
\hline 3. & Conservation & $\begin{array}{l}\text { Britton and Clark } \\
\text { (1987) } \\
\text { Kangas et. al (1995) } \\
\text { Oppermann (1993) }\end{array}$ \\
\hline 4. & Positive impacts maximized & $\begin{array}{l}\text { Planning and } \\
\text { development with full } \\
\text { participation }\end{array}$ & Woodley (1993) \\
\hline 5. & $\begin{array}{l}\text { Local and tourist needs satisfied } \\
\text { Role, affinity and } \\
\text { utilization of the } \\
\text { community }\end{array}$ & Murphy (1985) \\
\hline 6. & $\begin{array}{c}\text { Increasing local benefits } \\
\text { Local ownership } \\
\text { Leasing to locals } \\
\text { Partial ownership } \\
\text { Profit sharing } \\
\text { Direct payment from tourism } \\
\text { revenue }\end{array}$ & $\begin{array}{l}\text { Local involvement } \\
\text { control } \\
\text { Decision-making }\end{array}$ & $\begin{array}{l}\text { National Ecotourism } \\
\text { Plan (1997) }\end{array}$ \\
\hline
\end{tabular}

The critical factor concerning local community participation is community control, which means that communities have the power to decide whether or not tourism is an appropriate development avenue for them to pursue and in what form it should be pursued. It stresses the importance of encouraging such groups to participate in decision-making and the implementation of policy. Focus is given to the level of participation adopted (the degree of power sharing involved) and the scope of participation (in what decision arenas people were being invited to participate). The existence of participation levels, measures of degree of power sharing, scope of community involvement, 
methods and decision-making structure being employed in the process and to whom power is being devolved, all contribute to the perception of success.

\subsection{Indicators}

A study at the Central Balkan National Park by Popova (2003) suggested that indicators showing impact and success of ecotourism can assist in the better understanding of the impacts of ecotourism on the environment. Evaluation on whether the overall objectives of ecotourism have been met can be achieved by monitoring these indicators. To define whether a given region is sustainable in terms of tourism development impacts, a number of indicators are needed showing the relationship between tourism activities and the capacity of the area to sustain these impacts.

According to Bhattacharya and Kumari (2004), there is a need to develop an applied tool to measure threshold of tourism impacts and change in socioeconomic and environmental status. This can be done through developing Criteria and Indicator (C\&I) under the framework of sustainability. This should be a continuous process that encompasses societies responsibility towards sustainable livelihood generation through community-based ecotourism without any environmental degradation and erosion of cultural values.

Indicators are able to help managers and others to identify how communities change as a result of tourism development. Damage to the ecotourism resources could result in economic losses for those whose livelihoods depend on tourism, and, ecological and social losses for the local community.

According to Diamantis (2004), a good indicator is relevant, understandable, scientifically supportable and available when needed to make a difference to the decisions that tourism managers must make. 


\subsection{Discussion}

The constant evolution of ecotourism definitions reflects that it is still at an infancy stage. The emphasis may be changing over the years according to the industry's needs but the bottom line is, it has to conserve the environment and sustain the well being of local people. The elaboration of the definition may start from these two issues. Ecotourism today has been basically used as a tool, viewed differently according to the stakeholders. The government may see it as a foreign exchange earner without the similar adverse effects caused by mass tourism. Local villagers treat ecotourism as a way of personal betterment while tourists value ecotourism by their experience. Businesses use ecotourism as income generating means with ethics attached to it.

Tourism literature has shown that local community participation is seldom a straight forward issue in reality compared to a simplified theory model such as the one posed by Pretty and Arnstein. The literature usually highlighted the importance of the degree and scope of participation and only recent studies have included the quality of local community participation and its contribution to the success of development projects including ecotourism.

Here, defining success is closely related to the objectives of the chosen strategy and the process that communities undertake to achieve their goals. The various indicators that will be developed through the thesis are important to the stakeholder especially the planners and participants of ecotourism. However, since the research will be conducted in rural areas, there are other considerations that should be taken into account such as community pride and development of relationships. These are the dimensions of indicators that are less frequently mentioned in tourism literature.

The ecotourism concept would not fit the common definition of tourism without the element of community participation, which makes it critically significant. The study of the success of ecotourism will unavoidably include the success of 
local community participation, as it is one of the main elements. The literature review has given extensive definition and discussion on ecotourism and local community participation. However, it is also found that there is lack of writing in the subject of success and its indicators for ecotourism sites and local community participation. This is generally a concern to the writer as the study of success could contribute to the longevity of ecotourism sites and improve the process of local community participation.

The literature gaps highlighted the needs for attention to the specific aforementioned issues. Therefore, this thesis intends to fill the gap by tackling the issue of defining and measuring the success of ecotourism projects and local community participation. This is the reason why there were two research issues as previously discussed in Chapter One. Both issues i.e. 1) interpreting and developing the indicators for success of local community participation in Sabah, and 2) interpreting and developing the indicators for the success of ecotourism sites in Sabah, will address the gap from the literature review. The discussion from the literature review in this chapter also justifies the thesis research methodology.

With the intended literature gaps filled, this thesis contributes to a greater understanding of ecotourism development and local community participation. It will help local community participation advocates to evaluate and monitor the process with greater understanding. Ecotourism stakeholders may benefit from the knowledge to establish and operate successful ecotourism sites and local community participation process. Indicators developed from this thesis can be used as a baseline standard in auditing success. 


\section{CHAPTER 3. RESEARCH METHODOLOGY}

\subsection{Introduction}

The focus of this thesis is on the success of local community participation and ecotourism sites. Based on the research questions that expresses the need to develop and interpret indicators for success, it is essential to understand stakeholders' perceptions of success in local community participation and ecotourism sites, which includes a variety of factors such as financial sustainability, profitability, physical appearance and general satisfaction. The investigation focuses on what is meaningful to individuals and compares it to the industry. This has placed the research in an interpretive paradigm where the emphasis is on the richness of meaning.

The research issues need to be addressed by posing two key questions, asking about the success of both local community participation and ecotourism sites. These questions can be answered by completing eight research tasks, as outlined in Chapter One.

After taking a closer look, four groups of stakeholders have been determined as the main respondents for the research. These are the local community, government and NGOs, businesses and tourists. The government and NGOs are grouped together as they are great advocates of ecotourism and local community participation and often work together in Sabah. Tourists are determined as an important stakeholder as they are also directly involved in ecotourism and indirectly involved in local community participation advocacy, and the most effective data collection method for this group is using a survey with open ended questions. 


\subsection{Selection and Justification of Methodology}

There are two main methodologies employed in this thesis: 1) plans and policies analysis; and 2) comparative case studies. While the primary and secondary data research draws out the essential data to complete specific research tasks, analysing plans and policies and establishing case studies for research sites draws out other essential data of the ecotourism industry in Sabah. This is important to complete the research task of analysing the sets of indicators, where the findings from plans and policies and the case studies can give more insight and add justification to the analysis of the success of local community participation and ecotourism sites. This in turn, gives a valuable and realistic recommendation, not just to the academe, but to the industry as well.

Since the essence of this research is to understand the stakeholders' perception of success in local community participation and ecotourism sites, and also looking into what is meaningful to individuals and then comparing it to the industry, the nature of this research is purely qualitative. This type of research is able to build a strong and reliable foundation to uncover motivations, reasons, impressions, perceptions and ideas of individuals. According to Ida Peterson (1994), the characteristics of qualitative research includes extensive information from each respondent and a search for meaning, ideas and relevant issues. This can be justified with some understanding of the nature of qualitative research. According to Woods (2006), qualitative research consists of these features:

i. a focus on natural settings

ii. an interest in meanings, perspectives and understanding

iii. an emphasis on process

iv. inductive analysis and grounded theory 
Qualitative research is focused on natural settings as it is concerned with life as it is lived, things as they happen, situations as they are construed in the day-today, moment-to-moment course of events. It seeks lived experiences in real situations as this research is intended to. The research requires the researcher to spend time at these ecotourism sites, and interact with the stakeholders in order to understand the situation and gain familiarity on the issues that are in discussion.

Since perceptions are sought after, an interest in meanings, perspectives and understanding is essential in order to get the full view of the issue. The researcher has to interpret situations and discover the meanings of the perceptions and perspective on the success issue. Research methods have to be sensitive to the perspectives of all participants, and must sample across place and over time, as perspectives may vary accordingly. These features in qualitative research also require the researcher to be in close contact with the stakeholders, live with them and explore the nature of their interests and understand their relationships within and without.

According to Wood (2006), the validity of interactionists qualitative research commonly rests upon three main features, which are 1) unobtrusive, sustained methods; 2) respondents validation; and 3) triangulation. The validity of this research will be selected, justified and further explained at section 3.3.2. According to Tesch (1995) the analysis to qualitative data is not in dealing with a monolithic concept like 'statistics'. Qualitative researchers are quite adamant in their rejection of standardization. It is applied to a wide variety of principles and procedures. Qualitative researchers normally agree that the analysis is the process of making sense of narrative data. 


\subsubsection{Plan And Policy Analysis}

Official documents such as Malaysian Plans, National Tourism Policy, National Ecotourism Plan, Sabah Conservation Strategy, Outline Perspective Plan, Sabah Tourism Master Plan, and Sabah Ecotourism Guidelines are reviewed thoroughly. The documents are studied in detail during the research proposal development stage and analysis stage. The purpose of this exercise is to determine the context, importance and direction of ecotourism in Malaysia. Once that is established, it will help to set the framework and direction of the research.

The preparation and implementation of the plans and policies play a significant role in the tourism industry in Malaysia. They serve as guidelines to the stakeholders and also as a basis for more specific policies and plans at operational levels. The policy and plan analysis involves three basic steps (Fig. $3.1)$.

The identification and gathering of existing Plans and Policies for Malaysia revealed that there are three categories of such documents. The first is categorised under general such as Malaysian Plans and Outline Perspective Plan Sabah. The second category focuses on tourism and environment such as Sabah Tourism Master Plan and Sabah Biodiversity Conservation Strategy. The third category is specifically on ecotourism such as National Ecotourism Plan and Sabah Ecotourism Guidelines. 


\section{Figure 3. 1 Three Steps in Policy and Plan Analysis}

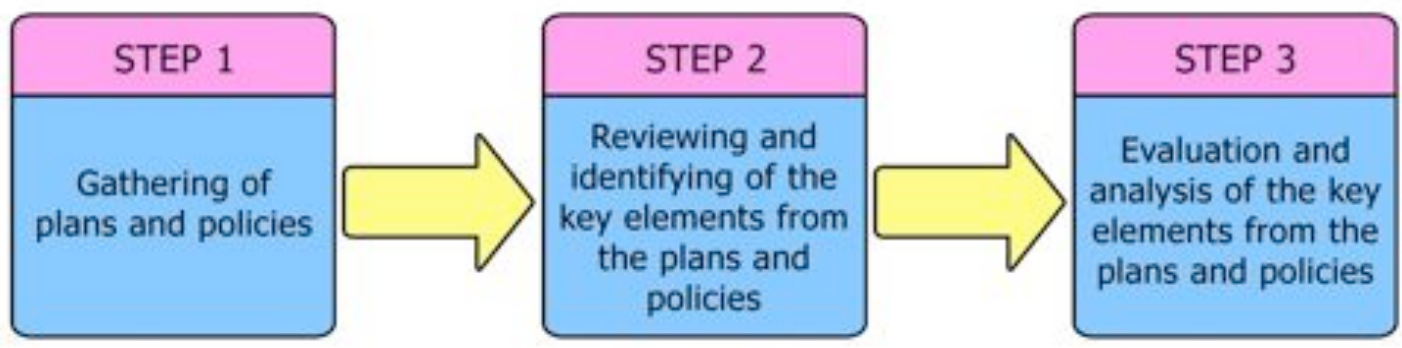

The Plans and Policies were reviewed against the literature review where it is analytically criticized based on the contemporary concepts of ecotourism and local community participation taken from the literature review. Key elements that are related to the research questions and objectives were singled out. Textual analysis was done prior to fieldwork and reviewed once the fieldwork was completed. The overall assessment and analysis of the policies and plans are presented in the next chapter, setting up the thesis analysis in the discussion chapter.

\subsubsection{Comparative Case Studies Method}

The methodology selected is based on the nature of this research which is the comparative case study method; case study being one of several methods of conducting social science research. Case studies are the preferred method when 'how' or 'why' questions are being posed, when the researcher has little control over events and when the focus is on a contemporary phenomenon within some real-life context. The case study aims to understand the case in depth, and in its natural setting, recognising its complexity and its context. It also has a holistic focus, aiming to preserve and understand the wholeness and unity of the case (Yin, 1994). 
This method is an empirical inquiry that investigates a contemporary phenomenon within its real-life context, especially when the boundaries between phenomenon and context are not clearly evident. It: 1) copes with the technically distinctive situation in which there will be many more variables of interest than data points, as one result; 2) relies on multiple sources of evidence, with data needing to converge in a triangulating fashion, as another result; and 3) benefits from the prior development of theoretical propositions to guide data collection and analysis (Figure 3.1).

In some fields, comparative case studies (or multiple-cases) have been considered a different 'methodology' than single-case studies. However, Yin (1994) stated that the choice between single and multiple-case designs remains within the same methodological framework with no broad distinction. The choice is considered one of research designs, with both being included under the case study strategy (Bordens and Abbott, 1991).

Comparative case study design has distinct advantages and disadvantages compared to single-case design. The evidence from multiple cases are often considered more compelling, and the overall study is therefore regarded as being more robust (Herriot \& Firestone, 1983). Conducting a multiple-case study research however, may require extensive resources and time beyond the means of a single researcher. This was taken into consideration before selecting this particular type of methodology.

When using a multiple-case design, the question of how many cases are deemed necessary or sufficient for the research arises. This research determined that five case studies are sufficient for this purpose. Five case studies give enough variety towards the local community participation structures and ecotourism sites. This method also uses sociological and anthropological field methods, such as observations in natural settings, interviews, and narrative reports. Open-ended 
questionnaires were also used, as tourist surveys are the most efficient method to draw out data from that particular group. This method is not necessarily a qualitative technique, though most case studies are predominantly qualitative. The research questions posed in chapter one requires a comparative study method as it involves multiple sites and each case study was chronologically developed.

\subsubsection{Concept Clarifications, Operational Definitions and Site Selection}

\section{Concept Clarification}

The concept clarification is essential in building the methodological framework. The framework specifies and sets up the parameters of the subject that needs to be researched. There are three items that need to be clarified before going into the field. These three items are the local community, ecotourism sites, and local community participation. Clarification helps to complete two research tasks, which are 1) Determine what local community is, in the Sabah context; and 2) Determine what makes a site an ecotourism site, in the Sabah context. Sets of questions were developed as a checklist for clarifying a concept. The questions were then grouped into two: major and minor considerations. Major consideration questions had to be answered and satisfied. They are the determinants of a subject. Minor consideration questions posed a finer inquiry into the major consideration questions. They refine the selection of a subject. 


\section{Table 3. 1 Local Community Clarifications}

\begin{tabular}{|c|c|}
\hline ITEMS TO CLARIFY & JUSTIFICATION \\
\hline \multicolumn{2}{|c|}{ MAJOR CONSIDERATIONS } \\
\hline $\begin{array}{l}\text { Are the local community living in the area or } \\
\text { adjacent to the area? }\end{array}$ & $\begin{array}{l}\text { Community selected must live in the area or adjacent to } \\
\text { the area and involved in ecotourism project or venture as } \\
\text { they are affected by ecotourism operations (e.g. access to } \\
\text { jungle/river, resources, and employment opportunities. }\end{array}$ \\
\hline What is the formal boundary of the village? & $\begin{array}{l}\text { Community must live within an official boundary of a } \\
\text { village as dictated by Sabah Land and Survey Department. }\end{array}$ \\
\hline $\begin{array}{l}\text { Are they originally from the village (were they } \\
\text { born there)? }\end{array}$ & $\begin{array}{l}\text { In some villages, residents who were not born in the } \\
\text { village are usually considered as an 'outsider'. They are } \\
\text { there because of reasons such as job opportunities e.g. } \\
\text { school teacher, plantation workers or married to local. A } \\
\text { community initiative project usually excludes these } \\
\text { residents but a non-community initiative (from both the } \\
\text { public and private sector) does not exclude them. } \\
\text { Therefore, the community selected is dependent on the } \\
\text { type of initiative involved. }\end{array}$ \\
\hline Do they live there? & $\begin{array}{l}\text { It is common to find villagers who live outside their own } \\
\text { village (i.e. second house, owned and rented in cities, } \\
\text { towns or other villages for various reasons, while still } \\
\text { retaining their own house back in the village. If there is an } \\
\text { event at the village, they usually travel back to participate } \\
\text { and be part of it. It is common that the villagers are } \\
\text { related to each other at various levels and most of the } \\
\text { events held in the village are considered 'family affairs'. } \\
\text { Therefore, the villagers who live outside the village are still } \\
\text { included as local community. }\end{array}$ \\
\hline \multicolumn{2}{|c|}{ MINOR CONSIDERATIONS } \\
\hline Do they belong to an ethnic group? & $\begin{array}{l}\text { It is common to find in a village that the ethnic origins of } \\
\text { the local community are homogenous with very few } \\
\text { variations as a result of intermarriages and migration. It is } \\
\text { possible to encounter the exclusion of other minor ethnic } \\
\text { groups in a community in many forms including local } \\
\text { participation. This has to be noted when a community is } \\
\text { selected. }\end{array}$ \\
\hline What are their nationalities? & $\begin{array}{l}\text { Some of the residents in a village are immigrants and/or } \\
\text { with refugees status from neighbouring countries, notably } \\
\text { Philippines and Indonesia. Their participation may be } \\
\text { limited only to employment. It is acceptable in Sabah that } \\
\text { the immigrants and refugees are excluded in any decision } \\
\text { making process in any major development project. The } \\
\text { community selected must be composed of Malaysian } \\
\text { citizens. }\end{array}$ \\
\hline Any issues of intermarriages? & $\begin{array}{l}\text { In most cases of intermarriage, the person who marries a } \\
\text { villager will not automatically be included in decision- } \\
\text { making process. However, in many cases, intermarriages } \\
\text { with immigrants and refugees will result in the spouse and } \\
\text { children from the marriage having the legal rights to } \\
\text { participate in any village events. The community selected } \\
\text { will include spouse and children from intermarriages with } \\
\text { 'outsiders' }\end{array}$ \\
\hline
\end{tabular}

The local communities are put in a framework where it clarifies the residency status of the locals, the boundary of the area that they live in i.e. village, subdistrict or district, origin and birthplace, nationalities and the social structure. The clarification is important as it determines who the local communities are. This will 
set the boundary for the community that is involved in local community participation activities within the ecotourism sites. The clarifications are determined as in Table 3.1.

The second item to be clarified is the ecotourism site. Many sites claimed that they are ecotourism sites yet they may not comply with the recommended ecotourism guidelines. Ecotourism sites should at least reflect the recommended guidelines set out in the Sabah Ecotourism Guidelines. The clarification sets the characteristics of ecotourism sites that are selected for this research. This also helps the sites to be as characteristically close as possible, and assists in building a strong foundation for the comparative case studies analysis that was chosen as one of the methodologies. The clarification is illustrated as Table 3.2.

\section{Table 3, 2 Ecotourism Site Clarifications}

\begin{tabular}{|l|l|}
\hline ITEMS TO CLARIFY & JUSTIFICATION \\
\hline Type of tourism activity? & MAJOR CONSIDERATIONS \\
\hline Type of attractions? & $\begin{array}{l}\text { In ecotourism, the prime motivation is the observation and } \\
\text { appreciation of natural features and related cultural assets. } \\
\text { Selected ecotourism sites must comply with these criteria. }\end{array}$ \\
\hline Community involvement? & $\begin{array}{l}\text { Ecotourism attractions may be classified in three basic } \\
\text { categories: flagship, complementary and support. Selected } \\
\text { ecotourism sites must have at least one flagship attraction } \\
\text { that gives them strong ecotourism potential. }\end{array}$ \\
\hline Practices? & $\begin{array}{l}\text { Successful ecotourism requires the creation and } \\
\text { involvement of local stakeholders (individuals and } \\
\text { communities), and an emphasis on local investment and } \\
\text { control and decision-making. Selected ecotourism sites } \\
\text { must have a degree of participation at various levels. }\end{array}$ \\
\hline Status of site protection? & $\begin{array}{l}\text { Good practices cover a broad range such as design criteria } \\
\text { for ecotourism facilities, zoning, architectural shape, } \\
\text { building technology, nature trails, refuse treatment, water } \\
\text { management, local employment etc. An ecotourism site } \\
\text { must at least practise one of them. }\end{array}$ \\
\hline Label? & $\begin{array}{l}\text { Ecotourism sites usually in or adjacent to land with status } \\
\text { of protection. There are many types of status such as } \\
\text { World Heritage Site, Wildlife Sanctuary and Forest Reserve } \\
\text { etc. An ecotourism site must have a site protection status. }\end{array}$ \\
\hline
\end{tabular}

The last item that needs to be clarified is the local community participation. The 
clarification involved determines the level and type of participation, selection of participation, decision-making process and goals of local community participation. This determines the guidelines for selecting local community participation as illustrated in Table 3.3.

\section{Iable 3, 3 Local Community Participation Clarifications}

\begin{tabular}{|c|c|}
\hline ITEMS TO CLARIFY & JUSTIFICATION \\
\hline \multicolumn{2}{|c|}{ MAJOR CONSIDERATIONS } \\
\hline Level and type of participation? & $\begin{array}{l}\text { Local community participation must have a form of } \\
\text { participation, including the 'weakest form' of participation } \\
\text { i.e. manipulative participation. }\end{array}$ \\
\hline Who is involved (individual/community)? & $\begin{array}{l}\text { Involvement varies from individuals, group of individuals to } \\
\text { the whole community. Local community participation must } \\
\text { at least include one type or level of participation. }\end{array}$ \\
\hline Who makes the decision? & $\begin{array}{l}\text { The decision maker has to be identified. This will give } \\
\text { insight on the scope of the local community participation } \\
\text { process. }\end{array}$ \\
\hline $\begin{array}{l}\text { Goals and objectives of local community } \\
\text { participation? }\end{array}$ & $\begin{array}{l}\text { The goal and objectives of local community participation } \\
\text { are either for local benefits or personal benefits (e.g. self } \\
\text { development) }\end{array}$ \\
\hline \multicolumn{2}{|c|}{ MINOR CONSIDERATIONS } \\
\hline Social structure? & $\begin{array}{l}\text { Usually men in Sabah are involved in all forms of local } \\
\text { community participation. Women and youth are usually } \\
\text { only involved when they are invited. Within the group of } \\
\text { men, it is normal to elect an existing leader to become the } \\
\text { representative or the voice in a committee. The existing } \\
\text { leaders are the Ketua Kampung (Headman), Pengerusi } \\
\text { jawatankuasa Kemajuan dan Keselamatan Kampung or } \\
\text { JKKK (Chairman of the Village Development and Security } \\
\text { Committee or VDSC), Guru Besar or Pengetua (Headmaster } \\
\text { or Principal of primary and secondary school) and the } \\
\text { Imam (Islamic leader who is in charge of leading the } \\
\text { prayer in a mosque or surau). The comprehensive social } \\
\text { structure in a community must be taken into consideration } \\
\text { when assessing the local community participation. }\end{array}$ \\
\hline
\end{tabular}

The clarification development is based on literature review and discussion with potential respondents. It is a useful exercise to ensure that the thesis has its framework and it has a clear direction based on the framework.

\section{Operational Definition}

This thesis adopted the World Conservation Union (1996) definition of ecotourism as its operational definition (pp 47). It has a comprehensive definition where nature and local community participation are both included. This definition 
fits into the idea of this thesis where discussion on both local community participation and ecotourism ideas are the central themes.

\section{Site Selection}

The site selection begins with the identification of ecotourism sites (Table 3.4). Ecotourism sites are selected based on the label that is used i.e. using the term 'ecotourism' in their marketing etc., and sites that fit into the ecotourism generic characteristics as dictated by the operational definition of the research. The sites listed were further trimmed using criteria that have been developed to ensure that the sites selected will do justice to the research. These characteristics were developed based on secondary research during the proposal research development. The selection criteria are as follows:

\section{Table 3, 4 Ecotourism Site Clarifications}

\begin{tabular}{|l|l|}
\hline ITEMS TO CLARIFY & JUSTIFICATION \\
\hline Type of activities & MAJOR CONSIDERATIONS \\
\hline Type of attractions & $\begin{array}{l}\text { The activities at the selected ecotourism site must have the } \\
\text { prime motivation of observation and appreciation of natural } \\
\text { features and related cultural assets. }\end{array}$ \\
\hline Community involvement & $\begin{array}{l}\text { Selected ecotourism sites must have at least one flagship } \\
\text { attraction. This refers to distinctive elements of natural } \\
\text { and/or cultural heritage, which are found in such a site. }\end{array}$ \\
\hline Eco-practices & $\begin{array}{l}\text { Selected ecotourism sites must have a degree of local } \\
\text { community participation at any level. }\end{array}$ \\
\hline Status of site protection & $\begin{array}{l}\text { The area and facilities at the selected ecotourism site } \\
\text { should incorporate at least one eco-design in its facilities, } \\
\text { environmental zoning, nature trails management, refuse } \\
\text { treatment practices, employing local communities and } \\
\text { similar concepts. }\end{array}$ \\
\hline & $\begin{array}{l}\text { Selected ecotourism sites must be in or adjacent to an area } \\
\text { with protection status such as World Heritage Site, Wildlife } \\
\text { Sanctuary and Forest Reserve }\end{array}$ \\
\hline
\end{tabular}

Initially, potential sites were those that were identified as ecotourism sites or ecotourism potential sites around Sabah based on the National Ecotourism Plan and also sites that were identified by Sabah Tourism Board ${ }^{3}$, which were not included in the National Ecotourism Plan. These sites are located at Turtle Island

\footnotetext{
${ }^{3}$ Interview with Sabah Tourism Board in 2003.
} 
Parks, Pulau Sipadan, Tunku Abdul Rahman Parks, Tambunan, Sepilok Forest Reserve, Danum Valley, Lower Kinabatangan Region, Keningau, Padas River, Kiulu River, Kudat, Lower Segama River, Gomantong and Batu Punggul. A total of 15 sites were selected all over Sabah. These sites underwent a selection process based on the characteristics as predetermined below and its feasibility as a study site (Table 3.5). 
Table 3. 5 Selections of Sites

\begin{tabular}{|c|c|c|c|}
\hline SITES & $\begin{array}{l}\text { SUMMARY ECOTOURISM } \\
\text { CHARACTERISTICS }\end{array}$ & $\begin{array}{l}\text { JUSTIFICATION FOR } \\
\text { ACCEPTANCE OR } \\
\text { REJECTION }\end{array}$ & VERDICT \\
\hline 1. BATU PUNGGUL & $\begin{array}{ll} & \text { Nature-adventure activities with } \\
& \text { local community participation } \\
\text { - } & \text { Employing eco-practices } \\
\text { - } & \text { Protected Area } \\
\end{array}$ & Ceased operation in 1999 & Rejected \\
\hline $\begin{array}{l}\text { 2. BORNEO } \\
\text { RAINFOREST } \\
\text { RESEARCH CENTRE, } \\
\text { DANUM VALLEY }\end{array}$ & $\begin{array}{ll}\text { - } & \text { Nature, Education and soft- } \\
\text { adventure with conservation } \\
\text { activities } \\
\text { - } \quad \text { Employing eco-practices } \\
\text { - } & \text { Protected Area } \\
\end{array}$ & No local community participation & Rejected \\
\hline $\begin{array}{l}\text { 3. SELINGAN } \\
\text { ISLAND, TURTLE } \\
\text { ISLAND PARKS }\end{array}$ & $\begin{array}{ll}\text { - } & \text { Nature and education activities } \\
\text { revolving around the turtle } \\
\text { colony } \\
\text { - } \quad \text { Protected Area } \\
\end{array}$ & No local community participation & Rejected \\
\hline $\begin{array}{l}\text { 4. PULAU SIPADAN, } \\
\text { SEMPORNA }\end{array}$ & $\begin{array}{ll} & \text { Diving, education, marine } \\
\text { ecotourism with conservation } \\
\text { effort } \\
\text { - } \quad \text { Protected Area } \\
\end{array}$ & No local community participation & Rejected \\
\hline $\begin{array}{l}\text { 5. TUNKU ABDUL } \\
\text { RAHMAN PARKS } \\
\text { (CONSISTING OF A } \\
\text { GROUP OF FIVE } \\
\text { ISLANDS) } \\
\end{array}$ & $\begin{array}{ll}\text { - } & \text { Marine ecotourism with } \\
\text { conservation effort } \\
\text { Protected Area }\end{array}$ & No local community participation & Rejected \\
\hline $\begin{array}{l}\text { 6. SEPILOK } \\
\text { REHABILITATION } \\
\text { CENTRE, SEPILOK } \\
\text { FOREST RESERVE }\end{array}$ & $\begin{array}{l}\text { - Rehabilitation of Orang Utan and } \\
\text { conservation of forest reserve } \\
\text { effort } \\
\text { Protected Area }\end{array}$ & No local community participation & Rejected \\
\hline $\begin{array}{l}\text { 7. RAFFLESIA } \\
\text { INFORMATION } \\
\text { CENTRE, TAMBUNAN }\end{array}$ & $\begin{array}{l}\text { - } \quad \text { Nature and education focusing } \\
\text { on conservation of the Rafflesia } \\
\text { Flower with local community } \\
\text { participation } \\
\text { - } \quad \text { Employing eco-practices } \\
\text { - Protected Area }\end{array}$ & $\begin{array}{l}\text { Feasible study site based on the } \\
\text { predetermined characteristics } \\
\text { Able to give government and } \\
\text { community dimensions to the } \\
\text { thesis }\end{array}$ & Accepted \\
\hline $\begin{array}{l}\text { 8. KG. SUKAU, } \\
\text { LOWER } \\
\text { KINABATANGAN } \\
\text { REGION }\end{array}$ & $\begin{array}{l}\text { - Nature and soft-adventure with } \\
\text { proboscis monkey as the key } \\
\text { attraction and few lodges that } \\
\text { employed environmentally- } \\
\text { friendly practices } \\
\text { - Includes conservation activities } \\
\text { - Protected Area }\end{array}$ & $\begin{array}{l}\text { Feasible study site based on the } \\
\text { predetermined characteristics } \\
\text { Able to give the business and } \\
\text { community dimensions to the } \\
\text { thesis }\end{array}$ & Accepted \\
\hline $\begin{array}{l}\text { 9. BATU PUTEH, } \\
\text { LOWER } \\
\text { KINABATANGAN } \\
\text { REGION }\end{array}$ & $\begin{array}{ll}\text { - } & \text { Nature and soft-adventure with } \\
\text { home stay and local culture as } \\
\text { the attraction } \\
\text { - Includes conservation activities } \\
\text { and effort } \\
\text { - Employing eco-practices } \\
\text { - Protected Area }\end{array}$ & $\begin{array}{l}\text { Feasible study site based on the } \\
\text { predetermined characteristics } \\
\text { Able to give the community and } \\
\text { NGO dimensions to the thesis }\end{array}$ & Accepted \\
\hline $\begin{array}{l}\text { 10. KAMPUNG BILIT, } \\
\text { LOWER } \\
\text { KINABATANGAN } \\
\text { REGION }\end{array}$ & $\begin{array}{l}\text { - Nature with home stay and local } \\
\text { culture as the attraction } \\
\text { Protected Area }\end{array}$ & $\begin{array}{l}\text { Feasible study site based on the } \\
\text { predetermined characteristics } \\
\text { but too close to Sukau and the } \\
\text { study needs more } \\
\text { representation around Sabah } \\
\text { geographically }\end{array}$ & Rejected \\
\hline 11. PADAS RIVER & $\begin{array}{l}\text { Soft-adventure with white water } \\
\text { rafting as the key attraction } \\
\text { Non-protected area }\end{array}$ & $\begin{array}{l}\text { No local community participation } \\
\text { Mainly for day trippers } \\
\text { Non-protected area }\end{array}$ & Rejected \\
\hline 12. KIULU RIVER & $\begin{array}{l}\text { Soft-adventure with white water } \\
\text { rafting as the key attraction } \\
\text { Non-protected area }\end{array}$ & $\begin{array}{l}\text { No local community participation } \\
\text { Mainly for day trippers } \\
\text { Non-protected area }\end{array}$ & Rejected \\
\hline
\end{tabular}




\begin{tabular}{|c|c|c|c|c|}
\hline $\begin{array}{l}\text { 13. LOWER SEGAMA } \\
\text { RIVER }\end{array}$ & & $\begin{array}{l}\text { Nature attraction } \\
\text { Non-protected area }\end{array}$ & $\begin{array}{l}\text { Not a popular ecotourism } \\
\text { attraction, therefore it is not } \\
\text { feasible in terms of number of } \\
\text { respondents } \\
\text { Non-protected area }\end{array}$ & Rejected \\
\hline $\begin{array}{l}\text { 14. KAMPUNG } \\
\text { RANTAI }\end{array}$ & $\bullet$ & $\begin{array}{l}\text { Nature and soft-adventure } \\
\text { attraction with Rafflesia and } \\
\text { traditional medicine garden as } \\
\text { the attraction with local } \\
\text { community participation } \\
\text { Employing eco-practices } \\
\text { Protected area }\end{array}$ & $\begin{array}{l}\text { Feasible study site based on the } \\
\text { predetermined characteristics } \\
\text { Able to give the community and } \\
\text { NGO dimensions to the thesis }\end{array}$ & Accepted \\
\hline $\begin{array}{l}\text { 15. KAMPUNG } \\
\text { BAVANGGAZO, } \\
\text { KUDAT }\end{array}$ & & $\begin{array}{l}\text { Nature and soft-adventure } \\
\text { attraction with home stay and } \\
\text { culture as the attraction with } \\
\text { local community participation } \\
\text { Employing eco-practices } \\
\text { Protected area }\end{array}$ & $\begin{array}{l}\text { Feasible study site based on the } \\
\text { predetermined characteristics } \\
\text { Able to give the community and } \\
\text { government dimensions to the } \\
\text { thesis }\end{array}$ & Accepted \\
\hline
\end{tabular}

Finally, five ecotourism sites were identified which fits the characteristics that were selected for this research after a process of elimination. The sites are as in Table 3.6.

During the process of elimination, the geographical locations of the sites were also taken into consideration. The location of these five sites are spatially spread out in the State of Sabah, which makes it representative to the research in terms of geographical locations. Kampung Bavanggazo is located in the north, both Batu Puteh and Sukau are located in the East and the Rafflesia Information Centre and Kampung Rantai are in the interior. The five sites were also selected based on their feasibility for case study comparison. All of them share the same characteristics as depicted in the earlier table i.e. type of attractions and activities where all these sites are involved in nature and culture, have local involvement, use eco-practices, and are protected. However, there are differences in the ownership. The local community runs Kampung Bavanggazo and Kampung Rantai ecotourism operations while Batu Puteh's operation involves both the local community and NGOs. Sukau's ecotourism operation is mainly run by the private sector and Rafflesia Information Centre is run by the government. While these differences in the ownership are found in the pool of the case study sites, this will not affect the results of the case study analysis as 
these sites share common characteristics. The differences also will give insights on the success factor, whether the government, private sector or locally owned operation have differences in the degree of success. This will add more justification in terms of reliability of the results.

\section{Iable 3, 6 Sites Selected with its Characteristics}

\begin{tabular}{|c|c|c|c|c|c|}
\hline $\begin{array}{l}\text { SITE/ } \\
\text { CHARACTERISTICS }\end{array}$ & $\begin{array}{l}\text { KAMPUNG } \\
\text { BAVANGGAZO }\end{array}$ & BATU PUTEH & SUKAU & $\begin{array}{l}\text { RAFFLESIA } \\
\text { INFORMATION } \\
\text { CENTRE }\end{array}$ & $\begin{array}{l}\text { KAMPUNG } \\
\text { RANTAI }\end{array}$ \\
\hline Type of activities & $\begin{array}{l}\text { Trekking/nature } \\
\text { walks } \\
\text { Demonstration of } \\
\text { traditional animal } \\
\text { traps } \\
\text { Visits to the field }\end{array}$ & $\begin{array}{l}\text { Wildlife watching } \\
\text { Participating in } \\
\text { villagers activity }\end{array}$ & Wildlife watching & Trekking & $\begin{array}{l}\text { Trekking } \\
\text { Participating in } \\
\text { villagers } \\
\text { activity }\end{array}$ \\
\hline Type of attractions & $\begin{array}{l}\text { Nature, culture } \\
\text { and } \\
\text { complementary }\end{array}$ & $\begin{array}{l}\text { Nature, culture } \\
\text { and } \\
\text { complementary }\end{array}$ & $\begin{array}{l}\text { Nature, culture } \\
\text { and } \\
\text { complementary }\end{array}$ & $\begin{array}{l}\text { Nature, culture } \\
\text { and } \\
\text { complementary }\end{array}$ & $\begin{array}{l}\text { Nature, culture } \\
\text { and } \\
\text { complementary }\end{array}$ \\
\hline $\begin{array}{l}\text { Community } \\
\text { involvement }\end{array}$ & $\begin{array}{l}\text { Everybody } \\
\text { involved. Each } \\
\text { family delegated } \\
\text { to one task and } \\
\text { has its own } \\
\text { committee }\end{array}$ & $\begin{array}{l}\text { MESCOT } \\
\text { members. } \\
\text { Some locals with } \\
\text { skills }\end{array}$ & $\begin{array}{l}\text { WWF-Malaysia } \\
\text { (Sabah) for } \\
\text { Partners for } \\
\text { Wetlands. } \\
\text { Projects as } \\
\text { consultant }\end{array}$ & $\begin{array}{l}\text { Sabah Forestry } \\
\text { Department, } \\
\text { hiring local } \\
\text { people to } \\
\text { become rangers }\end{array}$ & $\begin{array}{l}\text { Everybody } \\
\text { involved (every } \\
\text { villager }\end{array}$ \\
\hline Eco-practices & $\begin{array}{l}\text { Reuse practice, } \\
\text { conserving water } \\
\text { catchments on } \\
\text { Gomantong Hill }\end{array}$ & $\begin{array}{l}\text { Forest } \\
\text { conservation, } \\
\text { forest } \\
\text { restoration, } \\
\text { phonological } \\
\text { trails, nursery } \\
\text { propagation, tree } \\
\text { planting }\end{array}$ & $\begin{array}{l}\text { Waste } \\
\text { management, } \\
\text { solar energy, } \\
\text { reuse practice }\end{array}$ & $\begin{array}{l}\text { Conserving } \\
\text { Rafflesia species }\end{array}$ & $\begin{array}{l}\text { Conserving } \\
\text { water } \\
\text { catchments } \\
\text { that provides } \\
\text { water for the } \\
\text { Bundu Apin- } \\
\text { Apin area. }\end{array}$ \\
\hline $\begin{array}{l}\text { Status of site } \\
\text { protection }\end{array}$ & $\begin{array}{l}\text { Village Reserve } \\
\text { (5 Acres) }\end{array}$ & $\begin{array}{l}\text { Wildlife } \\
\text { Sanctuary Area } \\
\text { Virgin Forest } \\
\text { Reserve (Class 6) } \\
1000 \text { Hectares } \\
\text { for ecolodge }\end{array}$ & $\begin{array}{l}\text { Wildlife } \\
\text { Sanctuary Area }\end{array}$ & $\begin{array}{l}\text { Virgin Forest } \\
\text { Reserve ( } 356 \\
\text { hectares) }\end{array}$ & $\begin{array}{l}\text { Village Reserve } \\
\text { (11 acres) } \\
\text { Virgin Forest } \\
\text { Reserve Class I } \\
\text { (at the } \\
\text { surrounding } \\
\text { area of water } \\
\text { catchments) }\end{array}$ \\
\hline
\end{tabular}

The site selection also reflects the feasibility of conducting research at these sites, in terms of accessibility, data collection, cost, and permission. An initial enquiry was made to the authorities of the sites during the proposal development to ensure its feasibility. 
Since the research is focused on local community participation, it is essential to ensure that the sites have a certain level of local involvement in ecotourism operations. Local community participation is clarified as per based on the guidelines in Table 3.3. All of the sites have community involvement with different levels of participation. Since the levels of participation in all sites are different and in different contexts, this issue will be addressed in the analysis, where rank of importance will be used. There is another issue that needs to be addressed, which is the ownership. The sites have different ranges of ownership. Each community operates their own ecotourism operations and community participation projects at Kampung Bavanggazo, Batu Puteh and Kampung Rantai, while the government operates Rafflesia Information Centre. In Sukau, a pool of local tour operators are the main operators of the ecotourism industry. These differences will be highlighted in the analysis. 


\subsection{Data Collection Method}

\subsubsection{Introduction}

In $\mathrm{PhD}$ research, there is little room for a traditional research assistant. Rather, a well-trained and experienced researcher is needed to conduct quality case studies because of the continuous interaction between the theoretical issues being studied and the data being collected. The primary instrument for the fieldwork data collection and analysis in this research is the researcher. The researcher's past experience in the tourism field also helped him to improve research reliability and minimise the gaps between respondents and the researcher.

There were two fieldwork trips made during the course of this research. The first field trip was conducted at the end of $\mathbf{2 0 0 2}$ for the duration of six months. The main objective of the first field trip is to collect all the necessary primary data, which requires the researcher to spend many days interviewing respondents in both urban and rural areas (i.e. research sites). The field trip also provided the opportunity for the researcher to attend the $1^{\text {st }}$ Asia Pacific Ecotourism Conference in Kota Kinabalu, Malaysia.

Since the research is qualitative in nature, there is the need to triangulate the data in order to strengthen the validity and reliability of the data used. Therefore, a second field trip was required. This was done six months after the first field trip and lasted a duration of three months. The objective of this second field trip was to complete the data collection and to fill in the gaps that arose from the first field trip, to update the data and to triangulate the data by revisiting the sites and respondents and obtaining confirmation on data previously gathered. Triangulation is done in many ways depending on the availability of the respondents. It ranges from a form of presentation to the 
respondents or representative of respondents (e.g. Headmen of a village where a group of villagers were the respondents) to confirmation via post, where the data is in the form of hardcopy presentation slides. This field trip also provided the opportunity to the researcher to attend the $2^{\text {nd }}$ Asia Pacific Ecotourism Conference in Langkawi, Malaysia.

Data collection for this research is gathered from various sources of evidence. Evidence includes documentation, archival records, interviews, direct observations, participant-observations, and physical artifacts. The data collection method for this research can be justified as per Table 3.7. It is a useful overview of the six major sources, taking into consideration their comparative strengths and weaknesses. No single source has a complete advantage over any of the others. Various sources are highly complementary and it is better to use as many sources as possible.

The research gets its data from documentation, archival records, interviews and direct observation. The documentation and archival records were gathered from a variety of sources in Wellington, New Zealand and Sabah, Malaysia. Fieldwork notes were made during and immediately after each interview and observation session. Observation in this context includes listening as well as looking, everyday face-to-face interaction, and group meetings (with the local community) that depends heavily on both verbal and visual behaviours. In naturalistic observation, observers neither manipulate nor stimulate the behaviour of those whom they are observing and this is known as pure or direct and non-participant observation. Observations are made and recorded during fieldwork. The observations are useful in clarifying data especially during visits after interviewing the respondents. 
Table 3. 7 Six Sources of Evidence: Strengths and Weaknesses

\begin{tabular}{|c|c|c|}
\hline SOURCE OF EVIDENCE & STRENGTHS & WEAKNESSES \\
\hline Documentation/Literature & $\begin{array}{l}\text { Stable - can be reviewed repeatedly } \\
\text { Unobtrusive - not created as a result } \\
\text { of the case study } \\
\text { Exact - contains exact names, } \\
\text { references, and details of an event } \\
\text { Broad coverage - Long span of time, } \\
\text { many events, and many settings }\end{array}$ & $\begin{array}{l}\text { Retrievability - can be low } \\
\text { biased selectivity, if collection is } \\
\text { incomplete } \\
\text { Reporting bias - reflects } \\
\text { (unknown) bias of author } \\
\text { Access - may be deliberately } \\
\text { blocked }\end{array}$ \\
\hline Archival Records & $\begin{array}{l}\text { [Same as above for } \\
\text { documentation] } \\
\text { Precise and quantitative }\end{array}$ & $\begin{array}{l}\text { [Same as above for } \\
\text { documentation] } \\
\text { Accessibility due to privacy } \\
\text { reasons }\end{array}$ \\
\hline Interviews & $\begin{array}{l}\text { Targeted - focuses directly on case } \\
\text { study topic } \\
\text { Insightful - provides perceived causal } \\
\text { inferences }\end{array}$ & $\begin{array}{l}\text { Bias - due to poorly } \\
\text { constructed questions } \\
\text { Response bias } \\
\text { Inaccuracies - due to poor } \\
\text { recall } \\
\text { Reflexivity - interviewee gives } \\
\text { what interviewer wants to hear }\end{array}$ \\
\hline Direct Observations & $\begin{array}{l}\text { Reality - covers events in real time } \\
\text { Contextual - covers context of events }\end{array}$ & $\begin{array}{l}\text { Time-consuming } \\
\text { Selectivity - unless broad } \\
\text { coverage } \\
\text { Reflexivity - event may } \\
\text { proceed differently because it is } \\
\text { being observed } \\
\text { Cost - hours needed by human } \\
\text { observers }\end{array}$ \\
\hline Participant - Observation & $\begin{array}{l}\text { [Same as above for direct } \\
\text { observations] } \\
\text { Insightful - into interpersonal } \\
\text { behaviour and motives }\end{array}$ & $\begin{array}{l}\text { [Same as above for direct } \\
\text { observations] } \\
\text { Bias - due to investigator's } \\
\text { manipulation of events }\end{array}$ \\
\hline Physical Artifacts & $\begin{array}{l}\text { Insightful - into cultural features } \\
\text { Insightful - into technical operations }\end{array}$ & $\begin{array}{l}\text { Selectivity } \\
\text { Availability }\end{array}$ \\
\hline
\end{tabular}

Source: Yin (1994) 
Given the nature of infancy of the ecotourism industry in Sabah and lack of academic writings on it, there is little secondary data dealing with ecotourism and its local community participation. Therefore, primary research is used mainly to gather data for the thesis. Data is strengthened via the triangulation process.

\subsubsection{Validating Research}

There are a number of variations in validating qualitative research namely 1) unobtrusive, sustained methods; 2) respondent validation; and 3) triangulation. Based on the number of respondents and the time taken to acquire the data (short-term interaction), the unobtrusive/sustained method is rejected.

Respondents' validation is to test how faithfully the researcher represents the respondents view. Since there were a lot of interviews conducted within this research, it is important to ensure that all the data is validated and can be considered reliable. After the respondents were interviewed, the conversation that depicts the essence of the conversations was converted into a wordprocessed transcript and then sent back to the respondents so that they could then validate that the transcripts as correct and accurate.

Another method of validation in qualitative research that this research employed is triangulation, where information learned at an interview is reinforced by other sources. Triangulation implies that a single point is considered from multiple and independent sources. It means that the same phenomenon or research question is looked at from more than one source of data. Information coming from different angles can be used to corroborate, elaborate or illuminate the research problem. It limits personal and methodological biases and enhances a study's generalisability (Decrop, 1999). Triangulation is normally used to assist in establishing trustworthiness in qualitative research. Trustworthiness includes 
credibility (internal validity), transferability (external validity), dependability (reliability) and conformability (objectivity). It is usually implemented in a research design.

A major strength of case study data collection is the opportunity to use many different sources of evidence. It allows a researcher to address a broader range of historical, attitudinal and behavioural issues. The most important advantage presented by using multiple sources of evidence is the development of converging lines of inquiry, a process of triangulation. Therefore, any finding or conclusion in a case study is likely to be much more convincing and accurate if it is based on several different sources of information.

With triangulation, the potential problems of constructing validity can also be addressed, as the multiple sources of evidence for this research are essentially providing multiple measures of the same phenomenon. Using multiple sources of evidence is rated more highly, in terms of overall quality, than using only one single source of information (Yin, Bateman \& Moore, 1983). In addition to this, the second fieldwork was done to ensure the data collected is correct and up to date.

\subsubsection{Secondary Data Research}

Secondary data refers to the information collected for a purpose other than that of the researcher - in this sense the researcher becomes the secondary user of the data. Secondary data research is a necessary first step in any research design, and forms an important part of the literature review stage. Secondary sources should always be consulted first as one may find that the information needed is already there. Time, effort and fund can therefore be saved if there is available data, so secondary data research should always come before primary data research. In the secondary data analysis in this research, data from various 
sources are merged (where appropriate) in order to provide larger and more useable data sets if the data is compatible.

The secondary data research activities include:

i. Data search at libraries of Universiti Malaysia Sabah, Victoria University of Wellington, University of Otago, Dunedin and University of Canterbury, Christchurch;

ii. Data search at Sabah Tourism Board's research centre;

iii. Compiling personal previous research materials;

iv. Data search on the Internet;

v. Visiting research sites and respondents and collecting printed materials.

The researcher also attended relevant conferences, namely the $1^{\text {st }}$ Asia Pacific Ecotourism Conference in Sabah Malaysia, $2^{\text {nd }}$ Asia Pacific Ecotourism Conference in Langkawi, Malaysia and Seminar on Tourism Product Gaps \& Investment Opportunities in Sabah in Kota Kinabalu, Malaysia. The $1^{\text {st }}$ Asia Pacific Ecotourism Conference in Sabah was attended at the start of the first fieldwork. This presented a great opportunity to get updated information on ecotourism industry in Sabah and to get to know the players of the industry and set up interviews with them. There was a specific session on ecotourism and the major industry players attended it. Renewing contacts and getting updates were the benefits of attending that seminar. The $2^{\text {nd }}$ Asia Pacific Ecotourism Conference in Langkawi was attended at the start of the second period of fieldwork. There were relevant papers that related to local community participation and ecotourism in Sabah. Getting updates was the main benefit from attending the conference. 


\subsubsection{Primary Data Research}

The lack of academic writing on the subject of success for local community participation and ecotourism sites in Sabah made the primary data research crucial in this thesis. The key objective of primary data research is to obtain data, which is representative of the population. The main tool is an interview schedule, checklists for face-to-face interviews and a series of printed questions in the form of a questionnaire. It also includes a survey asking respondents direct questions in the form of self-administration questionnaires. The survey seeks explanations for observed variations. Both interview and survey are designed to address the research issues and answer the research questions as set in chapter one (Appendix 1-10). They were also designed to test the validity of published findings and established ideas in the literature review as per Chapter Two and the validity of these findings in the Sabah context. Interviews were conducted in English and Bahasa Malaysia (Malay Language). Both languages were mixed interchangeably most of the time. However, in the rural areas, Bahasa Malaysia (the official language in Malaysia) was used. In some villages, an interpreter was used to translate interviews verbally as some villagers speak only their own native language. Briefing on translation techniques were made to the translator by the researcher to get the most out of the exercise.

\subsection{Respondents}

In order to understand the contextual conditions of successful local community participation and ecotourism sites, data had to be gathered from various stakeholders. Four groups of stakeholders were identified and selected as the key respondents in this research due to their ability to give extensive information on the research issues based on their motivations, reasons, impressions, perceptions and ideas. This is the essence of qualitative research, which is the 
methodology of this research. All of them represent different groups of stakeholders in the ecotourism industry. They are 1) Local community 2) Government and its related agencies and Non-Governmental Organisations; 3) Businesses; and 4) Tourists.

In Malaysia, the government and its agencies together with the NonGovernmental Organisations are advocates of local community participation. They often work together in advocating this, by combining their resources and skills. In fact, one of the research sites that was selected for this research, Batu Puteh, is a good example where both government and NGOs work together to promote local community. In this site, WWF for Nature trained the local community in operating ecotourism activities. Sukau is also a good example where both government and NGOs worked together to gazette the Wildlife Sanctuary Area in order to conserve the area while promoting the ecotourism industry in the area to support conservation efforts (Bagul, 1999). In a research context, both the Government and its agencies and Non-Governmental Agencies are strong advocates of ecotourism and local community participation. While in other countries, NGOs may be in direct opposition to the government and its agencies, in Malaysia, they often work together in a consultative approach not just on project basis, but also in policy formation. Therefore it is imperative to put them both in one group as they both belong to the group that both has authority, resources and objectives when it comes to advocating ecotourism and local community participation. 
Table 3. 8 Respondents' Profile

\begin{tabular}{|c|c|c|c|c|}
\hline $\begin{array}{l}\text { TARGET } \\
\text { RESPONDENTS }\end{array}$ & $\begin{array}{l}\text { POPULATION } \\
\text { (Est.) }\end{array}$ & SAMPLE & $\begin{array}{l}\text { NO. OF } \\
\text { RESPONDENTS }\end{array}$ & $\begin{array}{l}\text { USABLE } \\
\text { QUESTIONNAIRES/ } \\
\text { QUALITY OF DATA }\end{array}$ \\
\hline Local Community & $\begin{array}{l}\text { Bavanggazo: } 30^{4} \\
\text { Batu Puteh: } 1200- \\
1400^{5} \\
\text { Sukau: } 2000 \\
\text { Rafflesia Information } \\
\text { Centre: } 24,000 \\
\text { Kampung Rantai: } \\
150^{6}\end{array}$ & $\begin{array}{l}20 \text { each village } \\
\text { TOTAL: } 100 \\
\text { respondents }\end{array}$ & $\begin{array}{l}20 \text { each village } \\
\text { with at least one } \\
\text { leader }^{7} \text { per village } \\
\text { TOTAL: } 100 \\
\text { respondents }\end{array}$ & $\begin{array}{l}100 \\
\text { Validated by } \\
\text { respondents } \\
\text { validation technique }\end{array}$ \\
\hline $\begin{array}{l}\text { Government } \quad \& \\
\text { NGOs }\end{array}$ & $\begin{array}{l}\text { Government: } 4 \\
\text { NGOs: } 3\end{array}$ & $\begin{array}{l}\text { Government: } 4 \\
\text { NGOs: } 3 \\
\text { TOTAL: } 7 \\
\text { respondents }\end{array}$ & $\begin{array}{l}\text { Government: } 4 \\
\text { with } 1 \text { on site } \\
\text { (Forestry } \\
\text { Department) } \\
\text { NGOs: } 4 \\
\text { (NB. Two staff } \\
\text { from PACOS) } \\
\text { TOTAL: } 8 \\
\text { respondents }\end{array}$ & $\begin{array}{l}8 \\
\text { Validated by } \\
\text { respondents } \\
\text { validation technique }\end{array}$ \\
\hline Business & $\begin{array}{l}285^{8} \\
\text { (NB. However only } 6 \\
\text { major companies are } \\
\text { involved in } \\
\text { ecotourism) }\end{array}$ & $\begin{array}{l}\text { TOTAL: } 14 \\
\text { respondents } \\
\text { (NB. Has direct } \\
\text { dealings with } \\
\text { research sites) }\end{array}$ & $\begin{array}{l}\text { TOTAL: } 14 \\
\text { respondents with } \\
4 \text { on site (mainly } \\
\text { in Sukau where } \\
\text { they have their } \\
\text { ecolodges) }\end{array}$ & $\begin{array}{l}14 \\
\text { Validated by } \\
\text { respondents } \\
\text { validation technique } \\
\text { and triangulation } \\
\text { method }\end{array}$ \\
\hline Tourist & $\begin{array}{l}\text { Bavanggazo: } 142 \text { per } \\
\text { month }^{9} \\
\text { Batu Puteh: } 44 \text { per } \\
\text { month }^{10} \\
\text { Sukau: } 279 \text { per } \\
\text { month }^{11} \\
\text { Rafflesia Information } \\
\text { Centre: } 204^{12} \\
\text { Kampung Rantai: } 10- \\
15 \text { per month }\end{array}$ & $\begin{array}{l}50 \text { each village } \\
\text { TOTAL: } 250 \\
\text { respondents }\end{array}$ & $\begin{array}{l}50 \text { each village } \\
\text { except Kampung } \\
\text { Rantai where } \\
\text { there are only } 14 \\
\text { respondents } \\
\text { TOTAL: } 214 \\
\text { respondents }\end{array}$ & $\begin{array}{l}214 \\
\text { Validated by } \\
\text { triangulation method }\end{array}$ \\
\hline
\end{tabular}

\footnotetext{
${ }^{4}$ Six households with average five people per household. Source: Milaad, A. (2004)

${ }^{5}$ Exact population could not be estimated as there are unregistered immigrants working at the oil palm plantation. Source: Miso Walai Homestay (2004)

${ }^{6}$ Thirty families with average five people per family. Source: Data collected from research site.

${ }^{7}$ Leader: Headman, Chairman of Village Security and Development Committee and Non-Formal Community Leader (such as Religious Leader, Headmaster of a School)

${ }^{8}$ Tour operator handling ecotourism and nature tourism packages in Sabah. However, not all are operated at the Research sites. Source: Sabah Tourism Board (2007)

${ }_{9}^{9}$ Average number of tourists per month to Kampung Bavanggazo in 2003. Source: Milaad, A. (2004)

${ }^{10}$ Average number of tourists per month to Batu Puteh in 2003. Source: Miso Walai Homestay (2004)

${ }^{11}$ Average number of tourists per month to Sukau in 2003. Source: Wildlife Department Kota Kinabalu (2004)

${ }^{12}$ Average number of tourists per month to Rafflesia Information Centre in 2003. Source: Tambunan Forestry Department (2004)

${ }^{13}$ Average number of tourists per month to Kampung Rantai in 2003. Source: Interview with PACOS representative.
} 


\section{Sampling}

In qualitative research, the samples are quite small and usually selected in a purposive rather than a probability-sampling procedure. According to Travers (2001) there are no hard and fast rules for how many people one needs to interview, since it will partly depend on the time available to collect, transcribe and analyze the data. Participants only need to be carefully selected so as to be relevant to the issues under study. Ida Peterson (1994) suggested that a 15-30sample size is appropriate but she did not mention the population size or how the sample size relates to the population size. Since the literature suggests that the sample size should be small, then the total sample allocated for the sites are according to feasibility (length of time, funding) of acquiring quality data. Therefore, the size of population does not play the decisional factor in determining the sample. The decision to select a small sample is elaborated later and in section 3.6 on limitation of the study. Table 3.8 summarize the respondents' profile.

\section{Selection of respondents}

The local community is the first group of respondents. They are residents of a village where the research sites are. The communities have different levels of involvement in ecotourism projects and differ by sites. Their input was giving information on the villagers' demographics, clarification of local community, level of participation, its process and their own personal view on the project. Their perception of success for local community participation and ecotourism were sought. Based on the population size and time spent to interview one villager, and with resources available to cover all five sites, it was determined that the sample for each village should be 20 people. The interviews lasted around 30 to 45 minutes but usually took longer as the researcher was entertained based on the local customs and courtesy. In Rafflesia Information Centre, the respondents are mainly workers at the Centre and they are all residents of Tambunan. The first contact with the villagers was the headman or the person in charge, where 
permission to do research was sought and the headman was informed of the purpose of the research. The headman or the person in charge made the presence of the researcher known to the village through word of mouth and meetings. Then, the researcher sought after those involved in the ecotourism activity for interviews. If the numbers of people who were involved was large, random sampling within that group was practiced.

The government and its related agencies and NGOs are the second group of respondents. These two are grouped together as they are advocates for local community participation and ecotourism as a whole, and they often work together in this matter. They are also involved in ecotourism in the state at various levels and in this research, they were selected based on their involvement at the research sites. The respondents from the government that were chosen based on relevancy to the research are staff from the Ministry of Tourism, Culture and Environment of Sabah, Sabah Tourism Board, Tourism Malaysia and Sabah Forestry Department. The interview was more of a relaxed and open discussion, as the researcher personally knows the respondents as they have been in his network since the researcher worked in the tourism industry from the year 1997. However, the selection of the respondents was based on the relevancy of issues of the research rather than on personal basis. There was at least one interviewee from each organisation. The interviews lasted around 45 minutes to one hour. Interviews were made through appointment and before it commenced, the intention and purpose of the research was made known and permission is sought.

The respondents are high-level staff either at managerial/decision-making level from an officer up to assistant minister level. There are multiple respondents from each government body. Information gathered from this group are type of ecotourism activity, type of ecotourism attractions, community involvement, practices, status of site protection, marketing label, level and type of 
participation, involvement degree, decision-making process, goals and objectives of local community participation, social structure, local community participation advocates, and composition of the committee ecotourism project committee including local community participation and projects. Their perception of success for both local community participation and ecotourism is also sought.

The Non Governmental Organizations (NGOs) selected are both international and local based NGOs. The selection is based on their involvement in the research sites at various levels. The NGO respondents are Partners of Community Organisation or PACOS, World Wide Fund for Nature, Malaysia or WWF-Malaysia (Borneo Programme) and Japan International Cooperation Agency or JICA. There was at least one interviewee from each organisation. Similar to the government group, the interview lasted between 45 minutes to one hour. Despite the interviewees being the researcher's contacts in the industry, the interviews were made formally through appointments and before it commenced, the intention and purpose of the research was made known and permission sought.

The respondents are high-level staff in the managerial/decision-making level. The information expected from this group is the clarification of ecotourism sites which involves all aspects of ecotourism and local community participation in the research sites. The perception of success for local community participation and ecotourism sites is sought as well.

The business respondents are individuals or groups that operate and run ecotourism sites, offer ecotourism tour packages, or both. They are Sabah-based businesses and have business interests in the research sites. Some of the respondents are urban-based tour operators while the others are eco-lodge operators at these ecotourism sites. Therefore, the interviews were conducted in both urban and rural areas. Respondents must operate a business in at least one of the research site. It is not common to find them operating in more than one 
research sites. They are either the owners or the management staff. Information gathered from this group are the clarifications of ecotourism sites including the business of ecotourism that they are involved in, activities and attractions, ecopractices, marketing label, local community participation and indicators for success. Business respondents were also asked about their perception of success for local community participation and ecotourism sites. 14 tour operators and eco-lodge operators were approached for this interview. Some operators may be involved in more than one site. These tour operators and ecolodge operators are the ones that have significant links with the research sites. The interview lasted between 45 minutes and an hour.

Tourists are the last of the respondent groups. They are ecotourists who were visiting, spending time or in transit at the research sites. Information expected from this group are tourist demographics, clarification of ecotourism site, community and their participation. Their views of success for local community participation and ecotourism site were also asked. Due to the low number of ecotourism operations at each site, where the number of tourists are small, the realistic number of respondents was limited to 50 at each site. After lengthy considerations of logistics, it is decided that self-completed questionnaires be used for the tourists. The questionnaires are set in the reception area of each site for easy accessibility with a sign explaining the purpose of the research, and is available in two languages i.e. English and Bahasa Malaysia, to cater to most of the foreign and domestic tourists. The questionnaires take about 15 to 20 minutes to complete. There was no incentive for completing the questionnaires, however, the personnel that work at the reception areas were told to encourage the tourists to undertake the questionnaires during their free time. Their views of the issues are essential as they are one of the stakeholders that make up for the success perception both for ecotourism sites and local community participation.

Data from the first three respondents i.e. local community, government and 
NGOs, and business, were gathered with informant interviews as they are the most efficient way to gather information for this research. The key person in each respondent group was able to give data that is valuable and of a certain quality with good depth in a sit-down interview. The data from the final group of respondents, the tourists, was also gathered through questionnaire survey. This specific tool was used as it is the most efficient way to gather information from the tourists. Tourists usually lack emotions to entertain interviews as they are on holiday and are trying to enjoy themselves. Time is especially limited if they are in a package tour or in-transit. Therefore, a short self-completed questionnaire without the formalities is ideal for this type of respondents. More details are explained in the next section.

\subsubsection{Informant Interview Experience}

Interviews are one of the main data collection tools in this research. It is a very good way of accessing people's perceptions, meanings, and definitions of situations and constructions of reality. The type of interview chosen is the structured interview. In structured interviews, respondents are asked a series of pre-established open-ended questions. For this research, the interview is standardised where all respondents receive the same questions in the same order and delivered in a standardised manner. Flexibility and variation are minimised.

The interview respondents were from three groups: 1) Local community; 2) Government and their related agencies; and 3) Business. Data was collected using a formal, structured interview. The selected respondents were asked the questions sequentially in a logical order and following a predetermined schedule, in effect the interviewer reads out the question. Pre-testing and piloting of a survey was done during the site reconnaissance. 
After the selection of sites, the researcher went to the 1st Asia-Pacific Ecotourism Conference in Kota Kinabalu. The conference was attended by a mix of different stakeholders in ecotourism from over 40 countries, but mostly from Malaysia. Since the conference was held at the capital city of the research site, it provided a good opportunity to have academic discussion on ecotourism in Sabah and to be acquainted with the potential respondents and key informants. The interview questions were pre-tested and piloted at the conference with some industry acquaintances that were present at the conference.

The selected respondents were contacted via telephone and e-mail to set up interview meetings with the exception of the local community. An information sheet that contained the description of research and the researcher with the questions were sent first to the intended respondents. The interviews usually took place at the respondent's office or place of work with the exceptions of a few interviews that took place in a public place e.g. restaurants and cafes. Notes were taken during the interview. The local community interviews started with the seeking of permission from the headman or person in charge in the village. Guided by the villagers, interviews with the local community were made at their homes or communal place such as the community hall.

The interview transcripts were then documented in a word processed form and sent back to respective respondents via e-mail and post for confirmation and amendments (if necessary). Most of the respondents responded and provided additional comments. A second visit was made to all the respondents and research sites to ensure the data was correct and updated. Preliminary data results were presented to key respondents (excluding local community due to logistic reason). 


\subsubsection{Questionnaire Survey Experience}

The survey data from the tourists were collected from self-administered questionnaires. There are two sets of questionnaires, one set in English and the other set in Bahasa Malaysia (Malay Language). The questionnaires guaranteed confidentiality (with a confidentiality clause in the beginning of the questionnaire) for the respondent so it removes any doubt from the mind of the respondent. Both open and closed ended questions are used in the questionnaires. Question scaling was employed with two types of scale:
i. $\quad$ Yes/No
ii. Five-point Likert Scale

The Likert technique presents a set of attitude statements. Subjects are asked to express agreement or disagreement on a five-point scale. Each degree of agreement is given a numerical value from one to five. Thus a total numerical value can be calculated from all the responses. The scaled questions technique was employed to seek measurement of attitudes and opinions based on the research questions as in Chapter 1. Both questionnaires were pre-tested and piloted during the site reconnaissance.

Before the commencement of the fieldwork, the researcher sought cooperation and agreement from research sites to leave the questionnaires for the tourists and selected contact persons. Once permission was granted, the researcher set up a questionnaire 'booth' at the reception area where it is the highest traffic point of tourists. The 'booth' was equipped with two boxes (for the 'blank' questionnaire and the completed questionnaire), an information sheet (brief description of the research and the researcher) and pens. The self-completed 
questionnaire requires only approximately 15 to 20 minutes of respondents' time. Follow up on questionnaire monitoring was done constantly using telephone or e-mail with the contact person. After a predetermined period, the questionnaires were picked up or sent by the contact person via post. 


\subsection{Fieldwork and Data Analysis}

\subsubsection{Fieldwork Experience}

After the site reconnaissance, there were minor changes in the questionnaires. This was expected as the original questionnaires were based on 'desk' research. These changes ensured that the questionnaires fit the respondents and also enhanced the smoothness and logical flow of the interview schedule. More respondents were added as the fieldwork progressed. The $2^{\text {nd }}$ period of fieldwork was done to fill in the gaps left from the $1^{\text {st }}$ period of fieldwork by collecting more secondary data and getting updates from the field.

\subsubsection{Observation And Its Evaluation}

Direct observation was made during the field visit to each site. Assuming the phenomena of interest is not purely historical, some relevant behaviours and environmental conditions were observed. Observational evidence is often useful in providing additional information about the topic being studied. This is where first hand information is verified. A large part of information gathered from the interviews and surveys are tested for its validity by field observation. It also adds some new dimension for understanding either the context of the phenomenon being studied.

\subsubsection{Data Analysis and Indicator Development}

The data from the survey was analysed using a matrix of categories and placing the evidence within set categories. This analysis will be used for indicator development. Two of the objectives of this thesis are to develop indicators for ecotourism site success and its local community participation. These are derived 
from the research question, which focuses on the assessment of success for ecotourism sites and its local community participation and how the two are related. The indicators that were developed from this thesis help to determine the context of success for ecotourism sites and local community participation for the industry, while practical knowledge is derived from this thesis findings.

Indicators are mainly used to measure information, which decision-makers may use to reduce the chance of unknowingly making poor decisions. The indicators are also able to reduce the wide range of potential information to a set of usable and meaningful measures of those factors important to the decision-maker. Indicators are not an end in themselves, but rather a vehicle for better understanding of a phenomenon.

The indicators that were developed from this thesis were derived from the data collected across five research sites from four selected groups of stakeholders. Each of the indicators are based on the interviews and survey analysis and then clustered into groups based on the themes that emerged from the data. These sets of indicators form the basis for indicator analysis and success analysis. The indicators are analysed based on its variations within and between the groups of stakeholders and sites. 


\section{Indicators Analysis Framework}

Each of the indicators that were derived from the interviews and survey analysis were then clustered into groups based on the themes that emerged from the data where the themes form the basis for indicators analysis and success analysis. Thematic analysis is a process for encoding qualitative information. This may be a list of themes; a complex model with themes, indicators, and qualifications that are causally related; or something in between these two forms. A theme is a pattern found in the information that at a minimum describes and organizes possible observations or at the maximum interprets aspects of the phenomenon. A theme may be identified at the manifest level (directly observable in the information) or at the latent level (underlying the phenomenon). The themes may be initially generated inductively from the raw information or generated deductively from theory and prior research (Boyatzis, 1988).

However, indicator identification needs to address the issue of the weight of the importance of each indicator or determining which indicator is more important than the other. The indicators' importance can be based on the variables sequence, depending on the data collection process. This variable sequence is developed through the interpretation of qualitative data.

The variable sequence should address the issue of disparity of the data collection for all respondents. There are three groups of respondents where the data was collected through interviews while the other was obtained through surveys. The data should be sifted and put in a matrix based on themes. These themes will show some patterns where qualitative information is encoded for the researcher to draw his opinion. The next step would be to rank the importance established to the indicators. In order to do this, the variables sequence should be formed in 
a logical way, based on the observation of the data by the researcher. This logical sequencing can be used as the basis in analysing the success indicators.

In the logical sequence, there are two important variables involved, which are the stakeholders and the sites. The stakeholders' variables are sequenced based on each stakeholder's involvement and how much they are affected by the local community participation process. At the top of the sequence is the stakeholder that has the most involvement and is most affected by local community participation and ecotourism. At the bottom of the sequence is the group that has the least involvement and is least affected by local community participation and ecotourism. The ranking of the sequence is based on the literature review in Chapter Two and the case studies in Chapter Five. The sequence of stakeholders (Figure 3.2) is as follows:

\section{Fiqure 3,2Stakeholder's Sequence}
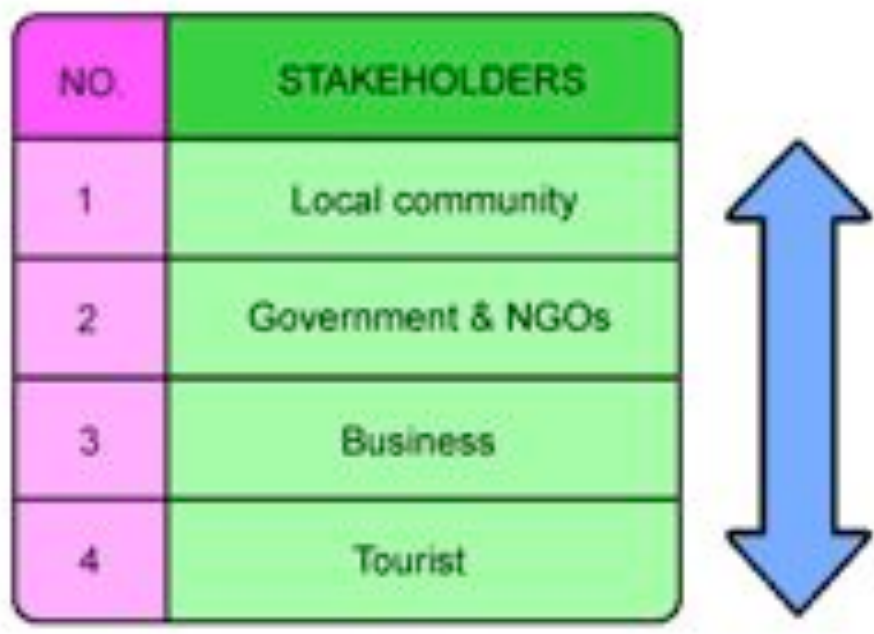

\section{Most inwolved and affected}

Least involved and affected

The second variable, the sites, are sequenced based on the initiative of ecotourism and local community participation. Based on the case studies in Chapter Five, the top of the sequence is where the local community owns and 
operates the sites, and the bottom is where the local community has the least involvement. The sequence for the sites (Figure 3.3) is as follows:

Figure 3, 3 Site Sequence

\begin{tabular}{|c|c|c|}
\hline NO. & SITES & INITIATIVES \\
\hline 1 & $\begin{array}{c}\text { Kampung } \\
\text { Bavanggazo }\end{array}$ & Owned and managed by local community \\
\hline 2 & Batu Puteh & $\begin{array}{c}\text { Managed by local community with an international NGO and } \\
\text { government with high stake for local community }\end{array}$ \\
\hline 3 & Rantai & Managed by local community with local NGO \\
\hline 4 & Sukau & Dominated by business with some local community \\
\hline 5 & $\begin{array}{c}\text { Rafllesia } \\
\text { Information Centre }\end{array}$ & Run by the government with a handful of local community \\
workers
\end{tabular}

These sequences will address the issues relating to the indicators developed from this research such as establishing the importance of indicators, the variations between stakeholders and sites and variations between the groups of stakeholders.

This research recognized that there are certain limitations to this model. This is because the model does not categorize the indicators as 'output' or 'input' indicators. The indicators that are based on 'output', show that the sense of success of the local community participation and ecotourism sites are as a result of the ventures. The indicators based on 'input', on the other hand, show the sense of what contributes, or something that enters to the process, which resulted in the success of local community participation and ecotourism site for any ventures. Indicators that are based on 'input' and 'output' are usually 
measured based on its own objective. Therefore, this is not inline with the proposed research methodology.

The models suggested in this methodology mixed the indicators indiscriminately as it focuses on the importance of the indicators' substance. It is based on perception and the categorization is done for analysis rather than producing the end-indicators. These models are based on the success perspective from the literature review done for this research. The potential indicators from the literature review identified and analysed against the indicators from the research.

These indicators will ultimately help planners and managers of tourism to anticipate ecotourism business strategies, which may lead to its success. The indicators that are developed from this thesis can also be the tools for managers today and an investment in the future, since it can reduce the risk in decisionmaking. Local communities may use these indicators to develop practical ways to measure progress for both themselves and locally established goals in term of outputs, activities and inputs. It helps them measure concrete results of ecotourism development efforts. 


\subsection{Limitation of the Study}

In appraising the findings of this study, it is important to interpret the results in the light of the following limitations.

\section{Methodological limitation}

The samples of the research are quite small and selected using a purposive rather than a probability-sampling procedure. Therefore, the inferences that are made based on qualitative research is normally subjected to evaluation using quantitative procedures.

\section{Limited Volume of Respondents (Ecotourists)}

Ecotourism sites usually have a low volume of ecotourists. Depending on the popularity of the site, the volume differs. The most popular sites, Sukau and Bavanggazo, receives an average of 5 tourists per week. The least developed site, Kampung Rantai, receives an average of 1 visitor per week. In order to get the desirable volume of tourists' surveyed, the researcher ideally has to stay at each of the five sites for a considerable length of time, which is inconvenient given the limited time and finances.

$\underline{\text { Time limitation }}$

Time constraints were experienced while gathering data from the respondents. Many respondents from the private sector were busy and this may affect the content of the interview data.

\section{Financial limitation}

Financial resources for both the PhD and fieldwork were limited. A better and bigger fund would have enabled a more conducive environment to carry out the field and PhD work. 


\subsection{Conclusion}

The methodology has outlined the way the research is done and explained it in detail. It starts with customising the research issues, questions and tasks into the research methods that can address them. It was decided that the research was going to be largely qualitative with a part to be quantitative. The two methodologies selected in this thesis are plans and policies analysis and comparative case studies method. Both methodologies are essential in outlining the current environment of the ecotourism industry and its local community participation activities. This will bring the central issues of the thesis into the discussion chapter where it gives in-depth justifications to the success perception that is developed from the thesis.

There are two main sources of data, secondary and primary. Secondary data is the first stage for any research and is essential in developing literature review and composing methodology. Primary data collection is the main activity and is where the data for the main body of the thesis comes from. It is also crucial in this thesis as there is lack of academic writing on the subject of local community participation and ecotourism success.

Four respondent groups were selected for this thesis on the basis that they are the main stakeholders of ecotourism and its local community participation. Therefore, their views are important, valuable and relevant to be analysed in this research and the results should be beneficial to them as well. They are the local community, government and NGOs, businesses and tourists. Data was gathered through interviews, with the exception of tourists, where a survey-based method was used. This is to maximize the gathering of data based on research logistics. 
The end of fieldwork is followed by data analysis and indicator development. The indicator development is the main idea of the thesis, where the perception of success from all stakeholders and all sites are turned into indicators. In the discussion chapters, the plans and policies, and the case studies are used to justify and give insight to the indicators from the result chapters. This should give some perspective to the thesis and its issues, and should be beneficial and applicable to the academics and the industry. 


\section{CHAPTER 4. PLANS AND POLICIES ANALYSIS}

\subsection{Introduction}

The evaluation of plans and policies is to determine the context, importance and direction of selected issue, area or industry for governance entities such as a country, a state or a region. The government and its agencies formulate and use plans in charting their own course and direction, in relation to the country's social, technological, economical and political environment. It helps to set the framework and direction of this research. It is also important to identify the intention of the government for the industry set against the implementation of the plans and policies. This is useful later in the thesis where the results are analysed against these plans and policies. This is to compare what has been outlined to what has been happening in the industry. The final analysis should be useful to plan and policy makers.

\subsection{Plans and Policies in Malaysia}

Plans are mainly long-term in nature but there are many short and medium-term plans. Policy, on the other hand, is a course that evolves from the plan. There are many definitions of public policy, ranging from a comprehensive definition such as: -

'A set of related decisions taken by a political actor or group of actors concerning the selection of goals and the means of achieving them within a specified situation where these decisions should, in principle, be within the power of these actors to achieve (Roberts, 1971 in Jenkins, 1978). 
...to a simple definition such as: -

'Public policy is whatever government chooses to do or not to do (Dye, 1992).'

However, in this analysis, the definition provided by Pal (1992) described the operational definition of this concept.

'Public policy is a course of action or inaction chosen by public authorities to address a problem or interrelated set of problems'

Therefore for a specific tourism policy, it is whatever the government chooses to do or not to do with respect to tourism.

Governments have an extraordinarily important role to play in the development of ecotourism. The commitment to national tourism and ecotourism planning development in Malaysia is very strong because it recognises that the tourism economies depend upon the quality of the environment. This commitment is reflected in the number of plans and policies in existence, which are either tourism-specific or have broader relevance to the tourism industry. A number of these plans and policies were published many years ago by the Malaysian government and Sabah State government. However, only recent and relevant plans and policies since 1990 have been selected for this review. The year 1990 is selected as this is the year that the ecotourism industry started in Malaysia. Many plans and policies that were written and developed since then were more focused on the industry.

There are eight official documents that were analysed in this exercise, namely: -

I. $\quad 6^{\text {th }}$ Malaysia Plan 


$\begin{aligned} \text { II. } & 7^{\text {th }} \text { Malaysia Plan } \\ \text { III. } & 8^{\text {th }} \text { Malaysia Plan } \\ \text { IV. } & \text { National Tourism Policy } \\ \text { V. } & \text { National Ecotourism Plan } \\ \text { VI. } & \text { Sabah Conservation Strategy } \\ \text { VII. } & \text { Sabah Outline Perspective Plan } \\ \text { VIII. } & \text { Sabah Tourism Master Plan }\end{aligned}$

There are two types of these plans and policies. They are national level and state level plans and policies. The national level plans and policies developed by the federal government and its agencies generally concern all the states and federal territories. However, there are specific plans and policies formulated exclusively for Sabah State (Figure 4.1). There are two types of plans and policies under review, which are general and tourism-specific. The general plans and policies cover a range of aspects and include tourism as one of their items. These are $6^{\text {th }}$, $7^{\text {th }}$ and $8^{\text {th }}$ Malaysia Plan, Sabah Conservation Strategy and Sabah Outline Perspective Plan. The tourism-specific plans and policies are developed specifically for tourism or a certain aspect of tourism. These are National Tourism Policy, National Ecotourism Plan and Sabah Tourism Master Plan.

Although the national level plans and policies are developed by the federal government and its agencies, the course of action and implementation however may be delegated to the state government. The national level plans and policies usually take precedence over state plans and policies. They also serve as a guide in formulating state plans and policies. For example, the state level plan, The Outline Perspective Plan of Sabah (OPPS), is developed in accordance with the national level plan, The Second Outline Perspective Plan (OPP2).

The state government develops the state level plan and policies in accordance with national level plans and policies. However, it also has the prerogative to 
formulate its own plan and implement its policies where the State's own environment dictates. The Sabah Conservation Strategy is an example of a very specific plan developed for the state of Sabah, which is known to have a high level of biodiversity and whose economy is very much dependent on natural resources. 
Eigure 4. 1. Structure of Plans and Policies Under Review

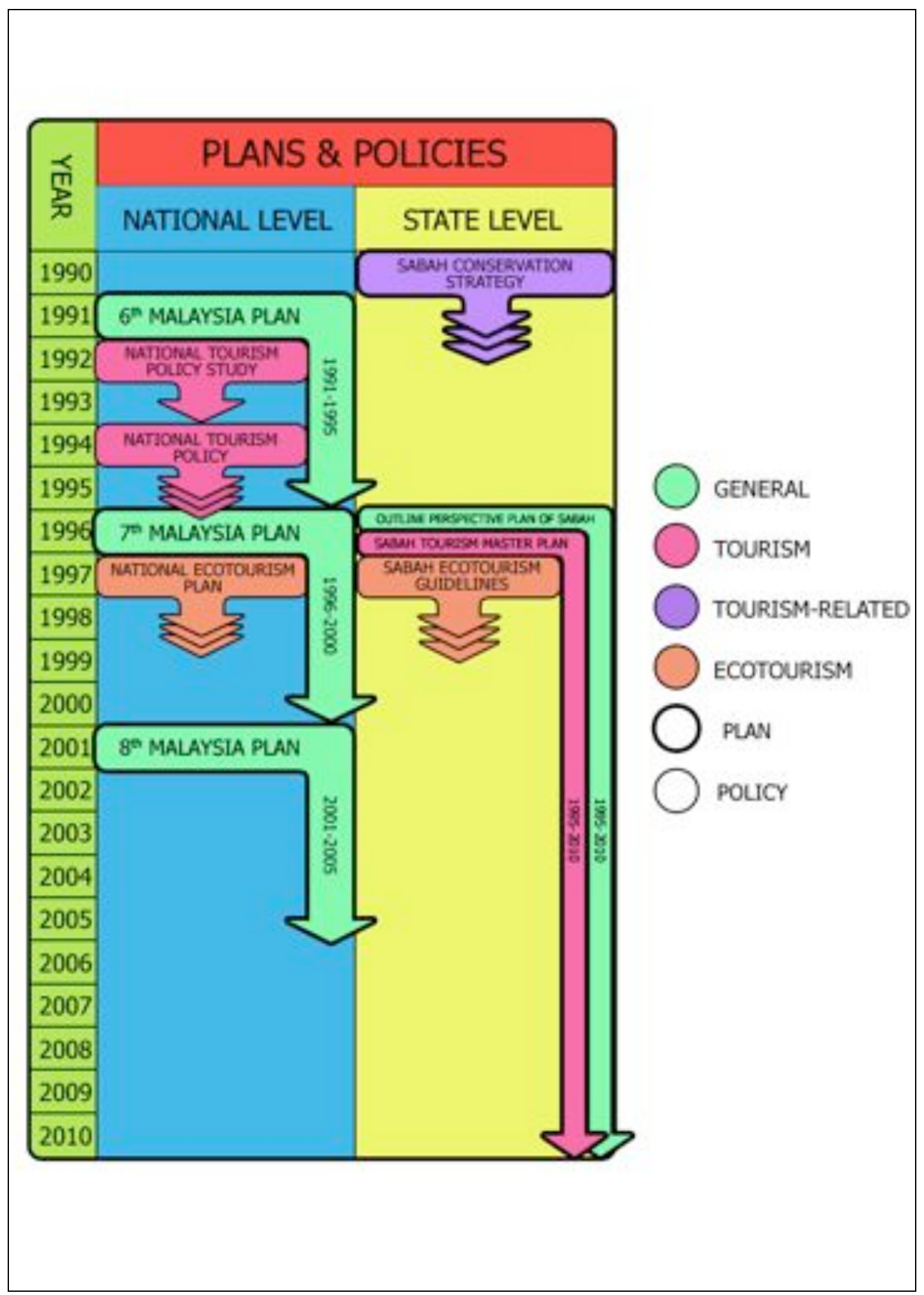


Malaysia is quite organised and systematic in formulating its plans and policies. The national plans and policies are done according to the long-term plans of the National Development Policy, which cover a period of 10 years. The state level plans and policies are mainly formulated in accordance with the national level plans and policies. However, in some cases, a long-term state plan or policy may be outdated if it would be based on medium-term national plan. For example, the Sabah Tourism Master Plan that spans over the period of 1995-2010 is based on the $6^{\text {th }}$ Malaysia Plan, which only covers the period of 1991-1995.

\subsection{Plans and Policies Under Review}

Eight official documents are under review in this chapter and they can be divided into two categories. The first category is the national level plans and policies, which are the $6^{\text {th }}$ Malaysia Plan, $7^{\text {th }}$ Malaysia Plan, $8^{\text {th }}$ Malaysia Plan, National Tourism Policy and National Ecotourism Plan. The second category is the state level plans and policies, which are the Sabah Conservation Strategy, Sabah Outline Perspective Plan and Sabah Tourism Master Plan.

\section{Malaysia Plan}

The Malaysia Plan (Rancangan Malaysia) is the Master Plan for the whole of Malaysia, which is published every five years under the Prime Minister's Department. It is a pragmatic blend of proven and new development strategies and programs. The formulation of the Plan was largely guided by objectives and strategies of the National Development Plan (NDP). The Malaysia Plans that are under study here are the $6^{\text {th }}, 7^{\text {th }}$ and $8^{\text {th }}$ Malaysia Plan.

The $6^{\text {th }}$ Malaysia Plan covers the period from 1991 to 1995 . The $7^{\text {th }}$ Malaysia Plan is the second phase in the Second Outline Perspective Plan. Both plans outline 
the economic and social development, which are an ongoing process since the 1990s.

The $8^{\text {th }}$ Malaysia Plan, which covers the period 2001-2005, is the first phase in the implementation of the Third Outline Perspective Plan (OPP3), 2001-2010. The OPP3, which embodies the National Vision Policy (NVP), charts the development of the nation in the first decade of the $21^{\text {st }}$ century. The Eighth Plan incorporates the strategies, programs and projects designed to achieve the NVP objectives of sustainable growth and strengthen economic resilience as well as create a united and equitable society.

\section{National Tourism Policy}

The National Tourism Policy is adopted from a National Tourism Policy Study, which was commissioned in 1990-1991. The overall policy thrust of the tourism sector is to achieve sustainable tourism growth to realise the potential of employment and income-generation effects at the national, state and local levels. It is a holistic and integrated approach that leverages on the innovation and vitality of the private sector, the hospitality, courtesy and civic-consciousness of the public as well as the support of the Government, all considered to elevate the tourism industry to a higher level of achievement.

\section{National Ecotourism Plan}

The National Ecotourism Plan published in 1997 provides a framework of ecology-based tourism development. It has 25 guidelines for the best approach towards ecology-based tourism. It aims to assist the Government at both Federal and State level in the development of Malaysia's ecotourism potential. The Plan is intended to serve both as an appropriate instrument within the overall sustainable development of Malaysia and the economy as a whole, and as an effective tool for conservation of the natural and cultural heritage of the country. 


\section{Sabah Conservation Strategy}

The Sabah Conservation Strategy was published in 1990. It identifies all aspects of the environment in Sabah and, hence, implies that conservation and human welfare are linked intimately with the use of two primary resources: Land and Natural Forests. Directly linked to the management of these resources and in need of immediate attention is the rationale for allocation of land and timber harvesting. With the aim of promoting socio-economic development, land and natural forests have been utilized to generate both the revenue and materials for development. The then Ministry of Culture, Environment and Tourism of Sabah (MOCET) carried out this project. WWF-Malaysia was commissioned by MOCET to prepare the Sabah Conservation Strategy. A range of recommendations was formulated in the strategy for the sustainable management of nature areas and natural resources of Sabah and has been endorsed and adopted by the Government.

\section{Outline Perspective Plan of Sabah}

The Outline Perspective Plan of Sabah was formulated in 1995 to chart the direction of state development over the 1995-2010 period. It was formulated with direct reference to the Second Outline Perspective Plan and Vision 2020. Vision 2020 started in 1991, when the government declared that it was the objective of the nation to become a developed nation in its own mould by 2020 . It envisions Malaysia to achieve an industrialized and a fully developed nation status by sustaining growth at 7 per cent per annum and initiating structural changes in the economy as well as within the manufacturing sectors. The key to the attainment of a fully developed nation is overcoming nine identified strategic challenges. The policies and strategies for the first phase of the Vision 2020 are spelled out in the Second Outline Perspective Plan, 1991-2000, (OPP2). The State Department of Development prepared the OPPS with the Institute for Development Studies (Sabah). 


\section{Sabah Tourism Master Plan}

The Sabah Tourism Master Plan is a guiding document for the development of the tourism industry in Sabah during the time frame 1995-2010. Its purpose is to establish policy development strategies and action plans to realize the tourism potential of the State within the context of the national development framework for the tourism sector.

Tourism in Sabah is very much influenced by the management issues of natural resources. Therefore, the Natural Resource Policy outlined in the $6^{\text {th }}$ Malaysia Plan (1991-95) was an important consideration in the preparation of the Sabah Tourism Master Plan (1996). This policy aimed to:

व Promote nature conservation by establishing additional protected areas like national parks, marine parks, wildlife sanctuaries and nature reserves.

- Promote nature and conservation education.

a Promote forest recreation.

口 Promote tourism through national parks and protected areas.

- Carry out scientific research.

\subsection{Review of National Level Plans and Policies}

\subsubsection{Introduction}

Prior to the 1970s, Malaysia gave relatively little emphasis to tourism, compared with the policies adopted by other ASEAN countries. Amendments to the law and the restructuring of the Tourism Development Corporation to form the Malaysia Tourism Promotion Board (Tourism Malaysia), and of the Ministry of Culture, Arts and Tourism, coincided with a general increase in the number of tourists, greater 
revenue, and greater policy emphasis on tourism. The environment element in tourism has been around in Malaysia for a while. Initially, environmental initiatives in Malaysia were confined to protected areas only, particularly National and State parks, forest reserves and wildlife sanctuaries that were gazetted under various laws. A structured and integrated form of environmental management covering the whole nation was formalised when a regulatory agency known as Department of Environment (DOE) was set up in 1974. The department's environment policies and strategies are geared towards ensuring economic, social and cultural progress of Malaysia, and enhancing the quality of its people, through environmentally sound and sustainable development. Environmental management in Malaysia was accorded high priority only in the 1980s. This new policy is directed towards integrating economic, social and cultural progress, which was in tandem with the global trend of environmental awareness on its degradation due to excessive pollution, global warming and the so-called greenhouse effect. Throughout this period, sustainable development and environmental management in the country was given greater emphasis and the regulatory framework was further enhanced. The Malaysian Government, through DOE, other relevant agencies and non-governmental organisations (NGOs), has been conducting campaigns to raise the level of awareness on sustainability and conservation issues throughout the country. These are reflected in the policies and plans under discussion.

\subsubsection{The Review}

By the beginning of the $6^{\text {th }}$ Malaysia Plan, tourism ranked as the third or fourth most important sector (varying from year to year) in the overall economy. The development thrust in the period 1991-1995 has been to expand and diversify the tourism base to reduce its dependence on a narrow range of activities and markets. The overall strategy has been to mobilise and channel investments to selected regions and activities having tourism potential, leading to increased 
employment, value-added, and linkages with other sectors of the economy. The evidence of interest in developing ecotourism in Malaysia is indicated in the $6^{\text {th }}$ Malaysia Plan (1991-1995) where it was recommended that the tourism sector should develop new tourism products including ecotourism. The $7^{\text {th }}$ Malaysia Plan (1996-2000) aims to improve existing strategies as well as introduce new ones that will enhance the image of Malaysia as a highly diversified and competitive tourist destination in this part of the world. One of the strategies includes: -

Diversifying into new products and services to cater to the varying demands and interests of international and domestic tourists.

Within the product development strategy, nature-based tourism, which includes eco- and agro-tourism that projects the country's tropical climate and terrain, was also to be developed and promoted. Under this strategy, the private sector is encouraged to develop potential sites for ecotourism activities, as identified in the National Eco-Tourism Plan, while the Government assisted in the provision of infrastructure development and basic amenities for designated eco- and agrotourism sites. Within the $7^{\text {th }}$ Malaysia Plan, a few ecology-based tourism projects around Malaysia had been in operation including a Wildlife Sanctuary in Lower Kinabatangan or Taman Hidupan Liar Hilir Kinabatangan in Sabah, which is one of the research sites for this thesis.

There is also a mention of community participation with the intent to increase the participation of rural communities in tourism-related activities. The participation of local communities will be enhanced through cultural and handicraft product development programs. This is only recommended for agrotourism and there is no mention of participation in decision-making.

In the $8^{\text {th }}$ Malaysia Plan (2001-2005), ecology-based tourism is mentioned as a type of tourism that involves visitation to natural pristine areas, promotes 
conservation with low visitor impact and provides opportunities for locals to be involved socio-economically. It also emphasises promoting a bigger role for the local community.

As indicated in the $8^{\text {th }}$ Malaysia Plan, RM1 billion is to be allocated to the tourism industry. Malaysia also has set up national funding programs for tourism enterprises (WTO, 2003). However, there is no provision for how much will be spent on ecotourism ( $8^{\text {th }}$ Malaysia Plan, 2000). Even though Malaysia has a strong positive policy towards the increase of tourism as indicated in the $6^{\text {th }}, 7^{\text {th }}$ and $8^{\text {th }}$ Malaysia Plans, the approach towards ecotourism as a sub-sector is less clearly defined.

The National Tourism Policy provides specific long-term policies and strategies to ensure a coordinated and integrated development of the tourism sector. The policies and strategies focus on the efficient development of the sector, while enhancing the quality of life of the local people and attempting to minimise possible detrimental socio-cultural and environmental impacts. Acknowledging the fact that tourism is a growing industry, the policy identifies ecotourism as one form of tourism to be expanded and sustained. This was mainly because ecotourism was recognised as a form of tourism that is likely to grow faster than any other form of tourism. The National Tourism Policy also identifies specific programs aimed at increasing the participation of the local population and maximising the economic opportunities from tourism. Within the National Tourism Policy, the main policy thrusts recommended are:
I. To generate foreign exchange;
II. To encourage equitable economic and social development throughout the country;
III. To promote rural enterprises;
IV. To generate employment; 
V. To accelerate urban/rural integration and cultural exchange;

VI. To encourage participation in the sector by all ethnic communities;

VII. To create an improved image of Malaysia internationally; and

VIII. To foster national unity.

From the policy thrusts, it is clear that the federal government also gives emphasis to rural and community development. This is specifically indicated in the policy thrusts, which encourage equitable economic and social development throughout the country, generating employment and encouraging participation by all ethnic communities in the tourism industry. These reflect the emphasis on ecotourism where local participation, ownership and business opportunities are encouraged particularly for rural people (Epler Wood, 2002). Community participation is necessary to ensure that benefits reach the community in the destination areas (Simmons, 1994). Cater (1994) and Wild (1994) suggested that ecotourism will encourage local employment and small development promotes higher economic multipliers.

The National Tourism Policy also outlined the approaches used in expanding tourism in line with the above general policies including:

I. The expansion of existing infrastructure and the provision of new infrastructure;

II. Education and training strategies that are designed to enhance the level of professionalism and to provide the supply of tourism personnel required;

III. Promotion of local entrepreneurship; 
IV. Encouragement of domestic tourism, through the development of appropriate facilities, travel opportunities, and resort development;

V. Development of diversified tourism products, designed for different market sectors (including ecotourists), which seek to use the natural and cultural features of the country; and

VI. Broadening the base of market demand, while focusing on intra-regional markets, reinforcing established long haul markets, and opening up new long haul markets.

Some of the suggested approaches apparently make an attempt to be more practical and address the challenges in community participation such as encouraging education and training strategies in enhancing the level of professionalism and promoting local entrepreneurship. They address the issue of structural limitation and lack of expertise suggested by Tosun (2000), where in general, he believes that there is a limited capacity of poor people, which can become an obstacle to community participation. These approaches clearly outline the intention to expand the capacity of industry players including local community, to participate in the industry.

It is also interesting to note that one of the approaches highlights ecotourism as one of the niche markets. It specifically mentions the use of natural and cultural features. This will have implications for the operational characteristics of ecotourism that the government uses. Some literature does not emphasise cultural features. For example, Cater (1994), Buckley (1994), Orams (1995), Stewart and Sekartjakrarini (1994) and Duffy (2002) suggest that ecotourism is characterised by its natural attractions, wildlife and wilderness habitats. The International Ecotourism Society (2000) defines ecotourism as a nature-based form of specialty travel, which involved 'responsible travel to natural areas which conserves the environment and sustains the well-being of local people'. There is 
however, no mention of culture or the cultural features of local community. However, The World Conservation Union (1996) includes culture as an element in the definition of ecotourism, albeit in brackets. It defines ecotourism as '...environmentally responsible travel and visitation to relatively undisturbed natural areas, in order to enjoy and appreciate nature (and any accompanying cultural features - both past and present) that promotes conservation, has low negative visitor impact, and provides for beneficially active socio-economic involvement of local populations'.

Of the above approaches, some enhance the opportunities for the development of ecotourism, but others may work against it. For example, the development of diversified tourism products and a broadening of the market base should encourage ecotourism development. The encouragement of domestic and intraregional tourism may do relatively little for ecotourism because the demand for ecotourism is at present relatively weaker amongst these travelers. The provision of infrastructure, and the development of resorts of the form that now encourages domestic tourism, may come into conflict with ecotourism in specific cases.

The National Tourism Policy recommends ecotourism, as one of the niche areas among many, which is in the high priority list for development. It is clustered among other niches namely fly-drive tourism, cultural tourism, meetings and conventions, riverine tourism, agro-tourism, hot springs/spa tourism and other special interests. Alongside, it also provides that the PATA Code for Environmentally Responsible Tourism should be adopted and enforced. The listing of riverine tourism and hot spring tourism as issues seemingly distinct from ecotourism give the impression that there is not yet a clear concept of the scope and role of ecotourism, and of the way in which it should be positioned within the field of tourism as a whole. The inclusion of ecotourism in the Tourism Policy, as one topic for future development, does provide a specific place for 
ecotourism within governmental policy. This position has been further strengthened by the formation of the Eco and Agro-Tourism Implementation Committee under the Ministry of Culture, Arts and Tourism.

The tourism sector is assuming a greater role in stimulating the economy during the $8^{\text {th }}$ Malaysia Plan period. The overall policy thrust of the tourism sector is to achieve sustainable tourism growth to realize the full potential of employment and income-generation effects at the national, state and local levels. The major programs implemented include the preservation and conservation of historical sites, provision and upgrading of tourism-related infrastructure as well as improvement in the quality of tourism products and services. Even though the National Tourism Policy seems not to have a clear concept of the scope and role of ecotourism as discussed previously, the National Ecotourism Plan, developed after the National Tourism Policy, compensates for the lack of concept clarity. However, local community participation is very much high in importance as it is one of the policy thrusts.

The government recognises that tourism can also generate social and economic costs, which may outweigh the benefits of tourism, leaving the local community worse off with tourism than without. These costs need to be identified and managed, which are steps in the conversion of merely nature-based tourism into ecotourism. Having recognized ecotourism as the fastest growing form of tourism, a more specific national ecotourism plan was drafted in 1995 and was accepted a year later. This was a strategic effort to focus on ecotourism as a niche market rather than grouping it within the broader mass tourism market. The National Ecotourism Plan was intended to serve both as an appropriate instrument within the overall sustainable development of Malaysia, and as an effective tool for conservation of the natural and cultural heritage of the country. 
The National Ecotourism Plan published in 1997 provides a framework for ecology-based tourism development. It has 25 guidelines for the best approach towards ecology-based tourism, including health and safety, conservation, selection of sites, zoning and carrying capacity. The National Ecotourism Plan Malaysia has identified the existing and potential ecotourism sites. It covers 14 sites, which are the states in Malaysia, namely Johor, Kedah, Kelantan, Melaka, Negeri Sembilan, Pahang, Perak, Perlis, Pulau Pinang, Sabah, Sarawak, Selangor and Terengganu, and the federal territories of Kuala Lumpur and Labuan. However it does not list the sites according to the location, rather they are grouped based on their geographical features and activities surrounding them. It lists coasts, mountains, lowland forests, rivers and lakes, and caves and limestone hills. There is also a specific section for local community participation, suggesting the importance of the issue to ecotourism.

In Sabah, it identifies various sites by geographical features (Figure 4.2). The current ecotourism sites are Turtle Island Parks (i.e. Pulau Selingan), Pulau Sipadan, Tunku Abdul Rahman Parks (Islands of Gaya, Sapi, Manukan Mamutik and Sulug), Sepilok Forest Reserve, Danum Valley, Lower Kinabatangan Region including the river, Padas River, Kiulu River, Lower Segama River, Gomantong and Batu Punggul. Kinabalu Park, Mount Trusmadi and Crocker Range National Park are identified as existing ecotourism sites with potential. The Lower Kinabatangan Basin is identified as a priority project area. Minor ecotourism sites include waterfalls around Sabah. 
Eigure 4. 2 Map of Existing, Potential, and High Priority Areas as

Suggested by National Ecotourism Plan and Research Areas in Sabah

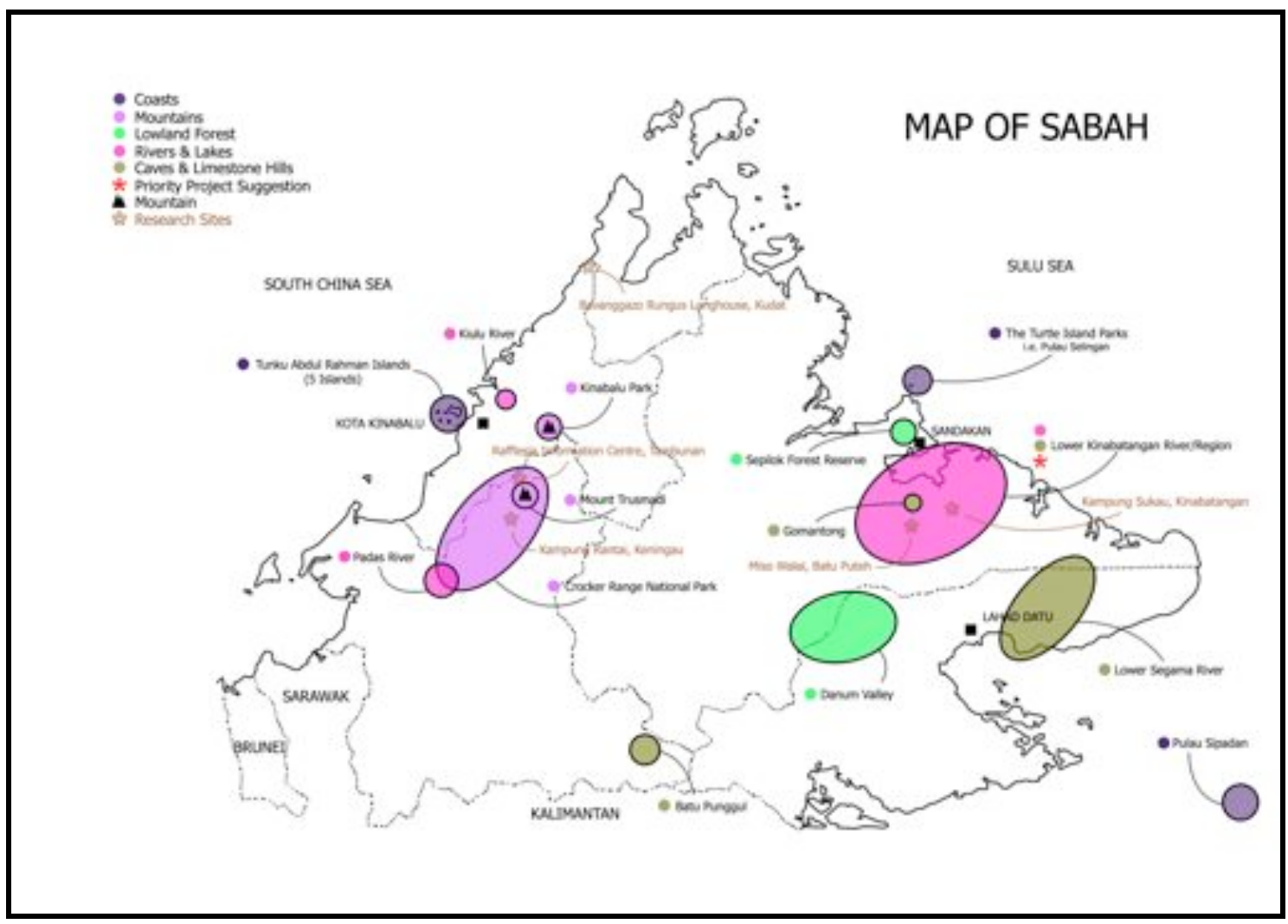

Source: National Ecotourism Plan (1997)

There are two areas noted in the plan needing rehabilitation through physical and management improvements. These areas are Batu Puteh and the Kinabatangan Floodplain. For example, in Batu Puteh, there is a need to remove graffiti on the walls of Batu Tulug and to construct steps and ladders to the caves. In the Kinabatangan Floodplain, there is the need to restore degraded forest. The suggested management for this is prevention of pollution by oil palm plantations/mills, control of tourism facilities and activities in Sukau, 
implementation of a quota system on boats entering Menanggul River, and lightening and spreading of visitor pressures. The Lower Kinabatangan was also identified as having cultural potential related to the ecotourism area. The main cultural group in the area is the Orang Sungai with its existing local or indigenous cultural tourism products. It has the potential of becoming a cultural gateway to this flagship area.

The Lower Kinabatangan has been selected as the priority project for infrastructural development and management. The aim of the project is to integrate ecotourism, rural community development and improve land use in the lower Kinabatangan river basin. A special project and management team was recommended to be formed under the Ministry of Tourism, Culture and Environment. The agencies that are recommended to be involved are the district offices, Sabah Wildlife Department, Agriculture Department, Fisheries Department, Rural Development Department, Rural Development Corporation, Education Department, Health Department and Department of Cooperative Development. The project expects to boost local involvement in the tourism industry, directly and indirectly at a pace suited to local conditions. It also predicted to receive strong social benefits through improved infrastructure, access and communications, and job creation.

One of the major challenges that face ecotourism is how to develop without destroying the environment. Although ecotourism has many examples where it has had a positive impact on the environment, negative environment fallout may occur such as over consumption of natural resources, disruption of wildlife and human congestion in natural area through the increase of ecotourists (Herbig and O'Hara, 1997). Some environmental impacts are unavoidable because of the environmental sensitivity of the area. These impacts are planned to be minimised by careful planning including the determination of carrying capacity and zoning, permissible construction types, and activities. The basic concept is to spread 
benefits, to access a wider area and to reduce adverse impacts. If this is done in line with prior planning, there should be large environmental benefits through the retention of riverside vegetation and forests on level ground, protection of wildlife population and protection of catchments. The project is in line with general Malaysian development principles, by providing infrastructure to stimulate private sector development. However, there is no mention of ecotourism, which should remain on small-scale, where the impacts can also be minimised this way as suggested by the general consensus among speakers and delegates at the $7^{\text {th }}$ PATA Adventure Travel and Ecotourism Conference and mart held in Balikpapan.

The National Ecotourism Plan outlined details on access, facilities, attractions and activities around Sabah. It also identified areas for ecotourism area development and ranked them in order of priority. However, it does not specifically identify new potential ecotourism sites in Sabah that can be developed. The Plan also outlines the Ecotourism Guidelines for Malaysia. These form a basis for specific activities and functions in all ecotourism areas (e.g. carrying capacity, health and safety); and for management of sites in specific habitats (e.g. caves, mountains). These guidelines are developed for planners, area managers, and the private sectors.

The guidelines recommend that every park, reserve and other areas used for forest tourism has a development and management plan, and, where possible, it should be prepared in consultation with other interested parties such as tour operators and non-governmental organisations. The national parks and other protected areas in Malaysia have been created for the protection and management of natural resources including wildlife. Tourism planned in this area should be developed in such a way that it does not interfere with this function. Parks contribute to national and international commitments to environmental protection, conservation of biological diversity and sustainable development. 
Large forested areas such as parks and reserves have important values as water catchments areas which are considered stabilisers of climate. The management plan should include broad inventories of assets suitable for tourism and contain more detailed scientific lists of species and habitats. Zoning according to type and intensity of permitted use are recommended. Development of physical facilities should be based upon site plans with consideration to zoning and architecture. Hotels, restaurants and stores should be located outside the park boundaries and tourist facilities within a park should ideally be owned by the government and operated on a concession system by the private sector. Buildings, wherever possible, should be of treated lumber and never exceed the height of the tree canopy, possibly limited to one or two storeys. Operators in forested areas should be able to demonstrate access to suitable expertise and be able to supervise and manage tourist behaviour.

Recreational Forests in Malaysia are typically small areas near the edge of Forest Reserves, near to the road and with a stream of waterfall. They have high recreational value for weekend visitors, picnickers, swimmers and family groups. Recreational Forests are also valuable in demonstrating the worth of forested areas above and beyond timber production. The guidelines suggest that the main aspects of site management should pertain to visitor control: parking, littering, and damage to vegetation by chopping, trampling and fire. The Forestry Department has a development plan for all of the Forest Recreation Areas in Peninsular Malaysia.

The guidelines recommend that the natural water levels should not be altered since rivers, waterfalls and lakes are all natural water bodies and are of high value in maintenance of the hydrological cycle. Natural vegetation should not be cleared except for specific planned purposes. Tourist activities such as jet skiing and water skiing may be permitted on artificial lakes within defined zones. Where quiet conditions are desired, battery-powered engines should be used, or boats 
should be rowed or poled. Artificial construction should be minimised and distances between lake or river margins and developments such as agricultural land should be such that sedimentation, eutrophication or entry of chemicals into the natural water body is prevented or minimised. Lakeshore and riverbank erosion control measures should be devised and enforced. Safety guidelines should be developed for each area; the presence of dead tree stubs must limit the location for water sports and diving.

The guidelines also include provisions relevant to local community participation, specifically under the Guidelines on Specific Practices. They recognise the local involvement and the generation of economic benefits as essential for the longterm success of ecotourism projects, noting that the local community has rarely been involved in management and decision-making. Successful ecotourism requires the creation and involvement of local stakeholders (individuals and communities) and an emphasis on local investment, control and decision-making.

The National Ecotourism Plan (1997) stated that there are several reasons why local benefits should be considered in the development of ecotourism projects:

I. Equity - conservation of the area for ecotourism may reduce traditional resource utilisation;

II. When residents receive benefits, they usually support the project;

III. Ecotourists, as consumers, often support the importance of tourism which benefits the local community.

The National Ecotourism Plan (1997) also stated that the mechanisms for increasing local benefits from ecotourism include:

I. Local ownership and management; 


\section{Leasing to local individuals or concerns; \\ III. Partial ownership; \\ IV. Profit-sharing arrangements between tourism industry and local residents; \\ V. Direct payments to communities from tourism revenues and local employment in tourism.}

In order to maximise the benefits to local communities from ecotourism, economic leakages need to be minimised. To the extent that ecotourists do not typically expect such luxurious accommodation, food and entertainment as other tourists, ecotourism should result in fewer leakages from local communities than conventional tourism.

Ecotourism can be good for local economic development because it often creates jobs and stimulates economic activities in remote regions that have historically benefited less from development programs, and where few economic alternatives exists. Even a small number of jobs may bring significant benefits to communities where populations are low and alternatives are few. There is the difficulty, however, of marginal community job creation with an ecotourism industry that is often owned and managed by people from outside the local region.

The National Ecotourism Plan shows that the government has a specific idea on how ecotourism should be run and operated. Details on the suggested practice covering the environment include the local community. The community can be involved through various levels. The involvement is not just on the business ventures but also on active involvement in conserving the environment. All involvement are geared towards giving benefits to the local community that in turn helps the conservation effort to the area. The guidelines also suggested that there should be consultation with other stakeholders such as tour operators and 
non-governmental organisations, reflecting an integrated development for ecotourism in Malaysia. The UNEPTIE (2004) also suggested that an integrated development among ecotourism stakeholders especially in developing policies that will protect and manage natural areas are one of the components of successful ecotourism.

The review shows that Malaysia is quite progressive in developing its ecotourism industry. The National Ecotourism Plan is an example where the government is pro-active in developing the industry. It is the objective of the National Ecotourism Plan to assist the federal government at both federal and state level in the development of Malaysia's ecotourism potential. The plan is intended to serve both as an appropriate instrument within the overall sustainable development of Malaysia and the economy as a whole, and as an effective tool for conservation of the natural and cultural heritage of the country. The guidelines are an extension of the ecotourism industry plans as detailed in the Tourism Policy. The detailed guidelines describe how ecotourism should be developed by including the participation of the local community, which is useful for planners and managers of ecotourism.

\subsection{Review of State Level Plans and Policies}

\subsubsection{Introduction}

In 1966, the State Government of Sabah created six state parks, including Kinabalu Park, Tunku Abdul Rahman Park, Turtle Islands Park and Tawau Hills Park, within which touristic activities are strictly controlled, and in which tourist facilities blend with the natural surroundings. These state parks are of course important foci of ecotourism in Sabah. In addition, there are several wildlife sanctuaries on the East Coast of Sabah such as Sepilok Orang Utan Rehabilitation Centre, Kinabatangan Wetlands, Danum Valley and the Semporna 
Islands such as Sipadan and Mabul Islands where tourists enjoy diving in the coral rich sea.

In place of the forest industry, the importance of tourism as means of regional economic development has been recognised since the mid-1980s. Currently, tourism is second only to the manufacturing sector in foreign exchange earnings and its economic importance has led to tourism being given greater emphasis. The introduction of ecotourism in Malaysia in the early 90's led to the development of The Sabah Master Plan. The Sabah Ecotourism Guidelines followed a few years afterwards. On a larger scale, Sabah as one of the members of BIMP-EAGA (Brunei Darussalam-Indonesia-Malaysia-Philippines-East ASEAN Growth Area) has identified ecotourism, as one of the main areas to be developed and as a main economic activity. 


\subsubsection{The Review}

The Plans and Policies under review include The Outline Perspective Plan of Sabah (OPPS), Sabah Conservation Strategy and Sabah Tourism Master Plan. The state level plans and policies adopted federal plans and policies. The OPPS is formulated based on the Second Outline Perspective Plan (OPP2), Vision 2020 and the National Development Policy (NDP). The Sabah Conservation Strategy was developed specifically for Sabah State in 1992 and published in the same year with the Malaysian National Conservation Strategy. The framework of the Malaysian National Conservation Strategy is the basis for guiding principles outlined in the Sabah Conservation Strategy. The Sabah Tourism Master Plan, published in 1996, is very much based on OPPS and the Natural Resource Policy as it is concerned with the management issues of natural resources.

The Outline Perspective Plan of Sabah (OPPS), which covers the period of 19952010 , is designed to meet the need to face the rapid changing global economic and political environment. Clear development strategies and directions are expected to define global competitive edge in different market and product segments. Therefore, OPPS aims to provide the framework to transform Sabah's economy from one based on the comparative advantage of rich resource endowments to one which creates its competitive advantage through knowledgeintensive industrial clusters driven by indigenous creative capability.

The OPPS is conceived upon the strategic framework to steer Sabah onto a new development trajectory and an era of rapid expansion. In essence, the OPPS provides the direction and guidelines to turn Sabah into an industrialised and prosperous state producing increasingly higher value-added and knowledgeintensive products within the context and time frame of Vision 2020.

According to the OPPS, tourism is identified as the area with the highest 
potential. Ecotourism is specifically mentioned as the main emphasis in view of the State's natural beauty and hence greater efforts will be geared towards preserving its rich heritage and culture. Sabah will continue to be promoted as one of the world-class tourist destinations. The government has made it clear that it will upgrade the existing tourist facilities and services so as to create a clean and friendly environment for the tourists.

In terms of human resource development in the tourism sector, service-oriented professionalism is the main emphasis. This includes enhancing the quality of services provided by tour operators, increasing the number of institutions offering tourism or hospitality related courses and conducting training and skills development in related industries like hotels and restaurants. Research and development on the unique flora and fauna in the state will be stepped up not only to provide more information and knowledge to interested tourists and educational groups but also to enhance understanding of their ecology and to devise effective conservation measures.

More and more hotels are planned to be built so the increasing demand can be met. Hence, the hotels and restaurants industry is anticipated to register a healthy growth rate of 14.7 percent per annum during the OPPS period. The state government also continued to increase the number and range of international flights into the state. At the same time, the government will work with relevant authorities to reduce the cost of flying to and from Peninsular Malaysia so as to encourage more inflow of tourists into the state.

It is quite interesting to see that the OPPS specifically mentioned ecotourism as a tourism product, having decided to capitalise on Sabah's natural beauty, its main asset, while satisfying the need to preserve its rich heritage and culture. However, all other descriptions in the OPPS are almost irrelevant to ecotourism industry. The human resource development only mentioned the development of 
urban-based tourism. The encouragement of business entities is more towards big business such as resort hotels. There is also the intention to increase the number and range of international flights into the state and reduce the cost of flying to and from Peninsular Malaysia to the state. The OPPS is more interested in developing the main tourism industry first, which may well encourage niche markets such as ecotourism. The details of ecotourism development are left to the Sabah government to develop in the Sabah Tourism Master Plan.

The OPPS however outlines the need for research and development on the unique flora and fauna in the state. This will lead to information and knowledge to tourists and educational groups in order to enhance their understanding of ecology and devise effective conservation measures. The two important components of awareness and conservation are very much in line with the ecotourism concept. The International Ecotourism Society (2000) and The World Conservation Union (1996), emphasise conservation of the environment in their definition of ecotourism. This is further supported by Butler (1992), Lindberg, Enriquez and Sproule (1996) and Epler Wood (2002) who suggest that ecotourism should satisfy conservation and development. Ballantine and Eagles (1994) assert that an ecotourist could be defined on the basis of an intention to learn about nature. The International Ecotourism Society (1999) and Epler Wood (2002) suggest that ecotourism is generally defined by its sustainable results, which includes educating visitors via interpretation and learning experience.

The OPPS serves as a useful guide for both the public and private sector in drafting their plans and policies for development in the years ahead. The private sector is encouraged to take the lead in driving the economy while the government will facilitate the private sector's effort through the provision of basic and higher order infrastructure, increased bureaucratic efficiency, a liberal economy and a stable political environment. 
Another important plan for ecotourism in Sabah, especially for the Kinabatangan Wetland region, is the Sabah Conservation Strategy, which has become the basis of the Sabah Biodiversity Conservation Project. The concept of biodiversity is particularly relevant to the tourism sector as it deals with the interface between nature, commerce and social processes. The Sabah Conservation Strategy was prepared under the auspices of the then Ministry of Tourism and Environmental Development (now the Ministry of Tourism, Environment and Culture). It provides a thorough guide to environmental policies and actions relevant to the environment and outlined several recommended strategies with regard to the environment. The guiding principles outlined are:

- Planning and implementation of all work concerned with natural resources must be holistic and multi-sectoral, emphasising a proactive approach at macro and regional levels rather than a reactive approach at micro and specific levels. The cause of the environmental problems rather than the symptoms must be tackled;

a The system for allocation of land use and tenure should shift during the next five years from being a piece-meal arrangement where private interests compete for land in the absence of a regional plan, to an integrated system where public interests and natural resource conservation take precedence in the context of regional plans;

a The target level of the annual expenditure of the state government should be reduced from RM1,500 million, typical of recent years, ideally to not more than RM1,000 million, a level which still reduces the pressure for continued high level of logging of natural forest.

The Sabah Biodiversity Conservation Project was agreed upon in 1994 with the 
signing of a Project Document and a government Project Agreement in December 1994. This project was to '...improve and sustain the use of biological resources of Sabah State' through three field components and a Project Coordination Unit. The field components were:

- Identification of Potential Protected Areas;

口 Management Support to Tabin Wildlife Reserve;

a Multidisciplinary Conservation Study of the Lower Kinabatangan Basin.

There are three immediate objectives defined for the Sabah Biodiversity Conservation Project:

a Objective 1: To enhance the capacity of the (then) Ministry of Tourism and Environmental Development of Sabah and relevant government agencies in the conservation of biological diversity and management of biological resources;

a Objective 2: To strengthen biodiversity conservation and local development on selected sites

a Objective 3: To improve the quality and availability of information on biological diversity and its value and significance to communities.

The project has contributed to the formulation of new legislations related to the conservation of biodiversity:

I. Cultural Heritage (Conservation) Enactment, 1997

II. Wildlife Conservation Enactment, 1997

III. Conservation of Environment Enactment, 1996 
The Kinabatangan component is a prime factor for the ongoing effort to gazette the Kinabatangan Wildlife Sanctuary and the Identification of Potential Protected Areas component has provided proposals for gazettement of several new areas. The Tabin, the Kinabatangan and the Identification of Potential Protected Areas components were instrumental in providing essential data on biodiversity from all project areas. The project Co-ordination Unit provides training and management systems for the storage and analysis of such information. The project team is confident that the present level of achievement of the immediate objectives in the end will contribute to the achievement of the development objective.

The Sabah Biodiversity Conservation Project is seen to successfully complete the outputs planned by achieving the objectives within the organizational framework. Since the production of the Kinabatangan component report in 1996, at least seven recommendations have been acted on and another seven are in the process of being taken up.

The Sabah Conservation Strategy has suggested that management of natural resources should be holistic and multi-sectoral. This is where ecotourism fits as one of the tools in conserving the environment. This is reinforced by the ideas of Ashton (1991), Emmons (1991) and Cater (1994) who claim that ecotourism should promote conservation of natural resources aside from proving financial gain for the host country and the local people. There has also been an increase in the creation of tourism plans and policies with ecotourism built around protected area as a core priority nationwide (Holtz and Edwards, 2003) and Sabah seems to follow this trend.

Sabah's first tourism master plan (also known as Sabah Tourism Policy: 19811990) was completed in 1981. Its focus was on physical development strategies, and options for organisation of the tourism sector. The first master plan clarified what the role of the State should be by indicating the State Government 
responsibilities to coordinate the planning and development of tourism, initiate and conduct research into the social, cultural and economic feasibility of tourism related projects and make recommendations to the government, and undertake joint tourism promotional efforts with Tourist Development Corporation (now Tourism Malaysia) and the Sabah Tourist Association. The first tourism master plan was not fully adopted by the State Government but some recommendations, including reactivating the Sabah Tourism Promotion Corporation (suspended in 1978 and now known as the Sabah Tourism Board), were subsequently implemented.

The second tourism master plan (also known as Sabah Tourism Development Guidelines: 1990-1995) is more comprehensive and provides guidance to the State through the period of the $6^{\text {th }}$ Malaysia Plan. The plan recognizes that the State has a unique characteristic of 'unspoilt nature' and encourages the industry to spread to the rural regions. Furthermore, it urges the State to protect and conserve the environment and culture without conflicting with other forms of desirable development. This plan also instigates awareness of tourism and its benefits to the people of Sabah.

The current status of Sabah tourism policy is based on the Sabah Tourism Master Plan compiled by the Ministry of Tourism and Environmental Development, the State Government of Sabah, which outlined Sabah's tourism development plan from 1995 to 2010. The Master Plan begins with an overview of the economy of Sabah, and tourism places within the new economic development of Sabah, which could replace the forestry sector. Within the plan as well, there is a Natural Resources Policy, which is in tandem with the $6^{\text {th }}$ Malaysia Plan in promoting nature conservation, education, forest recreation, tourism through the creation and development of national parks and protected areas and carrying out scientific research. In this scheme, 'ecotourism' is considered to hold a strategic position in which Sabah makes use of tourism without destroying its unique 
'unspoiled nature' (State Government of Sabah, 1996). Sabah Tourism Board (2000) clearly emphasise nature-based sites and activities for tourism development in Sabah.

The Sabah Tourism Master Plan (1996) has indicated that the East Coast of Sabah will be further developed as nature-based tourism sites including ecotourism. There are areas that are already being developed as ecotourism sites such as the Lower Kinabatangan wetland area, Danum Valley Conservation Area and the recent ones such as Maliau Basin and Tabin Wildlife Reserve. In the Sabah Tourism Master Plan, 'nature tourism' and 'ecotourism' are considered to hold a strategic position in which Sabah makes use of tourism without destroying its unique 'unspoiled nature'. It is also a potentially supportive approach to sustainable regulation and utilization of natural resources.

The Sabah State government recognises that ecotourism could only work out well if the entrepreneurs involve the participation of local community leaders and people at large in their respective areas. Entrepreneurs, mostly urban based, usually have the capacity in terms of capital and business know-how where the local community lack. The local community on the other hand has the capacity in terms of assets (lands), authority (native rights) and local knowledge, which is essential to the entrepreneurs. Mutual understanding and cooperation between the operators and local community would not only promote integration but also generate better income through the tourism industry. Local communities will have job opportunities apart from supplementing their income. This indicates the state government's cognisance of the fact that local community participation is an important issue while realising that they may not have enough capacity to undertake ecotourism operations on their own.

The Sabah Master Plan discusses Sabah tourism within the Malaysian context and its evaluation of competitive and complementary destinations in the region. 
It then systematically analyses, evaluates and reviews tourism elements, which become the basis of tourism development strategies. Within the strategies, it recommends that there should be a provision for economic rationale for nature conservation. The strong emphasis on nature-based tourism provides wide scope for using the income generated by tourism to help justify conservation. While the emphasis on nature remains, the State's whole tourism industry can be viewed as a mechanism for capturing the benefits from nature conservation. This is what most of the tourism authorities agreed on emphasising that successful ecotourism should promote the conservation of natural resources and at the same time, provide financial gain for the host country and the local people (Ashton, 1991; Emmons, 1991, Cater, 1994). This is true for developing countries, where governments have increasingly turned towards ecotourism to earn foreign exchange and at the same time, preserving the environmental resource base and compromising sustainability. The Sabah Master Plan, however, does not specify ecotourism as a tool for conservation or as a justification for determining the importance of nature.

The other strategy that has high relevance to local community participation is the dispersion of income to rural areas and employment generation. This strategy aims at deliberately promoting village-based styles or culture-based tourism and has the express purpose of dispersing the benefits of tourism to places where they are needed. Since nature tourism generally takes place in rural areas, it is thought to have a good potential to generate jobs because it demands labour outside the accommodation sector. In order for the fullest potential to be derived from tourism and ensuring that tourism jobs eventually go to Sabahans, a comprehensive human resource development plan has been recommended. This specifically includes facilitating local participation through management partnerships and through the provision of advisory services for communities interested in developing tourism, which will enhance the social dimension of tourist development. This indicates that there is a strong interest in promoting a 
high level of local community participation in the tourism industry. This is in line with the resolution made at the World Ecotourism Summit (2002) that communities should be able to take more control of management and should be involved in managing resources and benefits (directly and indirectly). Partnership as a form of participation is insightful, as the rural community may not have the capacity to be involved in the management of tourism. This is supported by Tosun (2000) where he identified that a lack of expertise is prevalent in rural communities. The generally limited capacity of rural communities can become a major obstacle in the tourism development process. 


\subsection{Conclusions}

The plans and policies have been critically reviewed based on the literature review rather than the actual happening of the ecotourism industry in Malaysia. The main reason is that the review consists of national- and state-level plans and policies and this are quite generic. Therefore, criticism based on research which is at village-level will not do justice to the plans and policies. Therefore, a more effective way to review these plans is based on literature review, where extensive studies, albeit it may be non-local cases, have been done. Therefore the review is more conceptual in nature rather than process.

The plans and policies review reveals that Malaysia has been putting a lot of effort in developing and fostering the ecotourism industry, both at national and state levels. The three Malaysia Plans under review all indicated an interest in ecotourism where each plan showed different emphasis on ecotourism. The $6^{\text {th }}$ Malaysia Plan (1991-1995) shows evidence of interest in developing ecotourism in Malaysia. The federal government throughout the 6th till the 7th Malaysia Plan has taken an important step by formulating and implementing the National Ecotourism Plan. The $7^{\text {th }}$ Malaysia Plan (1996-2000) is the period where the private sector has been encouraged to develop potential sites for ecotourism activities as outlined in the National Ecotourism Plan. The $8^{\text {th }}$ Malaysia Plan (2000-2005) started to develop the operational concept of ecotourism by emphasising local community participation, socio-economically speaking. However, despite the growing interest in the industry, there is no mention on resource allocation specifically for ecotourism.

The National Tourism Policy outlines the actions that should be taken in developing and operating the tourism industry in Malaysia. In relation to ecotourism, the National Tourism Policy recommends this industry as high in 
priority for development even though the understanding of ecotourism as a concept is unclear. The policy thrusts also give emphasis on rural and community development identifying specific programs aimed at increasing the participation of the local population and maximising economic opportunities. Some approaches to local community participation show that the federal government is aware of the challenges in the participation process and more practical suggestions were forwarded.

The National Ecotourism Plan (1997) provides the essential framework on ecology-based tourism development. It covers the entire country and provides a comprehensive study on existing ecotourism sites, providing identification of potential development in certain areas. It also provides the Ecotourism Guidelines for Malaysia, which is handy for planners, managers and the private sector. The National Ecotourism Plan is an indicator of government initiative and enthusiasm in developing the industry. The plan is an appropriate instrument within the overall sustainable development of Malaysia and the economy as a whole, and as an effective tool for conservation of the natural and cultural heritage of the country.

Since Sabah has been identified as having the appropriate natural resources, the development of ecotourism in the state has taken a prominent place in national level plans and policies. Sabah has also managed to come up with a few plans and policies on its own in accordance with the national level plans and policies.

The Outline Perspective Plan of Sabah or OPPS (1995-2010) is a development strategy for the State of Sabah. It is designed to meet the need to face the rapidly changing global economic and political environment. Within the OPPS, tourism is identified as the area with the highest potential. Since the state views natural beauty as its main asset, ecotourism is specifically recommended in preserving Sabah's rich heritage and culture. Education and awareness seem to 
be important in the tourism strategies where tourists may enhance their understanding of ecology and devise effective conservation measures. The OPPS however did not elaborate on the issue of local community participation in ecotourism strategies. Consistent with other plans and policies under discussion, ecotourism in OPPS is considered more of a tool for conservation and providing economic opportunities. OPPS serves as a useful guide for both the public and private sector in drafting their plans and policies for development in the years ahead.

The Sabah Conservation Strategy (1990) provides a thorough guide to environmental policies and actions relevant to the state's environment and outlines several recommended strategies with regard to the environment. The Sabah Conservation Strategy has become the foundation for Sabah Biodiversity Conservation Project. This work is important especially in implementing efforts of conservation in selected areas of the state. This is where ecotourism was considered as a tool for conservation. The Sabah Biodiversity Conservation project is seen by the State as successfully completed when the objectives are met within the framework.

The Sabah Tourism Master Plan (1995-2010) outlines Sabah's tourism development plan and places tourism within the new economic development of Sabah. Ecotourism here is considered to hold a strategic position where Sabah capitalises on its assets without destroying its unique 'unspoiled nature'. The Sabah Master Plan, however, does not specify ecotourism to be the tool for conservation as many other plans and policies do. The Sabah Tourism Master Plan also promotes integration among stakeholders, namely the tour operators and the local community. This suggests smart partnerships between these two groups, as better income will be earned this way. The state government also realises that the local community may not have enough capacity to undertake ecotourism operations on their own. However, there is no strategy to incorporate 
local community participation in the industry. The Sabah Tourism Master Plan, however, provides direction for tourism industry for Sabah, and the government may develop policies based on these plans.

Many of the plans and policies consider ecotourism as an important industry to be developed. Many have cited reasons for developing it but the popular reasons that come across the plans and policies under review are 1) ecotourism is an important tool for conservation; and 2) ecotourism can provide desirable economic opportunities. Local community participation as an element in ecotourism is highly encouraged and has sparked interest among policy makers. The plans and policies are quite realistic in terms of strategies for local community participation. They show that there is a need for capacity building of the local people. Some are quite perceptive that the suggested strategies address many potential challenges, which are also suggested in the literature review. These plans have a strong focus on the development of ecotourism and its capabilities, as well as a high level of commitment to the rural people, which is a classic example of ecotourism planning.

The review has highlighted various essential points of ecotourism and local community participation in the context Malaysia and Sabah. These are the points that are under ongoing implementation, till the plans and policies validity expired or new plans and policies are created. These highlights are essential during the analysis stage of this thesis. The results are the outcome of implementation of these plans and policies, therefore, they give valuable analysis of the gap between what was on paper and what was in practice. It gives in-depth insight of the results while being useful to the policy makers. 


\section{CHAPTER 5 - CASE STUDIES}

\subsection{Introduction}

There are five sites that are selected for the purpose of this research. As mentioned earlier in the methodology chapter, the five sites will be analysed using the comparative case studies method. This is the preferred method when 'how' or 'why' questions are being posed, when the researcher has little control over events and when the focus is on a contemporary phenomenon within some real-life context. The case study aims to understand the case in depth, and in its natural setting, recognise its complexity and its context. It also has a holistic focus, aiming to preserve and understand the wholeness and unity of the case. The results of the comparative analysis are useful in discussing the main results of the thesis. They also help to justify the findings that are presented in later chapters.

\subsection{Research Sites}

Sabah (Figure 5.1), as part of Borneo, is romantically associated with impenetrable jungles and is considered a mystical, mysterious land. The tourism industry in Sabah is considered relatively young (Chan \& Yeoh, 2001). Tourism in Sabah began as a small-scale industry in the year 1986. It started by visits to a few of the natural features found abundantly in some protected or undisturbed areas. Few sites were developed as mass tourist attractions such as Tunku Abdul Rahman Park, Mount Kinabalu (the highest mountain in South East Asia) and the Orang Utan Rehabilitation Centre at Sepilok, Sandakan. 


\section{Figure 5, 1 Map of Sabah and Its Major Cities}

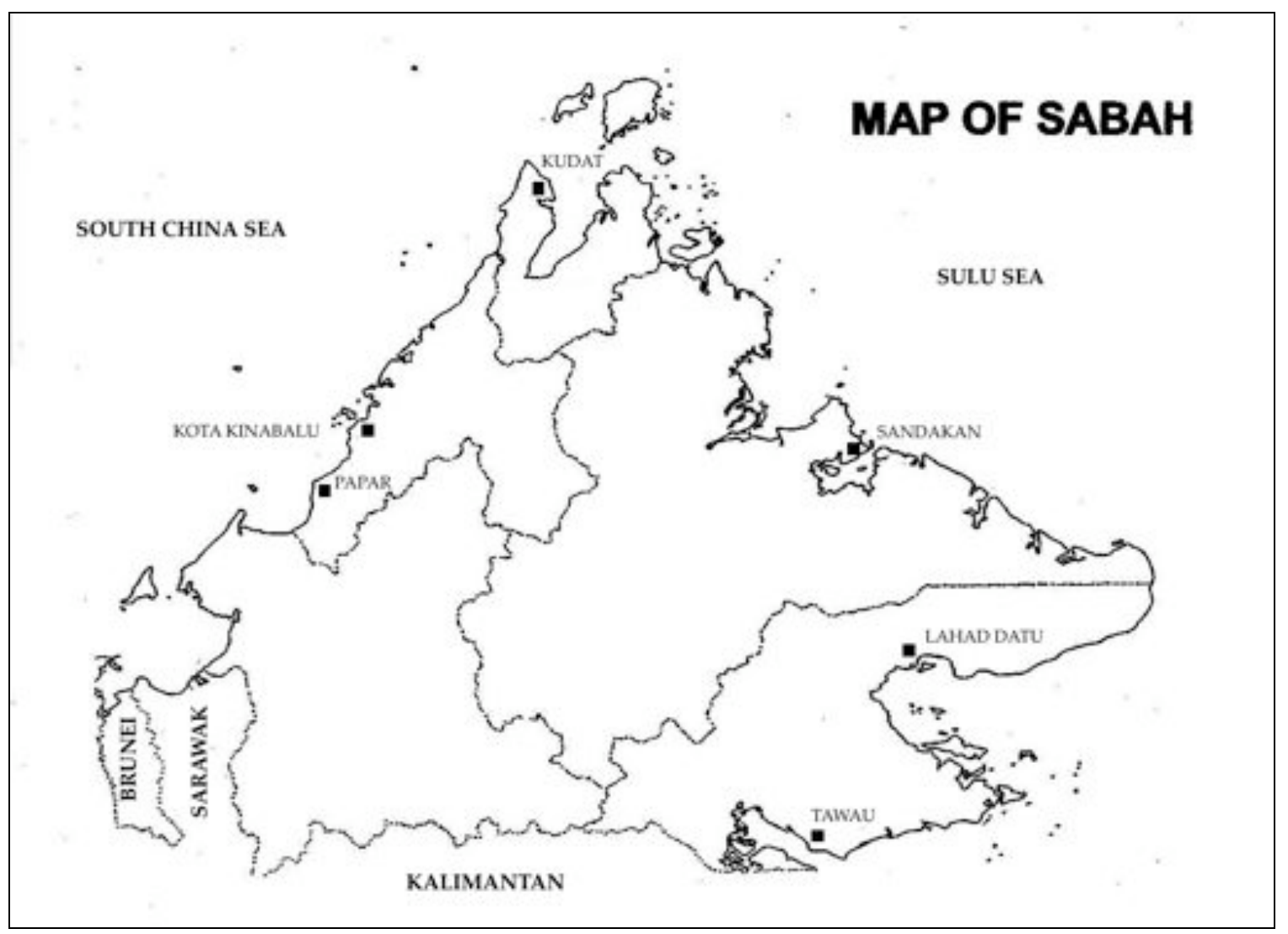

Sabah is popular with both domestic and international markets shown by the figures of tourist arrivals which are almost evenly distributed (Figure 5.2). The arrivals of visitors for 2002 and 2003 are at over 1 million. There is a trend of increasing visitor arrivals and it is expected to continue in the future.

Sabah has evolved from a 'value for money' destination to a 'nature adventure' destination. The year 2000 was declared as the Visit Sabah Year, where the marketing catchphrase was 'Sabah Natur(e)ally' which emphasised nature and culture. The Sabah Tourism Board (1999/2000) chose 10 brand images for Sabah including Kinabalu Nature, Wildlife, Exploring the Borneo Rainforest, Soft 
adventure activities, Tough wild adventure activities, Cultural experience, Diving and snorkeling, Islands and beaches for relaxation, to target their respective markets. The focus on nature and culture clearly puts Sabah's natural resources under the spotlight and at the same time, elevates nature-based tourism products such as ecotourism into prominence.

\section{Eiqure 5, 2 Visitor Arrivals to Sabah}

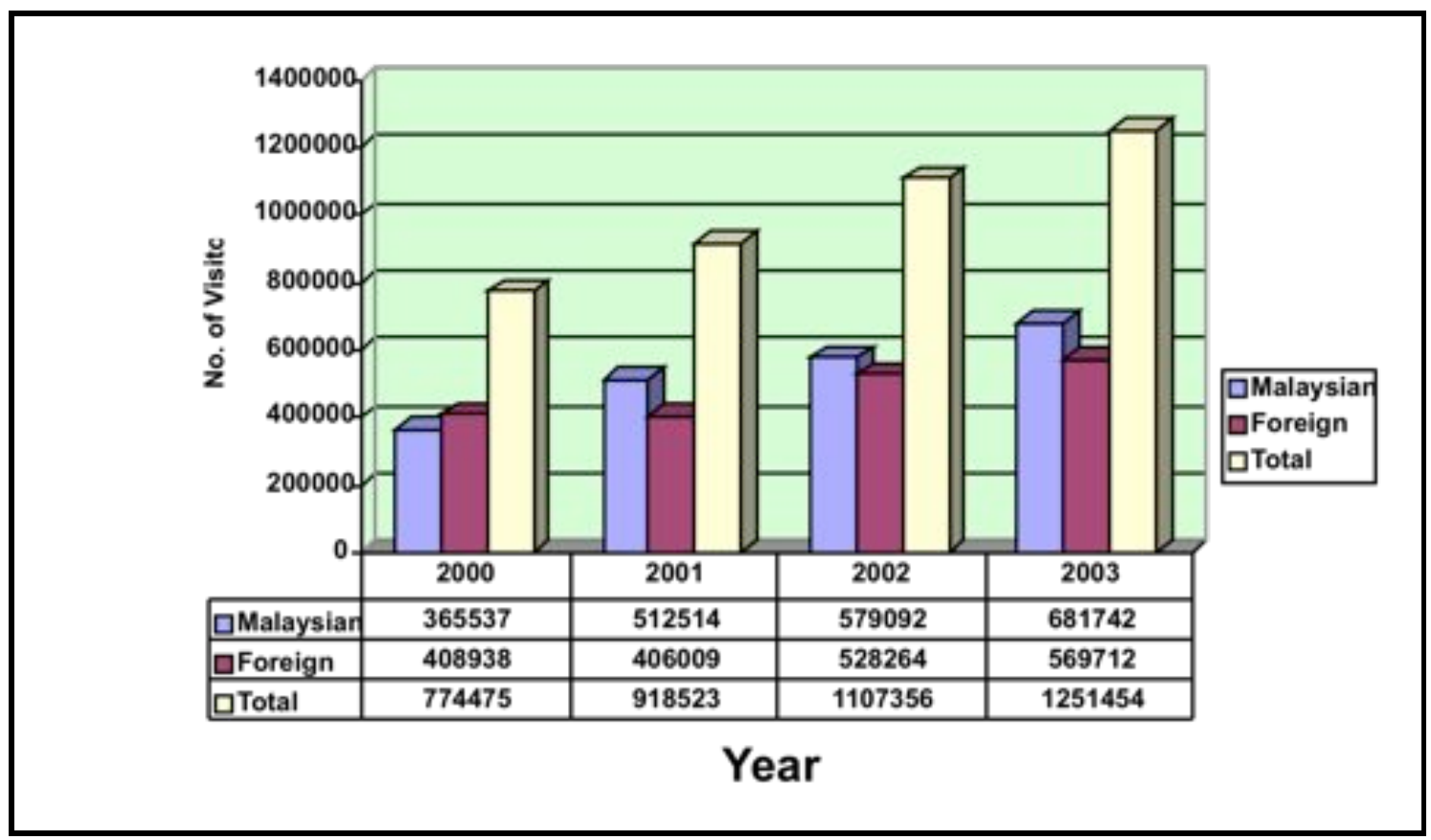

Source: Sabah Tourism Board (2004)

Ecotourism is now the main focus of the tourism industry in Sabah (Sabah Tourism Board, 2002). The main attraction is the diverse wildlife consisting of almost 200 species of mammals and over 500 species of birds with the Orang Utan as the flagship wildlife animal and the Rafflesia, the Slipper Orchid and the Pitcher Plant as the flagship plants. State government agencies such as the Forest Department, Wildlife Department and Sabah Parks are entrusted with the conservation and management of the state's natural resources - forest and wildlife (Chan \& Yeoh, 2001). The various ethnic groups, more than 30 of them, 
provide the rich and diverse cultural heritage. The stable Federal and State governments provide an environment that is conducive for a successful tourism industry in Sabah.

\subsection{Ecotourism Industry in Sabah}

Ecotourism industry in Sabah is mainly private sector-led. These are mainly urban-based tour operators and there are also a handful of local-run sites. The government and NGOs are supportive of this industry, and encourage private enterprises to get involved, develop and promote ecotourism destinations in the country based on the guidelines prepared by the relevant authorities. The private sector is mainly involved in developing ecolodges, organising tours and marketing products, and conducting training programs for members through various business associations.

Although the development of the tourism industry is mainly private sector-led, the Malaysian Government is also doing its share to support ecotourism development. In addition to the planning and coordinating functions, both the federal and the state governments have been providing funds to develop infrastructure facilities at various ecotourism destinations, as a stimulus to the private sector.

In Sabah, the important bodies for ecotourism are 1) Ministry of Tourism, Culture and Environment; 2) Sabah Tourism Council; 3) Sabah Tourism Board; 4) State Development Office 5) Sabah Parks and Sabah Wildlife Department, which are constituents of the Ministry of Tourism, Culture and Environment 6) Sabah Forestry Department; and 7) State Fisheries Department.

Some non-governmental organisations (NGOs) are also instrumental in 
promoting ecotourism in Sabah, with World Wide Fund for Nature (WWF) Malaysia and the Partners for Community (PACOS) being the notable ones. WWF-Malaysia was established in 1972 and has since worked on scientific research, policy work, environmental education, public awareness programs and ecotourism training. PACOS is a local NGO that encourages tourism as a means for community development.

There are also instances where international funding agencies are involved in promoting ecotourism in Malaysia. Among these agencies are the Danish aid agency, DANCED (Danish Cooperation for Environment and Development), and GTZ of Germany (Deutsche Gesellschaft für Technische Zusammenarbeit). GTZ is involved in supporting conservation in the Sabah rainforests.

There has been a lot of government encouragement for entrepreneurs especially in the rural community to set up small and medium scale tourism enterprises in rural areas. The Sabah Tourism Master Plan (1996) states that an important goal of tourism development, including ecotourism, in rural areas is to maximise community participation and distribution of socio-economic benefits to the rural communities. One of the main strategies to improve the living standards of rural populations in Sabah, in the context of tourism development, is the promotion of community enterprises. It is a collective activity initiated by the community themselves to raise socio-economic standards, improve their environment and subsequently uplift their quality of life. Based on the concept of self-help, mutual help and common ownership, the community enterprise encourages the participation of the local community in conceptualising their development needs and in the decision making over control of scarce economic resources (IDS/COMMACT, 1998). 


\subsection{Ecotourism Sites}

Among many ecotourism sites in Sabah, five were selected based on the set of criteria discussed in Chapter Three. Each section explores the sites as separate case studies and the case study matrix has been used to analyse the case studies. Each case study gives historical background to the area and details on its ecotourism operation and local community participation. It also highlights the attractions and activities that are available at the site. The case studies are also accompanied by visitor statistics, which not only shows the pattern of visitors to the sites but also suggests that each site is a small-scale operation with a small number of visits on average. All of the research sites can be referred to in Map 4.1.

\subsubsection{Kampung Bavanggazo}

Kampung Bavanggazo (Figure 5.3) is situated on the northern tip of Sabah in the Kudat district approximately $130 \mathrm{~km}$ north of Kota Kinabalu, the capital city of Sabah. It is a 3-hour drive from Kota Kinabalu. The Rungus people, who are a sub-tribe of the Kadazandusun indigenous ethnic group, inhabit the village. Rungus people can only be found at the Kudat and Bengkoka Peninsula. The villagers are mainly farmers and many of its women are quite renowned in their handicraft making skills originating from the adjacent Tinangol Village. The Bavanggazo Village area was formerly under Tinangol Village, and was formerly registered as a village by the villagers who already owned land in this part of the Tinangol Village. Bavanggazo (lit. big river) got its name from a river that runs through the area.

In 1992, the Sabah Tourism Board (then Sabah Tourism Promotion Corporation) invited 15 villagers from Kampung Tinangol at the Matunggong district to build a 
traditional Rungus long house for an exhibition in Kuala Lumpur, the capital city of Malaysia. They were overwhelmed and inspired by the visitors' response that when they went back to their village, they built a traditional Rungus longhouse exclusively for tourism. It was named Bavanggazo Rungus Longhouse. In early August 1992, construction of the first long house with nine rooms started. It was built using local materials. Water supply came from two natural water reservoirs on the top of Gomantong Hill. Initially, 20 families were involved in the establishment of the longhouse. Now, there are only nine families involved in the full time operations and management of the Bavanggazo Rungus Longhouse. The others opted to go back to their original village i.e. Kampung Tinangol.

\section{Figure 5. 3 Map of Bavanggazo Rungus Longhouse}

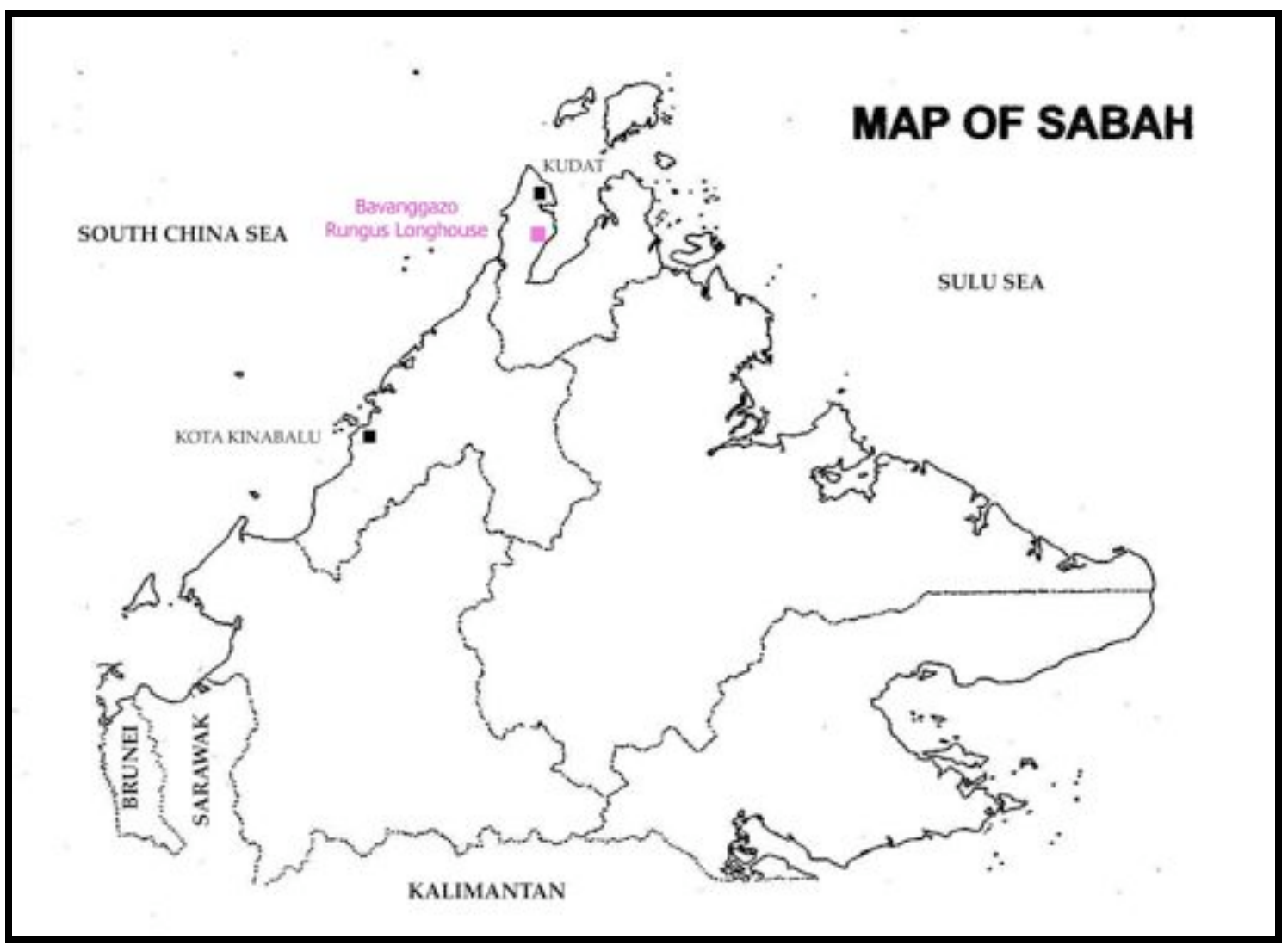

Bavanggazo Rungus Longhouse offers homestay products to visitors and has 
become a living museum. It was gazetted as a five-acre village reserve. Next to it is another reserve for water catchment on Gomantong Hill. The surrounding villages managed to specialise in one industry such as Sumangkap Village on gong making and Gombizou Village on honeybee farming. Bavanggazo decided on tourism as their sole industry. There was support from the state government in the form of seed funding and consultation. The Sabah Tourism Board was consistently giving consultation to the Bavanggazo Rungus Longhouse committee.

At present, the Bavanggazo Rungus Longhouse consists of one traditional Rungus Longhouse with 10 rooms where each room can accommodate two persons, three one-bedroom chalets which are suitable for a couple or a small family, a reception and a souvenir shop. The longhouse and chalets are made from wood and bamboo and the roof is made from nipah leaves. The longhouse and chalets are not equipped with modern amenities but adorned with traditional items for the traditional authentic ambiance and for many years kerosene lamps were used to achieve that. The kerosene lamps have since been replaced with normal electric lamps cleverly concealed in the kerosene lamps since it is more practical during windy nights. Bathrooms are modern and a gravity pipe provides water supply. The normal package offered is accommodation with dinner and breakfast. Lunch is provided on request. The food served is traditional Rungus food that is gathered either from the forest or from their own garden. The community also sells all sorts of Rungus handicrafts. After dinner, there is a traditional performance, which includes three dances i.e. Mongigiol Sumundai, Mangatip-atip and Manaradan, and a musical performance using the unique nose flute called Mongurali. A welcome drink of coconut juice is served on arrival. Other services include customised handicrafts e.g. sash woven with names. The Bavanggazo Rungus Longhouse package costs RM120 (Approx. US\$34) for one person. For a group of 2-10, it costs RM70 (Approx. US\$20) per person while it costs RM65 (Approx. US\$18) per person for a group of 11 or more. 
One activity that the tourists usually do is jungle trekking around the village. Guided by a local guide, trekking up to the highest point of Gomantong Hill, visitors can see the scenic Mount Kinabalu, a World Heritage Site, and the South China Sea. Visitors are also brought to Torongkungan Beach. Besides enjoying nature, visitors also have the chance to see some interesting sights such as the beehives where the villagers get their honey supply. They are also treated to a demonstration of traditional animal traps, while visits to corn and paddy fields, and rubber tapping at the rubber estate provide the local livelihood experience.

Each villager is involved in every level of Bavanggazo Rungus Longhouse operations. At the operational level, there are men and women who work full time and part time for the longhouse. The children help out in any odd jobs in the spirit of gotong royong ${ }^{14}$ and perform dances to the visitors. There is a gotong royong for the whole village every Saturday.

The operation has created a system where each family is delegated one job including landscaping, facility cleanliness, facility maintenance, lighting and bathroom cleanliness and maintenance. Each family has its own leader and committee. In the decision-making level, Bavanggazo Rungus Longhouse has its own committee. The committee consists of chairman, deputy chairman, secretary, treasurer, committee member for cleanliness, gotong-royong, facility maintenance and maintenance (non-facility).

Since STB and Bavanggazo Rungus Longhouse work together rather closely, the minutes of the committee meetings are submitted to STB. This practice aims to

${ }^{14}$ Gotong-royong is a concept exclusive to the Malay world (Malaysia and Indonesia). It includes the whole of the village working together on a task voluntarily without expecting any monetary rewards. 
update STB with the affairs of Bavanggazo Rungus Longhouse in order for STB to give better advice and guidance. STB is not involved with the operations of the longhouse Its involvement is limited to giving advice.

Bavanggazo Rungus Longhouse operations have provided the villagers with employment opportunities. However, villagers still derive their main income from their main occupation, which is farming, while the longhouse work provides them with supplementary income. The average income from Bavanggazo Rungus Longhouse is between RM200 (Approx. US $\$ 57$ ) to RM500 (Approx. US\$142) per month depending on the season. A fund was created from longhouse operations so that villagers can get free-interest loans. Two percent of the operational profits are allocated for the welfare of the villagers.

The villagers are no strangers to local community participation projects. They have been in several projects based on the agriculture industry. In 1995, contract farming was initiated by the Agriculture Department for short-term crops although it failed because of unexpected unsuitability of the soil. After that, the Koperasi Pembangunan Desa or KPD (Rural Development Cooperation) started Markisa fruit plantation but it did not prosper, as the market demand was not good. A honeybee project was also proposed but it never reached the implementation stage because of participant-related problems.

The tourists that visit Bavanggazo Rungus Longhouse are from both domestic and international segments. Most of them are 'walk-in' tourists. Many international tourists come with a tour operator or independent tourist guides. Foreign tourists usually stay overnight. Based on the survey conducted from 2002-2003, the tourists were mainly youths (less than 20 years old) and adults (31-40 years old). Most of them were educated, having at least secondary level qualifications. Visitor arrivals are shown below (Fig. 5.4). 


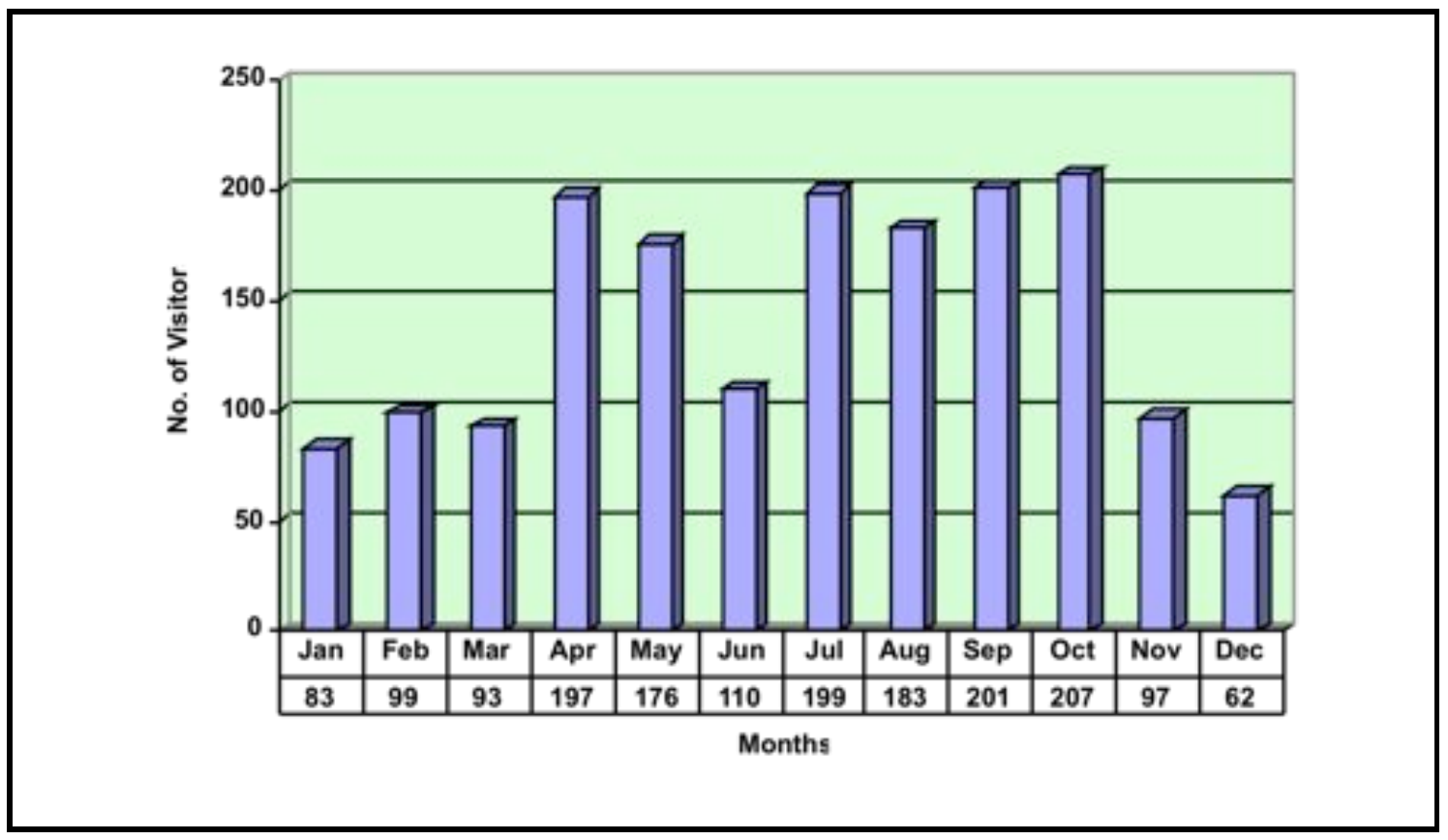

Source: Milaad, A. (2004)

\subsubsection{Kinabatangan Wetlands}

Kinabatangan Wetlands, which is the home of two research sites i.e. Batu Puteh and Sukau, is located in the eastern part of Sabah. The Kinabatangan River is one of Borneo's longest and most important rivers. This waterway has played an important part in the lives of the Sabah people for centuries. It is the largest remaining forested floodplain in Sabah. Originating from southwestern Sabah, the Kinabatangan River flows $560 \mathrm{~km}$ through eastern Sabah out to the Sulu Sea. The river and its surrounding rainforest wetlands also make up one of the richest ecosystems on the planet.

The region is home to a variety of animals including rare and endangered ones endemic to Sabah and Borneo such as the Proboscis Monkey, Orang Utan and Pygmy Elephant, making it an increasingly sought-after tourist destination. Much 
of the Kinabatangan remains a mystery. Sharks and rays, usually thought of as sea creatures, live in freshwater in the Kinabatangan River but little is known about them.

The Kinabatangan Wetlands has a diverse ecosystem that helps maintain water quality and quantity - a function vital to all life on earth. Botanical studies by WWF-Malaysia (2003) have identified 11 vegetation types of which the main ones are: 1) Forest over limestone outcrops; 2) Aquatic vegetations; 3) Freshwater and riverine forest; 4) Coastal and mangrove forest; 5) Lowland dipterocarp forest; 6) Seasonal swamp forest; and 5) Tidal swamp forest. Kinabatangan Wetlands is one of the most productive and significant among the many types of wetlands for fishing, forest product, transportation and waterfiltering system. It is used to regulate water flow and floodwaters and is home to many rare and endangered species.

Kinabatangan Wetlands that surround the Kinabatangan River are special as they have a high biodiversity, which makes them valuable as an ecotourism site. The lower Kinabatangan has only recently begun to be valued as a nature-adventure and ecotourism destination. More and more tourists are becoming interested in visiting what remains of the wild areas of Borneo. 


\section{Figure 5, 5 Map of Kinabatangan Wetlands}

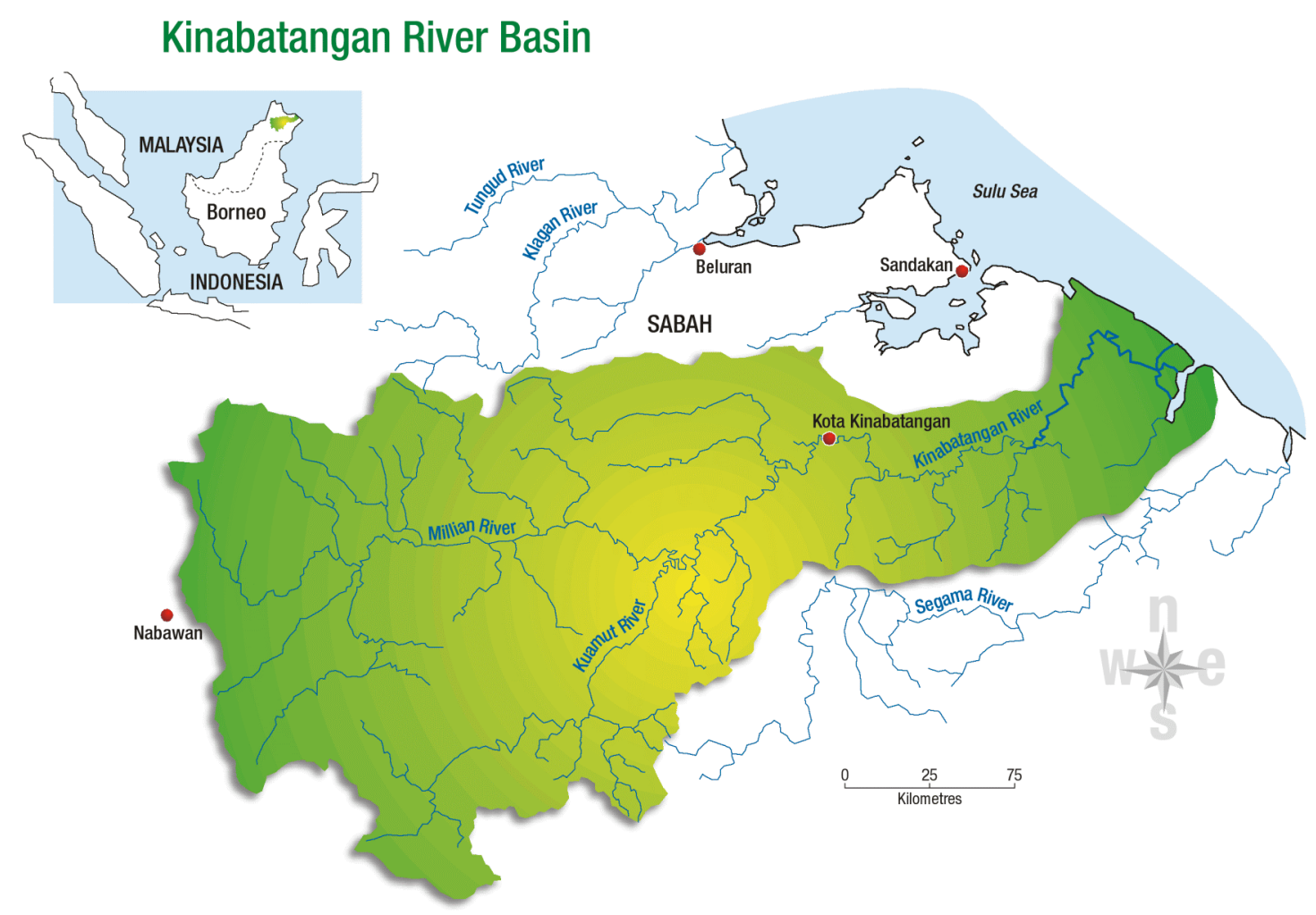

Source: www.panda.org (2005)

Rapid industrial development and changes from forestry to commercial agriculture have posed several threats to the area. As of 1996, more than 50 percent of the area's virgin forest had been cleared and replaced by cash crop oil palm plantations. WWF-Malaysia (2003) has documented six threats to the Kinabatangan Wetlands:

1. Severe land use changes - loss of wildlife species due to insufficient habitat to support breeding populations.

2. Ineffective implementation of existing laws and procedures - 
continued logging causing extreme degradation of most forested areas.

3. Carrying capacity has exceeded what is considered a healthy balance between human and wildlife - insufficient planning of tourism development leading to poor quality of products.

4. Environmental impacts of sustainable development - dominance of the landscape by oil palm to the extent that it is no longer attractive to tourists.

5. Over consumption of natural resources - insufficient integration to the native socio-economy.

6. Lack of awareness - Ecotourism development guidelines not enforced, lodges are concentrated in one village.

The same study also documented opportunities of Kinabatangan Wetlands, which are:

1. General awareness and willingness to improve and apply environmental legislation.

2. Promising initiatives and growing environmental awareness.

3. Worldwide attention of Kinabatangan as a wetland area with high biodiversity of tourism value.

4. Opportunities to improve on quality of tourism experience.

5. Existence of relatively intact vegetation and wildlife resources.

6. Increasing willingness of local communities to participate in tourism development.

7. Growing awareness of local communities of the need to develop alternative sources of income and the need for conservation efforts.

WWF-Malaysia (2003) has documented the activity of local community participation in the Partners for Wetlands project, in Kinabatangan Wetlands. 
Local communities are encouraged to participate as they are in a good position to comment, monitor and report any illegal activities. With that, they are able to protect the environment where ecotourism can prosper. Participating in the development of livelihood, the local communities also can ensure that some natural resources survive while improving their dependence on resources that may not be available in the future.

Ecotourism is deemed to be important to the Kinabatangan Wetlands. It has been cited as the economic rationale to preserve its integrity. The government is encouraging its growth because when responsibility is practised, it allows for the protection of biodiversity. It has also been recognised that ecotourism can maximise its potential by relying on the maintenance and restoration of natural features. There are five main sites for ecotourism development at the Kinabatangan Wetlands namely Batu Puteh, Bukit Garam, Kampung Sukau, Kampung Bilit and Kampung Abai. Two of these sites, Batu Puteh and Kampung Sukau, are research sites for this thesis. 
5.3.2.1 Batu Puteh

Figure 5. 6 Map of Batu Puteh

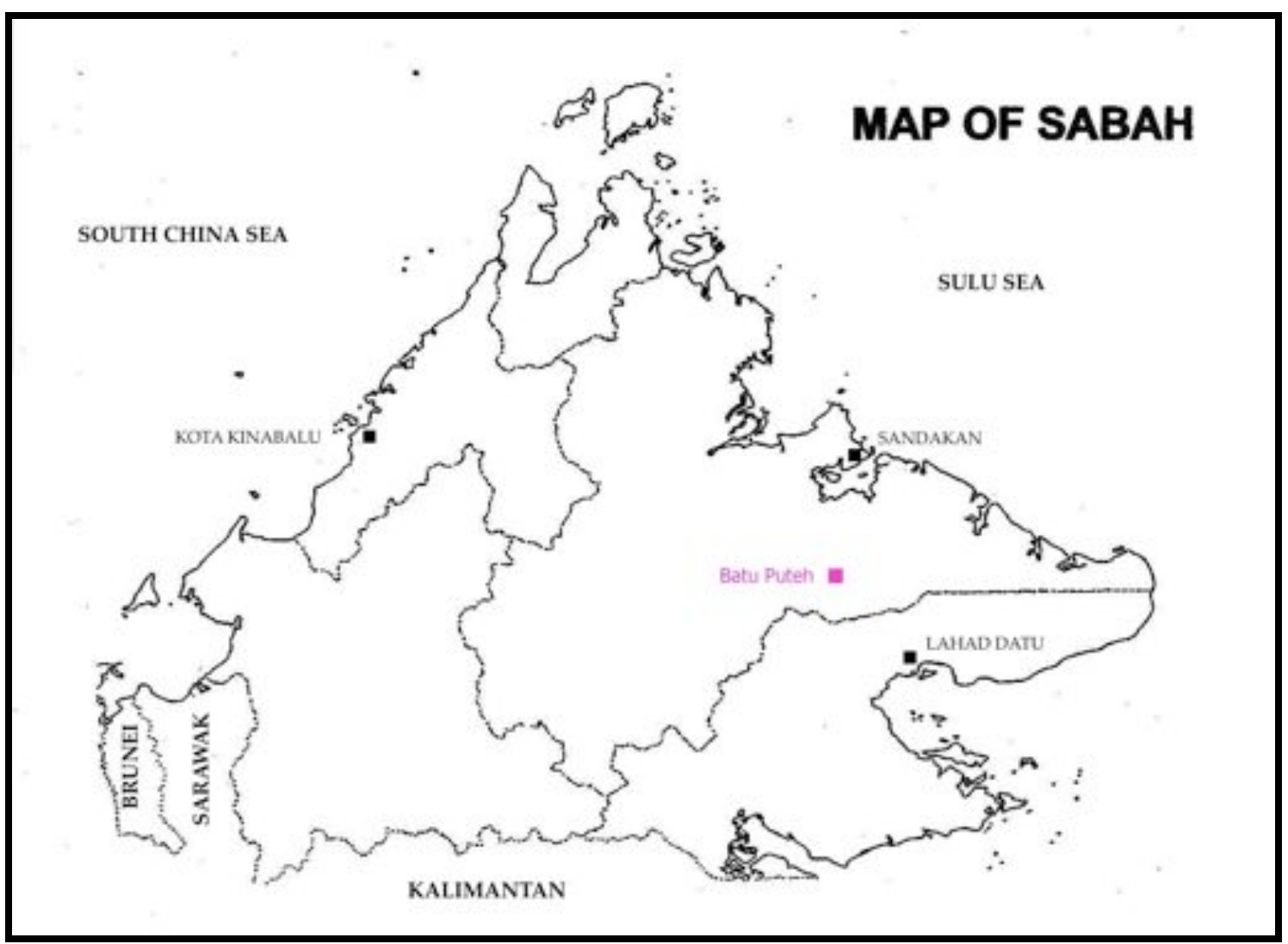

Batu Puteh is situated along the main highway between the eastern Sabah cities of Sandakan and Lahad Datu (Figure 5.6). It is a 6-hour drive from Kota Kinabalu and 2 hours from the east coast city of Sandakan. It has 1200-1400 people living there and generally there are more women than men. The exact population is hard to estimate since there are immigrants working in the oil palm plantation.

Batu Puteh got its name from a big block of white rocks. The main landmark of the village is a large bridge over the picturesque Kinabatangan River. However, the main centre for Miso Walai Homestay and MESCOT activities are in Mengaris 
Village. Batu Puteh is easily accessible by public transport, private car and boat. Most of the areas surrounding Batu Puteh are gazetted as a wildlife sanctuary.

The Orang Sungai ethnic group dominates the population and more than $90 \%$ of the population are Muslim. They speak the Sungai Language with more than 10 dialects. The Orang Sungai are popular with their unique stories, folklore and arts, especially performing arts. They also have a unique knowledge of the environment. Locals are involved in a number of economic activities such as working in the oil palm plantation. While some are working with the private and the government sectors, only a handful still work as a subsistence farmers/fishermen. The villagers' houses are mostly situated along the main road or the river. Most houses are wooden and simple. Squat toilets are common and bathing can be done in the bathroom or with the rest of the villagers at their local washing pond, wells or communal river spots. Group bathing is an important part of the social life of the community. The villagers expect the ecotourism project to provide social development with community integration, and personal and skill development through training and experience, while maintaining their existing culture and providing welfare such as soft loans to improve their houses to meet Homestay Association requirements (pers. comm. with the Villagers, 2003).

In the 1980's, the government and villagers of Batu Puteh realised that there was a decreasing number of habitats around the Batu Puteh area and a growing concern emerged to conserve the surrounding forest. Since April 1997, WWFMalaysia has been working in collaboration with the state government to help the local community develop sustainable community-based tourism in the Lower Kinabatangan. A number of development and business plans have been prepared and MESCOT (Model Ecologically Sustainable Community Based Conservation and Tourism) was started in Batu Puteh. 
MESCOT is supported by WWF-Malaysia (Sabah), Ministry of Tourism, Culture and Environment of Sabah and Sabah Forestry Department. WWF-Malaysia' role is to act as a facilitator for the local villagers in developing ecotourism products through training, awareness activities and initial networking with relevant organisations. MESCOT organises its activities within the sub-district of Batu Puteh. This includes four villages, which are Batu Puteh (village of the same name), Mengaris, Perpaduan and Paris. Under MESCOT, the Miso Walai Homestay project was started in 1997 and fully running from June 2000. In February 1997, an old house was rented and renovated to make it the MESCOT headquarters. Miso Walai originates from the local Sungai language, which is the indigenous people of this region, meaning 'together as one house'. Miso Walai Homestay is a registered association comprising of the coordination committee and regular members who open up their homes to visitors, who stay and experience the local rural way of life.

MESCOT also coordinates transport services including boat, handicraft and recreational ecotourism activities. It focuses on encouraging more ecotourists and responsible visitors. It hopes to reduce tourism pressures further downstream of Kinabatangan River while providing alternative and supplementary livelihoods to the local community (pers. comm. with MESCOT chairman, 2003). It encourages local people to get involved in conservation efforts in the surrounding areas. The conservation-based activities include forest restoration, ecotourism, Phenological trails (a special trip to a site with outstanding beauty for education and awareness), nursery propagation, tree planting and silviculture.

MESCOT is also making efforts in forest conservation and rehabilitation in the Lower Kinabatangan with the support of major multinational companies and international organisations from time to time such as RICOH, Shell and Discovery Channel. Shell, the oil company, contributes RM200,000 (Approx. US $\$ 57,142$ ) 
towards the building of ecolodges and the maintenance of its surrounding forest reserve. RICOH, the camera company, is sponsoring the forest rehabilitation project.

The ecocamp sites were provided by the Forestry Department and the area is estimated at 1000 hectares and is gazetted as a Virgin Forest Reserve (Class 6). MESCOT has to pay fees to the Forestry Department for occupying the space. Within the site, there are three lakes, namely Lake Tongols, Lake Biandung and Lake Kabui. Lake Tongols is considered beautiful and unique because of the shape and the flora and fauna there. Lake Biandung dries up during the drought season, while Lake Kabui becomes turbid at the same time. The ecocamp, once completed, will consist of 10 chalets, three decks, staff quarters and walk boards. Locals and MESCOT members will be employed. Raleigh International is spending two years helping to build the ecocamp for which is completed in 2004.

MESCOT focuses specifically on training village youths in planning and related business skills. It aims to foster personal development through tourism activity. Its membership is open to youth from the age of 18-35 years. MESCOT members are also taught the English language, desktop publishing and management skills. They are encouraged to contribute to the expansion and development of the organisation and Batu Puteh. To be a member, villagers have to pay RM10 (Approx. US\$2) for registration. Most of the members are interested in tourism. Members are trained internally and have the opportunity to attend workshops and seminars organised by the Ministry of Tourism, Culture and Environment.

Another MESCOT activity is members FAM (Familiarisation) trips for exposure. This activity is quite popular among members. So far, the members have gone to popular tourist attractions such as Danum Valley and World Heritage Site Mount Kinabalu and Mulu National Park in the neighbouring state of Sarawak. Besides experiencing the touristic activities conducted, they also learn about the tourism 
operations in each site. So far, the members have implemented several operations such as:

1. Miso Walai Homestay

2. Maya do Talud (Boat service)

3. Tulun Tokou (Handicrafts)

4. Kem Tinbaan Tungog (Tungog Forest Eco-Camp)

5. Kelab Berkayak MESCOT (MESCOT Kayak Club)

In the beginning, the MESCOT project was under criticism from the local community, as it required a considerable amount of planning at the beginning of its operations. The local community also expected something tangible to come out from the formation of MESCOT in the short term. The locals were reluctant to join because they felt 'embarrassed' and intimidated by the idea of speaking English to the tourists (pers. comm. with the Villagers, 2003).

The MESCOT committee organised the rotation of the homestay and attended to the small details in receiving visitors to the village. This includes arrival briefings, 'do's and don'ts' in the village and information dissemination on local attractions and activities. Special community activities are arranged for groups. The activity of the locals varies from day to day, and season to season. For instance, Miso Walai Homestay has made a standard formula that is agreeable for the host families. They now offer a wide variety of activities, which can fit into daily or multiple day programs for visitors. They developed a trail for visitors, The Mengaris Trail. It joins the Mengaris and Batu Puteh villages, forms a loop starting at the Kinabatangan Bridge and winds along the riverbank back to the main road near Batu Tulug Museum. Visitors can see wild plants among cultivated orchard trees, animals and birds, as well as sites of historical and cultural interest along the way. Interesting flora such as edible medicinal plants including ferns and flowers and fruit trees can be seen along with fauna such as 
butterflies, birds and monkeys. There are also three age-old burial sites of families that settled in the area generations ago. The central feature of this trail is Batu Tulug, a limestone outcrop with ancient burial remains.

One of the favourite activities is the fish-trap making demonstration. It only costs RM20 (Approx. US\$5) to participate and an extra RM80 (Approx. US\$22) if the visitor wants to buy the trap. Other activities such as participating in planting and harvesting the hill rice are season dependent. Tourists can also participate in community service, where lawn trimming using local chopper/cleaver is the most popular. The boat service has a rotation system. There are 50 people within the rotation and the charge for a trip is RM20 (Approx. US\$5) for two hours. During the peak season, everybody has the chance to earn money from the boat service. However, MESCOT members understand that the Miso Walai activity only provides side income.

At present, MESCOT is in the process of setting up a co-operative called Koperasi Pelancongan (KOPEL). All the moneymaking operations (Miso Walai, Boat Services, MESCOT, handicraft and trek) would be put under KOPEL and a committee will manage the finances. The local community will own KOPEL and cooperative directors would be appointed from MESCOT. Locals can earn side income of between RM1,500 (Approx. US $\$ 428$ ) to RM3,000 (Approx. US $\$ 857$ ) annually. Houses belonging to the locals are improved as they were renovated from the income received from the homestay. 


\section{Figure 5. 7 Visitor Arrivals to Batu Puteh, Kinabatangan}

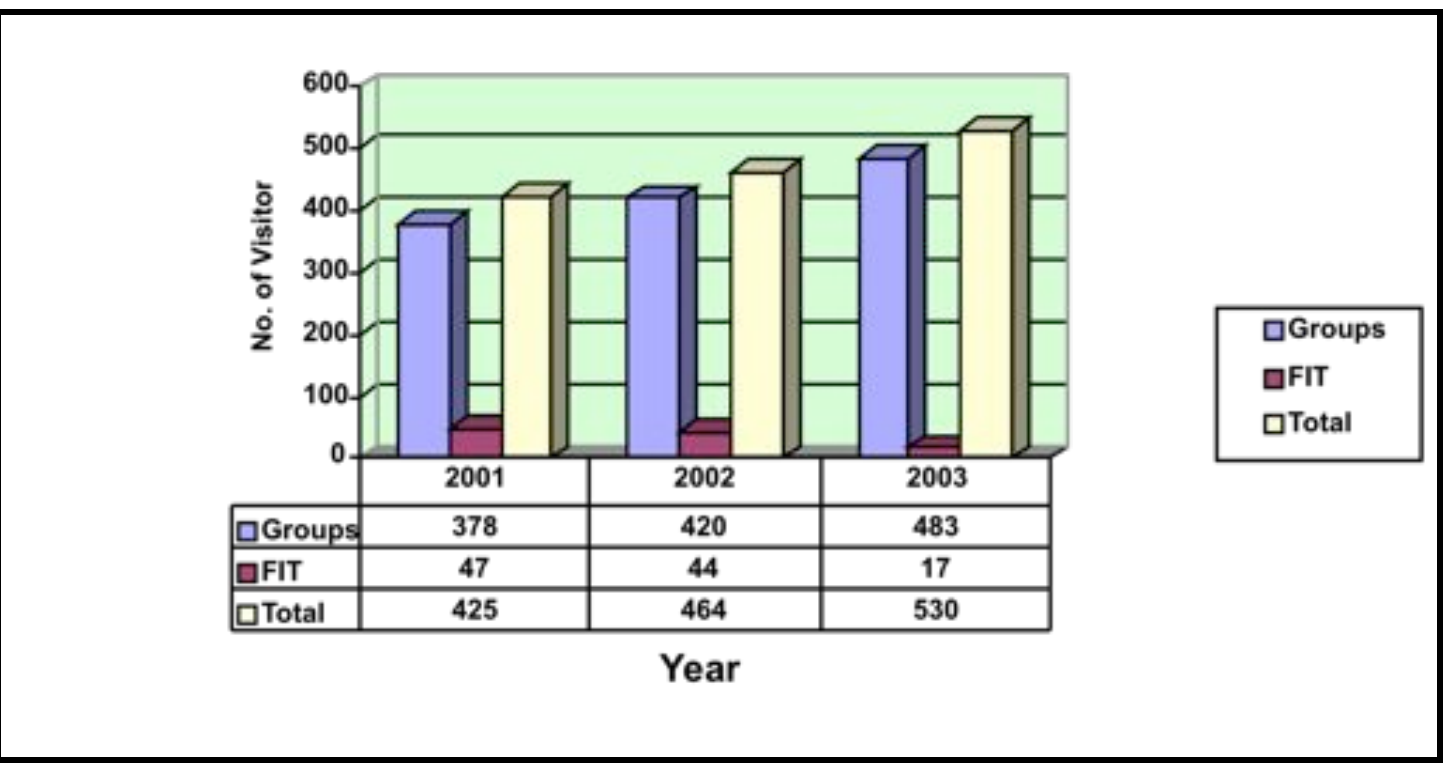

Source: Miso Walai Homestay (2004)

Note: FIT - Free Independent Traveler

In year 2003, Batu Puteh won the 'visionary village' award at the state and national level and became famous nationwide. In 2004, it won the Equator Prize from the Equator Initiative. The Equator Initiative is designed to reduce poverty through the conservation and sustainable use of biodiversity in the equatorial belt by fostering, supporting and strengthening community partnerships. Batu Puteh has become a model for other villages.

On average, tourists come to Batu Puteh once a week. There has been a steady increase in tourist arrivals over the years. Almost half of the tourists are 'repeat customers'. In its first year of operations in the year 2000, they had 1,200 bed 
nights and 2,600 visitors went on wildlife watching trips ${ }^{15}$. They received walk-in tourists but there were more group tourists from the Fulcrum Challenge, Operations Wallacea, World Challenge, Intrepid Travel, Sabah Holiday and Pan Borneo. The marketing for Batu Puteh is targeted at groups rather than FIT. This explains the high number of group visitors compared to FIT market (Fig 5.7). In 2001, they started the annual Kinabatangan River Expedition where participants stay overnight at Miso Walai. Based on the survey conducted from 2002-2003, tourists were mainly adults (21-40 years old) with at least secondary level education.

${ }^{15}$ Interview with the WWF for Nature Malaysia's Scientific Officer on research site (2003). 


\subsubsection{Sukau}

\section{Figure 5. 8 Map of Sukau}

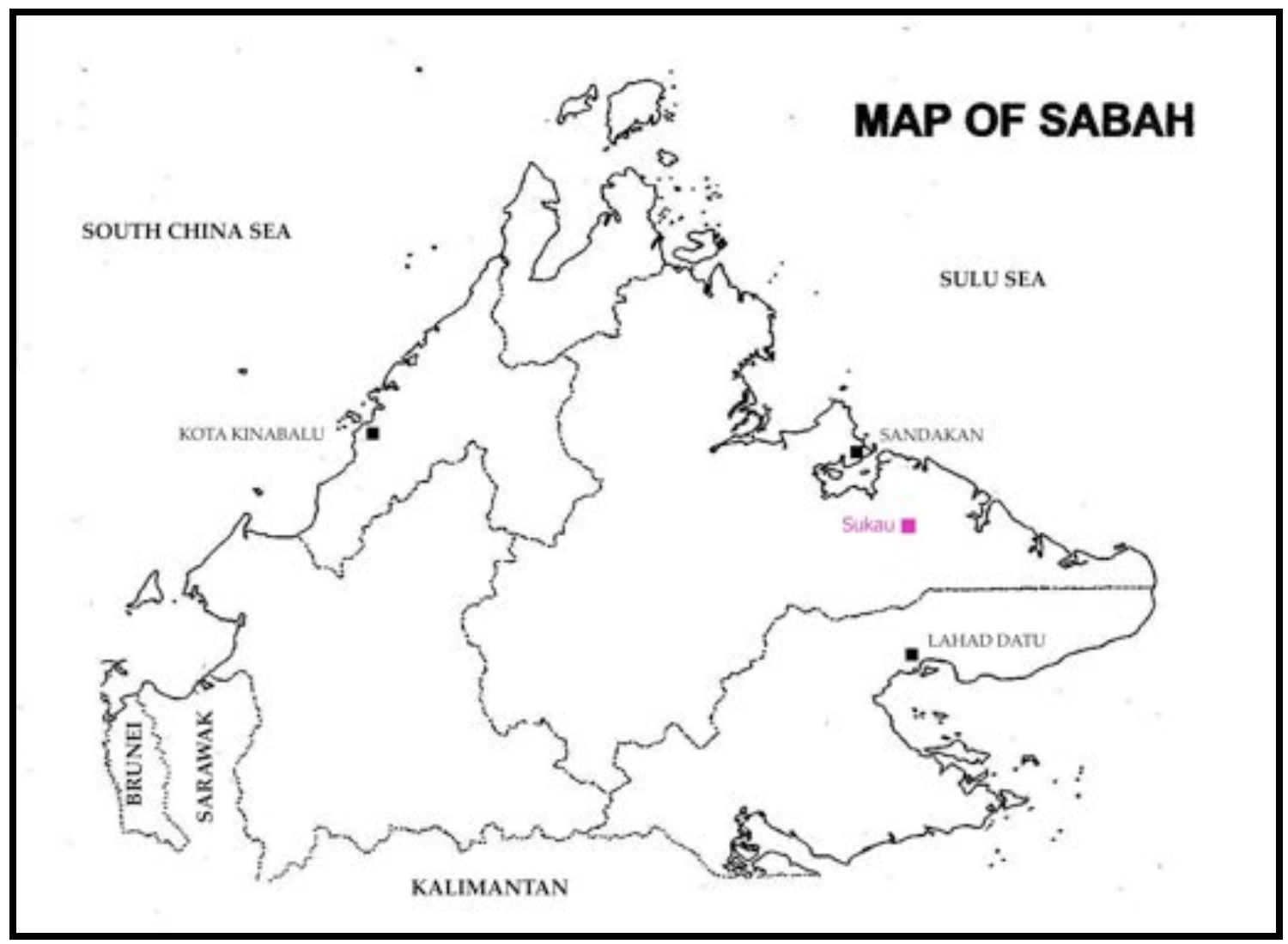

Sukau (Map 5.8) is located $70 \mathrm{~km}$ up the Kinabatangan River from the east coast city of Sandakan. It is a small village surrounded by the Wildlife Sanctuary Area and oil palm plantations. It has a population of 2000 and most of the villagers are self-sufficient farmers and low ranking government servants. A number of youths are working at the eight ecolodges scattered around Sukau Village. Sungai People inhabit the village and almost all of them are Muslim. Sukau is connected to the highway by a gravel road. Private transportation is infrequent. Another main transportation mode is by boat, which the villagers use to go to the Sandakan city or the neighbouring villages. 
Tourists started visiting the lower Kinabatangan, mainly the villages of Sukau, Abai and Batu Puteh, in the late 1980s. The number of visitors was small and infrequent. Sukau evolved into the main tourist attraction because of its proximity to the scenic Menanggul tributary where proboscis monkeys can be easily spotted from a boat, and the historical Gomantong Caves where edible bird nests are collected.

A tour operator based in Kota Kinabalu started the commercialisation of ecotourism in Sukau in the 1990s. He bought a piece of land from a villager near the Menanggul tributary and built an ecolodge there. Other lodges were built afterwards including one that is owned by Sabah Wildlife Department and one by a local entrepreneur. Sukau has a strong image as an ecotourism destination. The popularity of Sukau, where five tour companies currently operate lodges and river tours, is a good example of the ecotourism potential appropriately tapped.

A number of ecolodges in Sukau employ the practice of ecotourism. Solar technology is used for generating electricity and hot water. Boats are operated by electric motor during cruises into the tributaries. Raw food materials are bought mainly from the locals and local boat builders and carpenters are hired. Voluntary activities are also organised such as clearing of weeds from oxbow lakes and supplying 49 units of water tanks to the local villagers. Sixty-four acres of degraded riverine forest were adopted for a reforestation project in collaboration with Sabah Wildlife Department, Forestry Department, Rainforest Interpretation Centre, Drainage and Irrigation Department, Land and Survey Department, Rotary Club of KK, Kinabatangan District Office and Partners for Wetlands Programme under WWF-Malaysia. The pioneering lodge in Sukau has won awards such as British Airways 'Tourism for Tomorrow' Award, International Hotel and Restaurant Association 'Environment Award', 'Green Hotelier' Award and Green Globe Achievement Awards. 
However, there is a general agreement that the local community does not have a high level of involvement in the ecotourism industry, hence gaining a low level of benefits. Despite the efforts that some ecolodges had initiated to involve the local community in their operations, the extent of participation is limited. While a number of local youths are hired to work at the ecolodges, others employ nonlocals. A meeting with the villagers in 2002 showed discontentment at the exclusion of the locals while the industry was visibly prospering.

In 1995, WWF-Malaysia conducted a study of tourism carrying capacity (Fletcher, 1998). The study found that tourist numbers are increasing rapidly. The average number of tour boats cruising along Menanggul River for proboscis monkey sighting was one or two per day in 1992 but a recent study and field visit found out that it was exceeding 12 at one sighting. Proboscis Monkeys are only visible in the late afternoon, and their behaviour has altered in response to visitor pressure. While the study found that the number of Proboscis Monkeys might have declined only slightly over the last four years, the worry is that disturbance occurs at the crucial time when the Proboscis Monkeys should be settling to sleep. The well being of the Proboscis Monkey population may be a long-term concern. However, an immediate concern is that the quality of the ecotourism product has seriously declined because of crowding, engine noise, fumes, etc, from some tour operators that do not put much emphasis on ecopractice on their boats. However, there are several tour operators and ecolodges who do use ecofriendly battery-operated motorboats. The study also concluded that while ecological carrying capacity may have been exceeded only slightly, the physical carrying capacity has clearly been exceeded. The study recommended that the number of boats cruising the Menanggul River must be limited and that encouraging operators to spread their operations to other parts of the Lower Kinabatangan can reduce the pressure (Fletcher, 1998). 


\section{Eigure 5. 9 Visitor Arrivals to Sukau, Kinabatangan}

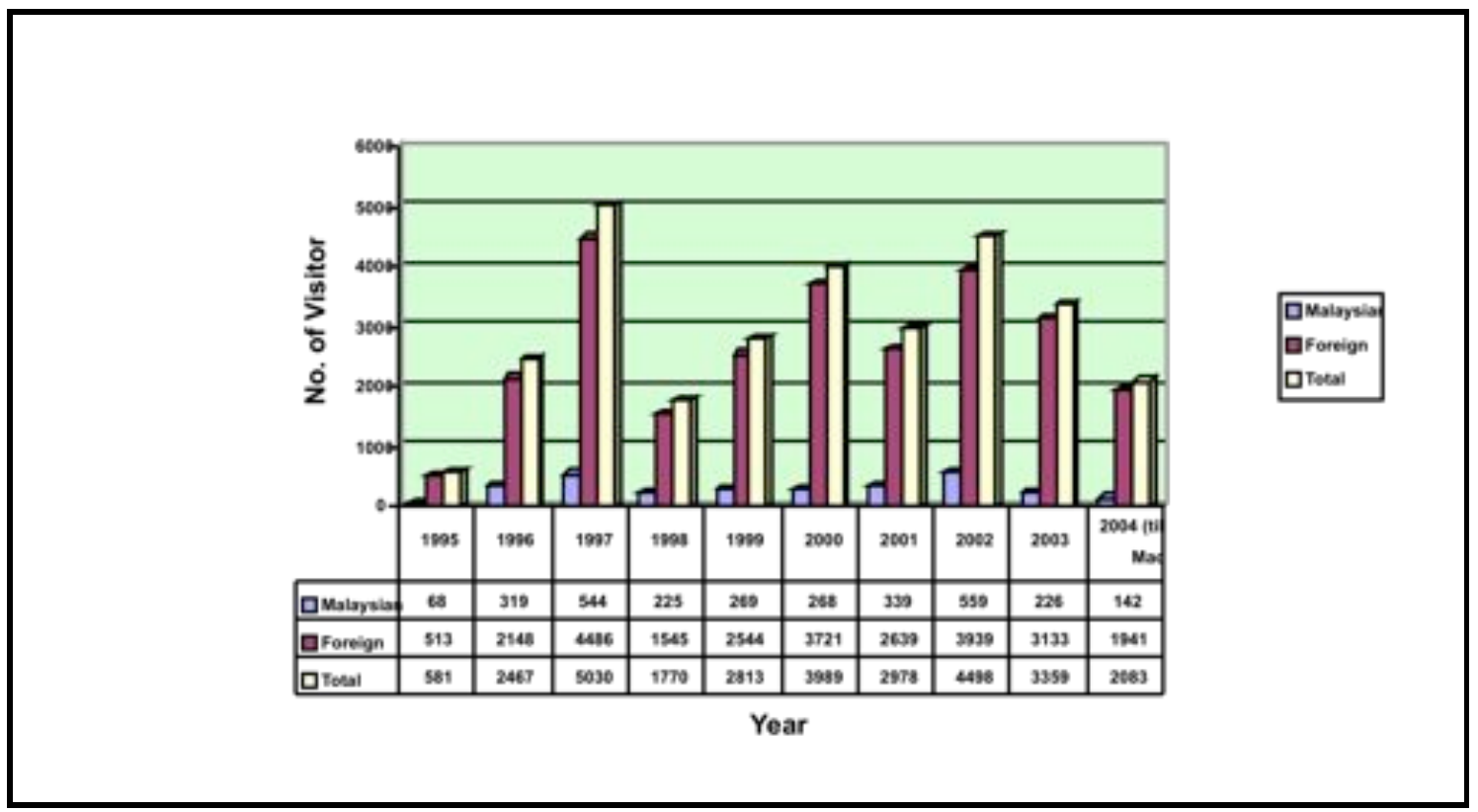

Source: Wildlife Department Kota Kinabalu (2004)

Most of the tourists that go to Sukau use tour operator services. They usually buy a tour package that has an add-on tour to Sandakan City and nearby Gomantong Cave. Most of them choose the popular 3 Day 2 Night package which consists of accommodation and food, a trip to Gomantong Cave, river cruises in the morning, evening and night, and a lecture on ecotourism in Kinabatangan Wetlands. Sukau enjoys patronage mainly from foreign tourists (Fig. 5.9). They usually come through an outbound tour operator from their country of origin. There is also a segment of foreign tourists who are expatriates in Malaysia and its neighbouring countries who are considered as foreign tourists in the statistics. Tourists who have participated in ecotours at Sukau were mostly affluent Europeans, usually older couples (Yamashita, 1998). Domestic tourists that come to Sukau are not big in number compared to the foreign market. There are few 
local tourists who think a specialised nature-based tourism package such as ecotourism is interesting and worth paying (pers. comm. with STB, 2005).

\subsubsection{Rafflesia Information Centre}

\section{Figure 5. 10 Map of Rafflesia Information Centre}

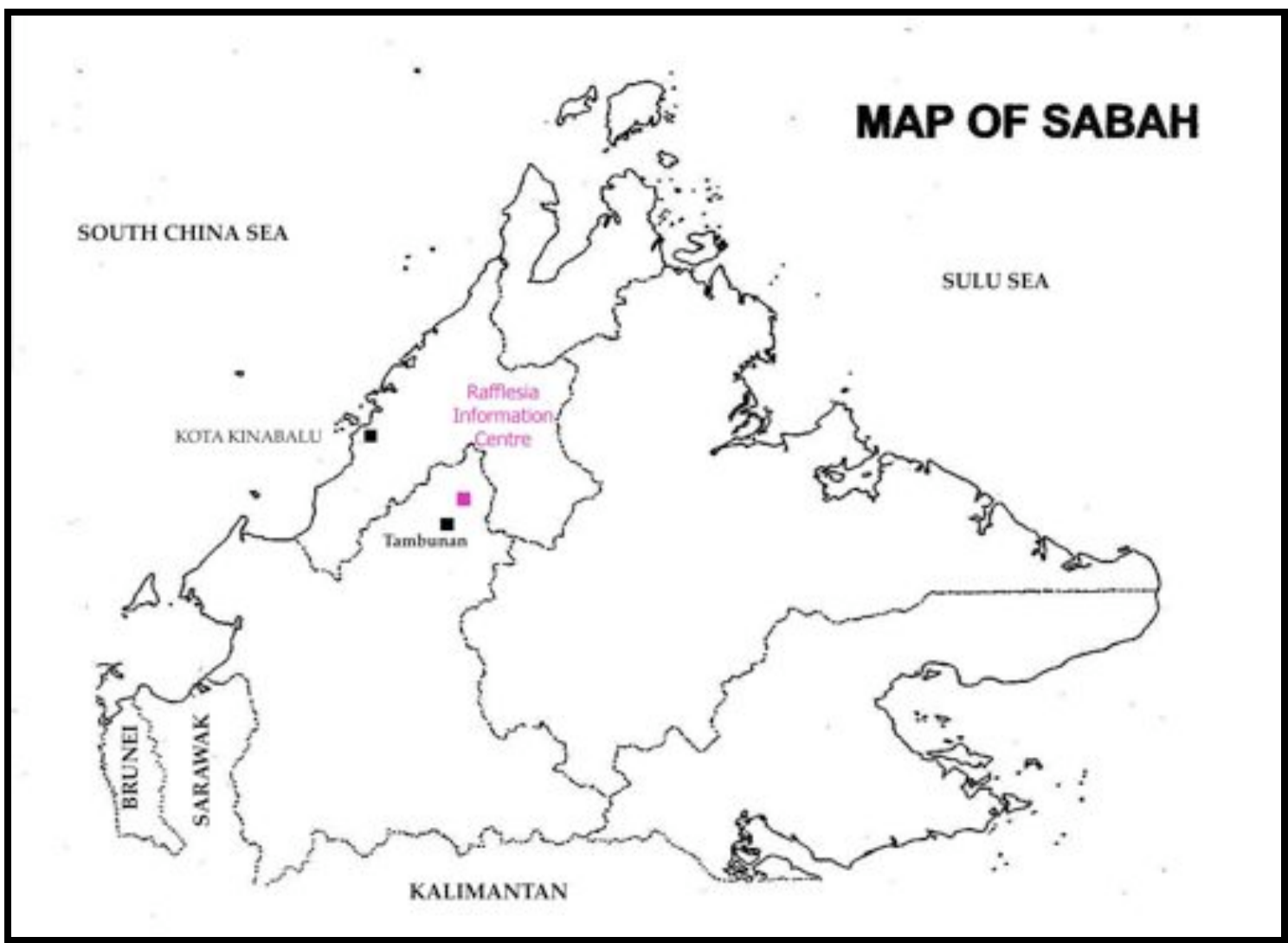

Rafflesia Information Centre (Figure 5.10) is located in the district of Tambunan. The centre is only $58 \mathrm{~km}$ away from Kota Kinabalu City and it only takes 1-hour to drive there. There is easy access by road from Kota Kinabalu city with the Tambunan Highway which passes close to the highest point of the Crocker Range over the Sinsuron Pass at 1670 m which has cool mountain air.

The Dusun people dominate the total population in Tambunan. The district 
covers an area of 134,540 hectares and has a population of about 24,000 . At an altitude of 650 to 900 meters, the climate is spring-like for the most part of the year.

The highlight of Tambunan is the chance to view the world's largest flower, the Rafflesia, at the Rafflesia Information Centre, run by Tambunan Forestry Department. The forest reserve where the Rafflesia can be found is also an area for education and scientific research for those who want to study the Rafflesia flower and its habitat. There is an opportunity for outdoor forest recreation and tourism in view of its easy access and pristine vegetation. Tambunan also offers other touristic interests such as waterfalls, lower montane orchids, rainforest, Sabah's second highest peak of Mount Trus Madi $(2,642 \mathrm{~m})$ and the culture of the Tambunan Kadazandusun people. The Rafflesia Information Centre is considered as an ecotourism site as it fits to the definition of ecotourism. It provides the platform to conserve the endangered species of Rafflesia and awareness to the visitors through its interpretation centre. This enhances the visitors' experience to see the elusive flower, which includes the interaction with local rangers. However, Rafflesia Information Centre is not commercially positioned as an ecotourism site.

Local indigenous communities have known Rafflesia long before it was discovered by the western world. This is evident by their traditional uses especially for medicinal purposes, as well as myths and folklore surrounding the Rafflesia. The locals here call it kukuanga, yak-yak or wusak-tombuakar. It is sometimes considered a taboo flower or 'flower of the spirits' because of its smell and its sheer size. The villagers around Tambunan are aware of the Rafflesia flower but they do not know the uniqueness of the flower. There are at least 18 species of Rafflesia and eight of them can be found in Borneo, namely $R$. arnoldii, R. borneensis, R. ciliata, R. keithii, R. pricei, R. tengku-adlinii, R. tuanmudae and $R$. witkampii. In Sabah itself, R. pricei, $R$. keithii and $R$. tengku-adlinii 
can be found. Rafflesia keithii is endemic to Sabah, distributed from the northern part of Mount Kinabalu to the Crocker and Trus Madi range extending as far south as Tenom and in Mount Danum within Sabah Foundation's Danum Valley Conservation Area to the east. This particular species is the largest flower in the world according to the Guinness Book of Records. Rafflesia pricei can be found from Mount Kinabalu to the Crocker Range and tends to have a large number of buds from 20 to 250 buds. Rafflesia tengku-adlinii is the rarest of all Rafflesia species. It is also one of the smallest. It only can be found at the Trus Madi range and on Mount Lotung within Sabah Foundation's Maliau Basin Conservation Area. All Rafflesia species in Sabah are seasonal.

A full bloom Rafflesia is elusive. It is not just extremely rare, it also requires 6-21 months to mature and bloom. It only blooms for 7 days despite the long period of maturing. If one manages to see a Rafflesia in a full bloom, it is certainly a rare treat. One prominent local Rafflesia expert believes that it is naturally going towards extinction because of its rarity and the high level of difficulty to reproduce. At this moment, the conservation status of $R$. keithii and $R$. pricei are vulnerable and $R$. tengku-adlinii is endangered.

The Rafflesia flower has been an interest to local and foreign scientists long before it became a tourism icon for Sabah. In 1984, a group of students from the Universiti Kebangsaan Malaysia (Malaysia National University) and The Sabah Society visited the Rafflesia in Tambunan. This established Rafflesia flower is a tourism asset. In 1991, the state government felt that there was an urgency to conserve the Rafflesia flower because of its vulnerability and its value. Conservation effort was consolidated with the establishment of the Rafflesia Information Centre in 1991 under the Tambunan Forestry Department.

The information centre is well equipped as a tourist centre; entrance is free. Rafflesia Information Centre also sells a range of souvenirs inspired by the 
Rafflesia flower and books on Rafflesia. Visitors to the Rafflesia Information Centre are able to see and learn about the Rafflesia and the forest that it grows in. The Rafflesia Information Centre provides ranger guide services to visitors. There are seven locally hired ranger-cum-guides employed at the centre. They charge the tourists a guide service of RM20 (Approx. US\$5) per trip. This service is highly encouraged as the Rafflesia flowers bloom usually in different parts of the forest at different times. The guide also ensures that visitors do not touch the highly sensitive flower and expose it to camera flashes. Visitors can also enjoy the attractive Mahua waterfall nearby. The Mahua waterfall is set in a virgin rainforest at the edge of Crocker Range National Park.

\section{Figure 5. 11 Visitor to Rafflesia Information Centre, Tambunan}

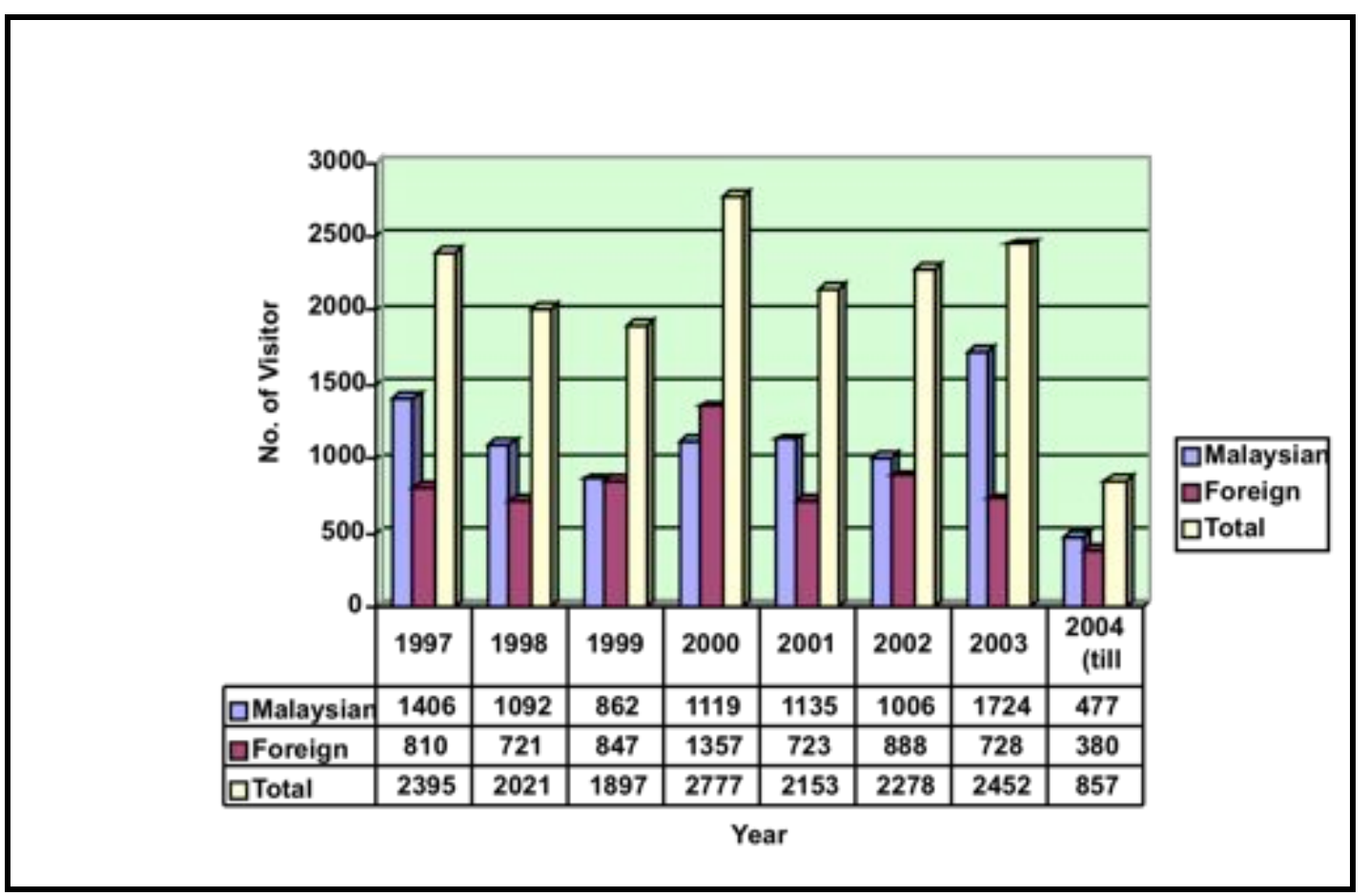

Source: Tambunan Forestry Department (2004)

Most of the visitors are 'walk-in' visitors. They are usually in-transit from other main destinations such as Kota Kinabalu, Sandakan, Kinabatangan Wetlands and 
Danum Valley. Therefore there is not much scope for providing accommodation and other services. There is also less opportunity for the local community to get involved directly with the centre as it main purpose is to conserve the Rafflesia flower and there are no plans to involve the local community in this conservation effort. The location of the flower is also a factor for the low involvement of the local community as the flowers are found in the virgin forest reserve and the state government owns this area. However, the staffs hired at the centre are locals from the surrounding area. There are also plans to provide more opportunities for the local community to get involved with the supporting business that is relevant to the centre (pers. comm. with Director of Tambunan Forestry Department, 2003). The centre works closely with the Sabah Tourism Board in providing information and updating the Rafflesia blooming site availability for the benefit of tourists. It also provides STB with monthly visitor statistics. According to the survey done in 2002 till 2003, tourists were evenly distributed between male and female and many of them were around 21-40 years old. A high number of the visitors were educated at tertiary level. The number of tourists visiting Rafflesia Information Centre is shown in Figure 5.11. 


\subsubsection{Kampung Rantai}

Fiqure 5. 12 Map of Kampung Rantai

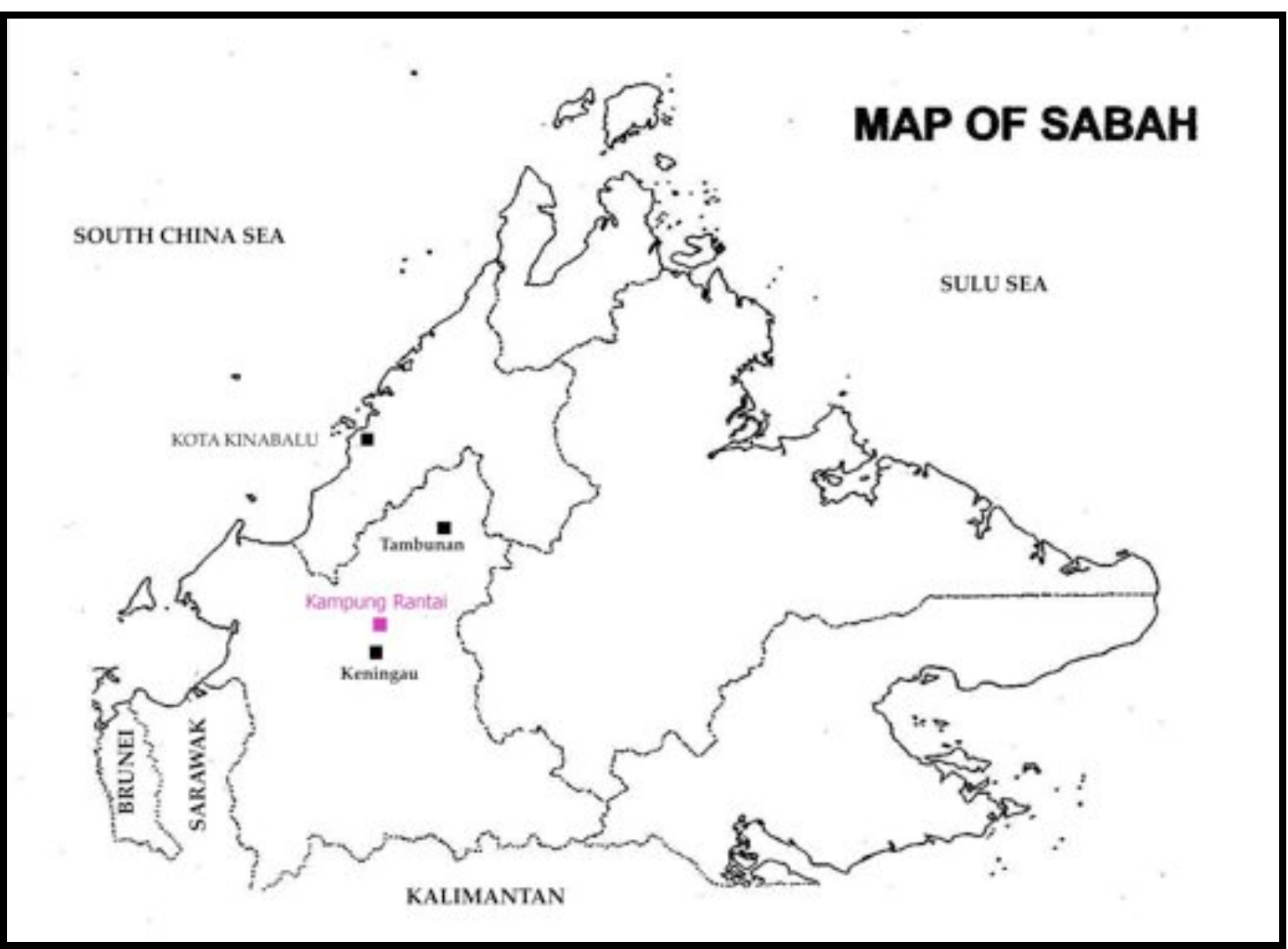

Kampung Rantai (Figure 5.12) was established in the 1950's by three families who came to the area to open a paddy plantation. The village area is 11 acres including 3 acres that have been gazetted as a cemetery. There are three nearby villages: Kampung Dongiluang, Kampung Tiga and Kampung Bundu. The people are all from the Dusun ethnic group. Most of the villagers are self-sufficient farmers who plant paddy and ginger.

While visitors can have a smooth drive from Kota Kinabalu on the highway up to the town of Bundu Apin-Apin, the $12 \mathrm{~km}$ road onwards to Kampung Rantai is rough gravel road. At present, there are 30 families living in Kampung Rantai. 
Kampung Rantai has a clean river running through it, the Apin-Apin River. However, clean water supply is provided through the gravity pipe provided by the Health Department.

Ecotourism in Kampung Rantai started in 1998. This is the youngest of the ecotourism projects in this research. It was one of the community development projects in the village and it is also an effort to diversify from the dominant ginger farming. The villagers, with the help of a local NGO, Partners for Community Organisation (PACOS) and Sabah Foundation did a field study of ecotourism potential by assessing the resources around Kampung Rantai that is rich with natural attractions, including a waterfall and Rafflesia flower. Visitors are locals and the only overseas visitors that they receive are from Indonesia. Visitors are able to stay at the village through the homestay program. In addition to staying with the villagers, visitors can also experience the livelihood of the village. They are able to learn how to cook local dishes and participate in villager activities. Cultural performances are shown on request. The homestay package, which includes accommodation and food, costs RM15 per night per person. Homestay fees go directly to the villagers. Among other sites in this research, this is the cheapest homestay by comparison. The villagers create and maintain traditional medicinal plant gardens as one of the attractions in the village. Another attraction near the village is the agro-farm nearby, where the deer farm is the highlight. Ecotourism in Kampung Rantai is focused on education and awareness, hence the adoption of the homestay program and the creation of traditional medicinal plant gardens.

One ecotourism activity is trying to conserve water catchments in the surrounding area, which is threatened by the logging industry, causing the water to be turbid and unhealthy for the people in surrounding areas especially paddy fields. The surrounding area of water catchments was finally gazetted as Virgin Forest Reserve Class I. Before 2004, ecotourism activity was interrupted for a 
while by a logging dispute that threatened water catchments in the whole Bundu Apin-Apin area. The legal battle had dire consequences to the ecotourism activity in Kampung Rantai. It was virtually stopped while the legal battle was on as time and resources were devoted away from ecotourism to the court.

In 2002, faced with the prospect of ecotourism growth, villagers formed a society called MAMAKAT (Koisaan Misompuru Manampasi Koburuon om Koubasanan Tulun Toku/Rural Community Conservation, Development and Culture Cooperative Society). It was modeled after MESCOT in Batu Puteh. The society allows villagers to automatically become members of MAMAKAT led by a duly elected committee. One of the major activities that MAMAKAT did was to organise an ecotourism workshop for the villagers with the participation of PACOS and the Ministry of Tourism, Culture and Environment. During the workshop, they discussed the direction of ecotourism that they would like to have, the opportunities that the villagers can have and discussion on the involvement and roles of stakeholders in the industry. MAMAKAT also organised FAM (Familiarisation) trips for its members to educate them on tourism operations. The villagers built a MAMAKAT building, which has a community hall and an office. However, in the early part of year 2004, the villagers were locked in a legal dispute again when they found out that illegal logging is still in practice in the Virgin Forest Reserve.

There are no statistics compiled that show the profile and number of tourists to Kampung Rantai. Therefore the only data on tourists are those collected during the fieldwork, through survey and interviews.

According to the fieldwork survey conducted in 2002 and 2003, tourists were educated adults from 21-50 years old. Most of the tourists were locals. The tourists normally visited the village either for recreation, business or VFR. Since the site is new and the marketing of ecotourism is non-consistent due to a few 
interruptions caused by legal battles, Kampung Rantai struggles to get tourists to the village. The village location, which is situated off the main road, also contributes to no 'walk-in' tourists. 


\subsection{Case Study Matrix}

A case study matrix is used to comparatively analyse the data from the five research sites (Table 5.1). The results from this comparative analysis show some common grounds and comparative advantages between the sites. It is also used in later chapters to give some depth to the success perception of ecotourism and local community participation. This helps to interpret and justify the success perception as set in the research issues.

The case study matrix enables selected variables to be compared across the five sites. The variables chosen are important elements of the area and of the ecotourism operations themselves.

The data from the case study matrix is analysed in the next section. 


\section{Table 5, 1 Case Study Matrix}

\begin{tabular}{|c|c|c|c|c|c|}
\hline $\begin{array}{l}\text { SITE/ITEM } \\
\text { CATEGORY }\end{array}$ & $\begin{array}{c}\text { KAMPUNG } \\
\text { BAVANGGAZO }\end{array}$ & BATU PUTEH & SUKAU & $\begin{array}{c}\text { RAFFLESIA } \\
\text { INFORMATION } \\
\text { CENTRE }\end{array}$ & $\begin{array}{c}\text { KAMPUNG } \\
\text { RANTAI }\end{array}$ \\
\hline LOCATION & $\begin{array}{l}\text { Northern tip of } \\
\text { Sabah } \\
\text { Kudat District } \\
130 \mathrm{~km} \text { north of } \\
\text { Kota Kinabalu } \\
3 \text { hours drive } \\
\text { from Kota } \\
\text { Kinabalu }\end{array}$ & $\begin{array}{l}\text { Batu Puteh sub- } \\
\text { district } \\
\text { Kinabatangan } \\
\text { district } \\
6 \text { hours drive } \\
\text { from Kota } \\
\text { Kinabalu } \\
2 \text { hours drive } \\
\text { from Sandakan }\end{array}$ & $\begin{array}{l}70 \mathrm{~km} \text { up the } \\
\text { Kinabatangan } \\
\text { river from the } \\
\text { East Coast city } \\
\text { of Sandakan }\end{array}$ & $\begin{array}{l}58 \mathrm{~km} \text { from Kota } \\
\text { Kinabalu to the } \\
\text { East } \\
1 \text { hour drive from } \\
\text { Kota Kinabalu }\end{array}$ & $\begin{array}{l}131 \mathrm{~km} \text { from } \\
\text { Kota Kinabalu } \\
\text { to the South } \\
\text { East } \\
2 \text { hours drive } \\
\text { from Kota } \\
\text { Kinabalu }\end{array}$ \\
\hline PEOPLE & $\begin{array}{l}\text { Rungus ethnic } \\
\text { group } \\
\text { Sub-tribe of } \\
\text { Kadazandusun } \\
\text { Unique - only } \\
\text { found at the } \\
\text { Kudat and } \\
\text { Bengkoka } \\
\text { Peninsula }\end{array}$ & $\begin{array}{l}\text { Sungai ethnic } \\
\text { group } \\
\text { Approximately } \\
1200 \text { population }\end{array}$ & $\begin{array}{l}\text { Sungai ethnic } \\
\text { group } \\
\text { Approximately } \\
2000 \\
\text { population }\end{array}$ & $\begin{array}{l}\text { Dominated by the } \\
\text { Kadazandusun } \\
\text { ethnic group }\end{array}$ & $\begin{array}{l}\text { Dusun ethnic } \\
\text { group }\end{array}$ \\
\hline LIVELIHOOD & $\begin{array}{l}\text { Mostly farmers } \\
\text { Handicraft- } \\
\text { makers - women } \\
\text { Villagers work } \\
\text { part-time at } \\
\text { Bavanggazo } \\
\text { Rungus } \\
\text { Longhouse }\end{array}$ & $\begin{array}{l}\text { Mostly work at } \\
\text { the Palm Oil } \\
\text { plantation } \\
\text { Some work with } \\
\text { the public and } \\
\text { private sector } \\
\text { Few work as } \\
\text { subsistence } \\
\text { farmers and } \\
\text { fishermen }\end{array}$ & $\begin{array}{l}\text { Self-sufficient } \\
\text { farmers } \\
\text { Lower ranking } \\
\text { government } \\
\text { servants }\end{array}$ & Various & $\begin{array}{l}\text { Self-sufficient } \\
\text { farmers }\end{array}$ \\
\hline $\begin{array}{l}\text { ASSISTANCE/ } \\
\text { SUPPORT }\end{array}$ & $\begin{array}{l}\text { Sabah Tourism } \\
\text { Board - } \\
\text { consultation } \\
\text { State } \\
\text { Government - } \\
\text { seed funding, }\end{array}$ & $\begin{array}{l}\text { WWF-Malaysia } \\
\text { (Sabah) - } \\
\text { facilitator } \\
\text { Ministry of } \\
\text { Tourism, } \\
\text { Culture and }\end{array}$ & $\begin{array}{l}\text { Private-sector } \\
\text { led }\end{array}$ & $\begin{array}{l}\text { Sabah Forestry } \\
\text { Department - } \\
\text { funding and } \\
\text { consultation }\end{array}$ & $\begin{array}{l}\text { PACOS } \\
\text { (Partners for } \\
\text { Community } \\
\text { Organisation) - } \\
\text { consultation } \\
\text { Sabah }\end{array}$ \\
\hline
\end{tabular}




\begin{tabular}{|c|c|c|c|c|c|}
\hline & $\begin{array}{l}\text { consultation } \\
\text { JICA (Japan } \\
\text { International } \\
\text { Cooperation } \\
\text { Agency) - } \\
\text { consultation in } \\
\text { empowering } \\
\text { women }\end{array}$ & $\begin{array}{l}\text { Environment of } \\
\text { Sabah - } \\
\text { Consultation } \\
\text { Shell - } \\
\text { RM200,000 for } \\
\text { ecolodges } \\
\text { RICOH - forest } \\
\text { rehabilitation } \\
\text { project } \\
\text { Discovery } \\
\text { Channel } \\
\text { Forestry } \\
\text { Department - } \\
\text { ecolodge site } \\
\text { Raleigh } \\
\text { International - } \\
\text { volunteers for } \\
\text { ecolodge } \\
\text { construction }\end{array}$ & & & $\begin{array}{l}\text { Foundation - } \\
\text { consultation }\end{array}$ \\
\hline $\begin{array}{l}\text { SITE PROTECTION } \\
\text { STATUS }\end{array}$ & $\begin{array}{l}\text { Village Reserve } \\
\text { (5 acres) }\end{array}$ & $\begin{array}{l}\text { Wildlife } \\
\text { Sanctuary Area } \\
\text { Virgin Forest } \\
\text { Reserve (Class } \\
\text { 6) } 1000 \\
\text { hectares for } \\
\text { ecolodge }\end{array}$ & $\begin{array}{l}\text { Wildlife } \\
\text { Sanctuary Area }\end{array}$ & $\begin{array}{l}\text { Virgin Forest } \\
\text { Reserve (356 } \\
\text { hectares) }\end{array}$ & $\begin{array}{l}\text { Village Reserve } \\
\text { (11 acres) } \\
\text { Virgin Forest } \\
\text { Reserve Class I } \\
\text { (at the } \\
\text { surrounding } \\
\text { area of water } \\
\text { catchments) }\end{array}$ \\
\hline $\begin{array}{l}\text { NATURE } \\
\text { ATTRACTION }\end{array}$ & $\begin{array}{l}\text { Gomantong Hill } \\
\text { Simpang } \\
\text { Mengayau Beach }\end{array}$ & $\begin{array}{l}\text { Oxbow lakes } \\
\text { Mengaris trail } \\
\text { Flora and fauna } \\
\text { Historical site } \\
\text { River } \\
\text { Rainforest }\end{array}$ & $\begin{array}{l}\text { Menanggul } \\
\text { tributary } \\
\text { Oxbow lakes } \\
\text { Proboscis } \\
\text { monkey } \\
\text { Gomantong }\end{array}$ & $\begin{array}{l}\text { Rafflesia flower } \\
\text { Waterfalls } \\
\text { Lower Montane } \\
\text { orchids } \\
\text { Rainforest } \\
\text { Mount Trus Madi }\end{array}$ & $\begin{array}{l}\text { Rainforest } \\
\text { Waterfalls } \\
\text { Rafflesia flower }\end{array}$ \\
\hline
\end{tabular}




\begin{tabular}{|c|c|c|c|c|c|}
\hline & & & $\begin{array}{l}\text { Cave } \\
\text { Rainforest }\end{array}$ & Cool mountain air & \\
\hline $\begin{array}{l}\text { CULTURAL } \\
\text { ATTRACTION }\end{array}$ & $\begin{array}{l}\text { Lifestyle } \\
\text { Food } \\
\text { Cultural } \\
\text { Performance: } \\
\text { Dance (Mongigol } \\
\text { Sumundai, } \\
\text { Mangatip-atip, } \\
\text { Marandan) } \\
\text { Music - } \\
\text { Mongurali }\end{array}$ & $\begin{array}{l}\text { Local stories } \\
\text { and folklore } \\
\text { Cultural } \\
\text { performance } \\
\text { Community } \\
\text { service }\end{array}$ & $\begin{array}{l}\text { Afternoon tea } \\
\text { with locals }\end{array}$ & $\begin{array}{l}\text { Kadazandusun } \\
\text { culture }\end{array}$ & $\begin{array}{l}\text { Lifestyle } \\
\text { Cultural } \\
\text { performance }\end{array}$ \\
\hline $\begin{array}{l}\text { COMPLEMENTARY/ } \\
\text { SUPPORTING } \\
\text { ATTRACTIONS }\end{array}$ & $\begin{array}{l}\text { Sumangkap } \\
\text { Village - Gong } \\
\text { making } \\
\text { Gambizou Village } \\
\text { - Honey Bee } \\
\text { Farm } \\
\text { Kudat - Beaches } \\
\text { and seafood }\end{array}$ & $\begin{array}{l}\text { Sukau } \\
\text { Sandakan } \\
\text { Gomantong } \\
\text { Cave }\end{array}$ & Sandakan & $\begin{array}{l}\text { Tambunan Village } \\
\text { Resort Centre }\end{array}$ & Agro farm \\
\hline COST FOR TOURIST & $\begin{array}{l}\text { Package } \\
\text { (Entrance fee, } \\
\text { accommodation, } \\
\text { breakfast and } \\
\text { performance) } \\
\text { RM120 (Approx. } \\
\text { US } \$ 34 \text { ) for } 1 \\
\text { person } \\
\text { RM70 (Approx. } \\
\text { US } \$ 20 \text { ) for } 2-10 \\
\text { person } \\
\text { RM65 (Approx. } \\
\text { US } \$ 18 \text { ) for } 11 \text { or } \\
\text { more person } \\
\text { Walk-in tourists } \\
\text { have to pay } \\
\text { RM2.50 (Approx. } \\
\text { US } \$ 0.70 \text { ) } \\
\text { entrance fee }\end{array}$ & $\begin{array}{l}\text { RM40 (Approx. } \\
\text { US } \$ 11 \text { ) per } \\
\text { night to stay } \\
\text { with homestay } \\
\text { family including } \\
\text { all meals }\end{array}$ & $\begin{array}{l}\text { Depending on } \\
\text { the lodges. A } \\
\text { room costs } \\
\text { from RM20m } \\
\text { (Approx. US\$5) } \\
\text { per night }\end{array}$ & $\begin{array}{l}\text { RM20 (Approx. } \\
\text { US } \$ 5 \text { ) for guide } \\
\text { fee }\end{array}$ & $\begin{array}{l}\text { RM15 (Approx. } \\
\text { US\$4) per night } \\
\text { to stay with } \\
\text { homestay family } \\
\text { including all } \\
\text { meals }\end{array}$ \\
\hline EVENTS & $\begin{array}{l}\text { Magahan Festival } \\
\text { (Festival of the } \\
\text { Dead) every } 31^{\text {st }}\end{array}$ & $\begin{array}{l}\text { Kinabatangan } \\
\text { River Expedition }\end{array}$ & $\begin{array}{l}\text { Proposed } \\
\text { Kinabatangan } \\
\text { Regatta }\end{array}$ & None & $\begin{array}{l}\text { Kaamatan } \\
\text { (Harvest } \\
\text { Festival) every }\end{array}$ \\
\hline
\end{tabular}




\begin{tabular}{|c|c|c|c|c|c|}
\hline & April & & & & $\begin{array}{l}30^{\text {th }} \text { and } 31^{\text {st }} \\
\text { May }\end{array}$ \\
\hline TOURIST ACTIVITY & $\begin{array}{l}\text { Trekking/nature } \\
\text { walks } \\
\text { Demonstration of } \\
\text { traditional animal } \\
\text { traps } \\
\text { Visits to the field }\end{array}$ & $\begin{array}{l}\text { Wildlife } \\
\text { watching } \\
\text { Participating in } \\
\text { villagers activity }\end{array}$ & $\begin{array}{l}\text { Wildlife } \\
\text { watching }\end{array}$ & Trekking & $\begin{array}{l}\text { Trekking } \\
\text { Participating in } \\
\text { village activity }\end{array}$ \\
\hline INVOLVEMENT & $\begin{array}{l}\text { Everybody is } \\
\text { involved } \\
\text { Each family } \\
\text { delegated to one } \\
\text { task and has its } \\
\text { own committee }\end{array}$ & $\begin{array}{l}\text { MESCOT } \\
\text { members } \\
\text { Some locals } \\
\text { with skills }\end{array}$ & $\begin{array}{l}\text { WWF-Malaysia } \\
\text { (Sabah) for } \\
\text { Partners for } \\
\text { Wetlands } \\
\text { Projects as } \\
\text { consultant }\end{array}$ & $\begin{array}{l}\text { Sabah Forestry } \\
\text { Department }\end{array}$ & $\begin{array}{l}\text { Everybody } \\
\text { involved (every } \\
\text { villager } \\
\text { automatically a } \\
\text { MAMAKAT } \\
\text { member) }\end{array}$ \\
\hline $\begin{array}{l}\text { AVERAGE INCOME } \\
\text { FROM } \\
\text { ECOTOURISM PER } \\
\text { PERSON }\end{array}$ & $\begin{array}{l}\text { RM200-RM500 } \\
\text { (Approx. US } \$ 50- \\
\text { US } \$ 142 \text { ) per } \\
\text { month }\end{array}$ & $\begin{array}{l}\text { RM1500- } \\
\text { RM3000 } \\
\text { (Approx. } \\
\text { US } \$ 428 \text { - } \\
\text { US } \$ 857 \text { ) per } \\
\text { annum }\end{array}$ & Not available & $\begin{array}{l}\text { RM40 (Approx. } \\
\text { US\$11) per go }\end{array}$ & Not available \\
\hline WELFARE & $\begin{array}{l}\text { Welfare fund } \\
\text { from profit }\end{array}$ & $\begin{array}{l}\text { Soft loan to } \\
\text { villagers for } \\
\text { homestay } \\
\text { related affairs }\end{array}$ & $\begin{array}{l}\text { Community } \\
\text { service by } \\
\text { certain } \\
\text { ecolodges }\end{array}$ & None & None \\
\hline $\begin{array}{l}\text { OTHER } \\
\text { COMMUNITY } \\
\text { PARTICIPATION } \\
\text { PROJECT }\end{array}$ & $\begin{array}{l}\text { Contract farming } \\
\text { by the } \\
\text { Agriculture } \\
\text { Department } \\
\text { Markisa Fruit } \\
\text { Plantation by the } \\
\text { Rural } \\
\text { Development } \\
\text { Corporation } \\
\text { All failed } \\
\text { Women } \\
\text { empowerment by } \\
\text { JICA }\end{array}$ & None & None & None & $\begin{array}{l}\text { Community } \\
\text { organizing } \\
\text { training } \\
\text { Community } \\
\text { socio-economic } \\
\text { training } \\
\text { Community } \\
\text { early child care } \\
\text { and } \\
\text { development } \\
\text { training } \\
\text { Community } \\
\text { research and } \\
\text { information } \\
\text { Public } \\
\text { awareness } \\
\text { activities } \\
\text { All by PACOS }\end{array}$ \\
\hline
\end{tabular}




\begin{tabular}{|c|c|c|c|c|c|}
\hline TOURISTS & $\begin{array}{l}\text { Mostly walk-ins } \\
\text { Foreigners } \\
\text { usually stay at } \\
\text { least overnight } \\
\text { Mainly adult (31- } \\
40 \text { years old) and } \\
\text { youth (less than } \\
20 \text { years old) } \\
\text { Educated (at } \\
\text { least from } \\
\text { secondary } \\
\text { school) } \\
\text { Locals and } \\
\text { Europeans }\end{array}$ & $\begin{array}{l}\text { Almost half are } \\
\text { 'repeat } \\
\text { customers' } \\
\text { Walk-in and } \\
\text { groups } \\
\text { Adult (21-40 } \\
\text { years old) } \\
\text { Educated (at } \\
\text { least from } \\
\text { secondary } \\
\text { level) }\end{array}$ & $\begin{array}{l}\text { Affluent } \\
\text { Mainly } \\
\text { Europeans } \\
\text { Older couple }\end{array}$ & $\begin{array}{l}\text { Evenly distributed } \\
\text { among male and } \\
\text { female } \\
21-40 \text { years old } \\
\text { Mainly educated } \\
\text { at tertiary level }\end{array}$ & $\begin{array}{l}\text { Mainly locals on } \\
\text { recreation, } \\
\text { business or VFR }\end{array}$ \\
\hline DECISION-MAKING & Committee & $\begin{array}{l}\text { MESCOT } \\
\text { Participant } \\
\text { membership } \\
\text { KOPEL }\end{array}$ & $\begin{array}{l}\text { Business } \\
\text { owners }\end{array}$ & $\begin{array}{l}\text { Tambunan } \\
\text { Forestry } \\
\text { Department }\end{array}$ & MAMAKAT \\
\hline $\begin{array}{l}\text { CONTRIBUTION TO } \\
\text { ENVIRONMENT }\end{array}$ & $\begin{array}{l}\text { Conserving water } \\
\text { catchment on } \\
\text { Gomantong Hill }\end{array}$ & $\begin{array}{l}\text { Forest } \\
\text { conservation } \\
\text { Forest } \\
\text { restoration } \\
\text { Phenological } \\
\text { trails } \\
\text { Nursery } \\
\text { propagation } \\
\text { Tree planting } \\
\text { Silviculture }\end{array}$ & $\begin{array}{l}\text { Set of code of } \\
\text { practice } \\
\text { Green policies }\end{array}$ & $\begin{array}{l}\text { Conserving } \\
\text { Rafflesia species }\end{array}$ & $\begin{array}{l}\text { Conserving } \\
\text { water } \\
\text { catchment that } \\
\text { provides water } \\
\text { for the Bundu } \\
\text { Apin-Apin area }\end{array}$ \\
\hline $\begin{array}{l}\text { VISIBLE } \\
\text { CONTRIBUTION TO } \\
\text { LOCAL } \\
\text { COMMUNITY }\end{array}$ & $\begin{array}{l}\text { Supplementary } \\
\text { work and income }\end{array}$ & $\begin{array}{l}\text { Alternative and } \\
\text { supplementary } \\
\text { work and } \\
\text { income }\end{array}$ & $\begin{array}{l}\text { Job creation in } \\
\text { operational } \\
\text { level } \\
\text { Purchase food } \\
\text { from the } \\
\text { villagers }\end{array}$ & $\begin{array}{l}\text { Job creation but } \\
\text { very small }\end{array}$ & $\begin{array}{l}\text { Supplementary } \\
\text { income }\end{array}$ \\
\hline $\begin{array}{l}\text { AWARDS/ } \\
\text { RECOGNITION }\end{array}$ & None & $\begin{array}{l}\text { 'Visionary } \\
\text { Village' award } \\
\text { at Sabah State } \\
\text { Level (2003) } \\
\text { 'Visionary } \\
\text { Village' award } \\
\text { at National } \\
\text { Level (2003) }\end{array}$ & $\begin{array}{l}\text { Sukau } \\
\text { Rainforest } \\
\text { Lodge } \\
\text { 'Tourism for } \\
\text { Tomorrow' by } \\
\text { British Airways } \\
\text { 'Environment } \\
\text { Award' by }\end{array}$ & None & None \\
\hline
\end{tabular}




\begin{tabular}{|l|l|l|}
\hline & Equator Prize & International \\
& from the & Hotel and \\
Equator & Restaurant \\
Initiative & Association \\
& 'Green Hotelier' \\
& Award by \\
& Green Globe \\
& Achievement \\
& Award \\
& & \\
& &
\end{tabular}




\subsection{Comparative Analysis}

\subsubsection{Introduction}

Comparative analysis starts with analysing the similarities of each site. This is where commonalities are found. Strengths (and weakness) are found in these commonalities as well. A detailed description elaborates each point. Next, the dissimilarities are analysed and this is when the sites distinguished themselves through various features. This is where a clear distinction between sites is made, and it can be seen what features are an advantage to what sites. The comparative analysis is an important section as research issues that attempt to interpret and develop the perception of success can be explained in-depth and justified with the results of the analysis.

\subsubsection{Similarities}

Based on the case study matrix, the location of the sites are far from the nearest city, at least 1 hour away by road or more than $50 \mathrm{~km}$ away. Each site is located in a rural area with outstanding natural environment with at least one outstanding geographical or natural feature such as a river, mountain or flower. This is a strong point for all sites where they have natural resources in the area, which is the main product of ecotourism. All sites are accessible by road and public transportation is available. However, sites such as Sukau and Kampung Rantai have no direct public transportation services. So far, this does not hinder tourists from coming to Sukau, but it also does nothing for the frequency of visitors to Kampung Rantai.

The ethnic groups residing at the sites are the ones that are generally known as 'rural' folks or indigenous groups. All of the sites have a dominant ethnic group residing in the area. The ethnic groups that are found in the research sites are 
the Rungus people in Kampung Bavanggazo, the Sungai people in Batu Puteh and Sukau, and the Dusun people in Kampung Rantai and the area surrounding Rafflesia Information Centre. This is clearly an advantage to each site as all ethnic groups have distinctive cultures that are an attraction to the site. These cultures are still imbedded in their identity and in their lifestyle.

The communities at all sites are composed mainly of farmers and labourers. Some are government servants. The similarities are that they are all low-income earners. Looking at the case studies, ecotourism and local community participation advocates have a hand in the sites. This is a good reason to establish ecotourism and get the support of the local community. The local community accepted ecotourism and participate in its activities where the obvious benefits are secondary income. All of the job opportunities are small and mainly provide secondary income.

With the exception of Sukau, all of the sites received assistance from other stakeholders. However, the level of assistance varies. Miso Walai Homestay is heavily funded by corporations and has a strong support from the Ministry of Tourism, Culture and Environment of Sabah and WWF-Malaysia (Sabah) as the facilitator. Bavanggazo Rungus Longhouse on the other hand received a lot of support from the government and its agencies, initially with monetary funding in the form of seed funding, and now with consultations. The operations run profitably without monetary assistance. Funding is very useful in the acceleration of development of a site.

All of the sites have their own infrastructures. These infrastructures exist from the product of gotong-royong, funding, or reinvestment of profit. These infrastructures are essential for the operation of ecotourism. Accommodation and shops are important in each site as they generate income. The size of these infrastructures range from small to medium, suitable for the nature of 
ecotourism. Sites that have been operating for some time have better infrastructures than the new sites. Kampung Rantai has the least developed infrastructures among all sites.

All of the sites have their own natural attractions and site protection status. However each site has different types of products. The offer of natural attractions is the main element in ecotourism operations. Some sites have advantages over the others in terms of the quality of the natural environment. The sites in Kinabatangan Wetlands have high quality of product, as it is a high biodiversity area. Rafflesia Information Centre and Kampung Rantai have an iconic flora attraction that is the Rafflesia flower. Batu Puteh and Sukau have an iconic fauna attraction that is the Proboscis Monkey. These are important to give a marketing edge to the sites. In addition to that, all sites offer ecotourism activities, which involve nature and culture, and the opportunity to learn and to enjoy them.

All of the sites have their own cultural attractions. The cultures are based on the dominant ethnic group that lives there. Kampung Bavanggazo, Batu Puteh, Sukau and Kampung Rantai have more interactive/participative cultural attractions. These sites offer the experience of living together with the locals and have cultural showcases. Kampung Bavanggazo has the most distinct cultural attraction in terms of its details. Tourists that came to Kampung Bavanggazo can experience the actual traditional culture and lifestyle of the Rungus people.

All of the sites have complementary or supporting attractions nearby. These are the add-on attractions to the sites and it is important to add more pull factor for the tourists to the site and entice tourists to stay longer. Kampung Bavanggazo, Batu Puteh and Sukau are well-known ecotourism destinations where most tourists will stay at least over night at the sites. They also have surrounding attractions, which are complementary to the ecotourism products. Rafflesia 
Information Centre is a stop-by attraction. Kampung Rantai also has few attractions nearby.

With the exception of Rafflesia Information Centre, all sites have a major festival/event. Kampung Bavanggazo has its Magahan Festival, Batu Puteh has its Kinabatangan River Expedition, Sukau has its Kinabatangan Regatta and Kampung Rantai has its Harvest Festival. Most of the festivals are culturally based and have been celebrated even before ecotourism started with the exception of Kinabatangan River Expedition and Kinabatangan Regatta. Both of these events were created and are conducted as a tourism activity at the sites. The creation of events show business savvy to the sites that are conducting them, as it becomes a pull attraction to the tourists.

All sites have policies and initiatives to contribute to the environment. First of all, some of the sites have an immediate stake in conservation. Kampung Bavanggazo and Kampung Rantai need conservation to safeguard their water catchments, which is the sole water supply for the villages. Batu Puteh pursued the reforestation program to rejuvenate the forests that are lost to illegal loggings. All sites have some form of conservation efforts and projects going on in the area and the areas surrounding it. However, only Rafflesia Information Centre has made conservation of a species a priority in its operation.

\subsubsection{Dissimilarities}

The case study matrix also highlighted the dissimilarities of each sites. This is where the distinctive features of each site can be distinguished and the advantages and disadvantages of each site to the others can be interpreted.

The cost to enjoy the site varies depending on the site. Kampung Bavanggazo, Batu Puteh and Sukau have the most comprehensive tourist packages among all 
the sites. This is attributed to the fact that they have been operating for quite a while (Kampung Bavanggazo and Sukau started ecotourism in the early 90s when ecotourism was just starting) and Batu Puteh has received professional consultation from WWF (Sabah). Rafflesia Information Centre only acts as an interpretation centre based on its purpose. Kampung Rantai's ecotourism was slow to develop due to legal battle interruption with timber companies. The most expensive place to visit among all the sites is Sukau where the industry is monopolised by urban-based tour operators.

The level of community involvement varies from site to site. The highest involvement of community participation is in Bavanggazo Rungus Longhouse and Kampung Rantai, where every body in the community is involved in the ecotourism operations. Batu Puteh involved some part of its population with the MESCOT activities, where ecotourism is the main business. The lowest involvement is Sukau where the ecotourism industry is monopolised by the urban-based tour operator. Rafflesia Information Centre, however, is run by a government agency i.e. Tambunan Forestry Department, where the involvement of local community is limited.

The average income per person gained from the ecotourism activity varies from site to site. Incomes are usually not high as the income is from a secondary employment. The nature of the employment is also the reason as it is structured to be paid when there is a job, not on a fixed monthly basis, with the exception of the very few full-time jobs in Sukau.

Only Kampung Bavanggazo, Batu Puteh and Kampung Rantai have a welfare fund specific for their community and their members. Sukau, on the other hand, has community development initiatives for the villagers. Others have none. Welfare funds are used to assist members of the community involved in the ecotourism operation when they need it. The funds sometimes are given as soft 
loans for reinvestment, such as fixing houses to be certified as a homestay house. It is important to note that Kampung Bavanggazo, Batu Puteh and Kampung Rantai have high levels of community participation. A community development initiative is where the tour operator initiate social program as part of their business activity, or as they like to say 'giving back to the community.

Some sites have experienced other community participation projects such as those related to the agriculture industry i.e. Bavanggazo Rungus Longhouse and Kampung Rantai. This gives them experience in conducting and participating in the local community participation process in the ecotourism industry.

The type of tourists that came varies by sites. Kampung Bavanggazo has a lot of FIT walk-ins and group overnight tourists. This is attributed to its popularity as a renowned tourism site in Sabah and the channels that the tourists came with. Batu Puteh has many tourists in groups from links with certain travel groups and volunteer groups. Tourists that go to Sukau are usually in a tour group on a tour package from both inbound and outbound tour operators. Tourists that go to the Rafflesia Information Centre are mainly walk-ins. It is a stop by for one leg of journey. Locals are the main type of tourists that go to Kampung Rantai, usually for business and VFR.

Decision-making varies from site to site, depending on the form/nature of organisation in each site. Committee-run sites are Bavanggazo Rungus, Miso Walai Homestay and Kampung Rantai. The similarity of these sites is that the community mainly runs them. The Sukau ecotourism industry is dominated by business operations and the industry direction is influenced greatly by the business community. The government operates the Rafflesia Information Centre. Therefore the relevant authority makes the decisions, in this case the Tambunan Forestry Department. 


\subsection{Conclusion}

The case study analysis shows more similarities rather than dissimilarities between and among the five sites. The most obvious are the nature and characteristics of the sites (location, environment, communities, infrastructure, conservation efforts and site protection status), funding and assistance received and job opportunities. This is consistent with the general ecotourism characteristics, and that is a small-scale operation; the products offered are nature-based with some level of involvement from the local community where benefits are channelled to the local environment and economies (Lash, 1998; Honey, 1999; Wearing, 1999; Epler Wood, 2001). It is important to note that all sites with the exception of Sukau received some form of funding and assistance. This raises the question on the viability of the ecotourism operations in these sites. It is not known whether without funding and assistance from outside agencies, these ecotourism sites would attain the same degree of success in terms of management, use of resources, profit, logistics and the like.

The dissimilarities are in terms of the type of packages offered by each site hence the type of tourists that come to each of the sites, level of community involvement, creation and dispersion of benefits, and previous community participation project involvement. Even with a lot of similarities, the nature of operations individualises each site. The analysis of the case studies used to discuss the results of the thesis will be in Chapter 8 i.e. Discussion. The case studies have come up with points where it influenced the nature and the dimensions of success for ecotourism sites and local community participation. Different sites may have different factors that contribute to the successes of the site and participation process. The sites may also have common factors that contribute to the success. The most obvious factor that resulted from the analysis is the product that the sites offers to the ecotourist. Each site markets 
different products that are still categorised as ecotourism products. Bavanggazo emphasised more on the culture side of ecotourism, while Batu Puteh and Sukau offers the wildlife of the Kinabatangan Wetlands. Kampung Rantai offers a pristine environment with culture while Rafflesia Information Centre specialises in showcasing the Rafflesia flower. Each site has their own advantage over others and is able to create their own market that contributes to the success. The operations of each site are also different from one another but each operation has also contributed to the success of the site and the participation process. These two factors are some of the examples where site characteristics have influence over the success indicators. The success perception and indicators can be justified more in-depth from the case studies points. 


\section{CHAPTER 6. LOCAL COMMUNITY PARTICIPATION SUCCESS}

\subsection{Introduction}

\subsubsection{Introduction to the Chapter}

The ecotourism literature discussed in the literature review stresses that local business owners and local communities must be involved. In the general environment of the ecotourism industry, opportunities to involve rural communities in tourism have attracted attention, and raised many expectations (Epler Wood, 2002). Prior to the publication of the National Ecotourism Guidelines (Malaysia) in 1997, there were no guidelines available for local community participation in any ecotourism ventures or projects. In Malaysia, the local community participation concepts employed in the ecotourism industry are based on existing projects and programs in the agriculture and fisheries industries. The community participation process adopted various examples, practices and models, which includes precedence in other local industries or existing ones from other sites, national or/and international (National Ecotourism Plan, 1997). Nevertheless, many examples and practices do involve the local community to some extent. The Malaysian National Ecotourism Guidelines, as discussed in the plan and policy chapter, recognised that successful ecotourism required the creation and involvement of local stakeholders (individuals and communities), and emphasised on local investment and control in decisionmaking. 
This chapter deals with the indicators for local community participation success. The chapter starts with the research findings. Here, the indicators that are derived from the data collected across five sites from four groups of stakeholders are presented. The findings are presented based on a thematic cluster. Each of the indicators is clustered to its group based on the themes that emerge from the data. This categorized the indicators into more specific indicators, therefore manageable for analysis. These indicators will be the basis for indicators analysis following after that i.e. indicators by stakeholders, indicators by site and a combination of both. The general indicators are explored in-depth and justified through the linkage with site scenarios and case studies. The indicators are analysed based on variations within and between the groups of stakeholders and sites. The indicators are first analysed by stakeholders and then by site. Discussion of the indicators analysis is presented and concluded towards the end of the chapter. The analysis uses the logical sequence of stakeholders and site in addressing the issue of distinguishing the importance of each indicator. Further explanation is explored in the next section.

As discussed in Chapter Three (Methodology), the findings are derived from interviews with three groups of stakeholders and a survey of a fourth, the tourists. They were chosen, as they are the groups that are involved in the industry and have, to some extent, some kind of involvement in the local community participation process. The four groups of stakeholders chosen as respondents are: the local community, the government and NGO's, the business community, and the tourists. The tourists and local community groups are further divided into the five research sites: Kampung Bavanggazo, Batu Puteh, Kampung Rantai, Sukau and Rafflesia Information Centre. The respondents contribute to the critical analysis of local community participation success through their providing their views on success. The indicator analysis by site presents the indicators specific to the site. The set of indicators is further 
subdivided by stakeholders. This presents more insightful analysis of the indicators.

\subsubsection{Indicators' Analysis Framework}

The previous chapter on methodology mentioned that indicators are mainly used to measure information, which decision-makers may use to reduce the chances of unknowingly making poor decisions. Indicators should be able to reduce the wide range of potential information to a set of usable and meaningful measures of those factors important to the decision-maker. It is mentioned in the literature that indicators are not an end in themselves, but rather a vehicle for the better understanding of a phenomenon.

The framework that has been developed in the methodology chapter stated that the indicators that are developed from this thesis are derived from the data collected across five research sites from four selected groups of stakeholders. The procedure is that each of the indicators derived from the interview and survey analysis is clustered in its group based on the themes that emerged from the data. These themes are the basis for indicator analysis and success analysis. The indicators will be further analysed based on its varations within and between the group of stakeholders and sites. Frameworks of analysis are presented in each result chapter.

Indicator identification raises the issue of the weight of the importance of each indicator. Depending on the data collection and the manner that the data were collected, the indicators' importance can be based on the variables sequence. This sequence is developed through the interpretation on qualitative data. The main reason for this process to be employed lies in the disparity of the data collection from all respondents. Three groups of respondents suggested the 
indicators through interview while one group suggested them through survey. The data from interviews are put in a matrix based on the emerging themes. The data from the survey are clustered together based on common themes and put into groups. These themes are then translated into indicators. At this point, there is no rank of importance established for the indicators. In order to put its rank of importance, the logical sequence of variables is used. These logical sequences are used both in analysing the success indicators for local community participation and ecotourism in this chapter and the next chapter.

The indicators analysis needs to employ a logical sequence of variables to establish the rank of importance for each indicator. There are two important variables involved here. They are stakeholders and sites. The first variable, the stakeholders, are sequenced based on each stakeholder's involvement and how much they are affected in the local community participation process. The top of the sequence is the stakeholder that has the most involvement and is most affected by local community participation and ecotourism. The end of the sequence is the group that has the least involvement and is least affected by local community participation and ecotourism. The ranking of the sequence is based on the literature review in Chapter Two and the case studies in Chapter Five. The sequence of stakeholders (Figure 6.1) is as follows: 


\section{Fiqure 6. 1 Stakeholder's Sequence}

\begin{tabular}{|c|c|}
\hline NO & STAKEHOLDERS \\
\hline 1 & Local community \\
\hline 2 & Government \& NGOS \\
\hline 3 & Business \\
\hline 4 & Tourist \\
\hline
\end{tabular}
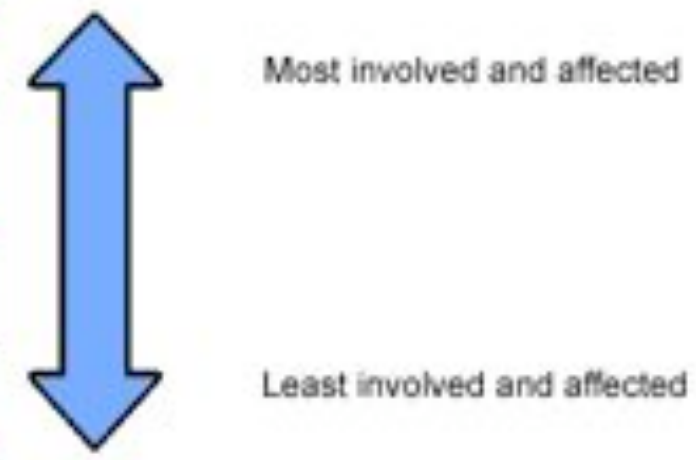

The second variable, the sites, are sequenced based on the initiative of local community participation in ecotourism. The top of the sequence is where the local community owned and operated the site and ends with the site that the local community has the least involvement. Based on the case studies in Chapter Five, the sequence for the sites (Figure 6.2) is as follows:

Figure 6. 2 Site Sequence

\begin{tabular}{|c|c|c|}
\hline NO. & SITES & INITIATIVES \\
\hline 1 & $\begin{array}{c}\text { Kampung } \\
\text { Bavanggazo }\end{array}$ & Owned and managed by local community \\
\hline 2 & Batu Puteh & $\begin{array}{l}\text { Managed by local community with an international NGO and } \\
\text { government with high stake for local community }\end{array}$ \\
\hline 3 & Rantai & Managed by local community with local NGO \\
\hline 4 & Sukau & $\begin{array}{l}\text { Dominated by business with some local community } \\
\text { involvement and initatives }\end{array}$ \\
\hline 5 & \begin{tabular}{c|} 
Rafflesia \\
Information Centre
\end{tabular} & $\begin{array}{l}\text { Run by the government with a handful of local community } \\
\text { workers }\end{array}$ \\
\hline
\end{tabular}


The sequences clarify issues that relate to indicators such as establishing the importance of indicators, the variations between stakeholders and sites and variations between the groups of stakeholders.

The principal purpose of the indicators, which are developed from this research, is to help stakeholders learn how to view the outcome of local community participation efforts. The entire process is anchored in this research that determined the ways in which stakeholders define success in the local community participation efforts. Stakeholders may use these indicators to develop practical ways to measure progress. This is to ensure that their resources were justifiably spent and that appropriate activities were carried out.

In order to establish consistency and further analyse the indicators developed from this research, the set of indicators will be compared with another set of local community participation success indicators that are drawn from the literature review. The comparison will also try to establish whether the indicators are new or applicable to other case study or site.

\subsection{Research Findings - General Indicators}

\subsubsection{Introduction}

As mentioned before, qualitative data analysis done at this stage is based on fieldwork data. Supplementary data were gathered from qualitative observations. Based on the data analysis, the results were then systematically interpreted and a thematic framework produced (Boyatzis, 1998). At the end of the chapter, the results are further elaborated by identifying the interrelationship among the results to address the research issues set out in the methodology section. 
There are two important notes that must be taken into consideration concerning the results from the analysis process. They are:

- Overlaps and similarities in the responses from the stakeholders in two questions:

1. What is your understanding of success of local community participation in ecotourism?

2. What are the success/failure factors for the local community participation in ecotourism?

口 Overlaps between indicators for the success of local community participation and indicators for the success of local ecotourism sites.

These overlaps occurred because of these factors:

a The question to respondents on success indicators and the question on factors for success are very similar. Many respondents repeated their answers for both questions.

a Many respondents feel that some indicators for local community participation contributed to ecotourism site success.

This has affected the results of the data and there should be some grey areas where both indicators are overlapping. This can be explained as local participation is a subset of ecotourism in this context. This issue has been identified as limitations in the methodolgoy section and conclusion section. 


\subsubsection{Indicators in General}

Based on the primary data collected from the field, the indicators can be divided into three groups. The first group is the indicators based on themes. These are indicators that have been identified from the data obtained from all stakeholders and all sites. They are clustered into emerging themes. These themes are developed first to assist in the next step of identifying specific indicators by stakeholder and site.

The second group of indicators is based on stakeholders. These are indicators specifically mentioned by each stakeholder as indicating the success of local community participation in general. Some of the responses also include indicators that are referring to a specific site or sites. The summary of indicators by stakeholders is divided into four groups who are the major respondents of this research.

The third group of indicators is the site-specific indicators. These are indicators that the respondents refer specifically to the five research sites. The analysis from the case studies is included to present what contributes to the development of success indicators.

The fieldwork has resulted in much useful primary data for interpreting the success of local community participation. It also provided first-hand information and impression of the actual local community participation process. Based on the fieldwork, there is strong evidence of local community participation in all research sites. However, the level of participation of the community differs from site to site and is mainly dependent on who is running the site. 


\subsubsection{Indicators by Theme}

As a result of the analysis, there are 15 indicators that have been identified in the primary data (Figure 6.3). At this stage, these indicators are general in nature and clustered into themes. These indicators are the basis for the other groups of indicators that are analysed later in this chapter.

The indicators presented in this section have been clustered based on emerging themes. It does not follow any type of sequence system, as there is no rank of importance established for each indicator. This is also to avoid confusion and overlapping of the analysis process in later sections. This section is basically documenting the indicators that emerged from all sources. Some of the indicators will be illustrated by quotes from stakeholders to emphasise the point.

The first theme is the visible community involvement and commitment. This can be seen from daily activities such as the locals working on an operational basis or having a meeting to discuss the management of the ecotourism project. A high level of commitment is also an indicator that there is visible effort and hard work put into the project by the participants. The traditional 'gotong-royong' is an excellent example of high commitment by the local community in working towards the success of the project. An NGO quoted that 'the locals usually have a gotong-royong every Saturday to clean up the area. They also work together to build new chalets (for tourists), shops and toilets'. 


\section{Fiqure 6. 3 Key Indicators from Primary Data}

\section{LOCAL COMMUNITY PARTICIPATION} SUCCESS INDICATORS

\begin{tabular}{cl}
\hline 1 & $\begin{array}{l}\text { Visible community involvement } \\
\text { and commitment }\end{array}$ \\
\hline 3 & Benefits received \\
\hline 4 & Higher level of participation \\
\hline 5 & $\begin{array}{l}\text { Improvement in standard of } \\
\text { living/More progressive }\end{array}$ \\
\hline 6 & $\begin{array}{l}\text { Increase in Capital/Finance/ } \\
\text { Revenue }\end{array}$ \\
\hline 7 & Improvement in Iocal economy \\
\hline 13 & $\begin{array}{l}\text { Conservation and promotion of } \\
\text { culture }\end{array}$ \\
\hline 19 & Attractiveness of the site \\
\hline 10 & Conservation of the environment \\
\hline 15 & Site enhancement
\end{tabular}


The second theme is the benefits for the local community. These stakeholders expressed this theme mainly in general terms. However, there are many specifics that came with their answers and the most popular choice is employment. This is an expected response since employment is the most obvious and talked about benefit generated from the tourism industry, be it from industry forums or academic writings. Other specific answers are knowledge, skills and experience that can be gained from the industry. The usual skills and knowledge gained are management, entrepreneurship, language and hospitality. However, there are also personal skills that can be gained, which empower individuals such as leadership, team building, and public speaking.

The third theme is the high number of tourists visiting. It is believed that the higher the number of visitors, the more successful it is for local community participation efforts. The number of visitors usually indicates the popularity and attractiveness of the site. Community activities are one of the important elements in attracting tourists to a site, such as cultural performances, handicraft as a cottage industry, and local events and festivals.

The fourth theme is the level of participation. The idea of this theme is that, the higher the level of participation, the more successful local community participation is. This was depicted earlier in Chapter 2 where the local community usually has little capacity to run an ecotourism project when it is first started and a higher level of involvement maximises the benefits received by the local community. The local community has to rely on outsiders to assist them in running the industry. Over time, they should have built their own capacity and increased their level of participation in the industry. The villagers of Bavanggazo have proved this with the operation of the Bavanggazo Rungus Longhouse. They started with many forms of assistance, especially from the Sabah Tourism Board and the Ministry of Tourism, Culture and Environment, and now they are operating the longhouse themselves. The government respondent quoted that 'local community participation should have a 
higher/bigger stake in the industry. The success will then be bigger and the benefits will be better. At this moment, the benefits for local community involved as operation workers are not much'. All these stakeholders viewed that the level of participation must be as high as it can be to be a good indicator on whether the local community participation project is successful or not.

The fifth theme is the improvement in standard of living. Besides individual economic improvement of the local community, other aspects such as infrastructure, hygiene awareness and education are also included. More and more locals involved in ecotourism have benefited from earning supplementary income. Besides having extra income, it is also evident that the villagers have been acquiring goods such as motorcycles or cars and improving/renovating and carrying out beautification to their houses. Homestay participants have made the most visible improvement in their houses as the houses have to achieve a certain standard set by the Ministry of Tourism, Culture and Environment. Houses that are designated for homestay must fulfil certain standards and criteria. For example, every toilet and bathroom must be modern, tiled and in good working order. The kitchen has to have a proper ventilation system and clean working space, while the bedroom must have proper beds, clean linen and sufficient lighting. Extra income from the homestay program has enabled the villagers to make more improvements to their houses. A local villager from Kampung Bavanggazo observed that 'before they were involved in ecotourism, they faced financial challenges especially in important things such as their children's school expenses. Now, it is a bit easier with the extra income from ecotourism? This is backed up with the quote from a government respondent that 'some of the locals engage in tourism as their primary income. Some of them are now able to buy a car'.

The sixth theme is the increase in revenue from ecotourism operations. This theme is also related to the success of ecotourism sites. As more tourists come, more money goes into the local economy. 
The seventh theme is the improvement in the local economy. Improvement can be seen with more new businesses or enterprises emerging and this is a factor for local business environment intensification. An NGO respondent said that 'if the visitors come to the site, it is successful as it increases the economy of the locals'. There is also a general improvement in the standard of living for the local community.

The eighth theme is the conservation and promotion of culture. Successful local community projects help to ensure that their local customs and traditions are observed, conserved or revived. The achievement of this is considered a success indicator for the local community participation process.

The ninth theme for success is the attractiveness of the site, which is indicated by the tourists. The attractiveness of the site refers to the place maintaining original local ambience, and also producing and selling quality by-products such as handicraft. This is an indicator that the place is well run by the local community.

The tenth theme is the conservation of the surrounding environment. It is suggested that conservation of the environment at any level indicates successful local community efforts. Environmental conservation has been considered as highly important in all sites. The local community made an effort to work together in order to ensure that certain aspects of their environment are conserved and preserved. An NGO respondent noted that 'in the 80s, it was realised that there is a decreasing number of habitats and a concern in conserving the forest. Ecotourism was promoted/introduced not only to solve the 80 s dilemma but to channel benefits to the locals as well'.

The eleventh theme is the development of infrastructure including site enhancement. Local community participation activities within the ecotourism industry usually lead to the development of infrastructure and site 
enhancement. Participation in homestay programs has resulted in the enhancement of a high number of houses which is beneficial to tourists and hosts. As one of the villagers commented during the interview, 'before this (ecotourism), we took our baths in the river, but now we don't have to'. Ecotourism usually leads to the establishment of better (looking) jetties, centres with local architecture and design (club houses, information centre etc.), better road facilities and nurseries or gardens such as the traditional medicine garden at Kampung Rantai or the tree nursery at Batu Puteh and Sukau. Therefore, the development of infrastructure and site enhancement is deemed to be a success indicator for local community participation.

The twelfth theme is local community development. The development of the community is divided into two: 1 ) the development of a community as a whole and 2) the development of individuals within the community. The development of a community as a whole is quite visible with better integration and cooperation among the community. There is a general peaceful feeling in the air and the locals interact with each other very well. Within the process of community participation, individuals may also improve themselves through knowledge, experience and skills gained from the participation process. Experience from the industry has given them higher self-esteem and confidence, which is valuable in self-development. There are one or two locals that took further initiatives, venturing into ecotourism enterprises on their own. For example, a local owns the Tomanggong Bed and Breakfast in Sukau and many villagers in Batu Puteh, Sukau and Kampung Rantai started homestay projects.

The thirteenth theme is the independence acquired by the local community from their participation in the ecotourism project. The government has provisions to assist the local community to start up their ecotourism project through subsidies such as seed funding and consultation, which are essential to the low-capacity community. However, the government's intention is also for the local communities to break away from depending on subsidies as the 
project progresses. Therefore, the government representative deemed that if the local community can be independent, not just in terms of finance but also in other aspects such as management, community consultations or conflict resolution, then it is definitely an indicator of successful local community participation. A government respondent noted that 'in Sabah, homestay is a success story. The host is able to become independent from the government. The government at the same time also tries not to create dependency'. The community also agreed with the government but only to a certain extent.

The fourteenth theme is that the local community is happy and motivated. A government respondent suggested that it is not just the welfare of the local community that should be taken care of, but their state of happiness and motivation as well. It is suggested that a successful local community project will result in a happy and motivated community. That community in turn can create a synergy of community efforts and ensure the success of the site.

The last success theme is a good understanding of the whole process, which is indicated by the business industry. The business industry has a difficult experience in comprehending the expectations of the local community. Therefore, a good understanding of participation aspects is an indication of success for local community participation. They suggested that the local community should have a realistic view of the industry's environment and expected benefits. A community that has been well informed and made an informed decision to be involved is usually easier to manage and more motivated in their involvement. 


\section{Indicators' Themes and Cluster}

With further examination of the key indicators from the primary data, all of the indicators can be further subdivided into three sub-clusters based on the indicators' nature of characteristics. The first cluster is a group of indicators that are related to the community and its well being. The second cluster is a group of indicators that are related to the business aspects of ecotourism. The third cluster is a group of indicators that are related to the environmental aspects of ecotourism. All of these sub-clusters are illustrated in Figure 6.4 below: 


\section{Figure 6. 4 Three Sub-Clusters of Local Community Participation}

\section{Success Indicators}

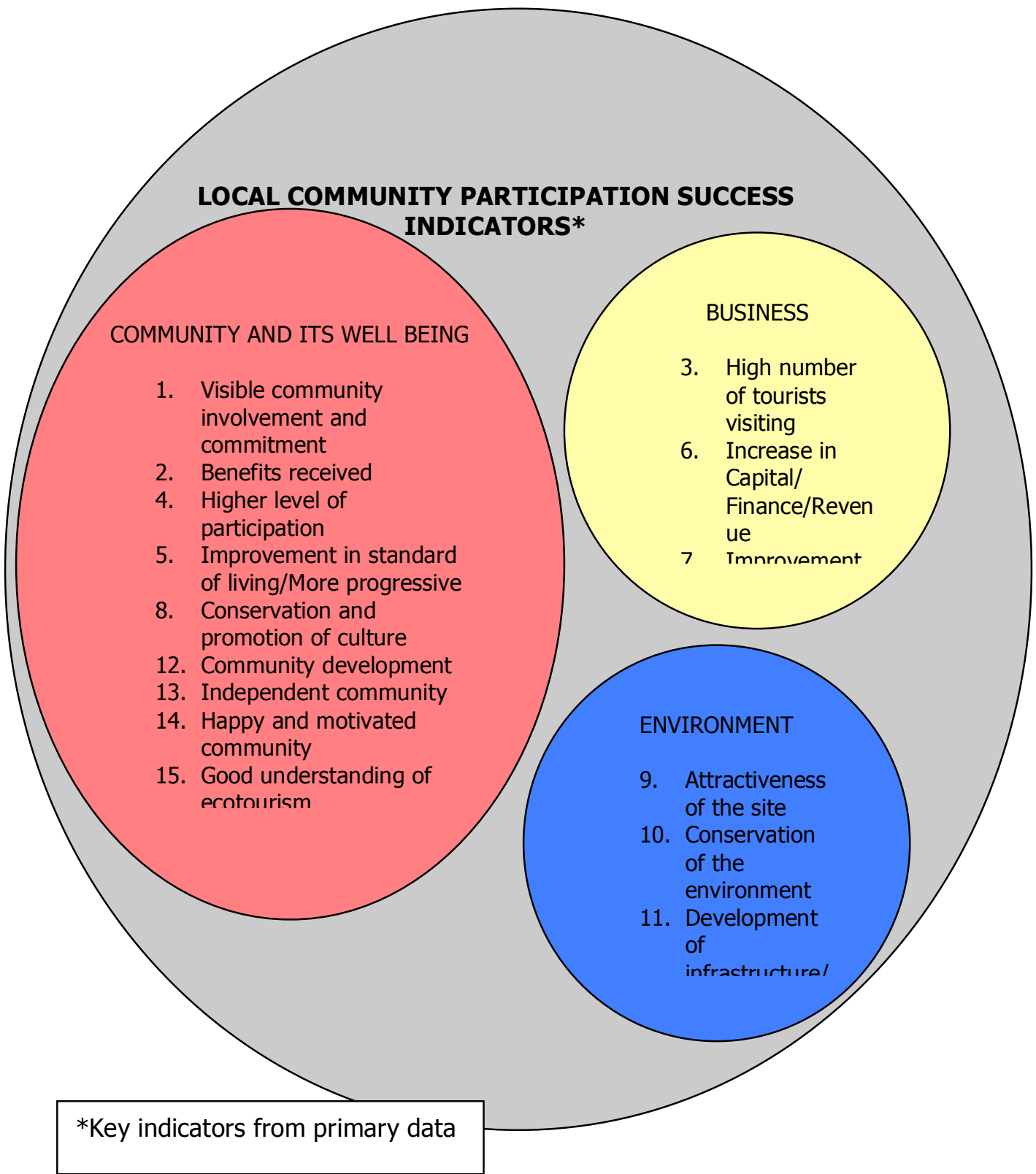

The first cluster, where the indicators are related to the community and its well being, includes visible community involvement and commitment, benefits received, higher level of participation, improvement in standard of living/more progressive, conservation and promotion of culture, community development, independent community, a happy and motivated community and good understanding of ecotourism. 
The second cluster, where the indicators are related to the business aspects of ecotourism, include high number of tourists visiting, increase in capital/finance/revenue and improvement to the local economy.

The third cluster, where the indicators are related to the environmental aspects of ecotourism, include attractiveness of the site, conservation of the environment and development of infrastructure/site enhancement.

The themes for local community participation success do not just cover the essential elements of ecotourism, i.e. conservation and well being of the local community, but extend to other aspects such as community development and business practices. This suggests that the practice of ecotourism and its perception of success are broader and go beyond the theoretical definition. However, from Figure 6.4, it is clear that the community and its well being issues are deemed more important by the respondents than business and environment based on the number of indicators. These sub-clusters are used in the analysis of the indicators. 


\subsection{Analysis of Indicators}

\subsubsection{Introduction}

The analysis of indicators begins with grouping the indicators into two. They are: 1) Indicators by stakeholder, and 2) Indicators by site. It is important to analyse the indicators by these two variables as both present different views of the indicators. Different stakeholders may have different views of success and it is important to distinguish which indicators are more important compared to others. The same goes for the sites, where each site may suggest a different view of success.

Indicators by stakeholder are a group of indicators that have been developed and clustered based on the group of respondents. Indicators by site are a group of indicators that have been developed from all respondents that refer to specific sites. Some respondents may also base their answers on the indicators on that specific site such as the local community and the local business. Analysis was done based on the analysis framework that was mentioned in the beginning of this chapter.

Based on the analysis of indicators by stakeholder, the rank of importance for success indicators for local community participation can be seen in Figure 6.5. The schedule shows an arrangement based on the logical sequence of the stakeholders as proposed in the earlier part of this chapter. It ranks the importance of each indicator based on the number of stakeholders who responded and the sequence of stakeholders. For example, the eleventh indicator is ranked higher than the twelfth indicator. In this case, the local community, which is at the top of the sequence of stakeholders, suggests the 
eleventh indicator as the highest ranked. Since the government and NGO group, ranked second in the sequence of stakeholders, suggest the twelfth indicator as highest, the indicator has to be ranked lower than the indicator suggested by the local community. This proposed the importance of indicators compared to the others. Figure 6.5 suggested that the highest ranked indicator by the stakeholders is the visible community involvement and commitment. All stakeholders suggested that community elements, especially involvement and commitment, are important in local community participation activity. The community sees that their efforts will make the activity successful. The Government, NGOs and Businesses need the support of the local community to make it successful. The tourists on the other hand sees that as a right practice to include local community in any ecotourism activity as part of their ethical conscience. The figure also suggests that the lowest ranked important indicator is the attractiveness of the site. The tourist respondent suggests this, where, being a tourist, he looks at high quality natural environment for their ecotourism environment.

\subsubsection{Indicators by Stakeholder}

The research revealed that out of 15 indicators, the local community suggested 10 of them. Both government and NGOs groups suggested nine indicators and the business group came up with the least indicators, only four. The tourists suggested seven indicators. These are illustrated in Figure 6.5.

The first indicator is that there is visible community involvement and commitment towards the industry (Sub-Cluster: Community and its well being). All of the stakeholders suggested this indicator. The responses from all sites show that the villagers see the community participation project not just from the economic point of view but also from the philosophical point of view. All sites 
(with the exception of Rafflesia Information Centre) at some level emphasize community support, unity and commitment in running the industry. This is attributed to the fact that these villages are small and most of the people who live there are related to one another. A matter of business may become a matter of family interest. Visible participation usually is an active one and there is commitment and unity among the community towards the industry. There is also suggestion that the commitment shown by the local community themselves can be measured by the number of participants from the total population, and time and effort invested in the local community participation activity. This can be observed with the frequency of community activities and infrastructure development such as 'headquarters', jungle trails and jetties.

The second indicator is being more progressive with the improvement in standards of living (Sub-Cluster: Community and its well being). The local community, government and NGOs and businesses suggested this indicator. Community participation introduces them to many modern skills such as management, language (especially English), and hospitality. They expect modern skills as an instrument to be more progressive in the modern world, where they can be on a par with people from the modern towns and cities. With the hospitality side of ecotourism, the locals are taught proper food handling which is similar to what is practised in a restaurant's kitchen. Economic improvement is the most obvious indicator of success. According to the respondents, many locals who have converted their livelihood from self-subsistence farming to tourism have experienced financial betterment in their income.

The third indicator is the increase in capital and revenue (Sub Cluster: Business). The local community, government and NGOs, and the business suggested this indicator. This suggests that the ecotourism industry is very much a businessoriented operation even though its other primary objectives are the conservation of the environment and community development. The ecotourism project must 
be financially sustainable and it can be measured by the amount of revenue gained from the operations. Healthy revenue with a steady increase is an indicator of success and it shows how well the community works together. In some aspects, the community participation activity is considered as a job, secondary nonetheless. Therefore the amount of capital and revenue that they acquire from any ecotourism activity based on their effort as a community is seen as indicator for success. 
Fiqure 6. 5 Indicators by Stakeholders

\begin{tabular}{|c|c|c|c|c|}
\hline $\begin{array}{l}\text { THEMES AND } \\
\text { RESPONDENIS }\end{array}$ & $\begin{array}{l}\text { LOCAN } \\
\text { COMMUNITY }\end{array}$ & $\begin{array}{l}\text { GOVERNMENT } \\
\text { AND NGOS }\end{array}$ & BUSINESS & TOURISTS \\
\hline 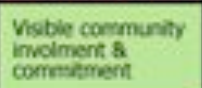 & $\Omega$ & 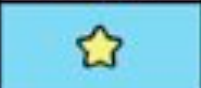 & 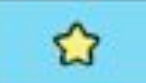 & {$[3$} \\
\hline 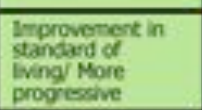 & $\tilde{\omega}$ & 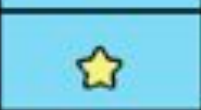 & 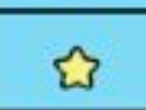 & \\
\hline $\begin{array}{l}\text { Inotade in } \\
\text { coptril francel } \\
\text { Rerenve }\end{array}$ & 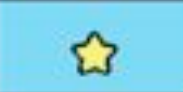 & 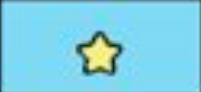 & 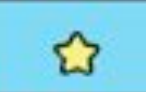 & \\
\hline 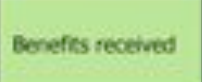 & 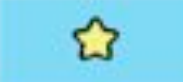 & 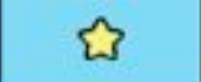 & & 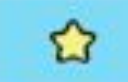 \\
\hline $\begin{array}{l}\text { Mon number of } \\
\text { tounts vistong }\end{array}$ & $\Omega$ & $\tilde{\omega}$ & & 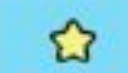 \\
\hline $\begin{array}{l}\text { Hoper leved of } \\
\text { portoposon }\end{array}$ & 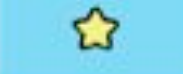 & 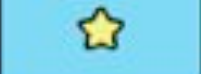 & & 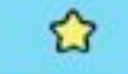 \\
\hline $\begin{array}{l}\text { Conservaton and } \\
\text { promotom of } \\
\text { punsere }\end{array}$ & 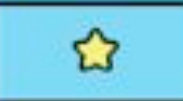 & & & 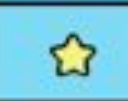 \\
\hline 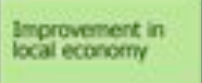 & & 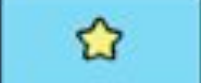 & & 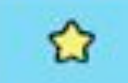 \\
\hline $\begin{array}{l}\text { Corservaton of } \\
\text { tre enveromentit }\end{array}$ & 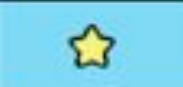 & & & \\
\hline 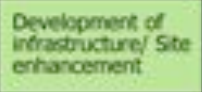 & $\tilde{\omega}$ & & & \\
\hline $\begin{array}{l}\text { Commusty } \\
\text { derdoprement }\end{array}$ & 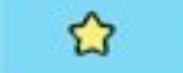 & & & \\
\hline $\begin{array}{l}\text { Jathondent } \\
\text { communty }\end{array}$ & & 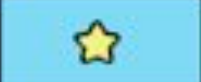 & & \\
\hline $\begin{array}{l}\text { Mspoy and } \\
\text { movivted } \\
\text { communty }\end{array}$ & & 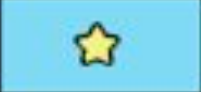 & & \\
\hline $\begin{array}{l}\text { Good } \\
\text { unsestanang of } \\
\text { eccosounism of }\end{array}$ & & & 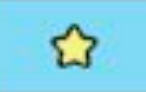 & \\
\hline $\begin{array}{l}\text { Atrativeness of } \\
\text { the ste }\end{array}$ & & & & $\tilde{\omega}$ \\
\hline
\end{tabular}

The fourth indicator is the benefits received by the local community through participation activity (Sub-Cluster: Community and its well being). The local community, government and NGOs suggested this indicator along with the tourists. There are economic benefits offered by the industry such as the opportunity for employment, secondary source of income or social benefits such 
as improvement of infrastructure, which help with their daily life. The general perception is that the bigger the benefits received, the more successful the local community participation.

The fifth indicator is the high number of tourists visiting the sites (Sub-Cluster: Business). The local community, government and NGOs, and the tourists suggested this indicator. They believe that the high number of tourist reflects the success of the site. This is also seen as a success of local community participation. There are instances that community conflicts had negative effects on an ecotourism site operation, and the site attractiveness and popularity declined along with the number of visitors.

The sixth indicator is the high level of participation within the community project (Sub-Cluster: Business). The local community, government and NGOs, and tourists suggested this indicator. They suggested that the more they are involved in the industry, the more successful the community participation project is. There is a general awareness that there is a lot of capacity building needed in order for them to be involved in the ecotourism industry. Despite some sites that have a high involvement of outsiders, i.e. NGOs, Government and business community, they still expect the industry to be left to them at some point in the future when they have enough capacity to do so. The higher they go up the ladder of participation, the more successful they are in terms of the participation process. With a higher level of participation, the community has a higher stake in the industry. In that sense they are empowered within that level and have more control over the operations of the industry.

The seventh success indicator is the conservation and promotion of culture (SubCluster: Community and its well being). The local community and the tourists suggested this indicator. Cultural conservation concerns the efforts by the local community to ensure that their traditions and customs do not dramatically 
change with the introduction of ecotourism. The local community are aware that their culture is unique and plays an important role in the ecotourism product. In some instances, some aspects of traditions and customs, which have not been practised since the 'modernisation' of the community by the government or certain religious institutions, have been revived to serve an authentic cultural experience to the visitors. With the visible cultural conservation working in favour of all the stakeholders, the local community deemed this as a success indicator of local community participation effort. This indicator however does have its weight leaned as an indicator for success for ecotourism sites.

The eighth indicator is the improvement of the local economy (Sub-Cluster: Business). The government and NGOs with the tourists suggested this indicator. Improvement can be seen with new development of infrastructure around the area and visible improvement in the standard of living for the community there. There are new businesses and enterprises emerging from the intensified business environment.

The ninth indicator of success for local community participation is the conservation of the environment (Sub-Cluster: Environment). The local community suggested this indicator. Villagers from all sites cited that the conservation of the environment at any levels should reflect the success of local community efforts. Sites such as Bavanggazo Village, Batu Puteh, Rafflesia Information Centre and Kampung Rantai put high importance on environmental conservation in their ecotourism activity. This conservation effort starts with the local community where they ensure that certain aspects of their environments are conserved or, where possible, rejuvenated. Preserving water catchments and reforestation programs are good examples of conservation efforts.

The tenth indicator is the development of infrastructure and site enhancement (Sub-Cluster: Environment). Only the local community suggested this indicator. 
This is where there is a positive and visible enhancement to the village. The villagers indicated that the local community participation activity and the ecotourism operations enhanced the village's infrastructure and visual beauty. For instance an improvement in the local housing where the houses are being 'upgraded' (painted houses, new roof, well-maintained garden, etc.) enhance the beauty of the village. This is particularly relevant to the sites which have homestay programs in its operations. The enhancement especially for houses in the village is due to the homestay guidelines that require the participants to meet certain standards (for their house) outlined by the Ministry of Tourism, Culture and Environment. Besides the villagers' houses, the general landscape of the villages also improved. This enhancement to the existing beautiful landscape has been achieved through community projects and efforts such as gotong royong.

The eleventh indicator is the development of the community (Sub-Cluster: Community and its well being). Only the local community suggested this indicator. There are two aspects involved here, where the first is the development of a community as a whole, and the second is individual development within the community. The notion of community development as a whole is skewed towards visible cooperation and integration among the community themselves. Besides that, the high and firm commitment shown by the local community to the project is also seen as a success for the whole process of local community participation. On the other hand, development for individuals in the community is more concerned with individual self-development. This self-development is experienced by the local community through their involvement in ecotourism. The local community suggested that the local community participation is successful when they felt that they have gained some level of knowledge and experience. Opportunities for them to join relevant courses to enhance their skill and knowledge that are valuable to the ecotourism industry are something that the villagers held valuable. Furthermore, the 
knowledge and experience gained has given them higher self-esteem and higher confidence level by being involved with project like ecotourism. Another aspect of individual self-development is the entrepreneurship opportunities for the local community. Some members of the community managed to become entrepreneurs, taking advantage of the opportunity offered by the industry. They are usually involved in a homestay program or running a business that supports the industry such as souvenir shops or catering. This is considered to be an indicator of success for local community participation.

The twelfth indicator is the independence of the local community (Sub-Cluster: Community and its well being), suggest only by the government and NGOs. In order to start an ecotourism venture, the local community usually applies for seed funding from various sources, especially the government sector. However, the government encourages them to be independent after the project takes off. The community is expected to find their own funding afterwards and the community in certain research sites has done so.

The thirteenth indicator is the state of happiness and motivation of the local community (Sub-Cluster: Community and its well-being). Only the government and NGOs group suggested this indicator. It is also in the interest of the government and NGOs to ensure the well being of the local community, not just in economic terms but also in social terms. The local community should be happy with the process of participation and there should be no long-running conflict among the community themselves resulting from the participation activity. This ensures continuous motivation for the local community to be involved in the ecotourism industry. A well-motivated community ensures the success of the local community participation process.

The fourteenth indicator is the understanding of the ecotourism industry by the community themselves, especially what they are involved in (Sub-Cluster: 
Community and its well being). Only the business respondent suggested this indicator. The business community had and still has a lot of issues with community expectations when they include the local community in their business operations. They are aware that it is essential to make them understand the realistic industry environment and its expectations. Communities that have been well informed and make an informed decision to be involved are easily managed and more motivated in their involvement. For the business community, that is a step forward to success.

The fifteenth indicator is the attractiveness of the site (Sub-Cluster: Environment). Only the tourist group suggested this indicator. Tourists regarded the attractiveness of a site as a success of local community participation. This notion may stem from the success indicator of the wellness of the community working together. It is suggested that the site that has original local ambiance and quality by-products, such as handicrafts, demonstrates that the place is well run by the local community. Hence, it is considered a success indicator of local community participation.

This part can be further analysed with reviewing what the stakeholders did not indicate as success factors. According to the Figure 6.5, the local community did not mention:

i. Improvement in local economy (Sub-Cluster: Business)

ii. Independent community (Sub-Cluster: Community and its wellbeing)

iii. Happy and motivated community (Sub-Cluster: Community and its well-being)

iv. Good understanding of ecotourism (Sub-Cluster: Community and its well-being); and

v. Attractiveness of the site (Sub-Cluster: Environment) 
This result suggested that the local community themselves do not see the business of ecotourism in a bigger picture as they do not indicate ecotourism as a tool to improve the local economy through local community participation. This suggested that the local community may see the local community participation as only for the locals or the individuals. The local community may not see happy and motivated community as the outcome of local community participation but as an end result to an outcome such as benefits received, improvement in standard of living, becoming more progressive and others as mentioned in Figure 6.5. Based on the case study in Chapter Five, it is not surprising to know that a good understanding of ecotourism is not considered as a success factor as most of the sites still need assistance from the government/NGOs and there are sites which have a top-to-bottom approach to development. The local community may not see attractiveness of the site as a success factor but they do see site enhancement as a success indicator. It may be possible that attractiveness in their context is subjective.

The government and NGOs did not mention:

i. Conservation and promotion of culture (Sub-Cluster: Community and its well-being)

ii. Conservation of the environment (Sub-Cluster: Environment)

iii. Development of infrastructure/site enhancement (Sub-Cluster: Environment)

iv. Community development (Sub-Cluster: Community and its well being)

v. Good understanding of ecotourism (Sub-Cluster: Community and its well-being)

vi. Attractiveness of the site (Sub-Cluster: Environment) 
It is perhaps not conventional that the Government and NGOs do not see all of the above as success factors but in the context of local community participation, these results suggest that these indicators are not relevant enough to be the success factors for local community participation. The indicators are probably more suited to be success factors for ecotourism sites. When looking back at the indicators that they have mentioned, those indicators are quite focused on the local community themselves.

Meanwhile, the business respondents did not mention:

i. Benefits received (Sub-Cluster: Community and its well-being)

ii. High number of tourists visiting (Sub-Cluster: Business)

iii. Higher level of participation (Sub-Cluster: Community and its wellbeing)

iv. Conservation and promotion of culture (Sub-Cluster: Community and its well-being)

v. Improvement in local economy (Sub-Cluster: Business)

vi. Conservation of the environment (Sub-Cluster: Environment)

vii. Development of infrastructure or Site enhancement (Sub-Cluster: Environment)

viii. Community development (Sub-Cluster: Community and its wellbeing)

viiii. Independent community (Sub-Cluster: Community and its wellbeing)

$\mathrm{x}$. Happy and motivated community (Sub-Cluster: Community and its well-being)

xi. Attractiveness of the site (Sub-Cluster: Environment)

Among all the stakeholders, the business respondents has the highetst nonmentioned indicators. There is large number of indicators with the nature of 
community and its well being that were not mentioned by the business respondents. This suggests that businesses are only focused on the local community participation process that involves visible community involvement, and commitment and improvement in standard of living/more progressive that may have visible output. Other indicators are less relevant to business operations from the business respondents' point of view. Again, similar to government and NGOs explanation, the indicators are probably not mentioned as they are more suited to ecotourism site success.

Finally, the tourists did not mention:

i. Improvement in standard of living/More progressive (Sub-Cluster: Community and its well-being)

ii. Increase in capital/finance/revenue (Sub-Cluster: Business)

iii. Conservation of the environment (Sub-Cluster: Environment)

iv. Development of infrastructure/site enhancement (Sub-Cluster: Enviroment)

v. Community development (Sub-Cluster: Community and its wellbeing)

vi. Independent community (Sub-Cluster: Community and its wellbeing)

vii. Happy and motivated community (Sub-Cluster: Community and its well-being)

viii. Good understanding of ecotourism (Sub-Cluster: Community and its well-being)

Tourists did not mention many of the community and its well being indicators. This suggests that these respondents may not be interested in the outcome of local community participation. They would rather know that there is existing involvement and commitment from the community as indicated in the earlier 
analysis and consider this a success factor for local community participation. The tourists also do not consider conservation of the environment and development of infrastructure/site enhancement as a success factor for local community participation. This suggests that the environment factors do not play an important part in local community participation success as perhaps this is less relevant.

The analysis revealed that the type of stakeholders determined the content and perspective of the indicators suggested. Each stakeholder group has both similar and different context of indicator content but they are not totally dissimilar. Therefore it is further justified to cluster them together. The latter part of the analysis revealed the perspective of each stakeholder on their motives and how they view the indicators by analysing what they do not include as success indicators. It also reinforced the fact that each stakeholder is an individual, while all of them have similar opinions on what constitutes success for local community participation. This formed the basis of further analysis in the later sections.

\subsubsection{Analysis of Indicators by Stakeholders}

The analysis of indicators by stakeholders started with profiling the matrix as in Figure 6.5, and interpreting it. The local community has come up with the most indicators (10), followed by the government and NGOs (9), tourists (7) and businesses (4). During the interviews with the local community and the local community leaders, the respondents had a lot to say about the success of local community participation. This is due to the fact that they are involved in the process. Since they also live in the area, they know what has been changed or evolved, and judge the changes whether they are positive or negative or both. The local community, who is the main stakeholder, also have their own 
objectives to achieve through local community participation and they can suggest what to look for in identifying success based on their experiences.

The government and NGOs also have contributed many success indicators for local community participation. Both have been playing a large part in advocating and assisting local community participation in all sites. Community projects in Kampung Bavanggazo, Batu Puteh and Kampung Rantai have been supported largely by the government and NGOs, in terms of funding and expertise. The development of Sukau and the Rafflesia Information Centre also has their support.

The tourists also contributed some indicators for the success of local community participation. They are the guests/customers/visitors to the site and they know what they are looking for, in terms of local community participation. By being at the sites, staying there, and interacting with the local community, the tourists can develop a sense of the community, and therefore, find out if community participation is successful or not.

The business community, however, contributed the least indicators among all other stakeholders. The business focuses on maximising profits as their responsibility towards its own stakeholders. Therefore, community participation is usually in their agenda either as part of complying with industry standards and expectations, or as part of their social program after certain profit has been made. The social program is usually categorised under marketing. Because the focus is not on local community participation, they have little to say on the success of local community participation.

This indicates that the indicators are selected based on how close the stakeholders are to the process of local community participation. The local community definitely are able to come up with a lot of indicators as this is all 
about them. The government and NGOs also can contribute many indicators as their organisations are geared towards development based on their own interests and they are also working closely with the local community on participatory activities. The tourists also depend on the local community participation as part of their experience, which is the essence of tourism. Their experience leads to different levels of satisfaction or motivation for different people. The business contributed the least indicators, as they are normally not concerned with community development but in profit making.

Generally, indicators that are contributed by all stakeholders are relevant to the community and its well being. This is so because the number of these indicators supersedes the other two groups of indicators. However, there is a notable absence of indicators that are relevant to the environment side of ecotourism compared to the government and NGOs, and the businesses. The government and NGOs interviews and case studies revealed that their organisations do put emphasis on the environment; however, they do not see that reflected in local community participation. This does not mean that the government and NGOs think that the local community contribution to the environment is not important as a success indicator. It is rather that the success indicators are stronger based on the other two thematic groups, i.e. community well-being and business sides of ecotourism.

The business respondents hardly mentioned anything on the environment besides the fact that the environment is the basis of their product. Conservation of the environment theoretically ensured the longevity of the ecotourism product. However, the linkage between local community participation to the environment side of ecotourism that is relevant to the business community seems not important to the respondents. The business respondents also contributed the least number of success indicators. 
When the indicators are analysed further, the findings show that there are three significant outcomes for the indicators by stakeholders. These significant outcomes are drawn out from the group based on its frequency and its exclusivity (by stakeholders) and gives further insights to the indicators. These are as follows:

\section{Outcome 1}

A significant indicator in general terms is 'visible community involvement and commitment. This indicator is agreed by all stakeholders, which suggests that local community involvement and their commitment to the local participation process are essential in the stakeholders perception in success. They believe that the visibility of the involvement, in term of registration, active involvement, support in the program/events and being committee members are essential. This is purely a perception based on exterior outlook. It does not probe into the interior elements of participation, whether it is high involvement (decisionmaking) or low involvement (manipulative participation). This element, while the strongest among all indicators, is also shallow in its outlook.

\section{Outcome 2}

A significant group of indicators can be drawn exclusively from the local community. These are conservation of the environment, development of infrastructure/site enhancement and community development. This suggests that the local community believes strongly that their well-being (physical, spiritual and environmental) are essentials to their local community participation process and output, and deemed this as success indicators. This can be perceived that the local community are self-involved by protecting their self-interest. It is seen that the local community participation projects/process should be beneficial to the local community first and foremost before any other stakeholders. This is inline with the plans and policies outline in Chapter 4 where community development is the agenda in national and state level strategies. 


\section{Outcome 3}

A significant group of indicators were detected from the government and NGOs group. These group indicators are exclusive to this group, which are independent community, and happy and motivated community. Based on the content of the indicators, it is suggested that the elements are revolved on the exterior look of the community. Independent, happy and motivated are suggested by government and NGOs without any further thought on the details. It is possible to see independent community within local community participation by referring to Pretty and Arnstein participation theory. However, the indicator that specified a happy and motivated community is very subjective. There is no index that deals with happiness and motivation developed for local community in the smaller-scale. This research theoretical framework does not link this issue to the National Happiness Index developed by the Kingdom of Bhutan. It is also difficult to determine happiness and motivation over time for the community. All of this shows that the government and NGOs perceived that the success of local community participation is based on the output of the local community participation process which revolved around the exterior look of the community.

All these outcomes reinforced the fact that each of the stakeholders are different and have different perspective of success. Their perspective can be very exclusive to their own group as explained in outcomes 2 and 3 . While all of them may not have a common ground, there is one or two perspectives that they all agreed on, which in this case is 'visible community involvement and commitment'. This also reinforced that the shared success indicators are the strongest indicators as they reflect every group's perspective. 


\subsubsection{Indicators by Site}

Indicators by site are a group of indicators that has been developed that refers to a site. This analysis revealed which indicators are important to certain sites. Different sites may have different outlook on what is successful for local community participation. The research showed that out of 15 indicators, there are nine indicators that are specific to Kampung Bavanggazo, six to Batu Puteh, five to Kampung Rantai, Sukau and Rafflesia Information Centre. These are illustrated in Figure 6.6.

\subsubsection{Kampung Bavanggazo}

The local community at Kampung Bavanggazo suggested there are three indicators for the success of local community participation derived from the Bavanggazo Rungus Longhouse experience. The first indicator is visible community involvement and commitment. The villagers suggested that there is visible community involvement in the Bavanggazo Rungus Longhouse operations. All of the villagers are involved in the operations at various levels. A high level of commitment is also an indicator as there is visible effort and hard work put in by the community. The villagers at Kampung Bavanggazo still practice gotongroyong, which is an excellent example of high commitment of local community in working towards the success of the project.

The second indicator is the conservation of the surrounding environment at Kampung Bavanggazo. The ecotourism activity in the village has managed to put effort into conserving the Gomantong Hill area where the villagers' main water reservoir is located. The conservation of the environment is suggested to be important for Kampung Bavanggazo. 
The final indicator that has been suggested by the villagers is the development of infrastructure. Bavanggazo village has grown from a 9-room longhouse to a 10- room longhouse, three 1-bedroom chalets, reception and souvenir shop. Traditional deco is applied to give a local authentic look. The road to the village has also been upgraded from gravel to sealed road over the years with the assistance of the government.

The government and NGOs group suggested three indicators for Kampung Bavanggazo. The first indicator is the benefits received by the villagers. The respondents noted that the villagers were given employment opportunities when the Bavanggazo Rungus Longhouse started.

\section{Figure 6. 6 Indicators by Sites and Stakeholders}
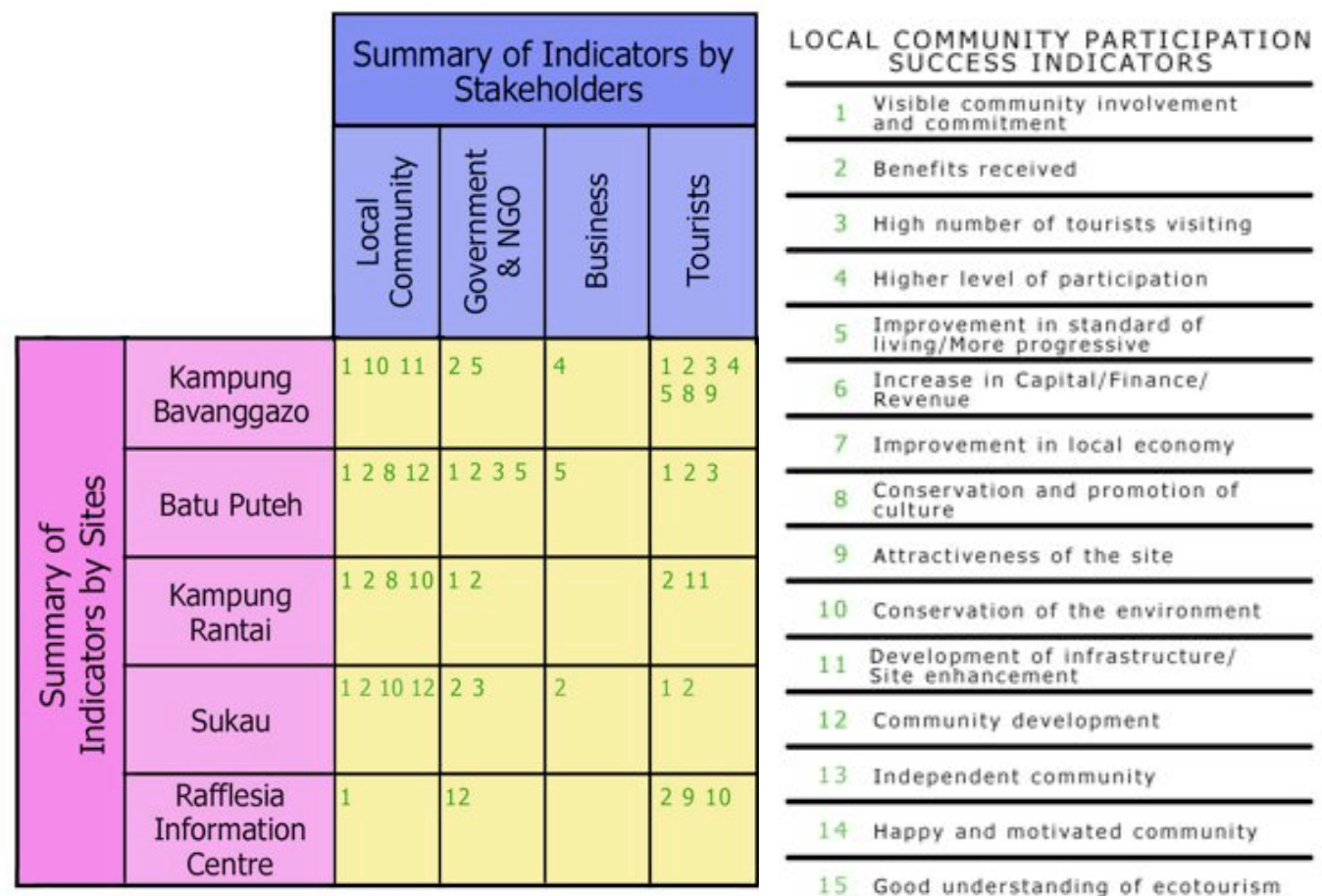

The second indicator is the improvement in standard of living. The government and NGOs groups suggested that there is an improvement in the standard of 
living that includes the village's economy, infrastructure, hygiene awareness and education.

The final indicator from the government and NGOs groups is the independence acquired by the local community from their participation in the ecotourism project. The government and relevant authorities provided provisions to assist the local community to start up Bavanggazo Rungus Longhouse operations when the community had a low capacity to run an ecotourism operation. However, the villagers have built their capacity and are now running their own operations.

The businesses suggested that the indicator for success of local community participation in Kampung Bavanggazo is the high level of involvement of the villagers in the ecotourism industry. In the Kampung Bavanggazo case, the whole village is involved in the operations of Bavanggazo Rungus Longhouse at various levels. There is visible community involvement and commitment there.

The tourists that came to visit Kampung Bavanggazo suggested seven indicators for the local community participation success. The first indicator is the visible community involvement and commitment at the village. They observed that the community work well together on the operations of Bavanggazo Rungus Longhouse. There is also high commitment towards the industry. The gotongroyong is regularly practiced once a week where tourists also joined in, and the local community put a lot of effort in running the place as a tourist destination as well as their home.

The second indicator is the benefits received by the villagers from the ecotourism industry. The most obvious benefit received by the villagers of Kampung Bavanggazo is the employment opportunity for all of them. Every one of the villagers is involved in the operations of the Bavanggazo Rungus Longhouse, and this has provided them with supplementary income. 
The third indicator is the high number of visitors coming to the village. The tourists observed that there is a high number of visitors coming to visit and stay at the Bavanggazo Rungus Longhouse. This indicated the popularity and attractiveness of the site.

The fourth indicator is the higher level of participation of the local community in the operations of Bavanggazo Rungus Longhouse. This high level is due to the local community owning and running the operations. They started with many forms of assistance from the STB and the Ministry of Tourism, Culture and Environment. After building their capacity, they are able to operate the longhouse on their own.

The fifth indicator is the improvement in the standard of living. In Kampung Bavanggazo, the improvement in the standard of living is not solely related to the economic improvement of the local community but to other aspects as well, such as the village's infrastructure, hygiene awareness and education.

The sixth indicator is the conservation and promotion of culture. The tourist suggested that the Bavanggazo Rungus Longhouse operation ensures that local customs and traditions are observed. Some of them are even revived like the traditional wedding ceremony.

The final indicator suggested by the tourists is the attractiveness of the site. The Bavanggazo Rungus Longhouse has been built and decorated based on traditional architecture and design. There is also an outlet where tourists can buy local handicrafts. Many people considered the beadwork of the Rungus people as the best in Sabah. These are definitely the factors that have made Kampung Bavanggazo an attractive site. 


\subsubsection{Batu Puteh}

The local community at Batu Puteh suggested that there are four indicators for local community participation in the ecotourism industry. The first indicator is the visible community involvement and commitment. The villagers suggested that this success indicator could be seen from daily activities such as villagers working on the operations of the industry. A high level of commitment is also suggested as an indicator when there is visible effort and hard work put by the villagers in the industry. The traditional gotong-royong that is still practised in Batu Puteh is an excellent example of the commitment to the local community participation activities by the villagers.

The second indicator is the benefits to the villagers themselves. They suggested that the employment opportunities for supplementary income are the main benefits for them. The main benefits received by the homestay program participants, i.e. Miso Walai, is not just in terms of income, but personal satisfaction as well. They also suggested that they benefited from the knowledge, skills and experience that they gained from the industry.

The third indicator is the conservation and promotion of culture. The Batu Puteh villagers suggested that the ecotourism industry has put their local (Sungai) customs and traditions, such as dancing, food and traditional livelihood at an international tourism circuit. They felt that it has given them a sense of achievement to know that their culture is known worldwide.

The final indicator from the villagers is community development that is encouraged by the ecotourism industry. The locals have come and worked together for the industry. They have put a collective effort to achieve personal objectives such as creating a better living for themselves and at the same time, achieving a collective objective such as conservation of the environment. This is 
proven by the creation of MESCOT 1997. This has created an environment where collective efforts are conducive, and they can learn from this for future local community participation projects.

The government and NGO suggested that there are four indicators of success in local community participation in Batu Puteh's ecotourism. The first indicator is the visible community involvement and commitment shown by the local community in Batu Puteh. They suggested that this success indicator could be seen from daily activities such as local community involvement in the operations of the industry. A high level of commitment is also suggested as an indicator when there is visible effort and cooperation among the local community in Batu Puteh.

The second indicator is the benefits received by the local community. They suggested that employment opportunities are the main benefits to them. The Miso Walai homestay program has created opportunities for the villagers to be micro-entrepreneurs. They suggested that they also benefited from the knowledge, skills and experience that they gained from training and development within the industry.

The third indicator is the high number of tourists that come to the Batu Puteh area. Since the Miso Walai homestay operations started in the month of June 2000 up till the end of year 2003, they had 1,200 bed nights and 2,600 people who went for wildlife watching trips. There are also a lot of repeat tourists to Batu Puteh. The government and NGO believed that the higher number of visitors, the more successful it is for local community participation efforts in Batu Puteh. The high number usually indicates the popularity and attractiveness of the site. 
The final indicator from the government and NGO is the improvement in the standard of living for the local community in the Batu Puteh. The Batu Puteh community involved in the Miso Walai homestay program enjoy the increase in improved infrastructure to their houses from MESCOT's soft loan. They also enjoy increased hygiene awareness and service skills.

The businesses suggested that ecotourism has assisted in progress for the locals at Batu Puteh. The ecotourism operations have encouraged many villagers to open up small businesses that support the industry such as making handicrafts, fish traps, gong and boats and this has provided supplementary income to their livelihood. The industry also encouraged the improvement of the locals' houses and their surroundings for the homestay program.

The tourists that came to Batu Puteh suggested that there are three indicators for local community participation in the ecotourism industry. The first indicator is the visible community involvement and commitment of the villagers in the industry. The visitors indicated that there are employment opportunities for the locals, and there are already locals working in the industry. They also indicated that the community program at Batu Puteh is working well. The tourists also noted that the villagers put a lot of effort and commitment towards the industry.

The second indicator is the benefits received by the local communities at Batu Puteh. Employment opportunities were presented with the creation of the ecotourism industry at Batu Puteh. Besides the opportunities of ecotourism businesses, the villagers are also having the opportunities to be involved in the homestay program. All of these brought and/or enhance their supplementary income.

The final indicator suggested by the tourist is the high number of visitors that visited Batu Puteh. The high number of visitors indicated the popularity of Batu 
Puteh to visitors both domestic and international. The tourists believe that the higher the number of visitors, the more successful it is for local community participation efforts.

\subsubsection{Kampung Rantai}

The villagers of Kampung Rantai suggested that there are four indicators for local community participation success based on their experience. The first indicator is the visible community involvement and commitment. This can be seen with the locals becoming members of MAMAKAT, and involving themselves in the decision-making (through village meeting) and operational side of the ecotourism industry.

The second indicator is the benefits received by the local community. The main benefit is employment opportunities where the local community can gain and increase their supplementary income.

The third indicator is the conservation and promotion of culture. The ecotourism industry helps ensure the Dusun customs and traditions of Kampung Rantai are observed and promoted to the visitors. This also helps in enhancing their handicrafts skill as ecotourism creates a niche market for it.

The final indicator suggested by the villagers is the conservation of the surrounding environment in Kampung Rantai. As mentioned previously in the case study, the villagers' livelihood depended on the water catchments in the Bundu Apin-Apin forest, and ecotourism helps to ensure the area is conserved. It has been gazetted as a Virgin Forest Reserve Class I. The local community suggested that the conservation of environment indicated successful local community efforts. 
There are two indicators that have been suggested by the government and NGOs groups for local community participation success in Kampung Rantai. The first indicator is the visible community involvement and commitment. There is visible evidence that the locals are working in the ecotourism industry seen from the villagers' daily activities as it has been integrated in the homestay program. There is also the MAMAKAT organization that coordinates the ecotourism industry at Kampung Rantai where the entire villagers are members. The traditional gotong-royong is also practised at Kampung Rantai.

The final indicator suggested by the government and NGOs group is the benefits received by the villagers. It provides employment opportunities for the villagers and increased their supplementary income. It also provides them with experience, knowledge and skills in the industry from their participation activities.

There is no specific indicator for local community participation at Kampung Rantai from the business respondents.

The tourists suggested there are two indicators for local community participation in Kampung Rantai. The first indicator is the benefits received by the local community from the participation activities. The villagers have the opportunity to work for their supplementary income, and be involved in relevant courses for self-development and skills with the creation of ecotourism industry in the village.

The second indicator is the development of infrastructure and site enhancement of Kampung Rantai. With the ecotourism industry in place, there are few facilities for the tourists built with local architecture and design. The village houses are improved for the homestay program, and the traditional medicine garden has been improved. 


\subsubsection{Sukau}

The villagers of Sukau suggested that there are four indicators for local community participation success based on their experience. The first indicator is the visible community involvement. Community involvement is at various levels. Some of the community are considered involved in the ecotourism industry as they are hired to work at the nearby ecolodges. There are also locals who run businesses such as ecolodges and convenience stores. Fairly recently, more local community became involved in the industry by participating in the homestay program.

The second indicator is the benefits received by the villagers. The benefit that the community has is the employment opportunities offered by the various ecolodges and tour operators that are operating in the village.

The third indicator is the conservation of the environment that surrounds Sukau. Various individuals and institutions already noted Sukau as an area with outstanding natural beauty. The high biodiversity of Sukau has made it a very valuable and a high quality ecotourism destination. However, the area surrounding it is encroached by the expansion of oil palm plantations, illegal loggings and shifting cultivation that pose threats to the biodiversity in the area. Therefore, the introduction of the ecotourism industry helps to conserve the area and its nature where laws are enforced on certain activities, and the ecotourism industry is slowly replacing the 'threatening' income generation activity such as through shifting cultivation. The local community also made an effort to work together to ensure that certain aspects of their environment are conserved and preserved. 
The final indicator that was suggested by the villagers is the community development at Sukau. The development of the community includes the development of the community as a whole and the development of individuals within the community. Recently, the villagers of Sukau have the experience of community development through the homestay program.

There are two indicators suggested by the government and NGOs groups. The first indicator is the benefits received by the local community. They suggested that employment opportunities are the main benefits to them. The recent creation of a homestay program created opportunities for the villagers to be a micro-entrepreneur. They also suggested that they also benefited from the knowledge, skills and experience that they gained from training and development within the industry.

The second indicator is the high number of tourists that come to Sukau. Sukau received a high number of visitors every year to the ecolodges that are available there. The government and NGOs believe that the higher number of visitors, the more successful it is for local community participation efforts in Sukau. The high number usually indicates the popularity and attractiveness of the site, which is the case of Sukau. It offers the iconic proboscis monkey and the river cruise activity that is very popular among the tourists.

There is one indicator for Sukau that was suggested from the business respondents. The only indicator is benefits received by the local community. The business mentioned that the ecotourism has provided employment opportunities to the locals.

The tourists that came to Sukau suggested that there are two indicators for local community participation in the ecotourism industry. The first indicator is the visible community involvement and commitment of the villagers in the industry. 
The visitors indicated that there are employment opportunities for the locals, especially for the youths to work at the ecolodges around Sukau.

The second indicator is the benefits received by the local communities at Sukau. Employment opportunities were created with the start of ecotourism industry in Sukau. The ecolodges are also buying goods and products from the villagers such as boats and food supplies.

\subsubsection{Rafflesia Information Centre}

The local community in the Tambunan area only suggested one indicator for local community participation success. The indicator is the visible community involvement and commitment in the Rafflesia Information Centre. The centre employed locals as their staff. The centre is a small and non-profit operation. There is only one indicator as there is no specific local community participation activity initiated by the centre.

The government and NGOs suggested that there is only one indicator of success for local community participation at the Rafflesia Information Centre. That indicator is community development. Community development here is more concentrated on the individuals within the community, especially with the locals that work with the centre. Individuals that work at the centre may improve themselves through knowledge, experience and skills gained from host-guest relationship. Experience from the industry has given them higher self-esteem and confidence, which is valuable in personal self-development.

There is no specific indicator for local community participation at Rafflesia Information Centre from the business respondents. The businesses do not have 
any linkages with the centre. They only use the centre as a small part of their package.

Tourists to Rafflesia Information Centre suggested three indicators for local community participation success. The first indicator is the benefits received by the local community from the surrounding areas. The locals are employed to run the centre, and also hired as rangers. Locals are ideal for the ranger job, as they know the place and its environment quite well.

The second indicator is the attractiveness of the site. The site attractiveness contributed to the fact that the area originally has an outstanding local environment. The area is protected with the status of Virgin Forest Reserve. This is an indicator that the place is well run by the locals.

The final indicator is the conservation of the environment. The local community supported the effort made by the Forestry Department to conserve the endangered Rafflesia flower. The effort is made with the awareness of the importance of the flower and its conservation.

\subsubsection{Analysis of Indicators by Site}

The analysis starts with identifying the thematic clusters for the indicators at specific sites. The first cluster is where the indicators are related to the community and its well being. The second cluster is where the indicators are related to the business aspects. The third cluster is where the indicators are related to the environmental aspects of ecotourism.

In Kampung Bavanggazo, there are nine indicators that are specific to the village. These are visible community involvement and commitment, benefits 
received, high number of tourists visiting, higher level of participation, improvement in standard of living, conservation and promotion of culture, attractiveness of the site, conservation of the environment and development of infrastructure/site enhancement. The indicators belong to three clusters. There are four indicators that belong to the community and its well being, and two indicators each that belong to both the business aspect and the environmental aspect. In Kampung Bavanggazo, this is a sign that the community aspect is the main emphasis of local community participation success, with almost an even/equal emphasis on business and environmental aspects. According to the case studies, the central focus on Kampung Bavanggazo is the community themselves where active efforts are made towards the business, especially on thandicraft, and the environment, where the water catchments need protecting.

In Batu Puteh, there are six indicators that are specific to the area. These are visible community involvement and commitment, benefits received, high number of tourists visiting, improvement in standard of living/more progressive, conservation and promotion of culture and community development. Indicators here belong to two clusters, which are the community and its well being and the business aspect. There are almost an equal number of both clusters, where there are four indicators that are relevant to the community aspect and three indicators that are relevant to the business aspect. This suggests that the success for this site emphasises the community and the business side of ecotourism. In Batu Puteh, the community involvement is active. The business of ecotourism has its boost recently with the launching of the cooperative KOPEL with new business ventures such as the ecolodges and boating services, in addition to Miso Walai Homestay. It is interesting that there is no indicator relevant to the environment especially since Batu Puteh is proactive in its reforestation program. 
In Kampung Rantai, there are five indicators that are specific to the area. These are visible community involvement and commitment, benefits received, conservation and promotion of culture, conservation of the environment and development of infrastructure/site enhancement. The indicators belong to all three clusters. There are three indicators that belong to the community aspect cluster and one each in both business and environmental aspect clusters. There are many indicators relevant to the community and its well being as in Kampung Rantai, local community participation, organised by MAMAKAT, is focused on the villagers' development.

In Sukau, there are five indicators that are specific to the area. These are visible community involvement and commitment, benefits received, high number of tourists visiting, conservation of the environment and community involvement. All of the indicators belong to the three clusters. Three indicators are relevant to the community and its well being, and one each relevant to both business and environmental aspects. There are many indicators relevant to the well being of the local community, suggesting that the community is still the focus for the success of local community participation even with the heavy presence of businesses. This is specific to the employment of the local community and the newly developed homestay project run by the locals.

In Rafflesia Information Centre, there are five indicators that are specific to the area. These are visible community involvement and commitment, benefits received, attractiveness of the site, conservation of the environment and community development. These indicators belong to only two clusters that are relevant to the community and its well being, and to the environment. The community, albeit limited in its participation, is involved by being hired as staff at the centre. Obviously, as the main purpose of the centre is to preserve the Rafflesia flower and educate the visitors on the importance of the flower and its conservation issues, it is no surprise that there are two indicators that are 
relevant to the environmental aspect but none from the business aspect. The government runs it and it is a non-profit making project.

Based on the analysis of indicators by sites, the rank of importance can be established as in Figure 6.7. The schedule shows an arrangement based on the logical sequence of the sites as proposed in the chapter on analytical framework. It gives rank of importance to each indicator based on the sequence and frequencies of responses given by stakeholders. The schedule suggests that there are two most important indicators, which are visible community involvement and commitment, and benefits received by the local community. It also suggested that the least important indicator is independent community.

The indicators that are site specific are i<llustrated in Figure 6.7. 
Eigure 6. 7 Indicators by Site

\begin{tabular}{|c|c|c|c|c|c|}
\hline $\begin{array}{l}\text { THEMES AND } \\
\text { SITES }\end{array}$ & $\begin{array}{c}\text { KAMPUNG } \\
\text { BAVANGGAZO } \\
\end{array}$ & BATU PUTEH & $\begin{array}{l}\text { KAMPUNG } \\
\text { RANTAI }\end{array}$ & SUKAU & $\begin{array}{l}\text { RAAFFESIA } \\
\text { INAORMAION } \\
\text { CENRE }\end{array}$ \\
\hline 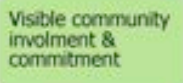 & $\tilde{\omega}$ & $\tilde{\omega}$ & $\tilde{\omega}$ & $\tilde{\omega}$ & $\tilde{\omega}$ \\
\hline Beneffits rececived & 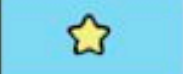 & 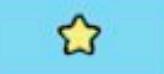 & $\tilde{\omega}$ & $\hat{\omega}$ & 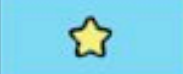 \\
\hline $\begin{array}{l}\text { Conservation of } \\
\text { the enviromment }\end{array}$ & 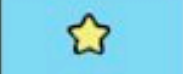 & & $\hat{\omega}$ & $\tilde{\omega}$ & $\hat{\omega}$ \\
\hline $\begin{array}{l}\text { Consenation and } \\
\text { promotoion of } \\
\text { culture }\end{array}$ & 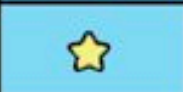 & 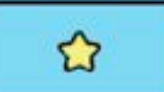 & 国 & & \\
\hline $\begin{array}{l}\text { High number of } \\
\text { tountsis visting }\end{array}$ & $\tilde{\omega}$ & 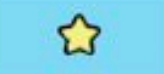 & & $\tilde{\omega}$ & \\
\hline 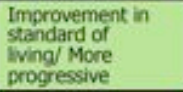 & $\hat{\omega}$ & $\tilde{\omega}$ & & & \\
\hline 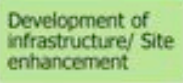 & $\tilde{\omega}$ & & 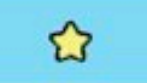 & & \\
\hline $\begin{array}{l}\text { Attractiveness } \\
\text { of the ste }\end{array}$ & 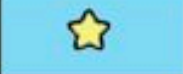 & & & & $\varepsilon$ \\
\hline $\begin{array}{l}\text { Community } \\
\text { oesertomente }\end{array}$ & & 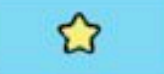 & & $\tilde{\omega}$ & \\
\hline $\begin{array}{l}\text { Higper lever of } \\
\text { particiostion }\end{array}$ & $\tilde{\omega}$ & & & & \\
\hline $\begin{array}{l}\text { Independent } \\
\text { communutyry }\end{array}$ & & & & & $\varepsilon$ \\
\hline
\end{tabular}

There are not many differences in the indicators by sites. The number of indicators suggested by each site ranges from five to nine, while the number of thematic clusters on the indicators from each site are evenly distributed. Little differences suggest that each site has similar experience in its local community participation process, therefore there are similar ideas on what success should be for local community participation.

Looking across the matrix in Figure 6.7, all the sites share two success indicators, which are visible community involvement and commitment, and benefits received. This shows that all sites suggested that these two indicators 
are important to their local community participation. A commonality like this suggested that these indicators are applicable to all sites, and own general traits that can easily be applicable to other sites. The idea of visible community involvement and commitment, and benefits received are the essentials for any local community participation project (Scheyvens, 2002). The most obvious involvement in all the sites is the employment of the local community. Indicators that are relevant to the community and their well being dominates all sites. This shows that the local community participation success is very much dependent on the focus to the locals and their well being that comes out with their participation.

Some sites differ in terms of the level of involvement. For instance, while the local community owned and operate the Bavanggazo Rungus Longhouse in Kampung Bavanggazo, the only involvement by the local community at Rafflesia Information Centre is working at the centre. This is the same that goes with benefits received. While the workers at Rafflesia Information Centre have jobs and earn their salaries, the locals at Kampung Bavanggazo became entrepreneurs, running their own business which provides income and added benefits such as personal development and improved village infrastructures. Therefore, there are definitely variations within the commonality in these two indicators. These variations are measurable and must be taken into account when making assessments of other sites with these indicators.

Based on the case study mentioned in Chapter 5, Kampung Bavanggazo has more experience in local community participation than any other sites. They started in the 90s and now independently manage the ecotourism operation. Therefore, it is no surprise that they have contributed more local community participation success indicators. This is followed by Batu Puteh which contributed six indicators. The Batu Puteh community also has a good ecotourism operation which started in the early 2000. However, the community has not been 
independent in its operation and are still relying on a NGO for assistance and relying heavily on outside funding. Therefore, it is understood that they contributed less indicators compared to the Kampung Bavanggazo. This concept is applied to Kampung Rantai, Sukau and Rafflesia Information Centre where these three sites are either new or do not have extensive local community participation, and hence have less indicators contributed. It is also no coincidence that the ranking of the villages based on the number of indicators contributed is similar to the logical sequence as mentioned in Methodology Chapter, i.e. Indicators Analysis Framework.

\subsection{Success Indicators: Research vs. Literature Review}

While this research attempts to develop indicators for Sabah with the selection of five sites as the case study, there are other previous studies that have developed similar success indicators. It is important to review both sets of the indicators from this research and the literature in order to establish consistency, applicability and to look for further insights into the indicators. The discussion in Chapter Two regarding the literature review that are relevant to the success factors in local community participation concludes that the success indicators focused on the output of the local community participation process such as local employment, the development of small businesses, effort in conservation, positive impacts and the increment of local benefits. The indicators are listed in Table 6.1.

When these indicators are compared to the research results, there are significant similarities in terms of the nature of the indicators. Local employment, conservation effort, positive impacts maximized and increasing local benefits are the shared indicators between this research and the literature review. This 
suggests that the indicators are not new and are applicable to other sites. However, upon closer inspection, these indicators are quite generic without any specific measurement to determine the level of success.

Table 6. 1 Local Community Participation Success from the Literature Review

\begin{tabular}{|l|l|l|l|}
\hline NO. & INDICATORS & MEASUREMENT & SOURCE \\
\hline 1. & Local employment & Higher Economic Multiplier & $\begin{array}{l}\text { Cater (1994) } \\
\text { National Ecotourism } \\
\text { Plan (1997) }\end{array}$ \\
\hline 2. & Small Business Development & Higher Economic Multiplier & Wild (1994) \\
\hline 3. & Conservation Effort & $\begin{array}{l}\text { Conservation effort } \\
\text { scale/existence }\end{array}$ & $\begin{array}{l}\text { Britton and Clark } \\
\text { (1987) } \\
\text { Kangas et. al (1995) } \\
\text { Oppermann (1993) }\end{array}$ \\
\hline 4. & Positive impacts maximized & $\begin{array}{l}\text { Planning and development } \\
\text { with full participation }\end{array}$ & Woodley (1993) \\
\hline 5. & Local and tourist need satisfied & $\begin{array}{l}\text { Role, affinity and utilization } \\
\text { of the community }\end{array}$ & Murphy (1985) \\
\hline 6. & Increasing local benefits & $\begin{array}{l}\text { Local benefits } \\
\text { - Local ownership } \\
\text { - Leasing to local } \\
\text { Partial ownership } \\
\text { Profit sharing }\end{array}$ & $\begin{array}{l}\text { National Ecotourism } \\
\text { Plan (1997) }\end{array}$ \\
\hline $\begin{array}{l}\text { Direct payment from } \\
\text { tourism revenue } \\
\text { Local involvement control } \\
\text { Decision-making }\end{array}$ & \\
\hline
\end{tabular}

Looking at the themes from the indicator success, three themes emerged which are 1) Local Community/Tourist and their well being, 2) Environment, and 3) Business. These themes are quite similar to the indicators developed through this research based on the earlier analysis. The themes for local community participation success from this research do not just cover the essential elements in ecotourism, i.e. conservation and well being of the local community but include environment and business practices. While it is clear that the community 
and its well being issues are regarded as more important by the respondents than the business and environment based on the number of indicators, it is difficult to determine this based on the indicators from the literature since the number of indicators is quite small.

Based on the analysis by stakeholders, the local community participation's indicators content are determined by the stakeholders. This has been shown in the earlier section where each stakeholder has both similar and different context of the indicator's content but they are not totally dissimilar when they are clustered together. This is reinforced in the analysis by the stakeholders where it suggested that each of the stakeholders is different and has a different perspective of success where each perspective can be very exclusive to its own group. While all of them may not have a common ground, there are one or two perspectives that they all agreed on, which in this case is 'visible community involvement and commitment'. This also reinforced that the shared success indicators are the strongest indicators as it reflects every group's perspective. However, the local community participation success indicators developed from the literature review does not indicate this. Most of parameters used suggested that the indicators are output based. With the exception of the National Ecotourism Plan (1997), each indicator is suggested by different stakeholders i.e. local employment (Cater, 1994), small business development (Wild, 1994) or conservation (Brittion and Clark, 1987; Kangas et. al., 1995; Oppermann, 1993). This draws similarities with the local community participation success from the research where each stakeholder is different but may agree to few perspectives.

Based on the analysis of indicators by site, it suggested that there are two most important indicators, which are visible community involvement and commitment, and benefits received by the local community. It also suggested that the least important indicator is independent community. The literature review also suggested indicators that related to the local benefits received and further 
specified local ownership, leasing to the local community, partial ownership and profit sharing. The local ownership aspect can be interpreted to an independent community where it is the least important indicator from this research. However, the most important one from this part of the analysis, which is visible community involvement and commitment, is not specified per se in the literature review.

There are other indicators that have not been mentioned in this research such as small business development and satisfied needs of tourists and locals which exist in the literature. However, these two indicators are not completely alien to the indicators developed by this research as it can fit into some of the indicators, based on individual interpretation. On the other hand, this research has come up with more indicators compared to the group on indicators from the literature review, but more specific and generally covering the same issues, i.e. community development, business and conservation. This suggests that localised cases such as this may produce more specific success indicators. It is logical that the development of indicators should be more comprehensive when involving a specific site.

\subsection{Discussion and Conclusion}

As discussed in the literature review in Chapter Two, many writers advocate local community participation in ecotourism, and they all agreed that it is a critical component of success for ecotourism. It is suggested that the success of ecotourism depends largely on local community participation. The Malaysian government also recognises that the creation and involvement of local stakeholders (individuals and communities), with the emphasis on local investment, control and decision-making, is essential to ensure successful ecotourism (National Ecotourism Plan, 1997). 
The five research sites that are selected in this research present five scenarios in the local community participation process with some similarities. Variables such as ownership, size, accessibility, outsiders' involvement and so on are very important in determining the perception of success. However, all of these sites were selected based on the criteria discussed in Chapter Three. Therefore, it is acceptable to use thematic clusters to identify success, where similarities are drawn from all sites. The first thematic cluster is the success based on stakeholders' groups as featured in Figure 6.4. This shows similarities of success based on each of the stakeholders' point of view. This has resulted in a long list of success themes. A further arrangement of these themes into a matrix, the frequency of occurrence based on stakeholders can be made. This determines the importance of each theme as an indicator.

A set of success indicators for local community participation is the outcome from this research. The data collected from the field has suggested 15 general indicators that are useful as a base data for further development of indicators as illustrated in Figure 6.3. The analysis of the indicators by theme revealed that there are three clusters of indicators. The first group is related to the community and its well being. The second group is related to the business side of ecotourism. The third group is related to the environment side of ecotourism. The indicators that are related to the community and its well-being are visible community involvement and commitment, benefits received, higher level of participation, improvement in standard of living/more progressive, conservation and promotion of culture, community development, independent community, happy and motivated community, and good understanding of ecotourism. The indicators that are related to the business side of ecotourism are the high number of tourists visiting, increase in capital/finance/revenue, and improvement in local economy. Finally, the indicators that are related to the environment side of ecotourism are attractiveness of the site, conservation of the environment and development of infrastructure/site enhancement. 
The most important success indicator determined by this research is the visibility of community involvement and their commitment towards local community participation efforts. This has been suggested through both analysis of indicators by stakeholder and site. Both rated this indicator as an indicator with the highest importance. This is also the only indicator that has been suggested by every stakeholder in every site! However, there are some indicators that are specific to certain stakeholders. This shows the relationship between what the stakeholders perceive as success based on their individual motives and the success of local community participation in general.

Back to the literature review, the operational ecotourism includes the elements of environment, conservation, tourism experience, and the well being of the local community involved. The two groups of indicators that are related to community and environment have relevancy in the operational ecotourism definition where there is emphasis on environment and its conservation effort, while providing beneficially active socio-economic involvement of local populations. Since the cluster theme includes business elements in it, the perception of success has gone beyond the theoretical definition of ecotourism where the community and environment are traditionally the essential elements. This research suggests that while the community and environment element is essential in ecotourism, the business elements are as important as the other two.

The analysis of indicators by stakeholder and site has come up with interesting results. Both have come up with their own rank of indicators that are based on the importance of each indicator. The indicator's importance is pre-determined using the logical sequence of stakeholders and sites based on prominent characteristics of both variables that contribute the most to local community participation. However, both ranks are not comparable to each other. This is where indicator importance can be seen through different perspectives. This 
research revealed that the size of the indicators contributed is based on how close the stakeholders are to the process of local community participation at the ecotourism site. Based on this analysis, the research revealed that, while all stakeholders are different and with different perspectives of the issues, the indicators contributed by them consist mainly of those relevant to the community and its well being with 'visible community involvement and commitment' as the strongest indicator.

The analysis by stakeholders revealed that the local community participation's indicators content is determined by the stakeholders. This result is further consolidated in the further analysis of the stakeholders where the analysis suggested that each of the stakeholders is different and has a different perspective of success where each perspective can be very exclusive to its own group. The research also revealed that the shared success indicators are the strongest indicators as they reflect every group's perspective. In this part of the analysis, the stakeholders agreed that 'visible community involvement and commitment' is the strongest indicator.

The analysis of indicators by site suggested that Kampung Bavanggazo local participation process has its concentration in the community, where many of the indicators that are specific to Kampung Bavanggazo mainly belong to the 'community and its well being' cluster. In Batu Puteh it is divided almost equally to 'community and its well being' and 'business' cluster. For Kampung Rantai and Sukau, the indicators mainly belong to the 'community and its well being', while for Rafflesia Information Centre, the indicators are divided almost equally to 'community and its well being' and 'environment cluster. This research suggests that the success indicators that are specific to the sites are mainly concerned on the community and the well-being of that community. 
Compared to the indicators that have been drawn out from literature review, it shows similarities. This suggests that the research results are consistent with other researches. This also suggests that the indicators are not new and are applicable to other sites. However, it is also noted that these indicators are still quite generic and there is the need explore on the content, i.e. measurement, parameters, content etc. Since the indicators are output based, they are measurable and some are quantifiable. However, this issue is not explored in this research as the indicators from this research emerged from the approach as outlined in the research methodology and not pre-determined. Further research that can determine the measurable and quantifiable characteristics (parameters) of success for local community participation should be useful as an extension to this research.

In conclusion, this research suggests that the indicators developed are still within the perspective of ecotourism. Based on the indicators' analysis framework, it is found that, while all stakeholders are different and hold different perspectives of success, the shared success indicators are the strongest indicators as every group agrees to it. The analysis of success indicators by both stakeholders and sites suggested that the success indicators that are specific to the sites are mainly concerned on the community and the well-being of that community, as many of the indicators contributed by them consist mainly of those relevant to that issues. This shows that the result of this analysis is consistent with the literature review and when compared to every angle of the analysis. 


\title{
CHAPTER 7. ECOTOURISM SITE SUCCESS
}

\subsection{Introduction}

\subsubsection{Introduction to the Chapter}

The second research issue for this thesis to address is to interpret and develop the indicators for success of ecotourism sites in Sabah. To recap, the operational definition of ecotourism selected for this research is illustrated to give the background of what an ecotourism site amounts to. The definition is adapted from the World Conservation Union (1996).

\begin{abstract}
'Ecotourism is environmentally responsible travel and visitation to relatively undisturbed natural areas, in order to enjoy and appreciate nature (and any accompanying cultural features both past and present) that promotes conservation, has low negative visitor impact, and provides for beneficially active socio-economic involvement of local populations'.
\end{abstract}

Therefore, the ecotourism site in this context is viewed as the site that has an ecotourism operation that fits the definition by the World Conservation Union and has been selected earlier based on the set criteria that were developed based on the literature review.

Success in general is often perceived as objective criteria subject to quantifiable analysis. In the ecotourism industry, success is usually based on the desired outcomes and achievement from the operations. Success is mainly grounded in the perception of individuals. McKercher (1998) have outlined the success factors 
for ecotourism businesses based on the business attributes itself such as business planning, marketing, market research, operational issues, ethical and environmental issues, and personal (operators) issues. Ecotourism business survival usually depends on the chance of learning the necessary skills to stay in business.

Path to success for ecotourism sites can also be closely indicated to ecotourism accreditation. Accreditation is usually used for benchmarking excellence of ecotourism operations (National Ecotourism Plan, 1997). There are a few award schemes such as Green Flag International, and the World Travel and Tourism Council's Green Globe but these are not awarded on a wide scale. Excellence that achieves accreditation is usually based on the standard of accommodation grounded in conventional and sustainable classification, integration of ecotourism concepts on the tour operations and the quality of destinations.

Based on the literature review, ecotourism should promote the conservation of natural resources and also provide financial gain for the host country and the local people (Ashton, 1991; Emmons, 1991; Cater; 1994). Schevyns (1999) argues that ecotourism ventures should only be considered 'successful' if local communities have some measure of control and share equitably in the benefits. This suggests that the outcomes of the ecotourism operations determine the success of the site.

This chapter presents the analysis of indicators for ecotourism site success. Firstly, the indicators are developed based on emerging themes. After that, they are further analysed according to stakeholders, then by sites. Discussion of the indicators analysis follows suit and concluded at the end of the chapter.

As mentioned in the previous chapter, the principal purpose of the indicators that are developed from this research is to help stakeholders learn how to assess the 
success of an ecotourism site. Stakeholders may use these indicators to develop practical ways to measure success, ensure efforts are justifiably spent, and appropriate strategies and activities are carried out. The stakeholders may be interested in learning the output of the activities and the outcome to the outputs in the short and long term.

\subsubsection{Indicators' Analysis Framework}

The identification of indicators for ecotourism site success also raises the issue of the rank of importance, the same issue in identifying indicators for local community participation. The indicators in this chapter are based on the data collected during fieldwork. This chapter also uses the same indicators' analysis framework as in the previous chapter.

As in the methodology chapter, the logical sequence of variables presents the sequences based on stakeholders and sites. The stakeholders' sequence is based on the amount of involvement and effect from ecotourism operations. The most important stakeholder in the sequence is the one that is the most involved and most affected by ecotourism. The sites' sequence is based on the initiative for ecotourism sites. The most important site in the sequence is the one that has the most initiative in ecotourism operations and that emphasise the important elements in the operational definition i.e. environment and local community. The rank of both variable sequences as in Figure 6.1 and 6.2 is unchanged for the usage of this chapter.

The set of indicators developed from this research will be compared with another set of local community participation success indicators that are drawn from the literature review to establish consistency and further analysed the indicators. 


\subsection{Research Findings - General Indicators}

\subsubsection{Introduction}

The fieldwork done has resulted in a lot of useful primary data for interpreting the success of ecotourism sites. It also provided first-hand information and the impression of ecotourism sites. Additional data is provided through supplementary data from qualitative observations. There are various dimensions of success at all sites, and this is explored further towards the end of the chapter. Based on data analysis, the results were then systematically interpreted and a thematic framework produced where the same procedure was employed to identify local community participation success indicators. This has been outlined in the methodology chapter and the same procedure also makes it easier for both success indicators, i.e. local community participation vs. ecotourism site, to be comparatively analyzed.

\subsubsection{Indicators in General}

Based on the collected data, the success indicators for ecotourism sites are divided into three groups. The indicators are first grouped based on the emerging themes as in Figure 7.1. These indicators are developed first to establish a base set for further analysis.

The second and third groups of indicators are used for analysis. The indicators are analysed based on stakeholders and sites. The second group of indicators are divided based on stakeholders. These are the indicators perceived by stakeholders as what constitute success for ecotourism sites. The third group of indicators are divided based on sites. These are the indicators referred 
specifically to a site. The indicators for each site are further subdivided based on its respondents.

\subsubsection{Indicators by Theme}

There are 21 indicators for ecotourism site success that emerged from the fieldwork of this research based on the survey and interviews with respondents (Figure 7.1). At this stage, the indicators are clustered into emerging themes. They will be the basis of the indicators analysis that is done in the later section of this chapter.

Similar to the previous set of indicators presented in Chapter Six, these indicators have been clustered based on the emerging themes. It is neutral in a way that it does not follow any type of sequence system, as there is no rank of importance established for each indicator during the thematic clustering process. This is also useful in avoiding confusion and overlapping of the analysis process in later sections. This section documents the indicators that emerged from all sources. Some of the indicators will be accompanied by quotes from stakeholders derived from the interviews to emphasise the point of the indicators.

The first indicator is visible and high level of local community participation in the ecotourism site. The local community displays good cooperation and demonstrates a spirit of unity among themselves in many instances such as in gotong-royong events, and their support towards organizations (MESCOT and MAMAKAT) that run the ecotourism operations. The homestay program usually demonstrates high visible local community participation, especially during its homestay activities where villagers and hosts alike take part. Within the participation process, the level of participation indicated the success of an ecotourism site. Most of the stakeholders suggested that a higher level of participation indicates greater success of a site. A government respondent said 
"it is good to see the villager slowly learning the trade and eventually getting more involved in the ecotourism operation". 
Eigure 7 1 Ecotourism Site Success Indicators

\begin{tabular}{|c|c|}
\hline \multicolumn{2}{|r|}{$\begin{array}{l}\text { ECOTOURISM SITE } \\
\text { SUCCESS INDICATORS }\end{array}$} \\
\hline 1 & $\begin{array}{l}\text { Visible local community participation/ } \\
\text { High level of participation }\end{array}$ \\
\hline 2 & High number of tourists \\
\hline 3 & Well-managed site \\
\hline 4 & Clear improvement in life and livelihood \\
\hline 5 & Improvement to infrastructures \\
\hline 6 & Meeting objectives \\
\hline 7 & Good cooperation among stakeholders \\
\hline 8 & $\begin{array}{l}\text { Practice good ecotourism management/ } \\
\text { Sustainable in every way }\end{array}$ \\
\hline 9 & Promote conservation of natural resources \\
\hline 10 & Preservation of culture \\
\hline 11 & Number of ecotourism establishment \\
\hline 12 & Happy and motivated community \\
\hline 13 & Benefits to community \\
\hline 14 & Being informative and educational \\
\hline 15 & Satisfied tourists \\
\hline 16 & Links to other good tourism site \\
\hline 17 & Good high quality ecotourism products \\
\hline 18 & High reputation \\
\hline 19 & Properly developed site \\
\hline 20 & Ability to draw interest with a 'wow' factor \\
\hline 21 & Ability to capitalise strengths \\
\hline
\end{tabular}


The second indicator is the high number of tourists. Most of the stakeholders suggested that a high number of tourists is an indicator of a successful ecotourism site. The high number suggests a strong pull attraction of the site and an ability to attract a high number of tourists to the place. A villager simply said "the more (tourists that come), the better (it is for business)"

The third indicator is a well-managed site. A well-managed site shows that the site is properly maintained and operated as a profitable business entity. The strengths of the site are enhanced and the weaknesses are minimised. The site is also a business operation; thus, it has to be profitable to be financially sustainable. The financial sustainability ensures the longevity of the operation.

The fourth indicator is improvement to the local community's standard of living. Many of the stakeholders suggest that improvement of the living standard of the community at the site indicates a successful ecotourism site. The local community noticed that there is an increase in their income with the ecotourism experience. Tourists may see this happening by comparing one site to another site previously visited by them, or when they come again to the same site. The improvement may come from the opportunity created by the industry, such as employment and business opportunities. One of the Batu Puteh villagers observed, "... It is evidential that we have a different and better lifestyle now, especially with basic and daily needs..."

The fifth indicator is the improvement to infrastructure. Infrastructure is improved with the introduction of ecotourism where it needs to have better access (land, water, air) and facilities such as jetties, village halls, headquarters and so on. This indicates that ecotourism is progressing well and growing. Improvements to infrastructures are usually needed to cater for current and future needs. The manager of Bavanggazo Rungus Longhouse stated, "...with 
the creation of Bavanggazo Rungus Longhouse, we were able to get funding to improve the road and build a better bridge for the benefit of the tourist and the villager too..."

The sixth indicator is seeing that the ecotourism project objectives are met. In every ecotourism venture, there is usually a set of objectives that set the operation's direction, which are specific to a site and may vary from site to site. Stakeholders normally strive to meet these objectives and when they do, the site is considered successful.

The seventh indicator is good cooperation among stakeholders. The success of ecotourism largely depends on the good relationships between its stakeholders. Ecotourism stakeholders have their own important role to play within the industry. Conflicts among stakeholders can cause problems to the industry, and good support from every one of them indicates the site is successful. A good example is when an NGO respondent observed, "...if there is a comparison between Kampung Bavanggazo and Kampung Tinangol (a neighbouring rival), there are more participative elements in the handicraft industry in Kampung Bavanggazo. This is because of the exposure through assistance from Sabah Tourism Board..."

The eighth indicator is good ecotourism management practice and sustainability in every way. The ecotourism concept requires certain practices to be observed. Many sites employ these eco-practices as part of their ecotourism operation. The implementation of the 3Rs (Recycle, Reduce and Reuse) is a standard environmental practice. Some sites have projects that try to conserve the environment. Ecotourism sites may also have programs and activities that involve the local community to ensure the locals' well being. A business operator in Sukau proudly mentioned, "...We are practising environmentally friendly practices, which include using electricity from solar-powered generator to heat 
up our water heater, or using battery-operated engine for boats so that there is no noise pollution. We even recycle our used cooking oil to light candles for dining tables in the evening..."

The ninth indicator is the conservation of the environment. Natural resources are the basis of the ecotourism product, and their conservation is essential for the environmental cause (including the local community) and to sustain the industry. Some sites have efforts to conserve the environment that incorporate the stakeholders including tourists. Most of the sites use ecotourism as a tool for conservation of the surrounding areas. The conservation of the environment is an indicator of a successful ecotourism site. Conservation is essential to the Rafflesia Information Centre as one of the scientists working there puts it "...it is an endangered species and it is our duty to conserve the flower. We need to educate the visitors on how important the flower is to biodiversity and the effort needed to conserve it..."

The tenth indicator is preservation of culture. Culture can be preserved with the creation of ecotourism. Ecotourism promotes local culture as one of the products. A lot of cultures have changed through the process of modernisation. Ecotourism has started a trend where the local community revived some aspect of their culture that has not been practised for many years. The ecotourism industry also reinforces the culture of the local community where it creates a platform for the locals to practice and exhibit their culture for the tourists. The preservation of culture through ecotourism is a success indicator of an ecotourism site.

The eleventh indicator is the number of ecotourism establishments. This indicator takes into account the number of ecotourism establishment available at the site. The more there are, the more successful the site is. The high number of 
ecolodges available in one site shows the high intensity of the ecotourism business there.

The twelfth indicator is a happy and motivated community. If the local community is motivated to be involved, put some effort into the industry and are happy with the way ecotourism is operating in their area, it is considered a successful ecotourism site. The stakeholders agree that there must be a win-win situation for any ecotourism venture, where everybody is happy with the process and outcome of the ventures. One business respondent pointed out "... there is no point in developing a site if the community does not want it. They must be happy with what they are doing and they become motivated to work harder..."

The thirteenth indicator is the benefits to the community. There are many aspects of benefits that the community can receive through ecotourism. These are collective benefits such as employment opportunities, culture appreciation and meeting new people. There are also individual benefits such as income earned from ecotourism, valuable experience and self-appreciation. An ecotourism site that generates benefits to the community is a successful ecotourism site. A tour operator said, "...we prefer to hire the locals not just because it is good practice, but they also know the area, and we buy our supplies such as food from them too..."

The fourteenth indicator is information and education. Awareness is an important element in ecotourism. The stakeholders including the tourists should know why ecotourism operates in such a way. They must know the value of conservation and how they can contribute to it. Awareness is usually done through information dissemination and education. An ecotourism site usually has facilities or programs for this. Designated key persons, such as local leaders or guides, can promote awareness through relevant talks. Interpretation centres are also useful for self-guided education process. 
The fifteenth indicator is a satisfied tourist. A successful ecotourism site must meet the expectations of its clients or visitors, the tourists. Ecotourists come to the site with a set of expectations that include the availability of a pristine environment to experience along with cultural activities with the locals. Ecotourism products such as the flora and fauna, geographical features and culture must be of high quality. Therefore, a satisfied tourist will find that his/her expectations are met or exceeded, and that indicates the ecotourism site is successful. A tourist that visited Rafflesia Information Centre quoted "...it is good to know the local community is hired to become guides here..."

The sixteenth indicator is a link to other good tourist sites. The main tourist site may tie up with other tourist sites for better and more enriching experiences, and give opportunities for tourists to extend their stay. The site becomes an icon for the area. For example, Bavanggazo Rungus Longhouse is the main attraction for Kudat District, and it has been attracting tourists to come to the district, which is benefiting other tourist sites as well. It is also the same case with Sukau, which is the main site for ecotourism in the Lower Kinabatangan Floodplains. Other sites such as Gomantong Cave and Kampung Bilit benefited from being associated with Sukau by having tourists make side trips there.

The seventeenth indicator is a good high quality ecotourism product. There are many aspects of a high quality ecotourism product. Most of the sites have a main product. Kampung Bavanggazo has its Bavanggazo Rungus Longhouse, Batu Puteh has the Miso Walai homestay, Sukau has Proboscis monkeys, and Rafflesia Information Centre has the Rafflesia flower. The Rungus Longhouse and the Miso Walai Homestay are unique. The Proboscis monkey is endemic to Sabah, while the Rafflesia flower is an endangered species, which make both very valuable in terms of its tourist value. The high-biodiversity, the uniqueness of the 
people, area and product all make for a high quality ecotourism product. This is an indicator of a successful ecotourism site.

The eighteenth indicator is high reputation. Some of the sites enjoy a high profile and international reputation. It is usually a combination of the stakeholders' efforts to develop and promote the site. A high reputation is successfully achieved to some extent. This will contribute further to the success of the site in future. A government respondent mentioned that, "...if you mention ecotourism, people will think of Sukau and that is a good thing..."

The nineteenth indicator is a properly developed site. A well-planned site is a pathway/ roadmap to a successful site. A properly developed site ensures that the goals and objectives of the site are achieved in due course. A well-planned site maximises the benefits received in an area and by its population. It also minimises the adverse impacts to the environment and the people that live in that area. The site will also be sustainable and most probably have a long life cycle. This is an indicator of a successful ecotourism site.

The twentieth indicator is the ability to draw interest with a 'wow' factor. A site that has the potential to draw interest is considered a successful site. This can be contributed to the tourism assets that they have. Tourism assets may be of high quality and unique and there is also good promotional effort put into it. The high quality and uniqueness of tourism assets contribute to the 'wow' factor of a site. As one government respondent put it "...a site has to be a 'must-stop' site such as Kudat and Kota Belud. There must be interests in the site added by the 'wow' factor..."

The twenty-first indicator is the ability to capitalise on strengths. Every site has its strengths and weaknesses. It can also identify its opportunities and threats. From these four elements, a site will know how to capitalise on its strengths to 
get an 'edge' in the ecotourism industry. A site may choose to be 'value for money' to attract more budget ecotourists. It also may choose to target the luxury market based on their products to reduce the number of tourists to within its carrying capacity and yet increase the number of tourist dollars coming to the site at the same time.

\section{Indicators' Themes and Cluster}

All of the themes can be further subdivided into three sub-clusters based on the nature of its characteristics. The first cluster is a group of indicators that are related to the meaning and aspiration of ecotourism. The second cluster is a group of indicators that are related to the business aspects of ecotourism. The third cluster is a group of indicators that are related to the social development of the site. All of these sub-clusters are illustrated in the diagram below on Figure 7.2 .

The first cluster where the indicators are related to the meaning of ecotourism includes visible local community participation/high level of participation, practice good ecotourism management/sustainable in every way, conservation of the environment, preservation of culture, benefits to the community, informative and educational, and properly developed site.

The second cluster where the indicators are related to the business aspects of ecotourism includes high number of tourists, well-managed site, meeting objectives, good cooperation among stakeholders, number of ecotourism establishments, satisfied tourists, links to other good tourism sites, good high quality ecotourism products, high reputation, ability to draw interest with a 'wow' factor, and ability to capitalise on strengths. 
The third cluster where the indicators are related to the social development of the site includes improvement to infrastructures, clear improvement in life and livelihood, and happy and motivated community.

The themes for ecotourism site success do not just cover the essential elements in ecotourism, i.e. conservation and social development of the community, but extend to business practices. This suggests that the practice of ecotourism and its perception of success in this research are broader and go beyond the theoretical definition. There are seven indicators that are related to the ecotourism meaning and aspiration, and there are three indicators that are related to the social development of the site. However, there are eleven indicators that are relevant to the business aspect of ecotourism. This suggests that the success of ecotourism sites depends much on the success of its business operations. These indicators can be further explored and justified through the linkage of the site scenario from the field and the case studies, and used in the analysis of the indicators. 


\section{Figure 7. 2 Three Sub-Clusters of Local Community Participation}

\section{Success Indicators}

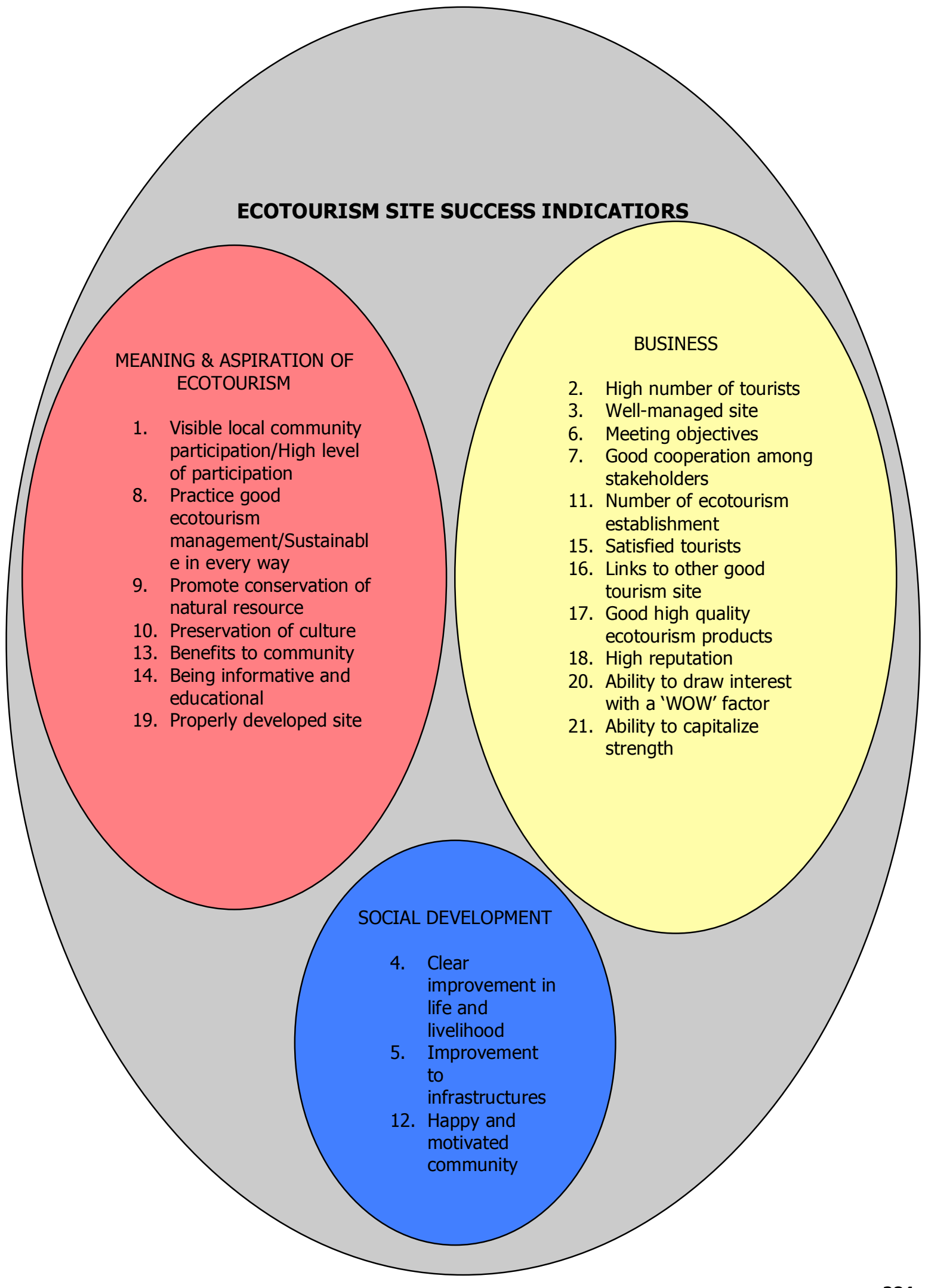




\subsection{Analysis of Indicators}

\subsubsection{Introduction}

The analysis of indicators started by grouping the indicators into two. They are: 1) Indicators by stakeholder, and 2) Indicators by site. Both groups of indicators are analysed as both present different views of the indicators. The indicators have to be analysed by the main two variables, i.e. stakeholders and sites. These variables are the basis to analyse the indicator importance. The assumption is that different stakeholders have different views of success and it is important to distinguish which indicators are more important than the others. This assumption is applied to the analysis based on sites, where each site may suggest different views of success.

Indicators by stakeholders are a group of indicators that have been developed and divided into each group of stakeholders for analysis purpose. Indicators by site are a group of indicators that has been developed from every respondent and it is specifically mentioned with regards to a site. The analysis is done based on the analysis framework that was mentioned at the beginning of this chapter.

\subsubsection{Indicators by Stakeholders}

The research revealed that out of 21 indicators, the local community suggested seven of them. Both government and NGOs groups suggested 12 indicators, and the business group has come up with the least indicators, only seven. The tourists suggested the most indicators, 15 all together. These are illustrated in Figure 7.3. 


\section{Figure 7. 3 Indicators by Stakeholders}

\begin{tabular}{|c|c|c|c|c|}
\hline 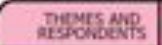 & choghinr & 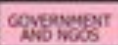 & susvess & Towersts \\
\hline 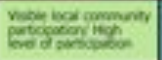 & 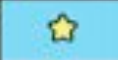 & $\vec{b}$ & 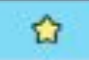 & $\Omega$ \\
\hline conterpestorion & 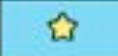 & 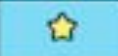 & $\hat{\omega}$ & {$[3$} \\
\hline 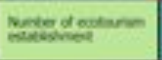 & 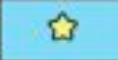 & 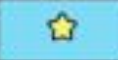 & $\Leftrightarrow$ & \\
\hline ourmpentin & 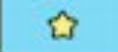 & $\Omega$ & 勻 & \\
\hline Lantors & 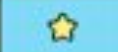 & 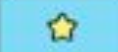 & & 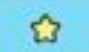 \\
\hline 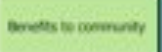 & 凸了 & & & {$[B$} \\
\hline 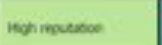 & 它 & & & 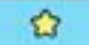 \\
\hline mos & & 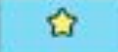 & 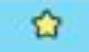 & \\
\hline monatin & & 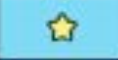 & & $\Leftrightarrow$ \\
\hline 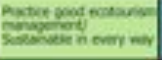 & & 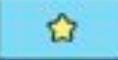 & & 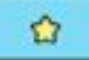 \\
\hline 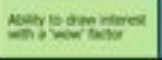 & & $\Omega$ & & 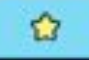 \\
\hline sment & & & $\hat{\omega}$ & 3 \\
\hline momenent abour & & & 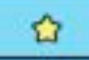 & 5 \\
\hline 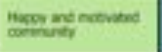 & & $\hat{\omega}$ & & \\
\hline 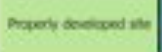 & & 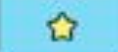 & & \\
\hline Nerisos & & $\widehat{\omega}$ & & \\
\hline 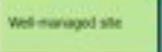 & & & & 四 \\
\hline 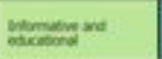 & & & & 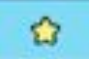 \\
\hline sentencouss & & & & \{ \\
\hline mand & & & & $\Omega$ \\
\hline 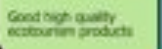 & & & & 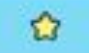 \\
\hline
\end{tabular}

The first indicator is visible local community participation (Sub-Cluster: Meaning of Ecotourism) including the level of participation by the local community. All stakeholders suggested this indicator. A successful ecotourism site should involve local community at certain levels. The number of community members that are involved with ecotourism and their level of participation are also indicators of success for an ecotourism site. The issue is further expanded that the local community should understand their role in their participation and their 
expectations must be realistic. The participation involved here refers not just to employment but is extended to various levels including decision-making. This indicator is very similar to the success indicator for local community participation that was discussed in Chapter 6.

The second indicator is good cooperation among stakeholders involved with the site (Sub-Cluster: Business). All the stakeholders suggested this. The success of ecotourism largely depends on the good relationship between the stakeholders. Ecotourism operations usually involve more than a single stakeholder. Within the sites in this research, there is usually good coordination efforts among stakeholders. Ecotourism advocates, the government, NGOs, local community and businesses, all have their own important roles to play, and depend on each other to make the industry work. Conflicts can cause problems in operations and process, and good support from every stakeholder indicates the site is successful. Tourists may observe non-conflict environment and visible unity among stakeholders as a success for a site.

The third indicator is the number of ecotourism establishments at a site (SubCluster: Business). The local community, government and NGOs, and the business respondents suggested this indicator. It takes into account the number of ecotourism establishments available at the site. The more there are, the more successful the site is. Ecolodges in Sukau are mainly owned by outsiders and only one is owned by a local, and this could indicate different interpretation of site success in terms of the local community's level of involvement.

The fourth indicator is the clear improvement in life and livelihood (Sub-Cluster: Social Development). Local community, government and NGOs, and the business respondents suggested that the improvement of the living standard of the community at the site is an indicator of a successful ecotourism site. Improvement may come from the opportunity created by the industry, such as 
employment and business opportunities. The local community noticed that there is an increase in their income and experienced new life with the tourism experience.

The fifth indicator is the number of tourists that come to the site (Sub-Cluster: Business). The local community, government and NGOs, and tourists suggested this. A high number of tourists suggested that the site is attractive and successful. The high number suggested that there is a strong pull attraction to the site, and the ability to command a high number of tourists to the place. Tourists also thought that the high number of visitation means that the place is popular among tourists and that encourages repeat visitation. The high number of visitors also suggests that the pull attraction of the site is strong, and thus able to command a high number of tourists to the place.

The sixth indicator is benefits to the community (Sub-Cluster: Meaning of Ecotourism), as suggested by the local community and tourists. There are many aspects of benefits that the community can receive through ecotourism. There are collective benefits such as unity, camaraderie, employment opportunities, culture appreciation and meeting new people. There are also individual benefits such as skills, income earned from ecotourism, valuable experience and selfappreciation. An ecotourism site that disseminates benefits to the community is a successful ecotourism site.

The seventh indicator is the high reputation of the site enjoyed (Sub-Cluster: Business). The local community and the tourists suggested this. Some of the sites enjoy a high profile and international reputation. It is usually a combination of stakeholders' efforts to develop and promote the site. Tourists are attracted to a site with high reputation, and thus considered it a successful site. This can also contribute further to its future success. 
The eighth indicator is meeting objectives (Sub-Cluster: Business). The government and NGOs, and the business respondents noted that in every ecotourism operation, there is usually a set of objectives that set the direction of the operations. There are usually a lot of benefits received by stakeholders when objectives are met. Objectives may differ from site to site and from one stakeholder to another. These sites strived to meet these objectives and once they did, it is considered successful.

The ninth indicator is the improvement of infrastructures (Sub-Cluster: Social Development). The government and NGOs, and the tourists suggested this. There are public infrastructures and facilities that are added and/or improved with the creation of the ecotourism industry. The improvement is the result of other stakeholders' support and tourist dollars that went into the local economy. This shows that the ecotourism site is doing well, and able to grow and contribute to the improvement of infrastructure to cater for current and future needs.

The tenth indicator is good ecotourism practices and being sustainable (SubCluster: Meaning of Ecotourism). The government and NGOs, and the tourists suggested this. The ecotourism concept requires certain practices to be observed. Many sites employ these eco-practices as part of their ecotourism operation. For example, the introduction of a forest rejuvenation project, conservation of surrounding area of importance or implementation of ecopractices in ecotourism operations indicates that the ecotourism site is successful. The implementation of the 3Rs (Recycle, Reduce and Reuse) is also a standard environment practice. Some sites have projects that try to conserve the environment. Ecotourism sites may also have programs and activities that incorporate the local community to ensure that the well being of the locals is looked after. It is seen successful when the ecotourism site manages to incorporate good eco-practices and sustainable practices in its operations. 
The eleventh indicator is the ability to draw interest with a 'wow' factor (SubCluster: Business). The government and NGOs, and the tourists suggested this. A site that has the potential to draw interest is considered a successful site. This can be attributed to the tourism assets that they have. Tourism assets may be of high quality and unique, and there is also good promotional effort put into it too. The high quality and uniqueness of the tourism assets contribute to the 'wow' factor of a site.

The twelfth indicator is promoting the conservation of natural resources (SubCluster: Meaning of Ecotourism). The business respondents and the tourists suggested this. Natural resources are the basis of ecotourism, and conservation is essential for the environmental cause (including the local community) and to sustain the industry. Some sites have made efforts to conserve the environment that incorporate the stakeholders including tourists. Most of the sites use ecotourism as a tool for the conservation of the surrounding area. The conservation of the environment is an indicator of a successful ecotourism site.

The thirteenth indicator is the preservation of culture (Sub-Cluster: Meaning of Ecotourism). Culture can be preserved with the creation of ecotourism. The business respondents and tourists suggested this. Ecotourism promotes local culture as one of the products. A lot of cultures have changed through the process of modernisation. Ecotourism has started a trend where the local community revived some aspect of their culture that has not been practised for many years. The ecotourism industry also reinforces the culture of the local community by creating a platform for the locals to practice and exhibit their culture for the tourists. The preservation of culture through ecotourism is a success indicator of an ecotourism site. 
The fourteenth indicator is the happy and motivated community (Sub-Cluster: Social Development). The government and NGOs suggested this indicator. It is perceived that the happiness of the people in the community in the ecotourism operations shows the site is well managed, and everyone is satisfied with the way it operates and the benefits received from it. This in turn, motivates them to do better for the ecotourism operation in the future.

The fifteenth indicator is a properly developed site (Sub-Cluster: Meaning of Ecotourism). The government and NGOs suggested this. This involves planning and developing the sites. Good planning involves not just the infrastructure but also the integration of the environment (which includes the local community) to the operation. The development of the site means taking into consideration the ecotourism meaning and aspirations.

The sixteenth indicator is the ability to capitalise on the site's strength (SubCluster: Business). The government and NGOs suggested this indicator. If a site is able to minimise costs and maximise ecotourism products, the site may choose to implement a 'value for money' strategy for its market. This is where a site shows that it can capitalise on its strength, and this is an indicator of a successful ecotourism site.

The seventeenth indicator is a well-managed site (Sub-Cluster: Business). The tourists alone suggested this indicator. A well-managed site shows that the site is properly maintained and operated profitability as a business entity. The strengths of the site are enhanced and the weaknesses are minimised. The site also has to be profitable to be financially sustainable as it is a business operation. The financial sustainability ensures the longevity of the operation. The tourist sees this from the site operations. 
The eighteenth indicator is the site being informative and educational (SubCluster: Meaning of Ecotourism). Only the tourists suggested this indicator. Awareness is an important element in ecotourism. Stakeholders including the tourists should know why ecotourism operates in such a way. They must know the value of conservation and how they can contribute to it. Awareness is usually done through information dissemination and education. Ecotourism sites usually have facilities or programs for this. Designated key persons, such as local leaders or guides, can promote awareness to the tourists through relevant talks. Interpretation centres are also useful for the tourists for a self-guided education process.

The nineteenth indicator is a satisfied tourist (Sub-Cluster: Business). The tourists suggested this. A satisfied tourist has his/her expectations met or exceeded. This is based on many factors, including the quality of the environment, the hospitality service and the value for money.

The twentieth indicator is the links to other good tourism sites (Sub-Cluster: Business). The tourists suggested this indicator. Other tourist sites may link with the site for better tourist experience. Associations to the site are also claimed to highlight the area. The site becomes an icon for the area. This is also good for the tourists where they can cover more area or attractions during their trip.

The twenty-first indicator is a good high quality ecotourism product (Sub-Cluster: Business). The tourists suggested this indicator. There are many aspects that make for a good high quality ecotourism product. Most of the sites have a main product. The high-biodiversity, the uniqueness of the people, area and product all make for a good high quality ecotourism product. This is an indicator for a successful ecotourism site. 
The analysis of indicators by stakeholders also provides some insight through review of what the stakeholders did not indicate as success factors. According to the Figure 7.5, the local community did not mention 14 indicators out of 21 . These non-mentioned indicators are mainly from the business clusters. This result suggests that the local community themselves do not see the business side of ecotourism as indicating the success of an ecotourism site. Based on the literature review, there is mention of the local community lacking capacity in business orientation. This is also mentioned in the case study in Chapter Five, where only one site out of five is running a fully operational independent ecotourism business, i.e. Kampung Bavanggazo.

The government and NGOs have not mentioned nine indicators out of 21 . The non-mentioned indicators belong to the 'meaning of ecotourism' and 'business' cluster. This indicates that all the 'social development' indicators are mentioned, which is justified with the nature and objective of the government and NGOs, where social development is embedded in their policies. This is also seen from Chapter Four where some of the plans and policies mentioned that tourism should be a tool for social development. With that in mind, the government and NGOs obviously would not mention some of the business themed indicators. However, they also do not mention some of the indicators from 'meaning of ecotourism' cluster, as it is shown from the plan and policy analysis that they are focused on what ecotourism means to them, hence contributed less to this type of indicators.

Meanwhile, the business respondents did not mention 9 out of twenty-one success indicators for ecotourism sites where the non-mentioned indicators are from the 'business' cluster. While the business respondents obviously have mentioned some business indicators, these non-mentioned business indicators are probably less important to them in indicating the success of ecotourism sites. These indicators are: 
i. High number of tourists (Sub-Cluster: Business)

ii. Benefits to the community (Sub-Cluster: Meaning of ecotourism)

iii. High reputation (Sub-Cluster: Business)

iv. Improvement to infrastructure (Sub-Cluster: Social development)

v. Practice good ecotourism management/Sustainable in every way (Sub-Cluster: Meaning of ecotourism)

vi. Ability to draw interest with a 'wow' factor (Sub-Cluster: Business)

vii. Happy and motivated community (Sub-Cluster: Social development)

viii. Properly developed site (Sub-Cluster: Meaning of ecotourism)

ix. Ability to capitalise strengths (Sub-Cluster: Business)

X. Well-managed site (Sub-Cluster: Business)

xi. Informative and educational (Sub-Cluster: Meaning of ecotourism)

xii. Satisfied tourists (Sub-Cluster: Business)

xiii. Links to other good tourism sites (Sub-Cluster: Business)

xiv. Good high quality ecotourism products (Sub-Cluster: Business)

Finally, on this analysis, the tourists have the least non-mentioned number of indicators. It has all types of indicators from the clusters with the highest being the business type of indicators. However, little can be drawn from this analysis for the tourists.

Similar to Chapter 6, this analysis explored what the indicators content are, based on the stakeholders' perspective. This analysis revealed that each stakeholder has a similar context in viewing what constitute success for ecotourism sites. The analysis further revealed each stakeholder's motives and his/her perspective of the indicators by analysing what they did not mention as success indicators. This, again, reinforced the fact that each stakeholder is an individual but is capable of having similar opinions of what constitutes success 
for local community participation. This result can be used in a later part of the analysis in this chapter.

The analysis of indicators by stakeholders also shows that the tourists suggested the highest number of indicators, followed by the government and NGOs. The local community and business both came up with the least number of indicators. Based on qualitative observations during the fieldwork, the tourists come up with various indicators, as the range of respondents that filled in the survey is quite big compared to the other group of respondents. They consist of international and domestic tourists from wide demographic backgrounds. The high number of respondents also contributed to the high number of indicators suggested. Secondly, the tourists have experienced other sites, which enabled them to compare and formulate certain characteristics that they regard as success indicators for an ecotourism site.

The government and NGOs came up with the second highest number of success indicators. They are both proactive advocates of the industry, and have been involved closely with other stakeholders, especially the local community and business, in developing and nurturing the ecotourism industry in Sabah. With extensive experience in the industry, naturally the respondents have lots to say about what they thought success for an ecotourism site should be. These respondents have a clear idea of the objectives of ecotourism site and what their desired contribution to the site are. This group is very much aware that certain policies and plans need to be followed and fulfilled, as guidance in developing the industry. This includes any projects or activities that are relevant to the industry, and they have certain goals and objectives that need to be fulfilled. The government and NGOs certainly have more than 10 years of industry experience in ecotourism, and even longer experience in the tourism industry itself. Therefore, it is expected that they would suggest a number of indicators. 
The local community and the business respondents suggested the least number of ecotourism site success indicators. Prior to the local community involvement in ecotourism, they mainly worked as farmers and fishermen. Since ecotourism is a business in nature and most of the villagers have a low-level capacity in handling the business aspect of ecotourism, it is understandable that they suggested the least number of indicators. The business respondents on the other hand are focused on business, so their attention is channelled in that direction. They also came up with the least indicators as they narrowly focused their attention on the business and ecotourism aspects.

The rank of importance for success indicator for ecotourism site can be seen in Figure 7.3. The schedule shows an arrangement based on the logical sequence of the stakeholders as proposed in the chapter on analytical framework. It determined the rank of importance for each indicator based on the sequence of the stakeholders' number of responses. Figure 7.3 suggests that there are two top ranked indicators and all stakeholders suggested them. These are visible local community participation/high level of participation and good cooperation among stakeholders. The lowest ranked indicators are well-managed site, informative and educational, satisfied tourists, links to other good tourism sites and good high quality ecotourism products.

The top ranked indicators that all the stakeholders agreed on belonged to two clusters. One is relevant to the ecotourism meaning and aspirations, and the other one is relevant to the business aspect of ecotourism. The perception of success that ranked top for all stakeholders has high relevancy on the ecotourism meanings and the business aspect of it.

The local community have come up with four business related indicators, two ecotourism related indicators and one social development indicators. This suggests that the perception of success by the local community is dominated by 
business success followed by ecotourism and social development success. This shows that the local community still sees ecotourism as a business venture, where they have the opportunity to take any business advantage that it has to offer. At the same time, it is also an avenue to improve their lives and social conditions. They are also aware of the importance of ecotourism and linked the concept to the success of the site.

The government and NGOs have come up with five business related indicators, three ecotourism related indicators, and all three social development indicators. This suggests that the perception of success by the government and NGOs is dominated by business success, followed by ecotourism and social development success. The government and NGOs also recognised that ecotourism is a business after all. Without the business incentives and revenues generated from ecotourism, the objectives of the project or venture are probably hard to achieve. The government and NGOs also emphasised on social development as they suggested all three related indicators.

The business respondents have come up with five business and ecotourism related indicators and one social indicator. This suggested that the perception of success by the business sector is equally divided by business and ecotourism success, and followed by social development success. This suggests that while the business sector strives to achieve their business objectives, they also put ecotourism concepts as important as their business objectives. This is logical as the business sectors should know their product, and know how to make a good product. To have a good ecotourism product, the ecotourism concept should be closely followed. It is also expected that there is only one social development related indicator as the business sector focuses more on maximising profits as they are responsible to provide revenue for its shareholders, and at the same time, prove its customers the service that they seek. 
The tourists came up with eight business related indicators, five ecotourism related indicators and one social indicator. This suggests that the perception of success by the tourists is dominated by business, followed by ecotourism and social development success. It is interesting to discover that even the tourists have come up with quite a number of business related indicators. Ecotourists are clients to the ecotourism business after all, and they expect the ecotourism experience when paying for them.

The analysis of the pattern in the indicators by stakeholders has come up with some important suggestions. Based on the size of the indicators, tourists came up with the most indicators. However, based on the logical sequence from the analysis framework, they are ranked the lowest based on their involvement and effect from ecotourism. It is also interesting to see that the local community, which is ranked at the top of the stakeholders' sequence, has come up with the least indicators (shared with business respondents). This scenario has a few explanations. The local community is not highly educated and has not been exposed to the industry, and these limitations reflect in their limited ideas of how ecotourism success can be interpreted.

This analysis does not just reconfirm that the business aspect of ecotourism dominates the indicator success for ecotourism sites, but also suggests that these indicators are evenly spread among stakeholders. This shows that all stakeholders suggest that the success of ecotourism site depends very much on the success of business operations. This held true for ecotourism sites as it is in fact a business operation, with the exception of non-profit sites such as Rafflesia Information Centre. This suggested that the perception of success goes beyond the theoretical boundary of ecotourism where the important elements are the environment and local community. 
When these indicators are analysed further, there are three significant outcomes for the indicators by stakeholders. These significant scenarios are drawn out from the group based on its frequency and its exclusivity (by stakeholders). These are as follows:

\section{Outcome 1}

There are two significant indicators from all stakeholders, which are 'visible local community participation/high level of participation' and 'good cooperation among stakeholders'. All stakeholders agree to these indicators, which suggest that local community participation, and integrated development and management of the site are essential in ecotourism site success. Stakeholders believe that the process of involving the local community in ecotourism site is essential. This suggests that the stakeholders view ecotourism not just as a tool for conservation or a business venture, but also as having emphasis on involving local community. They see the local community as part of the ecotourism package.

The stakeholders also believed that the good cooperation among stakeholders is essential and viewed as a success indicator of an ecotourism site. This suggests that the stakeholders are of the opinion that integrated development and management of ecotourism sites should produce successful ecotourism operation. Based on the case studies in Chapter Five, the active ecotourism sites, i.e. Kampung Bavanggazo, Batu Putih and Sukau, are those that have integrated development where inputs, assistance and cooperation in many levels were channelled to the site.

\section{Outcome 2}

The table of indicators by stakeholders also suggests that there are indicators that are generated exclusively from a single stakeholder. Based on its frequency, the government and NGOs came up with three indicators that are exclusively 
from them, which are 1) happy and motivated community; 2) properly developed site; and 3) ability to capitalise strengths. These indicators deal with the output of ecotourism for both the locals and the sites, which are the state of their happiness and motivation, and their acquired or enhanced skills to capitalise their own strengths. This is what the government and NGOs perceived as success, which is the benefit towards the recipients of ecotourism, i.e. local community and sights.

\section{Outcome 3}

Another significant group of indicators that generated exclusively from a single stakeholder is drawn from the tourists. There are five indicators that only the tourists came up with, which are 1) well-managed site; 2) informative and educational; 3) satisfied tourists; 4) links to other good tourism sites; and 5) good high quality ecotourism products. These indicators clearly focuses on the experience of the tourists, where they would like to see the ecotourism site properly developed and managed as ecotourism is linked with ethics, i.e. environmentalism and socialism, and the rest of the indicators deal with enhancing their experience on site. This is obviously the choice of success indicators for tourists as they are concerned with their own well-being, but within the group of indicators by stakeholders, these are deemed the weakest. This suggests that, while having a conscience is present and important in every ecotourist, his/her own individual need, i.e. touristic experience, is still important to them.

These scenarios reinforced yet again that the stakeholders are different and have different views of success. Based on this analysis, both from Chapter 6 and 7, each individual's needs are as important as the others. While integrated development and management may be important as suggested in Chapter 6, the individual needs of each stakeholders need to be addressed as well. This chapter has found that there are two strongest indicators as depicted in Scenario 1, while 
there are two other significant group of indicators, i.e. Scenario 2 and 3, which were drawn exclusively from government and NGOs, and tourists.

\subsubsection{Indicators by Site}

Indicators by site are a group of indicators that has been developed based on specific sites. The respondents mentioned success indicators based on specific sites during the interview. The research revealed that out of 21 indicators, there are 16 indicators for Kampung Bavanggazo, nine to Batu Puteh, seven to Kampung Rantai, 10 to Sukau, and nine to Rafflesia Information Centre. These are illustrated in Figure 7.4 .

\section{Eigure Z 4 Indicators by Site}

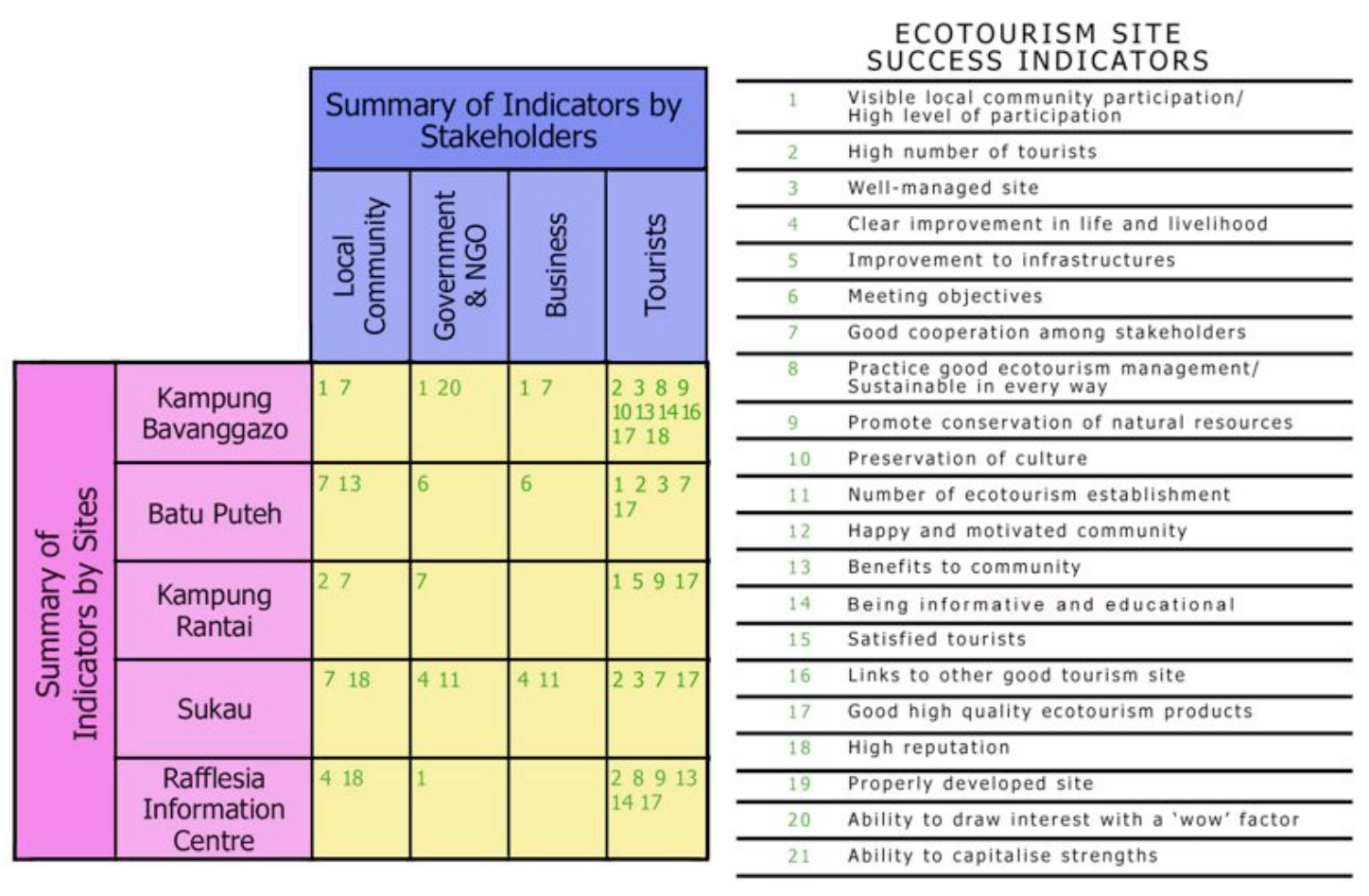




\subsubsection{Kampung Bavanggazo}

There are 13 indicators that are developed based on Kampung Bavanggazo's experience. There are two indicators each from the local community, government and NGOs, and business. Tourists suggested ten indicators (some indicators are overlapping among stakeholders).

The first indicator is the visible local community participation/high level of participation. The local community noted that the villagers are involved in the operations at various levels. Support from the local community is also seen as important to the success of the site. It is further suggested that the involvement comes from understanding the operation. The government and NGO respondents suggested that Bavanggazo Village has a very high participative involvement from the local community. The community takes part in the management and decision-making level as well as its operation, especially in employment and handicraft making. The Rungus people are renowned for their handicraft products. and Kampung Bavanggazo is quite experienced through the Bavanggazo Rungus Longhouse as they are exposed to the trade through participation in exhibitions and trade shows. The business respondents also agreed with the local community, the government and NGOs.

The second indicator is the high number of tourists that came to the village. Tourists are aware of the site, and there are many visitors (international and local) that visit the site. They see the site as interesting, attractive and good value for money, commanding high reputation, and suggested those as reasons that people come to Kampung Bavanggazo and return as repeat tourists. Based on the case study in Chapter Five, this site is well known, and the Sabah Tourism Board is promoting it aggressively. 
The third indicator is that Kampung Bavanggazo is a well-managed site. Tourists observed that families who live in Kampung Bavanggazo manage the Bavanggazo Rungus Longhouse. A committee runs it and every villager has a role in it. The size of the operations made it relatively easy to manage. With more than 10 years of experience, the tourists consider the village a wellmanaged site.

The fourth indicator is the good cooperation among stakeholders. The villagers observed that since the beginning, they have a good relationship with Sabah Tourism Board, the tour operators and the tourists. STB has assisted them in many aspects, while the tour operators have been bringing tourists to the village. The good relationship with tourists also created repeat tourist market. The business respondents also mentioned that it is easy to deal with the management of Bavanggazo Rungus Longhouse.

The fifth indicator is good ecotourism practice and sustainability in every way. The tourists observed that the local community in Kampung Bavanggazo uses local products and resources in their operations. They restrict the usage of electricity and use renewable natural resources such as used cooking oil for lamp oil, which gives an authentic feel to the longhouse. The longhouses are made of local natural materials.

The sixth indicator is promotion of conservation for natural resources. The tourists observed that Kampung Bavanggazo is a site that practises conservation of its natural resources. Conservation protects the water catchments at Gomantong Hill that is the main source of water to the village and another nearby village. The conservation of the surrounding environment also maintains the attractiveness and tranquillity of the area, thus making it a high quality ecotourism site. 
The seventh indicator is in the preservation of culture. The tourists suggested that the ethnic identity of the Rungus people is successfully conserved with the creation of Bavanggazo Rungus Longhouse. It is a living museum where the people practise their traditional culture for the tourists' benefits every day.

The eighth indicator is the benefits to the community. Ecotourism sites bring several benefits to the local community. Tourists listed several benefits, which they thought the local community enjoyed. These include earning potential with employment opportunities, culture appreciation, meeting new people, valuable experience and self-appreciation.

The ninth indicator is information and education. Tourists suggested that Bavanggazo Rungus Longhouse is an informative and educational site for tourists. By visiting and staying in the village, the tourists learned a lot about the area and its people, and the benefits of community-based ecotourism. They suggested that this is an indicator of a successful ecotourism site.

The tenth indicator is links to other good tourism sites. The tourists observed that there are other tourist sites like the nearby Kampung Tinangol, Kampung Sumangkap and Kampung Gambizou that are linked with Kampung Bavanggazo to create better tourist experiences. Kudat, which is a nearby town, has also claimed linkages to Kampung Bavanggazo as its main attraction for its tourism industry.

The eleventh indicator is a good high quality ecotourism product. The tourists observed that in Kampung Bavanggazo, there are the longhouses, well-preserved local traditions and culture, food, nature, cleanliness, conservation and sustainable development, education, awareness and information, management and implementation, local history, number of visitors, costume, site, high quality and authentic handicraft, price of goods, hospitality of the local community, and 
the uniqueness of the ethnic group of the local community. All of these make for a good high quality ecotourism product.

The twelfth indicator is the high reputation that Bavanggazo Rungus Longhouse enjoys. Tourists come to experience the Bavanggazo Rungus Longhouse because of its reputation as a very rewarding experience in culture and environment. It is the only living museum in Sabah as well. The operation has been carried out for more than 10 years, and they are internationally well known with the help of the Sabah Tourism Board, the marketing arm of Ministry of Tourism, Culture and Environment. They also receive a lot of repeat tourists over the years.

The last indicator is the ability to draw interest with a 'wow' factor. The government and NGOs recognised that the Bavanggazo Rungus Longhouse is quite unique in Sabah, and it definitely has an 'edge' over any other ecotourism site in the state.

\subsubsection{Batu Puteh}

There are seven indicators developed based on Batu Puteh's experience. There are two indicators from the local community, one each from the government and NGOs, and the business, and five from the tourists.

The first indicator is the visible local community participation/high level of participation. The tourists suggested this indicator based on their experience at Batu Puteh. They observed that many villagers are involved in ecotourism directly (by joining MESCOT), and indirectly (by being involved in the ecotourism business). The community is also involved in various levels from management to operations. The tourists also suggested that the local community in Batu Puteh work quite well together with spirit and endurance/enthusiasm. 
The second indicator is the high number of tourists that come to visit Batu Puteh. The tourists are aware that ecotourism is a business entity. Therefore, to get as many clients as possible within the limit of the operational capacity is a good business strategy. In addition, since the Miso Walai homestay started operating from June 2000 up till the end of 2003, they had 1,200 bed nights and 2,600 people who went for wildlife-watching trips. There are also a lot of repeat tourists to Batu Puteh. The tourists suggested that the high number of tourists to Batu Puteh indicated that it is a successful site.

The third indicator is a well-managed site. The tourists observed that Batu Puteh has a well-organised management and operational structure. It has the main body, which is MESCOT and under that, there are several operations that include the Miso Walai Homestay. The villagers managed the site very well with start-up assistance from WWF-Malaysia, and the Ministry of Tourism, Culture and Environment of Sabah. It practised the concept of community-based ecotourism very well.

The government and NGOs, and the business respondents suggested the fourth indicator for successful ecotourism sites. The indicator is meeting the objectives that have been set by the site. The ecotourism operations at Batu Puteh is organised by MESCOT, and it has a set of objectives that it has to achieve. These objectives also set the direction of MESCOT and the ecotourism industry in Batu Puteh. The site is considered successful when those objectives are met.

The fifth indicator is the good cooperation among stakeholders involved in the Batu Puteh ecotourism industry. The local community suggested that there is a unity between the advocates of ecotourism and the local community. WWFMalaysia and Ministry of Tourism, Culture and Environment have been playing important roles in developing the industry, and other organisations such as Shell, 
Raleigh International, Ricoh and Discovery Channel also support various projects in Batu Puteh. The tourists also observed that the stakeholders are well involved in the project. Efforts are coordinated and there are many joint efforts, notably the forest rehabilitation project, which is a main component of the ecotourism industry in Batu Puteh.

The local community suggests the sixth indicator. It is the benefits received by the community. Benefits include the opportunity in earning secondary income and providing valuable experience to the villagers. Some basic amenities in the village have also been upgraded.

The last indicator is the high quality of ecotourism products that Batu Puteh offers. The tourists suggested that the ecotourism products, such as the pristine river and floodplain environment, and the Sungai People culture, are of high quality. The natural environment in the surrounding area are said to be very pristine with attractive spots filled with diverse flora and fauna. In addition to that, there is also effort to disseminate awareness and relevant information on Batu Puteh ecotourism, its conservation effort and the program/itinerary that MESCOT has developed for tourists.

\subsubsection{Kampung Rantai}

There are six indicators that are developed based on Kampung Rantai's experience. There are two indicators from the local community, one from the government and NGOs, and four from the tourists. There is none from businesses, as there are no ecotourism businesses operating at Kampung Rantai.

The first indicator is visible local community participation/high level of participation. The tourists observed that the ecotourism industry here is 
organised and run by MAMAKAT, an association that consists of the villagers. The locals are very supportive of the industry. With the help of a local NGO, the locals run their own operation and make their own decisions.

The second indicator is the high number of tourists. The local community suggested the high number of tourist shows the site is running well, and has a good reputation in the industry. The community leader also added that the high increment in the number of tourist arrivals would indicate the growing success of an ecotourism site.

The third indicator is improvement to infrastructure. The tourists suggested that infrastructure such as roads, rest houses and telephone lines are improved with the development of ecotourism. Houses are improved for homestay programs. MAMAKAT headquarters are also built with local resources and local designs for operational uses, such as cultural performances or villagers meetings. The tourists also thought that the village is clean and has proper amenities.

The fourth indicator is good cooperation among stakeholders. It is suggested that the success of a site is due to the commitment of the main players of the industry including the local community. The community leader also added that a site is a successful site if there is a good cooperation from the local community to their leader. The local community also commented that it is the right time to be in the ecotourism industry, as the tourism industry has become important and there is a lot of encouragement from all advocates. They predicted that in the future, when the local community has been exposed to the industry, they could become more successful. The government and NGO respondents have also suggested the fourth indicator for ecotourism site success. Kampung Rantai usually coordinates its efforts with other stakeholders, notably PACOS, a local NGO. Since Kampung Rantai is in its infancy stage, cooperation from PACOS and 
others such as WWF-Malaysia is quite essential. Without their cooperation, it is hard to establish the industry with such limited capacity.

The fifth indicator is promotion of natural resources conservation. The tourists observed that the village has a pristine environment and is next to the Crocker Range. It has water catchments that supply the main water supply for the Bundu Apin-Apin area. The endangered Rafflesia flower is also found around the area, which made the conservation of the area essential. The villagers have successfully gazetted the surrounding area as a Virgin Forest Reserve. Conservation is essential to the ecotourism industry and the locals' livelihood, especially in terms of water supply.

The final indicator is a good high quality ecotourism product, suggested by the tourists. As it is located next to the Crocker Range and in an undisturbed environment, the village has a pristine surrounding environment. The Dusun culture is still preserved and its livelihood is unique to the tourists. The Rafflesia flower can be found in the area, and the village also has a traditional medicine garden, which is rare in Sabah.

There is no primary data indicator that is specific to Kampung Rantai from the business respondents as there is no business being operated in Kampung Rantai.

\subsubsection{Sukau}

There are seven success indicators that are developed based on Sukau's experience. There are two indicators each for local community, government and NGOs, and businesses. There are four indicators from the tourists. 
The first indicator is the high number of tourists to the site. A tourist suggested this indicator. Sukau is a very well-known ecotourism site in Sabah, and has been the pioneer for the ecotourism industry in the state. Since the industry is dominated by the business sector, a lot of tourists go to Sukau through tour operators. The high number of tourists to Sukau indicates a successful site by the tourist.

The second indicator is a well-managed site. The tourists have suggested this indicator. Sukau has been developed as an international ecotourism destination with efforts from all stakeholders. It has been monitoring its ecotourism activities and impacts. It manages to balance the impact to maximise the benefits and minimise the negative impacts. It has also been promoting conservation of the area and supporting the status of the wildlife sanctuary in the Lower Kinabatangan.

The third indicator is clear improvement in life and livelihood. The government and NGOs, and the businesses suggested this indicator. The local community is either involved directly, i.e. working in the industry, or indirectly, i.e. supporting the industry. In some aspects, improvements are based on the sense that the local community is more aware of their environment and they are trying to conserve the environment for the betterment of their lives. The government reckons that before the introduction of ecotourism, there is generally little concern on the surrounding environment from the villagers. There is also a general agreement that the changes experienced from the ecotourism development are usually for the better.

The fourth indicator is good cooperation among stakeholders. A number of local community members in Sukau thought there was an uneasy relationship between the local community and the business sector, but the relationship is improving. The government and NGOs have always been supportive of the 
industry, while the tourists contribute to the conservation of the surrounding environment. The tourists also suggested this as an indicator of ecotourism site success.

The fifth indicator is the number of ecotourism establishments. The government and NGOs, and the businesses suggested this. This indicator takes into account the number of eco-lodges available at the site. There were eight ecolodges in Sukau at the time of the survey, which is the highest number of ecolodges concentrated in one site in the whole country. The government and NGOs indicated that the number of ecolodges corresponds to the success of the site. However, the government respondents also noted that the number of ecolodges owned by local people also indicated a different interpretation of site success. This is seen as higher involvement from the local community compared to the ecolodges owned by outsiders.

The sixth indicator is good high quality ecotourism product that Sukau can offer. The tourists observed that Sukau has a pristine environment with high biodiversity and an iconic wildlife, which are the Proboscis monkeys, Sungai People culture, awareness and information on ecotourism and the surrounding wildlife sanctuary area, location of Sukau at the Kinabatangan Floodplains, and the program/itinerary on tour packages that are developed by the tour operators.

The final indicator is the high reputation of Sukau as an international ecotourism destination. The local community suggested that the success of the eight lodges established in the village has contributed to the high international profile that they currently enjoy. They also have the highest number of ecolodges in any ecotourism site in Malaysia. 


\subsubsection{Rafflesia Information Centre}

There are nine indicators developed based on Rafflesia Information Centre's experience. Two of the indicators are from the local community, and one from the government and NGOs. There are six indicators from the tourists, and none from the business sector. There is no business link between tour operators and the Rafflesia Information Centre.

There is only one indicator for ecotourism site success suggested by the government and NGOs. It is the first success indicator for the Rafflesia Information Centre, which is the visible local community participation/high level of participation. The government sees that the centre provides employment to the local community, where the centre's rangers and guides comprise entirely of locals.

The second indicator is the high number of tourists that come to Rafflesia Information Centre. This indicator was suggested by the tourists. The centre attracted a high number of local and international tourists with the endangered Rafflesia flower, which is also the biggest flower in the world. Tourists can also learn more about the flower and the centre's efforts to conserve it.

The local community at Kampung Rantai suggested the third indicator for ecotourism site success. It is the clear improvement in life and livelihood. They noted that there are benefits from the centre such as extra income, and personal development gained such as improved command of English language achieved from host-guest interaction.

The tourists suggested the fourth, fifth, sixth, seventh and eight indicators. The fourth indicator is the practice of good ecotourism management and being sustainable. The centre has been making an effort to conserve the endangered 
species of Rafflesia, and educate tourists on the importance of conservation efforts and the flower to the environment. Locally hired rangers are also available to guide tourists to visit the flower, and ensure at the same time that the flower is not harmed.

The fifth indicator is promoting the conservation of natural resources. The very existence of Rafflesia Information Centre is centred on conserving the Rafflesia flower. At the same time, the surrounding area has been gazetted as a Virgin Forest Reserve. This is to ensure that the surrounding habitat needed for the Rafflesia to grow is also protected.

The sixth indicator is the benefits to the local community. The local community benefits from the ecotourism industry with the inflow of tourists to the town of Tambunan, which helps local businesses. Some of the community have been hired by the centre to be forest rangers and guides.

The seventh indicator is informative and educational. The centre was established with the sole purpose of conserving the endangered Rafflesia flower. Awareness is not just limited to the tourists, who contribute to the conservation effort, but also to the local community. The local community was not aware of the importance of the flower and its status as an endangered species before the establishment of the centre. The increased awareness of the status of the Rafflesia flower puts value to the flower and this can support existing and future conservation efforts.

The eighth indicator is a good high quality ecotourism product. The centre has an iconic tourism product, i.e. the Rafflesia flower, that has been used for the tourism industry for many years and this has helped raised the profile of the centre. It is physically a beautiful flower, and its size and status as an endangered species makes it unique. The centre is located at a high sea level 
with a nice and cool temperate. A virgin forest with high biodiversity and other interesting geographical features, such as a waterfall, surrounds it. The centre is also located near other tourism sites such as Mount Trus Madi and Tambunan Village Resort.

The final indicator is the high reputation that the Rafflesia Information Centre has and the local community suggested this. Since Rafflesia is an iconic flower of Sabah, the establishment of the centre obtains a certain amount of attraction. The unique status of the flower makes it more valuable as a tourism product. The centre is known at the international level because of the flower.

There is no primary data indicator that is site-specific for Rafflesia Information Centre from the business respondents, as there is no direct linkage between businesses and the centre.

\subsubsection{Analysis of Indicators by Site}

There are two patterns that can be seen in this group of indicators. The first pattern is size based, and the second pattern is content based. A close examination revealed that Kampung Bavanggazo came up with the most indicators, 13, followed by Rafflesia Information Centre with nine indicators. Batu Puteh and Sukau both have seven indicators each. Kampung Rantai has the least indicators, which amounted to only six.

A high number of indicators suggests that Kampung Bavanggazo possesses a high number of success characteristics. It is also noted that Kampung Bavanggazo is on the top end of stakeholders' sequence in the analysis framework, based on the initiative in the industry. Bavanggazo Rungus 
Longhouse is the only site that is run entirely by the locals with some outside help.

Rafflesia Information Centre has the second highest number of indicators, which suggests that it is also quite a successful site within its own right. It is considered a 'hard core' ecotourism site where its sole purpose is to conserve the endangered Rafflesia flower. It also disseminates information and educates tourists as part of their effort in conserving the flower by raising awareness on the importance of conservation and the value of the flower.

Both Batu Puteh and Sukau have the same number of suggested indicators although with different varieties. Similar to Bavanggazo Rungus Longhouse and Rafflesia Information Centre, Batu Puteh and Sukau have been established as ecotourism sites and have also been successful in creating a name for themselves. Batu Puteh is prominent with its multi-award winning homestay project, while Sukau is prominent with its high reputation as a popular ecotourism destination in Malaysia. Both have wide experience as ecotourism destinations.

It is quite understandable that Kampung Rantai has the least number of success indicators. This might be attributed to the fact that it is the newest ecotourism site among all the sites, and it has just begun to establish itself a few years ago. It is no surprise that it has few success indicators since it does not have much experience that can contribute to the success indicators.

The analysis also found that within the thirteen success indicators for Kampung Bavanggazo, it has seven business related indicators and six ecotourism-based indicators. Kampung Bavanggazo has more than 10 years of experience in ecotourism; therefore the locals probably have more success indicators to suggest compared to other sites. They are almost equally divided but there are 
more business-based indicators. This shows that Bavanggazo Rungus Longhouse is not only recognised as a business entity but also a site that has incorporated the concept of ecotourism very well into its business operations.

Rafflesia Information Centre has nine specific success indicators based on its site. Unlike other sites, it has more ecotourism-based indicators compared to any other type of indicator. It has five ecotourism-based indicators, three businessbased indicators, and one indicator based on social development. It is not surprising that the indicators are more ecotourism based, as Rafflesia information Centre is a site that is dedicated to the conservation of the endangered Rafflesia flower. It is a 'hard-core' ecotourism site where conservation is its main priority.

Batu Puteh has seven site-specific success indicators, five business-based and two ecotourism-based. It is a lucrative business for the local community in terms of supporting their income, and it has also improved the local economy. However, it should not be forgotten that Batu Puteh also has quite an impressive effort in conserving the environment through its reforestation project.

Sukau has seven site-specific success indicators. It has six business-based indicators and one indicator that is based on social development. There is no 'ecotourism-based' indicator, which signifies that Sukau is dominated by businesses run by outsiders, and they are focused on profit-making and probably have no attachment or sentiment to the area. The business community has been developing the ecotourism industry in Sukau since the early 1990s. It has the highest number of ecolodges, and has a high reputation as one of the highest quality ecotourism sites in the world. Some of the ecolodges are multi-award winners, and Sukau also has its own iconic 'product' that is the Proboscis monkey. Therefore, it is natural for the indicators to point out the success characteristics of the business side of ecotourism as ecotourism in Sukau is 
essentially a business operation, first and foremost, and the development of the site is geared towards the health of the business.

Kampung Rantai has six success indicators that are specific to its sites. It has three business-based indicators, two ecotourism-based indicators, and one indicator based on social development. While it is understandable that the number of indicators is smaller compared to the rest based on its new experience in the industry, it is quite notable, even with the high involvement of a local NGO, that there are more success indicators specific to this village that is business-based.

This analysis has come up with some important suggestions. Based on the size of the indicators, the rank for the sites is 1) Kampung Bavanggazo 2) Rafflesia Information Centre 3) Batu Puteh and Sukau and 4) Kampung Rantai. At first glance, the two ends of the spectrum suggest that the number of indicators suggested may be related to the experience of the sites. Kampung Bavanggazo is one of the most experienced sites, while Kampung Rantai is fairly new in the industry compared with other sites. However, there is no significant pattern in the middle of the rank.

Based on the content of the indicators, all of the sites had suggested indicators that are dominated by business-based indicators. Every site, with the exception of Rafflesia Information Centre, has more business indicators suggested. This is also a similar conclusion to the analysis for the group of indicators by stakeholders. This suggests that the ecotourism site is still very much a business operation, and what makes a successful site depends on the health and the achievement of the business. 


\subsection{Success Indicators: Research vs. Literature Review}

There are other previous studies that have developed similar success indicators, which have been outlined in the literature review. This section will review both sets of indicators from this research and the literature in order to establish consistency and applicability, and further insights can be found with the indicators. Chapter Two has comprehensively discussed the success factors for ecotourism sites. The discussion has produced seven ecotourism site success indicators drawing from many literatures. These indicators are listed below in Table 7.1. 
Table 7. 1 Ecotourism Success Indicators from the Literature Review

\begin{tabular}{|c|c|c|c|}
\hline NO. & INDICATORS & MEASUREMENT & SOURCE \\
\hline 1. & $\begin{array}{l}\text { Conservation of natural resources to host } \\
\text { country and local people }\end{array}$ & $\begin{array}{l}\text { Creation of } \\
\text { conservation } \\
\text { area/effort }\end{array}$ & $\begin{array}{l}\text { Ashton (1991), } \\
\text { Emmons (1991), Cater } \\
(1994)\end{array}$ \\
\hline 2. & $\begin{array}{l}\text { Financial gain to host country and local } \\
\text { people/economic benefits }\end{array}$ & $\begin{array}{l}\text { Amount of money } \\
\text { Increased disposable } \\
\text { incomes to individuals } \\
\text { Holistic approach - } \\
\text { considering social, } \\
\text { environmental and } \\
\text { economic goals }\end{array}$ & $\begin{array}{l}\text { Ashton (1991), } \\
\text { Emmons (1991), Cater } \\
(1994) \\
\text { Wight (1994) } \\
\text { Mathieson and Wall } \\
\text { (1982) }\end{array}$ \\
\hline 3. & Control over development & $\begin{array}{l}\text { Some measure of } \\
\text { control (high degree) } \\
\text { Share equity in the } \\
\text { benefits }\end{array}$ & Schevyns (1999) \\
\hline 4. & Business success & $\begin{array}{l}\text { Finance } \\
\text { Sustainability in the } \\
\text { industry }\end{array}$ & Mc Kercher (1998) \\
\hline 5. & $\begin{array}{l}\text { Benefits of tourism maximized } \\
\text { - } \quad \text { Increased demand for tourism- } \\
\text { related business } \\
\text { Additional revenue to local retail } \\
\text { businesses and other services } \\
\text { Increased market for local } \\
\text { products } \\
\text { Employment of local labors and } \\
\text { - } \text { expertise } \\
\text { Source of funding for the } \\
\text { protection and enhancement/ } \\
\text { maintenance of natural attraction } \\
\text { Funding and/or volunteers for } \\
\text { fieldwork associated with wildlife } \\
\text { research and archaeological } \\
\text { studies } \\
\text { Heightened community } \\
\text { awareness of the value of local } \\
\text { indigenous culture and natural } \\
\text { environment }\end{array}$ & $\begin{array}{l}\text { Outcomes desired by all } \\
\text { stakeholders }\end{array}$ & $\begin{array}{l}\text { Wearing and Neil } \\
\text { (1999) } \\
\text { Lawrence et. al (1997) }\end{array}$ \\
\hline 6. & $\begin{array}{l}\text { Profound effect on the culture of the } \\
\text { destination }\end{array}$ & $\begin{array}{l}\text { Revival and } \\
\text { rejuvenation of ancient } \\
\text { festival and/or cultural } \\
\text { landmarks }\end{array}$ & $\begin{array}{l}\text { Wearing and Neil } \\
\text { (1999) }\end{array}$ \\
\hline 7. & Empowering local participants & $\begin{array}{l}\text { Level of empowerment } \\
\text { should build local } \\
\text { community's capacity } \\
\text { and promote self- } \\
\text { development to } \\
\text { individuals }\end{array}$ & Lawrence et. al (1997) \\
\hline
\end{tabular}

When the indicators from the literature review are compared to the indicators developed by this research, there is a significant similarity in terms of the nature 
of the indicators. Conservation, economic gains, tourism benefits to the local area and community with profound effect to the culture, are the issues that this research and the literature review have in common, with the exception of the issue of business success. This suggests that the indicators are not new and possibly applicable to other sites. When looked at closely, the indicators are more inclined towards a macro level, i.e. conservation, financial gain, economic benefits, culture effect, benefits of tourism, rather than at micro level, i.e. local site, local economy or local community. Overall, the research has developed more indicators compared to the one that has been drawn from the literature review. This suggests that while the indicators may be generic and applicable to other sites, a specific site may produce or develop more indicators based on its locality. This is consistent with the results from Chapter 6, i.e. success indicators for local community participation.

Based on the analysis by stakeholders, ecotourism site success' indicators content are determined by the stakeholders. This has been shown in the earlier section where each stakeholder has both similar and different context of the indicator's content but they are not totally dissimilar when they are clustered together. Based on the earlier analysis in Chapter Six, it suggested that each stakeholder is different and has a different perspective of success where his/her perspective can be very exclusive to his/her own group, and this is the same with this chapter. While all of them may not stand on common ground, there are two perspectives that they all agreed on, which in this case are 'visible local community participation/high level of participation' and 'good cooperation among stakeholders'. This also reinforced that the shared success indicators are the strongest indicators as they reflect every groups' perspective. However, ecotourism site success indicators developed from the literature review does not indicate shared indicators developed from the research. Most of parameters used suggests that the indicators are output based. 
Based on the analysis of indicators by sites, it suggested that there are two most important indicators, which are high number of tourists and good high quality tourism product. However, these indicators are not specified per se in the literature review.

This research revealed that the strongest indicators of ecotourism site success that have been developed are not found in the literature review. However, other indicators from the research have similarities in their context with the indicators from the literature review. While this suggests consistency in the indicators, the absence of the strongest indicators from this research from the literature review suggests that these may be the perspective that many other researchers or case studies have not considered or experienced.

\subsection{Conclusion}

The literature review in Chapter Two suggests that ecotourism success is based on what it achieves in site operations. This is based on the aims and objectives of ecotourism, either in general or specific to a site, and how well the aims and objectives have been achieved. Success is also based on individuals' perceptions, be it the government, tourist or local community. Many of the ecotourism operations, as discussed in the literature review, include local community as its main component. While the literature review does not explicitly discuss the success indicators for ecotourism sites, there are few indicators that can be drawn from many cases, sites and examples. These indicators show that the success of ecotourism sites are mainly concerned with the output of the ecotourism and mainly deals with macro elements. 
The success indicators that have been presented are based on the perception of stakeholders. There are 21 success indicators for ecotourism sites that have been developed through this research as shown in Figure 7.1.

The five research sites that are selected in this research presented five ecotourism sites with some similarities based on the definition of ecotourism set earlier in this thesis. However, there are many influences that shape the indicators, such as leadership, ownership, size, stakeholders' degree of involvement and so on. These sites were selected through a process that was set earlier as mentioned in Chapter Three. Therefore it is ideal to use thematic clusters to determine the general indicators since all sites have similar variables.

A set of success indicators for ecotourism sites is the result of this research which fullfils one of the research objectives. The results show that there are 21 indicators that can help to identify the success of an ecotourism site. From earlier sections, there are two significant segments of indicators that help with the analysis of this chapter. These segments are indicators by stakeholder and by site. The analysis of indicators by stakeholder is divided into four stakeholders that are the major respondents of this research. These indicators are general and not necessarily site-specific. The analysis of indicators by site were divided into five research sites, which are Kampung Bavanggazo, Batu Puteh, Sukau, Rafflesia Information Centre and Kampung Rantai. Stakeholders are used to further segment the indicators.

Some writers suggested that for ecotourism to be successful, it should promote the conservation of natural resources and also provide financial gain for the host country and the local people (Ashton, 1991; Emmons, 1991; Cater; 1994). It is also hailed as a potential sustainable development tool resulting from the growing threat to culture and biological diversity posed by the growth of global tourism. However, as the analysis revealed, there are more dimensions of 
ecotourism success than what the tourism literature has suggested. This research has shown that there are more characteristics that suggest that the site is successful besides the conservation of natural resources and financial gains.

The analysis of indicators by stakeholder and site has come up with interesting results. Both have come up with their own rank of indicators that are based on the importance of each indicator. The pattern of size has resulted in explaining the experience of ecotourism sites contributed to the number of success characteristics. A pattern of content is more interesting as it presents a new view of ecotourism site success. A closer look of the indicators revealed that there are three clusters of indicators. The first cluster is a group of indicators that reflect the meaning and aspiration of ecotourism. The second cluster is a group of indicators that is relevant to the business side of ecotourism. The third cluster is a group of indicators that are relevant to the social development of the site. The research has found that the themes for ecotourism site success do not just cover the essential elements in ecotourism, i.e. conservation and social development of the community, but extend to business practices as well. This suggests that the practice of ecotourism and its perception of success in this research are broader and go beyond the theoretical definition.

This research also shows that there are more indicators that are relevant to the business side of ecotourism. There are also quite a handful of indicators that reflect the meaning of ecotourism. This suggests that the respondents see the sites as a business operation, and the success of the site depends on the success of the business. Therefore the perceptions of success are based on what constitutes business ability and performance. This has been proven by the analysis of indicators by stakeholders and sites. Both suggest that the indicators contents are skewed towards business oriented indicators rather than any other orientations. However, since quite a handful of the indicators still reflect on the aspirations of ecotourism, this suggests that the respondents have strong 
feelings towards the operations of ecotourism. The meaning of ecotourism still has a strong presence in the indicators for success. This may be attributed to the fact that ecotourism is a unique niche of tourism that has rules and ethical beliefs embedded in it. Therefore, the adherence of the rules and objectives are also perceived as a success for ecotourism site. While the business side has to achieve performance, the concept of ecotourism that defines the characteristics of the business also has to be maintained. Only a few indicators are based on social development. This shows that there is still awareness on the issue of benefits received by the local community from ecotourism.

The business dimension is supported by McKercher (1998) where he identified that in order for an ecotourism business to be successful, business operations have to be healthy and in good order. These are business planning, marketing skills, market research, operational issues such as quality and strategic planning, ethical and environmental issues, and personal issues such as individual business skills. Wearing and Neil (1999) add that the major reason to undertake ecotourism is the benefits to business, the area and its community. They further elaborated that the benefits are mainly business based, such as demand for accommodation, food and beverage outlets, additional revenue to the local retail businesses, increased market for local products, and employment of local labour and expertise.

It is revealed in this research that each stakeholder's similar context in viewing what constitutes success for ecotourism site, as each stakeholder is an individual with his/her own perspectives and motives but is capable of having similar opinions on what constitutes success for local community participation. Chapter Six has suggested that the needs of each stakeholder must be addressed despite the integration of development and management in ecotourism sites. 
When the indicators from this research are compared to those that are drawn out from literature review, it shows similarities on the theme and issues. The indicators that are developed are noted to be generic and output based. These success indicators are measurable and some are quantifiable. However, the strongest ecotourism site success indicators by site are not specified per se in the literature review. Other indicators from the research have similarities in their context with the indicators from the literature review. This suggests consistency in the indicators, while the absence of the strongest indicators from this research from the literature review suggests that these may be the perspective that many other researchers or case studies have not considered or experienced. Suggestions of further research are made in the concluding chapter. Similar from the previous chapter, further research to look into the measurement and quantifiable characteristics (parameters) of success for ecotourism site success should be useful for this topic. 


\section{CHAPTER 8. DISCUSSION AND CONCLUSIONS}

\subsection{Introduction}

Studies on ecotourism and its local community participation are discussed and many academics agree that there are many critical components for ecotourism success. It is also said that the success of ecotourism depends largely on the success of local community participation. Comprehensive insights into both the development of indicators for success of local community participation and the success of ecotourism sites are still limited as discovered within the literature review. The complexity of the stakeholders' characteristics with their own individual needs and motives usually resulted in various perceptions of success. Therefore this research has come up with two research issues.

The first issue for this research is interpreting and developing the indicators for success of local community participation at ecotourism sites in Sabah. The ecotourism concept has stated that local community participation is deemed a critical component in ecotourism operation. The second research issue is interpreting and developing the indicators for the success of ecotourism sites in Sabah. Both issues are expected to be related to each other, where the first research issue is a subset of the second research issue. This research expected, that initially, the success of both local community participation and ecotourism sites would have considerable differences as different stakeholders (the respondents) also view and perceive success differently.

Chapter Six and Seven presented the indicators which are the central theme of this thesis. This research presented two groups of indicators, 1) Success indicators for local community participation and 2) Success indicators for 
ecotourism sites. These two groups of indicators, however different, are closely related to each other. In this concluding chapter, the review of the research findings is discussed based on the literature review, plans and policies analysis, and case studies. The overall view of the thesis and its conclusion follows suit.

\subsection{Results Discussion}

This research has come up with a number of success indicators for local community participation. The data collected from the field have suggested 15 indicators related to local community participation and also related to the success of ecotourism sites (Figures 8.1 and 8.2).

The research findings are in agreement with many of the tourism literature. McIntosh and Goeldner (1986) suggested that community involvement is essential for tourism development. D'Amore (1983), Murphy (1983), Ross (1991) and Simmons (1994) suggested that a successful tourism destination is dependent on local community involvement as they are seen as an important component of the tourism product. Cater (1994) and Wild (1994) suggested that economic benefits could be gained from successful local community participation. Positive impacts of ecotourism can be gained by successful participation by the local community (Woodley, 1993). The National Ecotourism Plan (1997) for Malaysia recognized that successful ecotourism projects are contributed by local involvement.

Ashton (1991), Emmons (1991), Cater (1994) suggested that successful ecotourism promotes the conservation of natural resources and provides financial gain for the host country and the host community. Schevyns (1999) suggested that the local communities with some measure of control, who share equitably in the benefits of ecotourism are considered successful. McKercher (1998), Wearing 
and Neil (1999) outlined the success of ecotourism operations based on business aspects. All of these points can be found in the success indicators. The variety of success indicates that there is a wide range of factors that contribute to success. This has been identified in the research findings where three themes of success were found on both success indicators for local community participation and ecotourism sites. These themes are those relevant to 1) the community and its well being, 2) the business side of ecotourism and 3) the environment side of tourism.

The operating definition of ecotourism for this research is adapted from the World Conservation Union that emphasizes the conservation of the destination and ensures the participation of the local community so they can benefit socially and economically. These are also emphasised from the themes emerging from the indicators. However, the theme that is relevant to the business side of ecotourism is rarely mentioned in the definition specifically and literature review in general. Business issues are overshadowed by issues such as the aim of conservation and sustaining the well being of the local community in tourism literature. The findings of this research showed that business elements are as important as any other elements in ecotourism and local community participation especially where success is concerned. The success of ecotourism business ensures the longevity of the site and its ecotourism activity including conservation efforts and community participation. 
Figure 8. 1 Local Community Participation Success Indicators

\begin{aligned} & LOCAL COMMUNITY PARTICIPATION \\ & SUCCESS INDICATORS \\ & \hline $1 \begin{array}{l}\text { Visible community involvement } \\ \text { and commitment }\end{array} \\ &$\hline 2 Benefits received \\ & \hline 3 High number of tourists visiting \\ & \hline 4 Higher level of participation \\ & \hline 5 $\begin{array}{l}\text { Improvement in standard of } \\ \text { living/More progressive }\end{array} \\ &$\hline 6 $\begin{array}{l}\text { Increase in Capital/Finance/ } \\ \text { Revenue }\end{array} \\ &$\hline 7 Improvement in local economy \\ & \hline 8 $\begin{array}{l}\text { Conservation and promotion of } \\ \text { culture }\end{array} \\ &$\hline 9 Attractiveness of the site \\ & \hline 10 Conservation of the environment \\ & \hline 11 $\begin{array}{l}\text { Development of infrastructure/ } \\ \text { Site enhancement }\end{array} \\ &$\hline 12 Community development \\ & \hline 13 Independent community \\ & \hline 14 Happy and motivated community \\ & \hline 15 Good understanding of ecotourism \end{aligned}




\section{Figure 8. 2 Ecotourism Site Success Indicators}

\begin{tabular}{ll} 
& \multicolumn{1}{c}{ ECOTOURISM SITE } \\
\hline 1 & $\begin{array}{l}\text { Visible local community participation/ } \\
\text { High level of participation }\end{array}$ \\
\hline 2 & High number of tourists \\
\hline 3 & Well-managed site \\
\hline 4 & Clear improvement in life and livelihood \\
\hline 5 & Improvement to infrastructures \\
\hline 6 & Meeting objectives \\
\hline 7 & Good cooperation among stakeholders \\
\hline 8 & $\begin{array}{l}\text { Practice good ecotourism management/ } \\
\text { Sustainable in every way }\end{array}$ \\
\hline 9 & Promote conservation of natural resources \\
\hline 10 & Preservation of culture \\
\hline 11 & Number of ecotourism establishment \\
\hline 12 & Happy and motivated community \\
\hline 13 & Benefits to community \\
\hline 14 & Being informative and educational \\
\hline 15 & Satisfied tourists \\
\hline 16 & Links to other good tourism site \\
\hline 17 & Good high quality ecotourism products \\
\hline 18 & High reputation \\
\hline 19 & Properly developed site \\
\hline 20 & Ability to draw interest with a 'wow' factor \\
\hline 21 & Ability to capitalise strengths \\
\hline & \\
\hline 14
\end{tabular}


The two major works on local community participation that this thesis has adapted to are 'Typology of Participation' by Pretty (1995) and 'Ladder of Citizen Participation' by Arnstein (1969). Both identified multi-layers of participation levels, with manipulative at the bottom end and self-mobilisation/citizen control at the top end. Menial jobs at a tourist resort are considered passive participants while having access to information on the pros and cons of tourism development with direct involvement in planning for and managing tourism based on the participant's interests and resources are considered active participation. These models have been helpful in explaining the local community participation process and its analysis of all research sites. The models help in developing further insights into the indicators.

Both sets of indicators have community involvement with high level of participation and commitment that were ranked highly important by respondents. The success indicators are also dominated by the indicators that are relevant to the community's well being. This suggests that community involvement plays a large role in success for local community participation and ecotourism sites. The case studies also show that there are various levels of participation as demonstrated in each and every site. Kampung Bavanggazo can be considered at the top end of the participation spectrum as suggested by Pretty and Arnstein's models as there, the locals own and operate Bavanggazo Rungus Longhouse. On the other hand, Rafflesia Information Centre is considered at the bottom end of the participation spectrum as locals are only hired to work at the centre. This suggests that the success indicators relevant to local community participation are also multi-layered, with various types of participation. This can be further developed into measurement of relevant success indicators, which is suggested at the end of this chapter. Despite certain criticism from Guijt and van Veldhuizen (1999), the models have been useful to this research. 


\subsubsection{Local Community Participation Success vs. Ecotourism Site Success}

As mentioned earlier, both research issues of local community participation success and ecotourism site success are related to each other. The first research issue is seen as a subset of the second research issue. This research expects that the success of both local community participation and ecotourism sites have considerable differences as different stakeholders (respondents) also view and perceive success differently.

After comparing both groups of indicators, it is possible to see that the two sets share nine similar indicators out of the 36 that have been developed. They are visible community involvement and commitment, benefits received, high number of tourists visiting, higher level of participation, improvement in standard of living/more progressive, conservation and promotion of culture, conservation of the environment, development of infrastructure/site enhancement, and a happy and motivated community group. These shared indicators account for more than half of each set of indicators. This suggests that both sets of indicators are closely related to each other. Many respondents feel that what contributes to the success of local community participation, also contributes to the success of the site. Based on the operating definition of ecotourism, the local community participation is a sub-set of the ecotourism site; therefore, discussion will centre on how local community participation success contributes to ecotourism site success.

However, looking closely at both sets of indicators, there is one significant difference between the success indicators for local community participation and ecotourism sites. There are more success indicators for ecotourism sites compared to local community participation. In fact, the indicators for ecotourism 
sites are almost double that than local community participation. There are eleven success indicators for local community participation and twenty-one success indicators for ecotourism sites. Both sets of indicators have similarities, namely indicators for visible community involvement, benefits received, conservation of the environment, conservation and promotion of culture, high number of tourist visitations, improvement in standards of living/more progressive, development of infrastructure/site enhancement and higher level of participation.

The set of success indicators for local community participation have three unique indicators that have no similarities to the other sets, which are attractiveness of the site, community development and independent community. For ecotourism sites, the unique success indicators are good cooperation among stakeholders, number of ecotourism establishments, a good reputation, meeting objectives, practise good ecotourism management/sustainable in every way, ability to draw interest with a 'wow' factor, happy and motivated community, properly developed infrastructure at the site, ability to capitalise on organisational strengths, well-managed site, informative and educational, satisfied tourists, links to other good tourism sites and good high quality ecotourism products. The main difference between both sets of indicators is the nature of the unique indicators of each set. The success indicators for ecotourism sites have more businessrelated indicators compared to the success indicators set for local community participation. This suggests that these success indicators for ecotourism sites are focused towards the business nature of the site, compared to local community participation, which emphasises on community and environment.

The foundations of ecotourism concept emphasises the importance of local community participation (Blank, 1989; Wearing and Neil, 1999; Hall, 2000; Epler Wood, 2002). Ecotourism stresses that local business owners and communities must be involved. Opportunities to involve rural communities in tourism have 
attracted attention, and raised many expectations (Epler Wood, 2002). Without proper preparation, risks in fostering local community participation in ecotourism ventures or projects are great. It is strongly advocated that the local community must be informed in advance of all the possible consequences of any tourism development. The local community involved must receive economic benefits and other tangible benefits (i.e. water, roads, and health clinics) from the ecotourism project and its tourist facilities. Facilities such as ecolodges, restaurants or campsites should be run by the local community or in partnership with them. It is also recommended that the local community must formally consent to development in their area.

The fieldwork and the responses from interviews suggests that the local community is the main driver for successful local community participation and ecotourism sites. It is their desire, need, effort, willingness and goodwill that drive the local community to achieve success in what they are doing. As the main bearer of the ecotourism costs, this gives them the incentives to be involved and to ensure that the effort they put in do bring them success. The success of sites such as Kampung Bavanggazo, Batu Puteh and Kampung Rantai are good examples where the local community has shown that their efforts made their participation and sites a success. However, there are also other drivers of success that the local community needs. Other stakeholders, who usually play the role of active advocates such as the government and NGOs, show that their effort also contributes to the success of local community participation and ecotourism sites.

It is suggested that local community participation success contributes to the success of ecotourism sites. This can be explained through other views from tourism literature. The local community is usually seen as an important component of ecotourism product (D'Amore, 1983; Murphy, 1983; Simmons, 1994). Ross (1991) observed that, if pleasant and satisfying experiences 
involving local residents are important in the destination images of tourists, and in their decision-making processes, then consideration of the well being of local community in the context of tourist development would seem critical. This research finds that the community themselves are the attraction of the area, especially with the accompanying cultural features. Kampung Bavanggazo, Batu Puteh, Kampung Rantai and Sukau, all emphasize activities that encourage interaction with the local community. The host-guest relationship also provides experiences not just for the tourist, but for the local community as well, in terms of entrepreneurship and personal development. It was also discovered that the development within the community, both as a group and as individuals, is one of the strong elements of a success indicator for local community participation.

Should residents of tourist communities come to believe that continual tourist development is destroying their physical and social environment, and that tourists symbolises this process, then a degree of unpleasantness may eventually characterise many host-guest interactions, which would ultimately damage the image of friendliness within the locals, so prized by overseas tourists at present. This suggests that local community participation is a crucial element in the ecotourism industry and the success of the industry is dependent on the success of the local community participation process. Only Sukau, as a case study, demonstrates this. The domination of businesses owned by outsiders have lead to the initial bitterness towards the ecotourism industry. Even though these businesses made an effort to involve the local community through buying supplies locally and employing local youths to work at the ecolodges, the local community felt that they were still not progressing proportionally to the industry. This has promoted a spell of hostility towards the industry, and unfortunately, this reflects upon the visitors. On the other hand, this situation also leads to the homestay initiative by the villagers, where some see that they have to take advantage of the prospering ecotourism industry in the area. Homestays have become a starting point for the local community to become micro-entrepreneurs. 
With a stake in the industry, the locals have more inclination towards efforts in conservation of the environment, and promoting an improved host-guest relationship.

Murphy (1985) stressed that, if tourism is to become the successful and selfperpetuating industry that many have advocated, it needs to be planned and managed as a renewable resource industry, based on local resources and community decision-making process. He also advocated the use of an ecological approach to tourism planning which emphasised the need for local control over the development process. The key theme in this suggestion is sustainability. This supports the indicators that have dimensions of sustainability in them such as good ecotourism management/sustainable practice in every way, properly developed sites, promote conservation of natural resources and the preservation of culture. This also suggests that there are some successes of the ecotourism industry that are dependent on the local community's role in the industry. All of the sites have stakes in conservation efforts. Conservation efforts in Kampung Bavanggazo and Kampung Rantai are focused on water catchment areas, which provide essential water supply to the ecotourism sites and the surrounding areas, for human and agricultural usage. Batu Puteh and Sukau are gazetted as a wildlife sanctuary by the State government, therefore, the degree of livelihood that depends on the forest before has now shifted to other industries, one of them being ecotourism. Ecotourism has been promoted as an alternative to hunting and shifting cultivation, as it conserves the area and the ecotourism product itself is dependent on the high quality of the environment. The government and NGOs noted that local communities are the best guardians for the area, as they know the area well and they also have a sense of place towards the area. The Rafflesia Information Centre, on the other hand, is committed to conserve the Rafflesia flower, as a scientific institution rather than a business organisation. All of these sites, with stakes on hand in the ecotourism 
industry, practise eco-friendly and sustainable development to ensure the longevity of the industry.

McIntosh and Goeldner (1986) highlighted the need for wider community involvement in tourism in their five goals of tourism development, in which they argued that tourism development should aim to:

1. Provide a framework for raising the living standards of local people through the economic benefits of tourism;

2. Develop an infrastructure and provide recreational facilities for both residents and visitors;

3. Ensure that the types of development within visitor centres and resorts are appropriate to the purposes of these areas;

4. Establish a development program that is consistent with the cultural, social and economic philosophy of the government and the people of the host area; and

5. Optimise visitor satisfaction.

This shows that in order to achieve development as suggested by McIntosh and Goeldner, local community participation has to be successful. This will ensure that development objectives can be successfully met. The five goals of tourism development are all related to the indicators that are developed from this research. Both indicators for local community participation and ecotourism success have listed many elements which include development of the community, development of infrastructure for the area, appropriate and sustainable development practices, and running projects that are appropriate to the area and host community. This shows that the findings that the research have outlined agree with McIntosh and Goeldner where community involvement is important in tourism development. 
It is true that ecotourism must be sustainable but it has to be a viable business too. The business has to develop the industry to meet the tourist market and attract ecotourists. The operators have to make money to survive. The key is to develop an ecotourism business that is financially successful while protecting or even enhancing the natural environment. Involvement from other interests or stakeholders such as the government is crucial in terms of funding, knowledge and concern. This supports the indicators which have an economic (including business, finance and management) dimension such as well-managed sites, meeting objectives, good cooperation among stakeholders, quality ecotourism products, links to other good tourist sites, ability to draw interest with a 'wow' factor, ability to capitalise strengths, high number of tourist visitations and an increase in capital/finance/revenue. However, this view suggests that there are also successes that do not depend on local community but rather on the practice of the industry itself.

This section suggests that success could not be attributed to efforts made by a single entity but by many. However, among the many, there are one or two factors that contribute to success more than the others including the local community. In other cases such as Sukau, Rafflesia Information Centre and Kampung Rantai, the groups that contribute more towards the success of local community participation and the site are not the local community but the business sector (Sukau) and the government (Rafflesia Information Centre). This is where local community participate but have no real control over the road to success. However, in Sukau's case, since it is the most developed site in terms of ecotourism with a high number of ecolodges and tourists coming to the area, it is perceived as one of the most successful ecotourism sites in Malaysia. Locals took the opportunity as a platform to establish a niche in the industry by promoting homestay programs, which gives a more direct benefit to the local community. 


\subsubsection{Indicators vs. Plans and Policies}

All of the plans and policies discussed in Chapter Four are comprehensively composed at both national and state levels. Many of the plans and policies consider ecotourism as an important industry to be developed. Many have cited reasons for developing it but the popular reasons that come across the plans and policies under review are 1) ecotourism is an important tool for conservation; and 2) ecotourism can provide desirable economic opportunities.

The plans and policies that are relevant to ecotourism in Chapter 4 indicated that they are going in the right direction where there is an emphasis on the local community. As discussed before, local community participation success contributes to a great extent to the success of ecotourism sites. Therefore the plans and policies cast a positive light on local community participation as an important element in ecotourism. This has been demonstrated in Chapter Four as highly encouraging and has sparked interest among policy makers. However, the plans and policies are quite realistic in terms of strategies for local community participation. They show that there is a need for capacity building amongst the local communities. These plans have a strong focus on the development of ecotourism and its capabilities, as well as a high level of commitment to these rural communities, which is a classic example of ecotourism planning.

Based on research findings, this holds true as many respondents recognise that local community capacity is generally limited and there is the need to build that capacity through education and experience. Governments and NGOs have been forefront on advocating the ecotourism industry and its local community participation activities. Both success indicators for local community participation and ecotourism sites are dominated by indicators that are relevant to the community and their well being. This shows that the plans and policies have 
been prepared based on the right direction of present ecotourism industry in Sabah.

The Malaysian Plans, which is the general outline of development and direction for Malaysia, has been emphasising local community participation but only mentions enhancing local community participation through cultural and handicraft product development programs. The research findings however suggests differently. It is found that the local community wants more than just being involved as a tourism product or the maker of products such as handicrafts. Many respondents feel that they want to be involved more in ecotourism operations, especially at a higher level and especially at the decisionmaking level, or becoming micro-entrepreneurs within the ecotourism industry. After establishing that ecotourism is a business concerned with nature, first and foremost, community involvement should also be included in the business side. There should be an indication in the Malaysian Plans to have a constant effort to increase the level of involvement of local communities in the ecotourism industry. Even though the Malaysian Plan is prepared for the general direction and achievement of all industries and sectors in Malaysia, the tourism industry being the second most important industry in Malaysia with ecotourism being the desired practice in the industry, integration of local community into the participation process should be outlined in detail with higher aims.

However, the National Tourism Policy outlined its strategies closely to the sets of success indicators of local community participation and ecotourism sites. The policy programs are aimed at increasing the participation of local communities and maximising economic opportunities. The policy thrusts are focused on rural and community development especially those that encourage equitable economic and social development throughout the country, generating employment and encouraging participation by all ethnic communities in the tourism industry. 
The National Ecotourism Plan has specific and comprehensive plans that cater to the ecotourism industry both in Malaysia and in Sabah. It outlines details on access, facilities, attraction and activities around Sabah. It also points out that the aspects of local involvement and generation of economic benefits are rarely integrated into management and decision-making in practice. Therefore, it emphasises that successful ecotourism requires the creation and involvement of local stakeholders (individuals and communities) and an emphasis on local investment, control and decision-making. The plan emphasises the environment side of ecotourism but the local community participation issues are not forgotten. This research suggests that there is relevancy of indicators to the business side of ecotourism. In general, the National Tourism Policy has captured the findings of this research as the community and its well being is recognised as the main element in the success of ecotourism and its local community participation.

The Outline Perspective Plan of Sabah is essentially a general development strategy of Sabah. Tourism is identified as the area with the highest potential and the state's natural beauty is recognised as the main asset. However, the OPPS did not focus on local community participation. Here, only the element of environment is reflected upon the indicators. Others such as the business aspect and the community development are not. However, it does emphasise education and awareness within the tourism strategy. Based on the research findings, indicators that are relevant to the environment have the least count from the total number of indicators. This shows that, even though environmental issues are the origin of ecotourism, it also counts as the least important in indicating success compared to issues such as community and their well-being, and ecotourism business. This suggests that the OPPS strategy is not parallel to the present needs of the state's ecotourism industry that are based on these research findings. This research clearly indicates that the local community's well being is the main issue that needs to be focused on to ensure that future ecotourism industry strategies address this issue. 
The Sabah Conservation Strategy provides a thorough guide to environmental policies and action. This is essential in implementing conservation in selected areas in the state. The plan only touches on the issue of conservation of the environment. Although it mentions that the management of natural resources should be holistic and multi-sectoral, where ecotourism fits as one of the tools in conserving the environment, it goes into detail on how the business and the community can contribute to the conservation of the area. The literature review indicates that the conservation efforts disseminate benefits to the local community and the area itself. This is true based on the research where Kampung Bavanggazo and Kampung Rantai ecotourism promote the conservation of water catchments at each village, where both are important sources of water supply to the villages and the surrounding areas. The indicator suggests that the conservation element in ecotourism is not as important as the business aspect for indicating success. This is based on the findings where indicators that are relevant to the environment have the least count from the total number of success indicators, both for local community participation and ecotourism sites. In order for conservation of the environment to work, perhaps it is better to focus more on the community's well being and the business side of ecotourism. It is more conducive to conserve the environment with the support of the local community that are committed to an ecotourism industry that is sustainable.

The Sabah Tourism Master Plan outlines Sabah's tourism development plan and places tourism within the new economic development of Sabah. Unfortunately, it does not specify ecotourism as a tool for conservation. While it promotes integration among stakeholders, especially between tour operators and the local community, it does not specify how the local community can achieve a higher level of participation. The plan mentions some details on success indicators, while the business elements on ecotourism are not elaborated. The Tourism 
Master Plan is clearly geared towards developing other types of tourism especially mass tourism and also outlines strategies on how to capitalise the nature of Sabah for tourism. There is a big gap between what has been outlined in the Master Plan and the research findings in this thesis. The success indicators show that there should be a focus on issues on local community and their wellbeing. Recognising that ecotourism is a business entity and business savviness is needed to run ecotourism sites is required, and at the same time, putting effort in conserving the environment. Since Sabah has put ecotourism as an important tourism niche in the tourism industry, the research findings should be useful in addressing the present needs of the industry and to develop further strategies for the future.

Looking at the indicators, there are three elements that have been identified, these are community well-being, conservation and business at both local community participation and ecotourism group of indicators. The review of plans and policies revealed that there are strategies for ecotourism to achieve community well being and conservation, but not so much on business. This is hardly surprising, as the literature also does not place much emphasis on the business aspect of ecotourism, as the main objective is to conserve the environment. Looking through the history of ecotourism, it originates from the concern of environmental degradation.

It is obvious that different plans and policies have different directions and strategies based on their objectives. However, it is also noted that these plans and policies also adopted different approaches to ecotourism. However, this research shows the more practical dimension of ecotourism where business is the essence of ecotourism and the success of ecotourism largely depends on the business aspect of it amongst other things. The comparative analysis between the indicators and case studies is bridging the gap where the indicators can fill in the plans and policies to make it more practical to Sabah. It is hoped in the 
future that tourism plans and policies for Sabah will include assessments of strategies where success indicators can be applied.

\subsubsection{Indicators vs. Case Studies}

The development of both sets of success indicators for local community participation and ecotourism is based on the current situation at the five research sites. The current situation was documented and analysed in each case study. The similarities that were found at all the sites suggested that certain indicators could be generalised and applicable to some extent to all sites. This suggests that there is a formed general opinion on the indicators of success for all sites. The differences that were found in the case studies suggest that indicators that are relevant to the differences may need to be further developed as it does not represent a common ground.

There are similarities at all the sites in terms of good access to the sites, ethnic groups, natural attractions, cultural products, complimentary/supporting attractions and major festival/events. These are all business related factors that contribute to some of the business related success indicators both for local community participation and ecotourism. All of these sites have the essential product that contribute to the development of ecotourism sites such as natural attractions, ethnic groups and its accompanying cultural features, major festivals and events, and complimentary/supporting attractions. The development or assurance of quality ecotourism products is an essential element in indicating the success of a site. All sites also have good access in terms of transportation infrastructure, which is beneficial to business operations.

Some similarities are related to the community's development and their well being. All the sites have mainly farmers and labourers residing in the village and nearby areas. This gives a good reason for ecotourism with local community 
participation activities to be established at all these sites. The creation of employment opportunities from ecotourism is usually the main reason for villagers to undertake and accept ecotourism. The acceptance of this industry and the commitment towards the industry are factors that contribute to the success indicators. Another factor is the infrastructure of the village. The development of infrastructure is seen to be the physical indication of success. Infrastructure development is a result of gotong royong, funding or reinvestment of profit.

Another similarity is based on the environment. This is also the main element of ecotourism. Obviously, these conservation efforts benefit the whole community and the area itself. Other than conserving the local environment, other elements such as water catchments, are conserved which is essential to the daily life of the local community and the tourists. The conservation of nature is good business practice in ecotourism as it ensures that the quality of the flora and fauna is retained. The effort and the outcome of environmental conservation contribute to the success indicators that are relevant to the environment and ecotourism.

The differences that arose from the case studies were analysed, and it is suggested that the indicators that are relevant to the differences might need to be further developed, as it does not represent a common ground. This is where some of the indicators are different from the others. However, the indicators are still applicable to all sites but with different measurements.

In the business aspect, all the sites had different prices offered for the experience of ecotourism, therefore this influenced the type of tourists that came to these sites and the expectations of the experiences that these sites should provide. With these variables i.e. prices, type of tourists etc., the stakeholders will be interpreting different success indications at different sites. 
Some differences are relevant to ecotourism. This is heavily skewed to the local community participation side of ecotourism. These differences showed the level of community involvement, average income per person from ecotourism and the decision-making process. All these elements varied from site to site and this affects the perception of success from the stakeholders. This is also related to the other difference that is relevant to the community. The final difference is the welfare fund. Only three villages have this scheme i.e. Kampung Bavanggazo, Batu Puteh and Kampung Rantai. These three villages have a high-level of involvement from the local community while the other two do not. Therefore, the perception of benefits to each site is varied.

It is important to note that all the sites with the exception of Sukau, received some form of funding and/or assistance. This raises the question of the success of the ecotourism operation at these sites. It is not known if, without funding and assistance from outside agencies, these ecotourism sites would attain the same degree of success in terms of management, use of resources, profit, logistics and the like. On the other hand, funding is needed to build capacity in the area and the local community there to be integrated into the ecotourism industry. Some sites received more funding than the others. Batu Puteh has been receiving the highest amount of funding, not just from the Government and NGOs but also from private companies. With that funding, they were able to achieve the level that they are at now and at the same time, win two awards based on its activities and local community participation. Kampung Rantai only gets assistance from PACOS and has received much less funding than Batu Puteh. The ecotourism business has not intensified yet. Funding is essential but it comes with expectations. The more heavily funded a site is, the more expectations are put on that site. 
The similarities show that the indicators that are relevant in this category have a high degree of applicability in all sites. They have a common ground and similar situation. The differences show that some indicators have variations. The analysis of local community participation success indicators by site suggests that there are two success indicators that are similar to all sites, which are visible community involvement and commitment and benefits received. This shows that all sites agreed to these indicators to some extent. The level of involvement and amount of benefits received may differ. Local community involvement usually means employment opportunities at the ecotourism sites. With indicators that are relevant to the community and their well being dominated at all sites, this suggests that local community participation success is very much dependent on the focus of locals and their well being that arises from their participation.

The analysis for ecotourism success indicators by site suggests that the size of indicators might be related to the experience of the site. Kampung Bavanggazo is the most experienced site with the most indicators based on village experience compared to other sites. Based on the indicators' content, all sites suggested indicators that are dominated by business related indicators with the exception of Rafflesia Information Centre.

However, the development of both sets of indicators takes into account the different perceptions that they have. Therefore, the indicators developed can be applicable to any site, but with different kinds of measurement.

\subsection{Overall view of the Thesis}

This research essentially sets out to identify indicators for local community participation success and indicators for site success. The first research issue that this thesis addressed is defining and measuring the success of local community 
participation at ecotourism sites in the Sabah context. As mentioned before, local community participation is deemed a critical component for ecotourism operation. A set of local community participation success indicators will become valuable in making the right first step in any future ecotourism project. In this research, 15 indicators were developed where the characteristics focused on the community and its well being, the business aspect of ecotourism and the environmental aspect of ecotourism.

\section{Table 8. 1 Summaries of Objectives}

\begin{tabular}{|c|c|c|}
\hline RESEARCH OBJECTIVES & Checklist & CHAPTER LOCATED \\
\hline $\begin{array}{l}\text { 1. Determine what local community means } \\
\text { in the Sabah context. }\end{array}$ & $\sqrt{ }$ & $\begin{array}{l}\text { Chapter } 1 \\
\text { Chapter } 3\end{array}$ \\
\hline $\begin{array}{l}\text { 2. Determine what makes a site in the } \\
\text { Sabah context. }\end{array}$ & $\sqrt{ }$ & $\begin{array}{l}\text { Chapter } 1 \\
\text { Chapter } 3\end{array}$ \\
\hline $\begin{array}{l}\text { 3. Analyse plans and policies relevant to } \\
\text { the local community participation and } \\
\text { ecotourism sites in Sabah. }\end{array}$ & $\sqrt{ }$ & Chapter 4 \\
\hline 4. Establish case studies for research sites. & $\sqrt{ }$ & Chapter 5 \\
\hline $\begin{array}{l}\text { 5. Develop indicators for local community } \\
\text { participation success. }\end{array}$ & $\sqrt{ }$ & Chapter 6 \\
\hline $\begin{array}{l}\text { 6. Develop indicators for ecotourism site } \\
\text { success. }\end{array}$ & $\sqrt{ }$ & Chapter 7 \\
\hline $\begin{array}{l}\text { 7. Analyse the sets of indicators based on } \\
\text { plans and policies, and case studies. }\end{array}$ & $\sqrt{ }$ & Chapter 8 \\
\hline $\begin{array}{l}\text { 8. Thesis discussion and concluding } \\
\text { remarks }\end{array}$ & $\sqrt{ }$ & Chapter 8 \\
\hline
\end{tabular}

The second research issue that the thesis addresses is the issue of defining and measuring the success of ecotourism sites in the Sabah context. The sites were 
selected according to the research context. This is done to ensure that the application of the ecotourism concept is valid, as this will affect the results of the research. In this part of the research, 21 indicators were developed where the characteristics focused on the meaning and aspirations of ecotourism, business aspects of ecotourism and social development.

The developments of success indicators of both local community participation and ecotourism sites have presented an insight into the characteristics that make up the success factors. Each characteristic has also presented its importance within the whole set of indicators. The thesis has also managed to establish sets of indicators ranked with its importance. With the two sets of indicators of local community participation and ecotourism sites, a relationship between both has been established. It is interesting to analyse the relationship between both indicators and develop patterns and opinion as suggested in the previous section. This analysis suggests that success could not be attributed to the effort made by a single entity but by many. Since local community participation is a sub-set of the ecotourism site, it contributes largely to the success of the ecotourism site. These indicators are very useful in assessing the dimensions of success for local community participation and ecotourism site in Sabah.

This thesis presents eight chapters altogether and has completed all its objectives (Table 8.1) that the research sets out to explore and examine. Each of the objectives of this research has been addressed where this enables the research to establish and set its direction. The literature advocates that local community participation is a critical component of ecotourism. Ecotourism success may depend largely on the success of community participation, as it is one of the more important elements in its current definition. The literature gaps as mentioned in Chapter Two highlight the need for defining and measuring success of local community participation and ecotourism sites. The gap has been bridged from the results and analysis. The results have come up with two sets of 
success indicators and suggest that the business aspect of ecotourism dominates the characteristics of these indicators.

An analysis of the plans and policies explores these indicators in-depth and ties them in with the research findings and literature review in the concluding chapter on the indicators in the industry. The case studies have helped to understand the development of the indicators and show how the similarities and differences of the sites may pose issues in success measurement against the indicators. All of these findings hope to contribute to the greater understanding of ecotourism development. It also helps local community participation advocates to evaluate and monitor the process with greater understanding. Ecotourism stakeholders may benefit from the knowledge to establish and operate successful ecotourism projects. 


\subsection{Conclusions}

\subsubsection{Introduction}

This research attempts to understand the concept of success for local community participation and ecotourism sites and develop sets of indicators for those successes, in particular reference to Sabah in Malaysia. There are two main research issues that have been addressed in this thesis: 1) Interpreting and developing success for local community participation at ecotourism sites, and 2) Interpreting and developing the success of ecotourism sites. These research issues have led to the development of research questions. These questions were followed by nine research objectives that set the direction and the content of the thesis. As stated previously in Chapter One and Three, this study has adopted a case study methodology with the emphasis on comparative analysis. This final section shows how each of the chapters have contributed to the thesis as a whole. The contributions of the research to the academic and industry are outlined. This section will also identify directions for further study.

\subsubsection{Research Syntheses}

The thesis has provided the contributions that add to the literature in ecotourism especially those that deal with the success of local community participation and ecotourism sites. However, one must bear in mind that the indicators that have been developed here are based on ecotourism sites which have not reached its maturity yet as shown in the case studies. Therefore, it is expected that the indicators will evolve as the local community participation process and the sites evolve.

The indicators for local community participation success depends on variables such as ownership, size, accessibility, and outsiders' involvement and these are 
very important in determining the perception of success. The analysis of the indicators of local community participation by theme revealed that there are three clusters of indicators, where one cluster is related to the community and its well being and the other one is related to the business side of ecotourism. The last cluster is related to the environment side of ecotourism. The most important success indicator determined by this research is the visibility of community involvement and their commitment towards local community participation efforts where all the stakeholders at every site rated this indicator as an indicator with the highest importance. The literature review only emphasised on the environment and its conservation efforts while outlining beneficially active socioeconomic involvement of local populations. Therefore this research suggests that while the community and the environment element is essential in ecotourism, the business elements are just as important in making sure that the local community participation process is successful.

There are several significant findings of this research for local community participation. It was found that the number of the indicators contributed is based on how close the stakeholders are to the process of local community participation in the ecotourism sites. The research also revealed that, while all stakeholders are different and have different perspectives of the issues, the indicators contributed by them consist mainly of those relevant to the community and its well being with 'visible community involvement and commitment' as the strongest indicator. This leads to the findings that the shared success indicators are the strongest indicators as it reflects every group's perspective. It was found that the success indicators that are specific to sites are mainly concerned with the community and the well-being of that community.

On the other hand, the conclusion made from the ecotourism site success indicators that were developed by this research imply that these indicators are mainly concerned with the output of ecotourism and these are mainly dealt with 
at macro elements. The indicators are influenced by many variables that shape the indicators such as leadership, ownership, size, stakeholders' degree of involvement and so on.

It is found that there are more dimensions of ecotourism site success than what tourism literature suggests. This research has provided more insight on what is success besides conserving the natural resources and having financial gains. There are three clusters of indicators revealed by this research. The first cluster is a group of indicators that reflect the meaning and aspiration of ecotourism while the second cluster is a group of indicators that is relevant to the business side of ecotourism. The third cluster is a group of indicators that are relevant to the social development of the site. These clusters, which were developed from the thematic analysis, suggest that the practice of ecotourism and its perception of success in this research are broader and go beyond the theoretical definition. It is also revealed that there are more indicators that are relevant to the business side of ecotourism but there is still awareness on the issue of benefits received by the local community from ecotourism.

The research revealed that each stakeholder has a similar context in viewing what constitutes success of an ecotourism site as each stakeholder has their own perspectives and motives but capable of having similar opinions which constitute success for local community participation. There are several significant findings of this research for ecotourism site success indicators. The research revealed that, while all stakeholders are different and with different perspectives of the issues, the indicators contributed by them consist mainly of those relevant to local community participation with 'visible local community participation/high level of participation' where it is related to the meaning of ecotourism, and the business element with 'good cooperation among stakeholders' as the strongest indicators for ecotourism site success. This again leads to the findings that the shared success indicators are the strongest indicators as it reflects every group's 
perspective. It is found that business-based indicators mainly dominate the success indicators that are specific to the sites, which is similar to the indicators by stakeholders' analysis.

While there are one or two shared indicators, there are more indicators that are not shared among the stakeholders. This implies that, while the stakeholders need to work together in the industry as promoted by the literature review and plans and policies, each of the stakeholders have different sets of objectives, directions and motives. This research has justified that each stakeholder has an important role in the ecotourism industry and this is supported by the literature review and plans and policies where integrated development is one of the best approaches in making ecotourism work and successful. These findings should be taken seriously by the stakeholders as this also may be the hindrance of success if the integration of every stakeholder does not produce the synergy needed. The plans and policies are usually quite clear on paper on what can be done to achieve success, but the mechanics in reality to achieve this success is not that easy if all the main players have different directions. Therefore, rather than outlining the strategies of the ecotourism industry and what are the roles of the stakeholders in the industry, this research implies that there should be more consideration to explore or depict more on how the stakeholders can come together and combine their expertise and capacity, re-interpret their role to suit the industry and decide what orientation they should take. Based on this research, business orientation should be more feasible to achieve success in the industry.

When interpreting the indicators by site, clearly there is not much difference between indicators that are specific to stakeholders and sites. The local community participation's strongest success indicator showed that the 'visible community involvement and commitment' as site specific which is the same with the stakeholder specific indicator. The ecotourism site's strongest success 
indicator profiled 'good cooperation among stakeholders' as site specific which also acts as a stakeholder specific indicator. However, another indicator which is 'visible local community participation/high level of participation' is mentioned from all sites except Sukau. This can be explained by the fact that Sukau's ecotourism industry has been dominated by businesses and the local community thought that the level of local community participation is not high in that village. Therefore, the locals don't see that as a success indicator. This is also similar to local community participation success indicators where both stakeholder- and site-specific indicators mention the same indicators. This research suggests that these indicators are rated highly as a success factor from all stakeholders despite their differences and from all sites despite their level of development. These findings should be used by policy makers if they would like to develop strategies where an ecotourism development is integrated as the operational framework, where all the stakeholders come together to contribute. These indicators are the common factor for the stakeholders where they can aim and set their objectives in order to achieve success for both local community participation and the site itself. These findings also contributed a body of knowledge to the literature review, not just in terms of its common objective aspects, but also on the fact that there is a similarity in success of local community participation and ecotourism sites. Both placed the importance of visible local participation as its strongest indicators. This indicates that local community participation is important in the ecotourism industry and the success of the sites depend on it, and this indicator is rather important compared to the other indicators that have been put forward by the literature.

The literature review showed significant similarity in terms of the nature of indicators in terms of community well being, conservation of the natural area and development of the area. However, this was rarely mentioned when discussing the importance of the issue of business success. The indicators from the literature review are more inclined towards macro level for example conservation 
of the area, financial gain, economic benefits, culture effect, benefits of tourism rather than at micro level i.e. local site, local economy or local community. On the other hand, there are many indicators from this research that belong at the micro level, which are more specific such as visible local community participation, large number of tourists, satisfied tourists independent community and, a happy and motivated community. This is clearly a different dimension of success where one is quite general while the other is quite specific. This can be explained as the literature review draws heavily on its arguments from the definition of ecotourism where the elements of ecotourism are quite general and open to individual interpretation. The literature review also aims to approve or disprove the theory of ecotourism by making comparisons where the comparative common ground should be generic to be analytically feasible. This research takes several steps further by analysing an indicator not just generally, but analysing it further by using stakeholders and sites in the same area i.e. State of Sabah. This is clearly a significant contribution, where the indicators are much finer and much more reliable as it takes into account all stakeholders from all sites. Overall, the research has developed more indicators compared to the one that has been drawn from the literature review. This suggests that, while the indicators may be generic and applicable to other sites, a specific site may produce or develop more indicators based on its locality. This is consistent with the results from Chapter 6 i.e. success indicators for local community participation.

The research revealed that both local community participation and ecotourism site success indicated that the important indicators are concerned with local community. This is quite similar with what the plans and policies have outlined. This is an indication that the government is heading in the right direction in developing the ecotourism industry and encouraging local community to be involved in the industry. The plans and policies recognise that the local community is an integral part of ecotourism. There is also the indication that the 
local community should be more involved in the business side of ecotourism, however there is not much emphasis on the business aspect of ecotourism. This has not been accounted for since most of the literature do not recognise the importance of business in conserving the natural environment and contributing to the well being of the local community. The absence of the business aspect also can be contributed to the fact that ecotourism, on the national and state level, is mainly used as a tool for development or conservation. The policy makers also do not recognise that business is an important factor in development and conservation. Conservation will not be achieved if local community are still struggling to make ends meet, even with awareness of conservation, unless if they have a stable income and able to take care of themselves. Therefore, the implication from this research is that the business environment should be promoted in parallel with the ecotourism industry.

\subsubsection{Research Contributions}

This thesis provides comprehensive insights into the success of ecotourism sites and local community participation in ecotourism in Sabah. It has developed two sets of success indicators and managed to explore the applicability of the indicators to the industry by understanding their characteristics in-depth. The indicators are quite consistent with those others drawn from the literature review, however, there are more indicators developed in this research, which are site-specific indicators. The analysis also shows that there are issues that need to be addressed with regards to these indicators. These indicators are outputbased, therefore there is a need to establish the measurement or the parameters of these indicators to make it more quantifiable and more meaningful. Another aspect that the research identified is that the strongest indicators are those that were agreed by stakeholders and the recipients that the benefits are both the site and the local community. While this is emphasising the importance of local community in the ecotourism set up, it is also suggesting that a set up of an 
integrated development and management among stakeholders, of local community and ecotourism with the common objective and common operational process, are seen as successful. This may not be realistic as there is a specific scenario that suggests that the stakeholders do have the inclination to see success based on their own needs and motives. However, this research has outlined these criticisms constructively in the results chapters. All of these findings, which have been discussed on the research syntheses sections, are useful to academics and stakeholders of ecotourism industry.

Nevertheless, this research has contributed to a greater understanding of ecotourism development. It will help local community participation advocates to evaluate and monitor local community participation with greater understanding. Ecotourism stakeholders, especially local community, government and NGOs, and also the business may benefit from this thesis in terms of knowledge in establishing and operating a successful ecotourism site.

This thesis has also bridged some of the gaps in the issues of the success of local community participation and ecotourism in the tourism literature. The research synthesis has outlined that there are new findings that are based on indicator development, local community participation process and ecotourism operation. The literature review also reveals that there are very limited discussions on tools or procedures to develop indicators even though there are ample discussion on the successes of ecotourism sites and local community participation.

This research has attempted to use this knowledge i.e. ecotourism and local community participation while filling the gaps i.e. success indicators, drawing from the experiences of Sabah. In this regard, it may be seen as a pioneer study. It provides an extended body of knowledge to existing studies in the field and supplements extensions to any existing success indicators that have been developed by certain organizations. It also contributes to the localisation of 
successes and challenges that the other studies may have encountered by redefining successes in ecotourism and local community participation.

\subsubsection{Suggestions for Further Research}

There are two issues that the researcher strongly feels would benefit from further research. These are the issues that may enhance the significance of this study and will take the study to the next level. These are 1) Measurement and applicability; and 2) Cross culture differentiation in developing indicators.

\section{Measurement and applicability}

There are two issues that can be further developed. This research has identified that the indicators developed are output based and need to have some level of measurement to make it more meaningful. Therefore, the first issue in the research limitation is the measurement of indicators. Some of the sites shared the same indicators but the case studies have shown that different areas have different environments that contribute to different degrees of success. The differences of the degree of success need to be identified and further developed so that the indicators have some sort of measurement that can be used in practice. With the development of measurement, the second issue of applicability can be studied. While the body of indicators have been developed, there is still a need to explore the issue of integrity of indicators. This is where the indicators can be tested in the industry, and how it can be adjusted to suit different environments.

\section{Cross culture differentiation in developing indicators}

This thesis also presents two sets of indicators that are developed in a specific site. It is found from the thesis that the indicators are quite consistent with the 
indicators that have been developed through literature review. However, ecotourism sites and local community participation are found across the world and it would be interesting to study the cross culture differentiation in developing these types of indicators. Some cultures may give different emphasis on different aspects. This research has identified, from the Sabah point of view, the importance of business elements as a success factor in both local community participation and ecotourism sites. Culture definitely will play a major role in shaping these indicators. The cultural differences can be examined from a range of states (Malaysia) to regions (Asia). Cross-cultural studies will also lead to the applicability of these indicators in other sites outside Sabah and make this study more useful across the region.

\subsubsection{Final Remarks}

This study is a first step in measuring success for local community participation and ecotourism site, in particular, Sabah's cases. Using the results of this study, the findings should be able to facilitate further research. The researcher encourages the practical application of the indicators that have been developed in this thesis.

It is envisioned that the work from this thesis can be put to use not only in assessing the performance of local community participation and ecotourism sites, but developing specific indicators in specific sites. The performance of site and local community participation processes are quite critical to any ecotourism operation, or any activity in any tourism segment. Ecotourism is particularly close to the heart of the researcher as it involves local people, who bear most of the cost of tourism development, the environment (including accompanying cultural features), where its conservation is essential to mankind, and the experience of the tourists, where experiencing other cultures and places promotes more human integration and understanding. 


\section{BIBLIOGRAPHY}

Acott, T. G., La Trobe, H. L., \& Howard, S. H. (1998). An evaluation of deep ecotourism and shallow ecotourism. Journal of Sustainable Tourism, 6(3), 238-253.

Addison, G. (2001). The great ecotourism debate. Retrieved October 25, 2001, from www.outthere.com

AFP. (2002, November 4). Asia-Pacific tourism facing tough times. Daily Express.

Allen, W. (2002). Improving the use of collaborative approaches within natural resource management. Retrieved August 16, 2002, from http://nrm.massey.ac.nz/changelinks/ par_eval.html

Al-Sayed, M., \& Al-Langawi, A. (2003). Biological resources conservation through ecotourism development. Journal of Arid Environments, 54(1), 225-236.

Aman, M. (2004). Halatuju Pembangunan dan Kemajuan Negeri Sabah. (s.I.)

Andriatis, K. (2005). Community group's perceptions of and preferences for tourism development: Evidence from Crete. Annals of Tourism Research. 29(1), 67-90.

Arnstein, S. (1969). Ladder of citizen participation. Journal of the American Institute of Planners. 35(4), 216-224. 
Ashton, R. E. (1991). Fundamentals of ecotourism. A workbook for nonprofit and travel programs. Paper presented at the Ecotourism Management Workshop, June 18-22, 1991. Washington, D.C.

Ashton, R. E. (1991). Land use planning and ecotourism. In J. A. Kusler (Ed.), Ecotourism and Resource Conservation, Vol. 1, pp. 45-53. Madison: Omni press.

Ateljevic, J. (2002). Small tourism firms: Owners, environment and management practices in the centre stage of New Zealand. Ph.D. Thesis, Victoria University of Wellington, Wellington.

Ayala, H. (1995). Eco resort: a 'green' master plan for the international resort industry. International Journal of Hospitality Management, 14 (3-4), 351374.

Ayala, H. (1996 a). Resort ecotourism: A master plan for experience management. The Cornell Hotel and Restaurant Administration Quarterly, $37(5), 46-53$.

Ayala, H. (1996 b). Resort ecotourism: A paradigm for the 21st century. The Cornell Hotel and Restaurant Administration Quarterly, 37(5), 54-61.

Ayala, H. (1997). Resort ecotourism: A catalyst for national and regional partnerships. The Cornell Hotel and Restaurant Administration Quarterly, $38(4), 4$.

Bachrach, P. \& Botwinick, A. (1992). Power and empowerment: A radical theory on participatory democracy. Temple University Press, Philadelphia. 
Ballantine, J., \& Eagles, P. F. J. (1994). Defining the Canadian ecotourists. Journal of Sustainable Tourism, 2 (4), 210-214.

Barnett, P. (2001). Fair trade in tourism. In Industry and environment ecotourism and sustainability (July-December 2001 ed.), (Vol. 24). Paris: United Nations Environment Programme, Division of Technology, Industry and Economics.

Baum, T. (1996). Tourism and the host community: A cautionary tale. Tourism Management, $17(2), 149-150$.

Baum, T. (1999). Themes and issues in comparative destination research: the use of lesson drawing in comparative tourism research in the North Atlantic. Tourism Management, 20 (5), 627-633.

Beard, C., \& Hartmann, R. (1997). Naturally enterprising: Eco-design, creative thinking and the greening of business products. European Business Review, $97(5), 237-243$.

Beeton, S. (1998). Ecotourism - A practical guide for rural communities. Collingwood: Landlinks Press.

Beeton, S. (2001). Book Review: Ecotourism: Impacts, potentials and possibilities. In Stephen Wearing and John Neil (Eds.), ButterworthHeinemann, Oxford, 1999, Tourism Management, 22 (5), 576-578.

Belsky, J. (1999). Misrepresenting communities: The politics of community-based rural ecotourism in gales point manatee, Belize. Rural Sociology, 64 (4), 641-666. 
Bernama. (2001, February 24). US slowdown won't affect Malaysian tourism, says Ng. Daily Express, pp. 1.

Bernama. (2001, April 10). Sustainable tourism development: Mahathir. Daily Express, pp. 1.

Bernama. (2002, October 16). Kadir: Blast will not affect tourism. Daily Express.

Bernama. (2002, December 1). Travel warnings adverse for tourism: Mahathir. Daily Express.

Bernama. (2003, January 26). Japanese activist: Immense benefit from ecotourism. Daily Express.

Bernama. (2003, April 4). Malaysia to focus on domestic tourism. Daily Express.

Bernama. (2003, April 27). Tourism Malaysia sets up task force. Daily Express.

Bernama. (2003, March 21). 'Tourism may be affected'. Daily Express.

Bernama. (2003, May 10). Tourism sector expected to get a boost. Daily Express.

Besleme, K., Maser, E., \& Silverstein, J. (1999). A community indicators case study: Addressing the quality of life in two communities. San Francisco: Redefining Progress.

Bhattacharya, P. and Kumari, S. (2004). Application of Criteria and Indicator for Sustainable Ecotourism: Scenario under Globalization. Working Paper for IASCP Bi-Annual Conference on "The Commons in an Age of Global 
Transition: Challenges, Risk and Opportunities" at Oxaca, Mexico. 9-14 August 2004.

Birley, G., \& Moreland, N. (1998). A practical guide to academic research. London: Kogan Page.

Black, T. R. (1993). Evaluating social science research. London: Sage Publications.

Blamey, R. K. (1995). The nature of ecotourism, Occasional Paper No. 21. Canberra: ACT: Bureau of Tourism Research.

Blamey, R. K. (1997). Ecotourism: The search for an operational definition. Journal of Sustainable Tourism, 5(2), 109-130.

Blangy, S., \& Nielson, T. (1993). Ecotourism and minimum impact policy. Annals of Tourism Research, 20(2), 257-360.

Blank, U. (1989). The community tourism industry imperative: The necessity, the opportunities, its potential. State College, PA: Venture Publishing Inc.

Bordens, K. S., \& Abbott, B. B. (1991). Research design and methods - A process approach. Mountain View, California: Mayfield.

Botrill, C. G., \& Pearce, D. G. (1995). Ecotourism: towards a key elements approach to operationalising the concept. Journal of Sustainable Tourism, $3(1), 45-54$.

Boyatziz, R. E. (1998). Transforming Qualitative Information - Thematic Analysis and Code Development. Sage Publications, New York. 
Boyd, S. W. (2000). Managing ecotourism: an opportunity spectrum approach. In C. Ryan \& S. Page (Eds.), Tourism Management - Towards the New Millennium. Oxford: Pergamon-Elsevier Science.

Boyd, S. W., \& Butler, R. W. (1996). Managing ecotourism: an opportunity spectrum approach. Tourism Management, 17(8), 557-566.

Brandon, K. (1993). Basic steps toward encouraging local participation in nature tourism projects. In K. Lindberg \& D. E. Hawkins (Eds.), Ecotourism - $A$ guide for planners and managers (Vol. 1). Vermont: The Ecotourism Society.

Briedenhann, J., \& Wickens, E. (2004). Tourism routes as a tool for the economic development of rural areas--vibrant hope or impossible dream? Tourism Management, 25(11), 71-79.

Britton, S., \& Clark, W. C. (1987). Ambiguos alternative: tourism in small developing countries. Suva, Fiji: University of the South Pacific.

Brohman, J. (1996). New directions in tourism for third world development. Annals of Tourism Research. 23(1), 48-70.

Boo, E. (1992) Ecotourism: The potentials and pitfalls. Country case studies. WWF, Baltimore.

Buckley, R. (1994). A framework for ecotourism. Annals of Tourism Research, 21(3), 661-665. 
Buckley, R. (2001). Book review: Ecotourism: An Introduction: By David A Fennell. Routledge New York, 1999, in Annals of Tourism Research, 28(1), 256-258.

Buckley, R. (2003). Book review: Natural area tourism: Ecology, impacts and management. Annals of Tourism Research, 30(2), 497-499.

Buckley, R. C., \& Clough, E. (1997). Who is selling ecotourism to whom? Annals of Tourism Research, 24(2), 479-480.

Budowski, G. (1976). Tourism and environmental conservation: conflict, coexistence, or symbiosis? Environmental Conservation, 3, 27-31.

Burton, F. (1998). Can ecotourism objectives be achieved? Annals of Tourism Research, 25(3), 755-758.

Butler, J. R. (1992). Ecotourism: It's changing face and evolving Philosophy. Paper presented at the World Congress on National Parks and Protected Areas IV, February 10-21, Caracas, Venezuela.

Butler, R. W. (1990). Alternative tourism: Pious hope or Trojan horse? Journal of Travel Research, 28(3), 40-45.

Butler, R. and Hinch, T. (Ed.), (1996). Tourism and Indigenous People. International Thomson Business Press, Cornwall.

Campbell, L. M. (2002). Conservation narratives and the "received wisdom" of ecotourism: case studies from Costa Rica. International Journal of Sustainable Development, 5(3), 300-325 
Campbell, L. M. (1999). Ecotourism in rural developing communities. Annals of Tourism Research, 26(3), 534-553.

Carter, S., \& Jones-Evans, D. (2000). Enterprise and small business - Principles, practice and policy. Edinburgh: Financial Times-Prentice Hall.

Cater, E. (1993). Ecotourism in the Third World: Problems for sustainable development. Tourism Management, 14(2).

Cater, E. (1994). Ecotourism in the Third World - Problems and prospects for sustainability. In E. Cater \& G. Lowman (Eds.), Ecotourism - A sustainable option? (pp. 69-86). Chichester: John Wiley and Sons.

Cater, E. (1997). Ecotourism: Dimensions of Sustainability. Paper presented at the Ecotourism for Forest Conservation and Community Development, Bangkok, Thailand.

Cater, E., \& Lowman, G. (1994). Ecotourism a sustainable option? London: John Wiley and Sons.

Ceballos-Lascurain, H. (1996). Tourism, ecotourism and protected areas. Gland: IUCN - The World Conservation Union.

Ceballos-Lascurain, H. (2001). Integrating biodiversity conservation planning into the tourism sector. In Industry and environment - Ecotourism and sustainability (July-December ed.), (Vol. 24). Paris: United Nations Environment Programme, Division of Technology, Industry and Economics. 
Chan, J. K. L., \& Yeoh, E. L. (2001). A monograph - Marketing and positioning Sabah as tourist destination (1st ed.), Kota Kinabalu: Universiti Malaysia Sabah.

Chapman, D. (2003). Management of national parks in developing countries: a proposal for an international park service. Ecological Economics, 46 (1), 17.

Clarke, J. (1997). A framework of approaches to sustainable tourism. Journal of Sustainable Tourism, 5(3), 224-233.

Corp., K. I. (2002). The study on development for enhancing rural women entrepreneurs in Sabah, Malaysia .Inception report of verification survey Outline of pilot projects. Kota Kinabalu: Ministry of Agriculture and Food Industry Sabah, Malaysia

Craig-Smith, S. J. (2002). Book Review: Ecotourism in the less developed world: David B Weaver; CAB International, UK, 1988, ISBN 085199 223-4, p. 258. Tourism Management, 23(6), 643-645.

D'Amore, L. J. (1983). Guidelines to planning in harmony with the host community. In P. E. Murphy (Ed.), Tourism in Canada: selected issues and options. Victoria: University of Victoria.

D'Amore, L. J. (1996). Ecotourism: A sustainable option? In Erlet Cater, Gwen Lowmen, John Wiley, and Chichester (Eds.), Annals of Tourism Research 23(1), 237-239.

Davidoff, P. (1965). Advocacy and pluralism in planning. Journal of the American Institute of Planners, 31(4), 305-322. 
De Beer, G., \& Elliffe, S. (1997). Tourism development and the empowerment of local communities. Cape Town: Development Policy Research Unit, University of Cape Town.

De Silva, C., \& Kotagama, S. (2001). Medirigiriya: A community-based ecotourism program in Sri Lanka that integrates conservation and development. In industry and environment - Ecotourism and sustainability (July-December 2001 ed.), (Vol. 24). Paris: United Nations Environment Programme, Division of Technology, Industry and Economics.

Decrop, A. (1999). Triangulation in qualitative tourism research. Tourism Management (20), 157-161.

Denman, R. (2001). Guidelines for community-based ecotourism development (Guidelines). Gland: WWF International.

Diamantis, D. (1998). Consumer behavior and ecotourism products. Annals of Tourism Research, 25(2), 515-518.

Diamantis, D. (2004). Ecotourism: Management and Assessment. Thomson Learning, London.

Din, K. H. (1996). Tourism development: Still in search of a more equitable mode of local involvement. Progress in Tourism and Hospitality Research, 2, 273-281.

Doan, T. M. (2000). The effects of ecotourism in developing nations: An analysis of case studies. Journal of Sustainable Tourism, 8(4), 288-304. 
Doorne. (Stephen). The last resort: A study of tourism policy, power and participation on the Wellington Waterfront. Ph.D. Thesis, Victoria University of Wellington, Wellington.

Dowling, R. (1996). Ecotourism in Thailand. Annals of Tourism Research, 23(2), 488-490.

Dowling, R. K. (1998). Global ecotourism: a report on 'World Ecotourism '97', the first world congress and exhibition on ecotourism, Rio de Janeiro, Brazil, (December 15-18), 1997. Tourism Management, 19(5), 481-483.

Dowling, R. K. (2004). Book Review: Ecotourism program planning: David A. Fennell; CABI Publishing, Wallingford, 2002, ISBN 085199610 8. Tourism Management, 25(3), 415-416.

Dowling, R. K., \& Weiler, B. (1997). Ecotourism in Southeast Asia. Tourism Management, 18(1), 51-57.

D'Sa, E. (1999). Wanted: Tourists with a social conscience. International Journal of Contemporary Hospitality Management, 11(23), 64-68.

Duffy, R. (2002). A trip too far: Ecotourism, politics and exploitation. Sterling: Earthscan Publication.

Eagles, P. F. J. (2002). Book review: A trip too far: ecotourism, politics and exploitation. In Rosaleen Duffy (Ed.). Environmental impact assessment review, 22(6), pp. 728-730. Earthscan

Edwards, B. (1998). Charting the discourse of community action: Perspectives from practice in rural Wales. Journal of Rural Studies, 14(1), 63-77. 
Economic Planning Unit. (1991) Sixth Malaysia Plan. Economic Planning Unit, Prime Minister's Department, Putrajaya.

Economic Planning Unit. (1996). Seventh Malaysia Plan. Economic Planning Unit, Prime Minster's Department, Putrajaya.

Economic Planning Unit. (2001). Eight Malaysia Plan. Economic Planning Unit, Prime Minister's Department, Putrajaya.

Emmons, K. (1991) Education planning and ecotourism: Targeting school students. In J.A Kusler (ed.) Ecotourism and resource conservation. Omnipress, Madison.

Epler Wood, M. (2001). Ecotourism and sustainable development. UNEP Industry and Environment, 10-14.

Epler Wood, M. (2002). Ecotourism: Principles, practices and policies for sustainability. Paris: United Nations Environment Programme, Division of Technology, Industry and Economics and the International Ecotourism Society.

Fairclough, N. (2003). Analyzing discourse - Textual analysis for social research. London: Routledge.

Farrell, B. H., \& Runyan, D. (1991). Ecology and tourism. Annals of Tourism Research, 18, 26-40.

Fennell, D. (1998). Ecotourism. Routledge, Oxon.

Fennell, D. (1999). Ecotourism: An introduction. Routledge, Oxon. 
Fennell, D. (2001). A Content analysis of ecotourism definitions. Current Issues in Tourism. 4(5), 403-421

Fennell, D. (2003). Ecotourism (Second ed.). London: Routledge.

Fennell, D. \& Cruise Malloy, D. (1997). Code of ethics in tourism: Practice, theory, synthesis. Channel View Publications, Clevedon.

Finn, M., Elliott-White, M., \& Walton, M. (2000). Tourism and leisure research methods: Data collection, analysis and interpretation. Essex: Pearson Education Limited.

Fletcher, P. (1998). The lower Kinabatangan: The importance of community consultations in ecotourism development. Paper presented at the Ecotourism for Forest Conservation and Community Development, Chiang Mai, Thailand. FAO.

Fontana, A., \& Frey, J. (1994). Interviewing: The Art of Science. In N. K. Denzin \& Y. S. Lincoln (Eds.), Handbook of qualitative research (pp. 361- 376). Thousand Oaks: SAGE.

Forsyth, T. (1995). Business attitudes to sustainable tourism: Self-regulation in the UK outgoing tourism industry. Journal of Sustainable Tourism, 3, 210231.

Foucat, V. S. A. (2002). Community-based ecotourism management moving towards sustainability, in Ventanilla, Oaxaca, Mexico. Ocean \& Coastal Management, 45, 511-529. 
Frangialli, F. (Ed.). (2001). World tourism (2001, July-December ed.), (Vol. 24). Paris: United Nations Environment Programme, Division of Technology, Industry and Economics.

Friedmann, J. (1992). Empowerment. Cambridge MA: Blackwell.

Fuller, D., Buultjens, J., \& Cummings, E. (2005). Ecotourism and indigenous micro-enterprise formation in northern Australia opportunities and constraints. Tourism Management, In Press, Corrected Proof.

Gaigher, M. J. (1992). Care groups in Venda: Primary health care knowledge as a strategy for community development. Unpublished DPhil, University of the Orange Free State, Bloemfontein.

Gearing, J. (1999, October 29). 'We Are Not a Zoo'. Asiaweek, 25.

Getz, D. (1994) Residents' attitudes to proposed tourism development: a longitudinal study in Spey Valley, Scotland. Tourism Management. Vol 14 (4), p.247.

Gilbert, J. (1997). Ecotourism means business. Wellington: GP Publications.

Gillham, B. (2000). Case study research methods. London: Continuum.

Gossling, S. (1999). Ecotourism: a means to safeguard biodiversity and ecosystem functions? Ecological Economics, 29 (2), 303-320.

Government of Sabah. (1991) Outline Prospective Plan of Sabah. Retrieved from www.sabah.gov.my. 
Gray, J. (2002). Book review: Tourism in Southeast Asia. Annals of Tourism Research, 29 (4), 1179-1181.

Guijt, I., \& van Velhuizen, L. (1999). Participation and sustainable agriculture: Comparing experiences with PRA and PTD. London: IIED.

Gupta, V. (1999). Sustainable tourism: Learning from Indian religious traditions. International Journal of Contemporary Hospitality Management, 11 (2-3), 91-95.

Halhead, V. (2001). Participatory rural appraisal, rural development lessons from the North Scotland: How can people come together to promote local development. Scotland.

Hall, C. M. (2000). Tourism planning: Policies, processes and relationships (1st ed.). Essex: Pearson Education Limited.

Hang, P. L. K. (2002). The world ecotourism summit: Final report: World Tourism Organization, Madrid: Tourism Management, In Press, Corrected Proof.

Harris, C. A. (2002). Women and power: A study of New Zealand women business travelers. UnpublisPhD, Victoria University of Wellington, Wellington.

Hasse, J. C. (2001). Stakeholder perceptions of tourism development in Marahau/New Zealand. Unpublished PhD, Victoria University of Wellington, Wellington. 
Hatton, M. J. (2002). The character of community-based tourism. Retrieved February 28, 2002, from http://142.214.107.190/tourism/index.cfm

Hatton, M. J. (2002). Kampung Desa Murni, The homestay program. Retrieved February 28, 2002, from http://142.214.107.190/tourism/index.cfm

Hatton, M. J. (2002). A living culture, Tamaki Maori Village. Retrieved February 28, 2002, from http://142.214.107.190/tourism/index.cfm

Haywood, K. M. (2000). Responsible and responsive tourism planning in the community. In C. Ryan \& S. Page (Eds.), Tourism management - Towards the new Millenium (1st ed.). Oxford: Pergamon-Elsevier Science.

Herbig, P., \& O'Hara, B. (1997). Ecotourism: A guide for marketers. European Business Review, 97(5), 231-236.

Herremans, I., \& Welsh, C. (1999). Developing and implementing a company's eco-tourism mission statement: Tread softly revisited. Journal of Sustainable Tourism, $7(1)$, 48-76.

Herriot, R. E. \& Firestone, W.A. (1983). Multisite Qualitative Policy Research: Optimizing Description and Generalizability, Educational Researcher. 12(2), p14-19.

Higgins, B. R. (1996). The global structure of the nature tourism Industry: Ecotourists, tour operators, and local businesses. Journal of Travel Research, 35(2), 11-18.

Higham, J. E. S., \& Carr, A. (2002). Profiling tourists to ecotourism operations. Annals of Tourism Research, 29(4), 1168-1171. 
Hiller, H. (2001). "Place" as a determinant of travel and focus for travel writing. Retrieved February 27, 2002, from www.planeta.com/ecotravel/period/metplace.html

Hinch, T. (2001). Indigenous territories. In D. Weaver (Ed.). The encyclopedia of ecotourism. (pp. 345-357). CABI, Wallingford.

Ho, J. L. (2002). Physical development of tourism products in Sabah focusing on the aesthetics and design aspects. Paper presented at the Seminar on Tourism Product Gaps and Investment Opportunities in Sabah, Kota Kinabalu, Institue for Development Studies (Sabah), Kota Kinabalul.

Holden, A. (2003). In need of new environmental ethics for tourism. Annals of Tourism Research, 30(1), 94-108.

Holtz, C. \& Edwards, S. (2003). Linking biodiversity and sustainable tourism policy. In Fennell, D. A. et. al. (20003). Ecotourism Policy and Planning. CABI: Oxfordshire.

Homestay, P. M. W. (2004). Laporan Aktiviti dan Prestasi Tahun 2003 (Annual Report). Sandakan: Miso Walai Home stay. WWF for Nature (Sabah), Kota Kinabalu.

Honey, M. (1999). Ecotourism and sustainable development - Who owns paradise? Washington, DC: Island Press.

Honey, M. (2001). Certification programs in the tourism industry. In Industry and Environment - Ecotourism and Sustainability (July-December 2001 ed.), 
(Vol. 24). Paris: United Nations Environment Programme, Division of Technology, Industry and Economics.

Honey, M. (2002). Ecotourism and certification - Setting standards in practice. Washington DC: Island Press.

Hvenegaard, G. T. (1994). Ecotourism: A status report and conceptual framework. Journal of Tourism Studies, 5(2), 24-35.

Hvenegaard, G. T., \& Dearden, P. (1998). Ecotourism versus tourism in a Thai National Park. Annals of Tourism Research, 25(3), 700-720.

Ibarra, J. C. (2002). Can communities take the lead in developing Mexico's eco travel? Retrieved February 27, 2002, from www.planeta.com/planeta/99/0599communities.html

Ida Peterson (1994). Qualitative Research Methods for the Travel and Tourism Industry in Travel, Tourism, and Hospitality Research-A Handbook for Managers and Researchers, $2^{\text {nd }}$ Edition. (ed. by Brent Ritchie, J. $R$ and Goeldner, C. R). John Wiley \& Sons, Toronto.

Jenkins, R. L. (1978). Family Vacation Decision-Making. Journal of Travel Research, Vol. 16 (4), 2-7.

Jenkins, O. H. (1993). Understanding and measuring tourist destination images. International Journal of Tourism Research, Vol 1(10), 1-15.

Johnson, K. (2001, July 02). Different monkeys, same fate. Time Asia, 157. 
Johnston, R. (2000). Community. In R. Johnston, D. Gregory, G. Pratt \& M. Watts (Eds.), The dictionary of human geography (pp. 101-102). Oxford: Blackwell.

Jones, S. (2005). Community-based ecotourism: The significance of social capital. Annals of Tourism Research, 32(2), 303-324.

Joppe, M. (1996). Sustainable community tourism development revisited. Tourism Management, 17(7), 475-479.

Kangas, P., Shave, M., \& Shave, P. (1995). Economics of an ecotourism operation in Belize. Environmental Management, 19(5), 669-673.

Khalifah, Z., \& Tahir, S. (1997). Malaysia: Tourism in perspective. In F. M. Go \& C. L. Jenkins (Eds.), Tourism and economic development in Asia and Australasia (pp. 177-196). London: Cassell.

Khan, M. (2003). ECOSERV - Ecotourists' quality expectations. Annals of Tourism Research, 30(1), 109-124.

Khan, M. M. (1997). Tourism development and dependency theory: mass tourism vs. ecotourism. Annals of Tourism Research, 24(4), 988-991.

Kiss, A. (2004). Is community-based ecotourism a good use of biodiversity conservation funds? Trends in Ecology \& Evolution, 19 (5), 232-237.

KL can help in tourism: Mahani. (2003, May 15). Daily Express. 
Koch, E. (1997, July 5). A vision of tourism for the New Southern Africa: Why tourism matters. Paper presented at the Action for Southern Africa's People-First Tourism Campaign.

Kraemer, B. (2001). Reducing the environmental impacts of cruise ships in the. In Industry and Environment - Ecotourism and sustainability (JulyDecember 2001 ed.), (Vol. 24). Paris: United Nations Environment Programme, Division of Technology, Industry and Economics.

Kubisch, A. C., Fulbright Anderson, K., \& Connell, J. P. (1999). Evaluating community initiatives: A Progress report. Retrieved 2002, August 16, from www.aspenroundtable.org/vol2/kubisch.htm

Kusler, J. A. (1991). Ecotourism and resource conservation: Introduction to issues. In J. A. Kusler (Ed.), Ecotourism and resource conservation: A collection of papers (Vol. 1). Madison, WI: Omnipress.

Kutay, K. (1992). Ecotourism marketing: Capturing the demand for special interest, nature and culture tourism to support conservation and sustainable development. Paper presented at the Third Inter-American Congress on Tourism, Cancun, Mexico.

Ladkin, A. (2000). Recent research in community participation in sustainable tourism, the measurement of sustainable tourism and financial issues in the hotel sector. International Journal of Tourism Research, 2, 67-75.

Lajiun, J. Vital to preserve, protect our natural tourism products. (2004, April 14) The New Sabah Times. 
Lash, G. (1998). What is community-based ecotourism? Paper presented at the Ecotourism for Forest Conservation and Community Development, Chiang Mai, Thailand. FAO.

Lassila, H. (2000). Problems in developing tourism entrepreneurship in a rural region: $A$ case study. Paper presented at the Tourism 2000: Time for Celebration?, Sheffield, United Kingdom.

Lawrence, T. B., Wickins, D., \& Phillips, N. (1997). Managing legitimacy in ecotourism. Tourism Management, 18(5), 307-316.

Lazim, R. (2003). Country paper (1). In D. A. Cruz (Ed.), Rural life improvement in Asia (pp. 125-132). Tokyo: Asian Productivity Organization.

Lea, J. P. (2000). Book Review: Ecotourism in the less developed countries: By David B. Weaver, CAB International, Oxon, 1998, 288 in Annals of Tourism Research, 27(1), 248-250.

Lennon, J. J. (2003). Tourism statistics - International perspectives and current issues. London: Continuum.

Lew, A. A. (1996). Adventure travel and ecotourism in Asia. Annals of Tourism Research, 23(3), 723-724.

Lew, A. A. (1998). Ecotourism trends. Annals of Tourism Research, 25(3), 742746.

Lewis, M. W. (1998). Iterative triangulation: A theory development process using existing case studies. Journal of Operations Management, 16 (4), 455469. 
Lindberg, K. (1991). Policies for maximizing nature tourism's ecological and economic benefits. Washington, D.C: World Resources Institute.

Lindberg, K. and Hawking, D. (1993). Ecotourism - A guide for planners and managers. (1st ed.), (Vol. 1). Vermont: The Ecotourism Society.

Lindberg, K., Enriquez, J., \& Sproule, K. W. (1996). Ecotourism questioned: case studies from Belize. Annals of Tourism Research, 23 (3), 543-562.

Lindberg, K., \& McKercher, B. (1997). Ecotourism: A critical overview. Pacific Tourism Review, 1, 65-79.

Lo, J. (2003). Gaps in service delivery in the tourism industry. Paper presented at the Seminar on Tourism Product Gaps and Investment Opportunities in Sabah, Kota Kinabalu, Sabah.

Loon, R. M., \& Polakow, D. (2001). Ecotourism ventures: Rags or riches? Annals of Tourism Research, 28(4), 892-907.

Lowe, P., Ray, C., Ward, N., Wood, D., \& Woodward, R. (1999). Participation in rural development. Dublin: European Foundation for the Improvement of Living and Working Conditions.

Luck, M., \& Kirstges, T. (2003). Global ecotourism policies and case studies Perspective and constraints. Clevedon: Channel View Publications.

MacDonald, R., \& Jollife, L. (2003). Cultural rural tourism - Evidence from Canada. Annals of Tourism Research, 30 (2), 307-322. 
McIntosh, R. W. \& Goeldner, C. R. (1986) Tourism: Principles, practices and philosophies. Wiley, New York.

Mader, R. (1999). Ecotourism research and promotion on the Web: experiences and insights. International Journal of Contemporary Hospitality Management, 11(2/3), 78-79.

Mader, R. (2002, January 19). Exploring ecotourism in the Americas: understanding community tourism. Retrieved January 22, 2002, from www.planeta.com/ecotravel/tour/community.html

Mader, R. (2002, February 28). Urban ecotourism: A conversation with Anna Gibson and Rachel Dodds. Retrieved March 01, 2002, from www.planeta.com

Malaysia, Ministry of Culture, Arts and Tourism. National ecotourism master plan Malaysia. (Master plan) (1997). Kuala Lumpur: Ministry of Culture, Arts and Tourism Malaysia.

Manning, E. W., \& Dougherty, T. D. (1995). Sustainable tourism: Preserving the golden goose. The Cornell Hotel and Restaurant Administration Quarterly, $36(2), 29-42$.

Mat Som, A. P., \& Baum, T. (2004). Planning for community ecotourism: Case studies of Perlis state park and Kedah eco-park in Malaysia. Paper presented at the New Zealand Tourism and Hospitality Research Conference 2004 - December 8-10. Tourism Research: Advances and Applications, Wellington, New Zealand. 
Mathieson, A., \& Wall, G. (1982). Tourism: Economic, physical and social impacts. New York: Longman.

McDonald, M., \& Wearing, S. (2004). Book Review: Global ecotourism policies and case studies perspectives and constraints. In M. Luck and T. Kirstages (Eds.), Channel View Publications, Frankfurt Lodge, Clevedon Hall, Victoria Rd., Clevedon, 2002, 216 p. hbk ISBN 1-873150-40-7. Tourism Management, 25(4), 529-530.

McKercher, B. (1998). The business of nature-based tourism. Hospitality Press, Victoria.

McKercher, B. (2001). Attitudes to a non-viable community-owned heritage tourist attraction. Journal of Sustainable Tourism, 9(1), 29-43.

McNeely, J. A., \& Miler, K. R. (1984). National parks, conservation and development: The role of protected areas in sustaining society. Washington DC: Smithsonian Institution Press.

Milaad, A. (2004). Visitor arrivals to Kampung Bavanggazo. (s.l.)

Miller, G. (2001). Corporate responsibility in the UK tourism industry. Tourism Management, 22(6), 589-598.

Milne, S. (1998). Tourism and sustainable development: Exploring the globallocal nexus. In C. M. Hall \& A. A. Lew (Eds.), Sustainable Tourism: A Geographical Perspective. New York: Longman. 
Ministry of Cutlure, Environment and Tourism (MOCET) (1990). Sabah Conservation Strategy. Ministry of Culture, Environment and Tourism (MOCET): Kota Kinabalu.

Miso Walai Homestay. (2004) Miso Walai Homestay Kinabatangan River. Retrieved from http://www.mescot.org/MisoWalaiHomestay_Home.html

Mitchell, R. (2000, October). Community tourism in Peru: The Island of Taquile, Lake Titicaca. Retrieved February 27, 2002, from www.planeta.com/planeta/00/0010peru.html

Moore, S. A. (2004). Ecotourism policy and planning. In David A. Fennell and Ross K. Dowling. (Eds.), CABI in Annals of Tourism Research, 31(3) 736737.

Morrissey, J. (2000). Indicators of citizen participation: Lessons from learning teams in rural EZ/EC communities. Community Development Journal, 35(1), 59-74.

Mowforth, M., \& Munt, I. (1998). Tourism and sustainability. London: Routeledge.

MTCE, \& IDS. (2003). Determining gaps: An overview of processes and perceptions of tourism product development in Sabah. Paper presented at the Seminar on Tourism Gaps and Investment Opportunities in Sabah, Kota Kinabalu, Sabah.

Murphy, P. E. (1983). Perceptions and attitudes of decision-making groups in tourism centers. Journal of Travel Research, 21(3), 8-12. 
Murphy, P. E. (1985). Tourism: A community approach. New York: Methven.

Naisbitt, J. (1994). Global paradox. New York: Avon.

Naisbitt, J. (1995). Global paradox. New York: Avon.

National Ecotourism Plan (1997). Ministry of Arts, Culture and Tourism.

Nelson, J. G. (1994). The spread of ecotourism: Some planning implications. Environmental Conservation, 21(3), 248-255.

Nepal, S. K. (2000). Tourism in protected areas: The Nepalese Himalaya. Annals of Tourism Research, 27(3), 661-681.

Newson, M. (2001). Encouraging and rewarding best practice: Australia's Nature and Ecotourism Accreditation Programme (NEAP). In Industry and environment - ecotourism and sustainability (July-December 2001 ed.), (Vol. 24). Paris: United Nations Environment Programme, Division of Technology, Industry and Economics.

Nientied, P., Ben Mhenni, S., \& De Wit, J. (1990). Community participation in low-income housing policies: potential and paradox. Community Development Journal, 25 (1), 42-55.

Norris, R. (1992). Can ecotourism save natural areas? National Park, 33-34.

Notzke, C. (1999). Indigenous tourism development in the arctic. Annals of Tourism Research, 26(1), 55-76. 
Oakley, P. (1991). Projects with people: The practice of participation in rural development. Geneva: International Labour Office.

Oppermann, M. (1993) Tourism space in developing countries. Annals of Tourism Research, Vol. 20 (3), p.535.

Orams, M. B. (1995). Towards a more desirable form of ecotourism. Tourism Management, 16(1), 3-8.

Orams, M. B. (2000). Towards a more desirable form of ecotourism. In C. Ryan \& S. Page (Eds.), Tourism Management - Towards the New Millenium (1st ed.). Oxford: Pergamon-Elsevier Science.

Orams, M. B. (2004). Book Review: Ecotourism: Stephen J. Page and Ross K. Dowling, Prentice-Hall-Pearson Education Ltd, London, 2002. Tourism Management, 25(1), 146-147.

PACOS. (2003). Partners of community organisations. PACOS. Rakan Membangun Masyarakat. Penampang: PACOS.

Pal, L. A. (1992) Public Policy Analysis: An Introduction. Scarborough: Nelson Canada.

Panos. (1995). Ecotourism: Paradise gained, or paradise lost? London: Panos Institute.

Pearce, D. G. (1989). Tourist development (2nd ed.). Essex: Longman. 
Pearce, D. G. (1993). Comparative studies in tourism research. In D. G. Pearce \& R. W. Butler (Eds.), Tourism research - Critiques and challenges. London: International Academy for the Study of Tourism.

Pearce, D. G. (2000). Tourism plan reviews: methodological considerations and issues from Samoa. Tourism Management, 21 (2), 191-203.

Pearce, P., Moscardo, G., and Ross, G. (1996). Tourism community relationships. New York: Pergamon, Kent.

Pengiran Bagul, A. H. B. (1997). The importance of ethnography information in ecotourism development. Paper presented at the Bengkel Halatuju Penyelidikan Unit Etnografi \& Pembangunan dan Unit Penyelidikan Psikologi \& Kerja Sosial, Kota Kinabalu, Sabah, Malaysia. Universiti Malaysia Sabah.

Pengiran Bagul, A. H. B. (2000). Ecotourism for rural development and biodiversity conservation. Paper presented at the Ecotourism in the New Millennium: World Ecotour 2000 - World Congress and Exhibition on Ecotourism, Brazil. (s.l).

Pengiran Bagul, A. H. B. (2000). Rural community-based ecotourism in Sabah: A Case Study of Bavanggazo Long House in Kudat. Paper presented at the Tourism 2000: Time for Celebration? Sheffield, England.

Pengiran Bagul, A. H. B. (2003). Ecotourism and local community participation: A closer look at Sabah ecotourism industry. In Y. Harun (Ed.), MalaysiaPapers on development, religion and politics (pp. 35-52). Wellington: Chair of Malay Studies, Victoria University of Wellington. 
Pengiran Bagul, A. H. B. (2004). Ecotourism and local community participation: A closer look at Sabah ecotourism industry. In Y. Harun (Ed.), Malaysia Papers on Development Religion, and Politics (pp. 32-49). Wellington: Chair of Malay Studies, Victoria University of Wellington.

Pengiran Bagul, A. H. B. (2004). Success indicators for ecotourism and local community participation. Paper presented at the New Zealand Tourism and Hospitality Research Conference 2004 - Tourism Research: Advances and Applications, Wellington, New Zealand.

Pengiran Bagul, A. H. B., \& Wan Hassan, W. S. (2005). Sabah's response to September 11 . The tourism experience. In B. Prideaux (Ed.), Crisis management in Tourism. Oxon: CABI.

Pera, L., \& McLaren, D. (1999). Globalization, tourism \& indigenous peoples: What you should know about the world's largest 'Industry'. Retrieved February 26, 2002, from http://www.planeta.com/ecotravel/resources/rtp/globalization.html

Pertubuhan-pertubuhan Bukan Kerajaan (Non-Governmental Organisations) Kota Kinabalu (088). (2002). Retrieved July 04, 2002, from www.sabah.org.my/bm/ngo/list_ngo/list_kk.asp

Pollnac, R. B., Crawford, B. R., \& Gorospe, M. L. G. (2001). Discovering factors that influence the success of community-based marine protected areas in the Visayas, Philippines. Ocean \& Coastal Management, 44 (11-12), 683710. 
Popova, Nikolina (2003), Ecotourism Impact / Success Indicators. Baseline Data 2002. Kalofer Pilot Region of Central Balkan National Park, prepared for BCBG-ARD project in Bulgaria, sponsored by USAID

Pretty, J. N. (1995). Participatory learning for sustainable agriculture. World Development, 23 (8), 1247-1263.

Price, M. (1994). Ecotourism: A sustainable option? In E Cater, G Lowman John Wiley, and Sons, Chichester. (Eds.), (1994). Global Environmental Change Part A, 6(3), 249.

Punch, K. (1998). Introduction to social research: Quantitative \& qualitative approaches (1st ed.). London: SAGE Publications Ltd.

Quan, H. (2001, December). Banff heritage tourism strategy. Retrieved February 27, 2002, from www.planeta.com/planeta/01/0112banff.html

Reid, D. G., Mair, H., George, W. (2004). Community tourism planning: A selfassessment instrument. Annals of Tourism Research. 31(3), 623-639.

Richard, T. (2000). The search for the sustainable. Paper presented at the Tourism 2000: Time for Celebration? Sheffield, United Kingdom.

Richards, G., \& Hall, D. (2000). Tourism and sustainable community development. London: Routledge.

Roarty, M. (1997). Greening business in a market economy. European Business Review, 97(5), 244-254. 
Rocharungsat, P. (2004, December 8-10). Community-based tourism: The perspectives of three stakeholder groups. Paper presented at the New Zealand Tourism and Hospitality Research Conference 2004 - Tourism Research: Advances and Applications, Wellington, New Zealand.

Rome, A. (2000). Book Review: Ecotourism and sustainable development: Who owns paradise? In Martha Honey. (Ed.), Island Press Washington, 1999 in Annals of Tourism Research, 27(4), 1069-1071.

Rosenow, J. E., \& Pulsipher, G. L. (1983). Tourism, the good, the bad, and the ugly. New York: Media Publishing.

Rosenthal, R., \& Rosnow, R. L. (1991). The Nature of behavioural research. In essentials of behavioral research - Methods and data analysis (2nd ed.), (pp. 3-25). New York: McGraw-Hill.

Ross, G. (1992). Resident perceptions of the impact of tourism on an Australian city. Journal of Travel Research, 30(3), 13-17.

Ross, S., \& Wall, G. (1999). Ecotourism: towards congruence between theory and practice. Tourism Management, 20(1), 123-132.

Ross, S., \& Wall, G. (1999). Evaluating ecotourism: The case of North Sulawesi, Indonesia. Tourism Management, 20(6), 673-682.

Ryan, C., Hughes, K., \& Chirgwin, S. (2000). The gaze, spectacle and ecotourism. Annals of Tourism Research, 27(1), 148-163. 
Ryan, C. \& Montgomery, D. (1994). The attitudes of Bakewell residents to tourism and issues in community responsive tourism. Tourism Management, Vol. 15(5), p.538.

Sabah, Ministry of Tourism, Environment, Science and Technology. (1996) Sabah Tourism Master Plan. Ministry of Tourism, Environment, Science and Technology: Kota Kinabalu.

Sabah, Ministry of Tourism, Enviroment, Science and Technology. Pelan Ekopelancongan Kebangsaan Malaysia - Garis Panduan Untuk Negeri Sabah. (N. L. Ahmad Zahari, Trans.) (1997). Kota Kinabalu: Ministry of Tourism, Environment, Science and Technology.

Sabah, Ministry of Tourism, Environment, Science and Technology, (2002).Sabah Homestay Directory. Sabah, Malaysia: Ministry of Tourism, Environment, Science and Technology, Sabah Tourism Promotion Corporation, Malaysia Tourism Promotion Board, Kota Kinabalu.

Sabah, Ministry of Tourism, Enviroment, Science and Technology. Sabah Structure Plan 2020. (Technical Report) (2001). Kota Kinabalu: Environment Conservation Department.

Sabah Tourism Board (2004). Sabah's Tourism. www.sabahtourism.com, Kota Kinabalu.

Sabran, M. S. (2003). Country Paper: Malaysia (2). In D. A. Cruz (Ed.), Rural life improvement in Asia (pp. 133-141). Tokyo: Asian Productivity Organization. 
Samsiar, W. A. (2004, April 14). Invest in quality ecotourism products. The New Sabah Times.

Sanabria, R. (2001). Evolving ecotourism alliances conserve biodiversity in the Galapagos Island. In Industry and environment - ecotourism and sustainability (July-December 2001 ed.), (Vol. 24). Paris: United Nations Environment Programme, Division of Technology, Industry and Economics.

Saxena, G. (2000). An examination of networking and collaboration amongst rural tourism providers: The case for relationship marketing. Paper presented at the Tourism 2000: Time for Celebration?, Sheffield, United Kingdom.

Scheyvens, R. (1999). Ecotourism and the empowerment of local communities. Tourism Management, 20 (2), 245-249.

Scheyvens, R. (2002). Tourism for development - Empowering communities (1st ed.), Essex: Pearson Education Limited.

Schoeman, D. C. (2002). Socio-political problems involved in establishing ecotourism in the Qwa-Qwa National Park. Paper presented at the Tourism 2000: Time for Celebration? Sheffield, United Kingdom.

Seale, C. (1999). The quality of qualitative research. London: Sage Publications.

Seventh Malaysia plan. (Planning) (1996). Kuala Lumpur: Economic Planning Unit, Prime Minister's Department of Malaysia. 
Sherlock, K. (1999). The role of community in tourism studies. International Journal of Contemporary Hospitality Management, 11 (2/3), 126-127.

Silva, M. (2001). Ecotourism in the Caribbean region: Seizing the opportunity. In Industry and environment - Ecotourism and sustainability (July December 2001 ed.), (Vol. 24). Paris: United Nations Environment Programme, Division.

Simmons, D. (1994). Community participation in tourism planning. Tourism Management, 15, 98-108.

Slinger, V. (2000). Ecotourism in the last indigenous Caribbean community. Annals of Tourism Research, 27 (2), 520-523.

Sofield, T. (2003). Empowerment for sustainable tourism development. Emerald Group Publishing, Bingley.

Spenceley, A. (2001). Local community benefits systems at two nature-based tourism operations in South Africa. In Industry and environment (JulyDecember 2001 ed.), (Vol. 24). Paris: United Nations Environment Programme, Division of Technology, Industry and Economics.

Sproule, K. W. (1996). Community based ecotourism development: Identifying partners in the process. In The ecotourism equation, measuring the impacts. New Haven, Connecticut: Yale University.

Sproule, K. W. (2001). Community-based ecotourism development: Identifying partners in the process. Retrieved November 14, 2001, from http://www.ecotourism.org/textfiles/sproule.txt 
Stafford, A. (2003). Bridging the gaps in current tourism products, New product development, service delivery, international trends and investment opportunities. Paper presented at the Seminar on Tourism Product Gaps and Investment Opportunities in Sabah, Kota Kinabalu, Sabah.

Stainer, A., \& Stainer, L. (1997). Ethical dimensions of environmental management. European Business Review, 97(5), 224-230.

Stankey, G. H., Cole, D. N., Lucas, R. C., Petersen, M. E., \& Frissel, S. S. (1985). The limits of acceptable change (LAC) system for wilderness planning. USDA general technical report INT-176. Ogden: US Forest Service, USDA.

Stewart, D. W., \& Kamins, M. A. (1993). Secondary research - Information sources and methods (Second ed.), (Vol. 4). Newbury Park: Sage Publications.

Stewart, W. P., \& Sekartjakrarini, S. (1994). Disentangling ecotourism. Annals of Tourism Research, 21, 629-642.

Strasdas, W. (2001). Ecotourism in development cooperation. In Industry and environment - Ecotourism and sustainability (July - December 2001 ed.), (Vol. 24). Paris: United Nations Environment Programme, Division of Technology, Industry and Economics.

Tambunan Forestry Department (2004). Visitors' Statistics. Tambunan Forestry Department: Tambunan.

Tesch, R. (1995). Qualitative Research - Analysis Types \& Software Tools. The Falmer Press, Hampshire. 
Teye, V., Sonmez, S. F., \& Sirakaya, E. (2002). Residents' attitudes toward Tourism development. Annals of Tourism Research, 29(3), 668-688.

Thomlinson, E., \& Getz, D. (1996). The question of scale in ecotourism: Case study of two small operators in the Mundo Maya region of Central America. Journal of Sustainable Tourism, 4(4), 183-200.

Tiraa, A., \& Wilmott, I. K. (2001). The Takitumu conservation area: A community-owned ecotourism enterprise in the Cook Islands. In industry and environment - Ecotourism and sustainability (July-December 2001 ed.), (Vol. 24). Paris: United Nations Environment Programme, Division of Technology, Industry and Economics.

Tisen, O. B., Ahmad, S., Bennet, E. L., \& Meredith, M. E. (1999). Wildlife conservation and local communities in Sarawak, Malaysia. Paper presented at the 2nd Regional Forum for Southeast Asia of the IUCN World Commission for Protected Areas, Pakse, Lao PDR.

Tosun, C. (2000). Limits to community participation in the tourism development process in developing countries. Tourism Management, 21, 613-633.

Tosun, C. (2005) Stages in the emergence of a participatory tourism development approach in the developing World. Geoforum, In Press, Corrected Proof.

Tosun, C., \& Jenkins, C. L. (1998). The evolution of tourism planning in thirdworld countries: A critique. Progress in Tourism and Hospitality Research, $4(2), 101-114$. 
Tosun, C., \& Timothy, D. J. (2003). Arguments for community participation in the tourism development Process. Journal of Tourism Studies, 14(2), 2-15.

Travers, M. (2001). Qualitative Research through Case Studies. Sage Publications. 2001.

Trousdale, W. J. (2001). Appropriate tourism impact assessment. Retrieved November 14, 2001, from www.ecotourism.org/textfiles/etspaper.txt

Twining-Ward, L. (2001). Monitoring sustainable tourism in Samoa. In industry and environment - Ecotourism and sustainability (July-December 2001 ed.), (Vol. 24). Paris: United Nations Environment Programme, Division of Technology, Industry and Economics.

UNDP (2004). Equator Initiative Home. Retrieved from www.equatorinitiative.org

UNEP. (2002). World ecotourism summit - WTO/UNEP summary of regional preparatory conferences to sere as discussion paper for the world ecotourism summit. Quebec: World Tourism Organization, UNEP.

United Nations. (2001). UNEP manual for the international year of ecotourism. (pp. 1-18). www.uneptie.org/tourism/home/html: United Nations Environment Programme.

United Nations Environment Programme (2001). About ecotourism. Retrieved November 14, 2001, from www.uneptie.org/pc/tourism/ecotourism/home.htm

Urry, J. (2002). The tourist gaze. London: Sage Publications. 
USA, Ecotourism Society. (1992). The ecotourism society documents. Washington DC: Ecotourism Society.

USA, Ecotourism Society. (1998). Ecotourism statistical fact sheet: General tourism statistics. Washington DC: Ecotourism Society.

Van der Duim, R., \& Caalders, J. (2002). Biodiversity and tourism - Impacts and interventions. Annals of Tourism Research, 29(3), 743-761.

Vourc'h, A. (2001). Tourism and local agenda 21s. In Industry and environment Ecotourism and sustainability (July-December 2001 ed.), (Vol. 24). Paris: United Nations Environment Programme, Division of Technology, Industry and Economics.

Walker, S. L. (1996). Ecotourism impact awareness. Annals of Tourism Research, $23(4), 944-945$.

Walker, S. L. (1997). Perceived impacts of ecotourism development. Annals of Tourism Research, 24 (3), 743-745.

Walker, S. L. (1998). Online ecotourism conference. Annals of Tourism Research, $25(1), 240-241$.

Wall, G. (1994). Ecotourism: Old wine in new bottles. Trends, 31(2), 4-9.

Wall, G. (1996). Perspectives on tourism in selected Balinese villages. Annals of Tourism Research, 23(1), 123-137. 
Wallace, G. N., \& Pierce, S. M. (1996). An evaluation of ecotourism in Amazonas, Brazil. Annals of Tourism Research, 23(4), 843-873.

Walpole, M. J., \& Goodwin, H. J. (2000). Local economic impacts of dragon tourism in Indonesia. Annals of Tourism Research, 27(3), 559-576.

Wearing, S. (1999). Ecotourism - Impacts, potentials and possibilities. Woburn: Butterworth-Heinemann.

Wearing, S. \& Neil, J. (1999). Ecotourism: Impact, potentials and possibilities. Woburn: Butterworth-Heinemann.

Weaver, D. (1991). Alternative to mass tourism in Dominica. Annals of Tourism Research, 18, 414-423.

Weaver, D. B. (1998). Ecotourism in the less developed world. Oxon: CAB International.

Weaver, D. B. (2001). Ecotourism as mass tourism: contradiction or reality? The Cornell Hotel and Restaurant Administration Quarterly, 42 (2), 104-112.

Weaver, D. B. (2005). Comprehensive and minimalist dimensions of ecotourism. Annals of Tourism Research. 32(2), 439-455.

Weaver, D. (2006). Sustainable Tourism. Butterworth-Heinemann, Oxford.

Wengraf, T. (2001). Qualitative research interviewing. London: Sage Publications. 
Wesche, R. (1997). Developed country environmentalism and indigenous community controlled ecotourism in the Ecuadorian Amazon. Geographische Zeitschrift, 3 and 4(84), 157-168.

Wheeller, B. (1991). Tourism's troubled times: Responsible tourism is not the Answer. Tourism Management, 12, 91-96.

Wheeller, B. (1993). Sustaining the ego. Journal of Sustainable Tourism, 1, 121129.

Whelan, T. (1991). Nature tourism: Managing for the environment. Washington, D.C: Island Press.

Wight, P. A. (1994). Environmentally responsible marketing of tourism. In E. Cater \& G. Lowman (Eds.), Ecotourism - A Sustainable Option? (pp. 3955). Chichester: John Wiley and Sons.

Wight, P. A. (1997). Ecotourism accommodation spectrum: Does supply match the demand? Tourism Management, 18(4), 209-220.

Wight, P. A. (2002). Theme A. ecotourism Policy and planning: The sustainability challenge. Paper presented at the World Ecotourism Summit, Quebec, Canada.

Wild, C. (1994). Issues in ecotourism. Progress in Tourism Recreation and Hospitality Management. Vol. 6, pages 12.

Wild, C. (1994). Issues in ecotourism. In C. P. Cooper \& A. Lockwood (Eds.), Progress in tourism, recreation and hospitality management (Vol. 6, pp. 12-21). Chichester: Wiley. 
Wildlife Department. (2004). Visitor arrivals to Rafflesia Centre. Wildlife Department, Kota Kinabalu.

Wildlife Department. (2004). Visitor arrivals to Sukau/Kinabatangan. Wildlife Department, Kota Kinabalu.

Wong, P. P. (2001). Trends in coastal ecotourism in Southeast Asia. In Industry and environment - Ecotourism and sustainability (July-December 2001 ed.), (Vol. 24). Paris: United Nations Environment Programme, Division of Technology, Industry and Economics.

Wood, P. (2006). Successful Writing for Qualitative Researchers, $2^{\text {nd }}$ Edition. Routeledge, Oxon.

Woodhill, J., \& Robins, L. (1998). Participatory evaluation for Land care and Catchment Groups. Canberra: Greening Australia Limited.

Woodley, A. (1993). Tourism and sustainable development: The community perspective. In J. R. Butler, J. G. Nelson \& G. Wall (Eds.), Tourism and sustainable development: Monitoring, planning, and managing. Waterloo: Department of Geography, University of Waterloo.

WTO. (2003). Assessment of the results achieved in realizing aims and objectives of the international year of ecotourism: World Tourism Organization.

WTO (2002). The World Ecotourism Summit 2002. www. www.worldtourism.org/sustainable/IYE/quebec 
WTO (2003). Asia-Pacific conference on sustainability certification of tourism activities. Kuala Lumpur, Malaysia: World Tourism Organization.

Wunder, S. (2000). Ecotourism and economic incentives -- An empirical approach. Ecological Economics, 32 (3), 465-479.

Yamashita, S. (1998). Tourism development in Sabah, Malaysia - A remark on ecotourism. Kota Kinabalu: Institute for the study of languages and cultures of Asia and Africa, Tokyo University of Foreign Studies.

Yeoman, J. (2000). Achieving sustainable tourism: A paradigmatic perspective. paper presented at the Tourism 2000: Time for celebration?, Sheffield, United Kingdom.

Yeoman, J. (2001). Ecotourism and sustainable development. Who owns paradise? Tourism Management, 22 (2), 206-208.

Yin, R.K, Bateman P.G \& Moore, G.B. (1983). Case Studies and Organizational Innovation: Strengthening the Connection, COSMOS Corporation. Washington, DC.

Yin, R. K. (1994). Case study research: Design and methods (2 ed.), (Vol. 5). Thousand Oaks: SAGE Publications.

Ziffer, K. (1989). Ecotourism. An uneasy alliance. Working paper No. 1. Washington DC: Conservation International.

(s.n.). Agenda 21 for the Travel \& Tourism Industry: Towards environmentally sustainable development. (2002). Retrieved June 19, 2002, (s.I.) 
(s.n.) 'A knockout blow to tourism'. (2003, May 3). Daily Express.

(s.n.) (2001, May 17) Assurance on tourism image. Daily Express.

(s.n.) Binsulok peat swamp as eco-tourism spot? (2001, February 18). Daily Express.

(s.n.) Build up tourism industry, urges Mahathir. (2002, June 1). Daily Express.

(s.n.) Checklist for tourist projects based on indicators of sustainable tourism. France: Groupe Developpement. (s.l.)

(s.n.) CM: Fee hike in tourism industry inevitable. (2001, December 5). Daily Express.

(s.n.) CM: Special attention to be given to tourism. (2003, March 31). Daily Express.

(s.n.) (2002). Contribution of the World Tourism Organization to the world summit on sustainable development. Johannesburg: World Tourism Organization.

(s.n.) Current focus is on nature tourism: Chew. (2001, July 9). Daily Express.

(s.n.). Diversifying, increasing tourism products. (2005, April 19). Daily Express.

(s.n.). Domestic tourism to offset \$ loss. (2003, April 15). Daily Express.

(s.n.) Don't get carried away by SARS publicity, tourism sector told. (2003, April 22). Daily Express. 
(s.n.) Ecotourism. (2002). Retrieved February 26, 2002, from www.tourismconcern.org.uk

(s.n.) (2001). Ecotourism: Facts and figures. In R. B. Francoise Ruffe, John Smith, and Thalia Stanley (Eds.), Industry and environment - ecotourism and sustainability (July-December 2001 ed.), (Vol. 24), (pp. 5-9). Paris: United Nations Environment Programme, Division of Technology, Industry and Economics.

(s.n.) Ecotourism must involve locals: Aklee. (2004, August 24). Daily Express.

(s.n.) Enriching the ecotourism experience through the preservation and promotion of Mayan culture. (2001). Retrieved October 25, 2001, from www.rarecentre.org

(s.n.) (2001). Environmental development. Retrieved November 05, 2001, from www.ysnet.org.my

(s.n.) (2003). Exotic adventure Sdn Bhd. (Company Profile) Kota Kinabalu: Exotic Adventure Sdn Bhd. Kota Kinabalu.

(s.n.) Govt all for golf tourism. (2001, May 11). Daily Express.

(s.n.) Have better tourism packages, says Karim. (2003, 11 May). Daily Express.

(s.n.) (2001) Indigenous peoples and conservation: Malaysia - conservation and sustainable use of Wetlands. (2001). Retrieved November 05, 2001, from www.panda.org 
(s.n.) (2002) International forum on indigenous tourism: Background paper. Retrieved February 27, 2002, from www.rethinkingtourismproject.org

(s.n.) (2002) International forum on indigenous tourism. Retrieved February 26, 2002, from www.rethinkingtourismproject.com

(s.n.) Karim: Gain support of locals in tourism. (2001, April 13). Daily Express, pp. 1.

(s.n.) Kerajaan Elektronik Sabah: Struktur Pentadbiran: Pengenalan. (2002). Retrieved July 04, 2002, from www.sabah.gov.my/administructure/default.asp

(s.n.) Kinabatangan - Berita Terkini. (2002). (Vol. Jun-Ogos 2002): WWF Malaysia.

(s.n.) Look for the unusual, eco-tourism bosses told. (2001, October 15). Daily Express.

(s.n.) Maintaining KK's tourism edge. (2002, January 30). Daily Express.

(s.n.) Malaysia to focus on domestic tourism. (2003, April 4). Daily Express.

(s.n.) Ministerial conference on cultural tourism and poverty alleviation. (2004). Hue, Vietnam: World Tourism Organization.

(s.n.) Miso Walai Homestay. (2001). Retrieved November 05, 2001, from www.misowalai.com.my

(s.n.) M'sian tourism is recovering well from 911. (2002, June 15). Daily Express. 
(s.n.) MTPC affirms tourism's vital role in economy. (2002, July 6). Daily Express.

(s.n.) Murphy, K. (1997). The ecotourism society. Annals of Tourism Research, $24(2), 483-484$.

(s.n.) Need to 'sell' Sabah to Japanese: STB. (2003, June 24). Daily Express.

(s.n.) Obtain sustainable development through environmental protection. (1999). Eastern Voice, Responsible Tourism: The Way Forward, 2.

(s.n) Participation. (2002). Retrieved April 29, 2002, from www.britcoun.org/governance/democ/participation/part1.htm

(s.n.) Participatory rural appraisal (PRA). (2002). Retrieved July 24, 2002, from www.iisd.org/casl/CASLGuide/PRA.htm

(s.n.) Participatory rural appraisal. (2002). Retrieved August 14, 2002, from www.tortuga.com/permacultura/Participation/pra.htm

(s.n.) Partners for wetlands. (2002, January 30). Retrieved August 05, 2002, from www.borneo-online.com.my/wwf

(s.n.) Partners for wetlands: Lower Kinabatangan floodplain, Sabah, Malaysia. (2001). Retrieved November 05, 2001, from www.borneo-online.com.my

(s.n) Profail KPD. (2002, June 25). Retrieved July 2, 2002, from www.sabah.gov.my/kpd/profail.htm

(s.n) Promote domestic tourism: Tham. (2003, April 29). Daily Express. 
(s.n.) 'Quantum leap' tourism strategy for Sabah. (2001, July 24). Daily Express.

(s.n.) RM714m tourism receipts last year. (2001, July 8). Daily Express.

(s.n.) RM914mil from tourism last year. (2002, June 5). Daily Express.

(s.n.) RM279m tourism losses. (2003, May 27). Daily Express.

(s.n.) Sabah targets RM1b in tourism revenue. (2001, August 5). Daily Express.

(s.n.) Sabah tourism not affected by blast. (2002, October 18). Daily Express.

(s.n.) 'SARS can be a blessing for ecotourism'. (2003, May 5). Daily Express.

(s.n.) Security to benefit tourism. (2002, December 23). Daily Express.

(s.n.) 'Small players have role in tourism too'. (2002, March 6). Daily Express.

(s.n.) Special Report: Tourism in the Kinabatangan - A potential tool for conservation. (2001). Retrieved November 05, 2001, from www.partnersforwetlands.org

(s.n.) Sustainability the keyword for Sabah's future: Chong. (2004). Daily Express.

(s.n.) Technical seminar on cultural tourism and poverty alleviation - Final report. (2004). Siem Reap, Cambodia: World Tourism Organization.

(s.n.) The Economics of hill rice cultivation among Dusun communities in Bundu, Keningau, Sabah, Malaysia. (2003). Retrieved December 3, 2003. (s.I.) 
(s.n.) 'Tourism in Sabah unaffected'. (2002, October 25). Daily Express.

(s.n.) Tourism in the mountains: Critical issues. (2002). Retrieved October 25, 2002 (s.l.)

(s.n) Tourism industry should involve all quarters: Chong. (2002, September 26). Daily Express.

(s.n.) Tourism is preserving nature, too. (2001, May 20). Daily Express.

(s.n.) Tourism Malaysia to promote three Sabah districts. (2003, April 15). Daily Express.

(s.n.) Tourism promotion will continue: Chong. (2002, October 22). Daily Express.

(s.n.) Tourism sector must refocus. (2001, September 18). Daily Express.

(s.n.) Tourism sector praises Cabinet. (2001, August 22). Daily Express.

(s.n.) Tourism: Sabah told to go for quality. (2001, October 13). Daily Express.

(s.n.) Vital to manage eco-tourism wisely: Karim. (2002, 1 February). Daily Express.

(s.n.) What tourism managers need to know. (1995). Madrid: World Tourism Organization. 


\title{
APPENDICES
}

\section{APPENDIX 1 - INTERVIEW STRUCTURE FOR LOCAL COMMUNITY}

\author{
VICTORIA UNIVERSITY OF WELLINGTON \\ Te Whare Wananga o te Upoko o te Ika a Maui

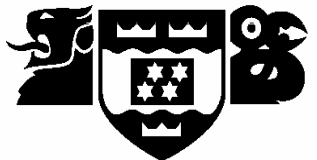

\section{ECOTOURISM AND LOCAL COMMUNITY PARTICIPATION}

\begin{abstract}
The purpose of this interview is to find out the factors for ecotourism site and local community participation success in Sabah. The interview should take approximately 30 minutes. The information you provide will be used as part of a PhD research project being conducted by Hassanal Bagul and supervised by Prof. Doug Pearce, Professor of Tourism, Victoria Management School, Victoria University of Wellington, New Zealand. The information gathered will be used solely for academic purposes. Your cooperation would be greatly appreciated.
\end{abstract}

Respondents: Local Communities

\section{STRUCTURED INTERVIEW CHECKLIST}

\section{Profile:}

1. Could you tell me about yourself?

2. Could you tell me about your family

3. Are you originally from this village (were you born here)?

4. Do you live here primarily (or lived in a $2^{\text {nd }}$ home somewhere else)?

\section{Clarifying Local Community Participation:}

1. Are you involved in the ecotourism industry?

2. If you are, what level and degree of participation are you in?

3. Could you tell me the process of local community participation in the ecotourism industry?

4. Is there any other form of local community participation in other industry, for e.g. agriculture?

5. Could you tell me the process of local community participation in the other industry?

6. What are the success factors of local community participation in ecotourism industry?

7. What are the success factors of local community participation in the other industry? 
8. Is the local community participation in the ecotourism industry successful?

9. What is your opinion on the local community participation as a whole?

\section{Indicators for Local Community Participation Success:}

1. To what extent did you (or/and the others) have control over the development process

2. What is the monetary cost of local community participation and how important it is to the success of the local community participation process?

3. To what extent are you (or/and the others) aware of the local community participation?

4. Is the decision-making process time consuming?

5. What are the effects on decision-making?

6. Are you (or/and the others) dependent on the outsiders?

\section{Indicators for Ecotourism Site Success:}

1. Has there been clear improvement in your life and livelihood? How has it changed?

2. Are you involved in the formulation of ecotourist venture?

3. Is there any 'Win-Win' situation where you and the tourist are satisfied?

4. Are there any positive experiences of ecotourism venture in your area?

5. Is there any positive image of ecotourism venture in your area?

6. Does the project promote conservation of natural resources? What are the benefits of conservation of natural resources for you?

7. Does the project provide financial gain for host country?

8. Does the project provide financial gain for local people? What benefits did you received from the project? 


\title{
APPENDIX 2 - INTERVIEW STRUCTURE FOR VILLAGE LEADERS 1
}

\author{
VICTORIA UNIVERSITY OF WELLINGTON \\ Te Whare Wananga o te Upoko o te Ika a Maui
}

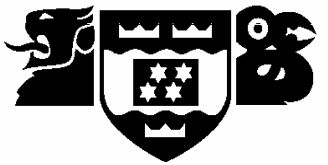

\section{ECOTOURISM AND LOCAL COMMUNITY PARTICIPATION}

\begin{abstract}
The purpose of this interview is to find out the factors for ecotourism site and local community participation success in Sabah. The interview should take approximately 30 minutes. The information you provide will be used as part of a PhD research project being conducted by Hassanal Bagul and supervised by Prof. Doug Pearce, Professor of Tourism, Victoria Management School, Victoria University of Wellington, New Zealand. The information gathered will be used solely for academic purposes. Your cooperation would be greatly appreciated.
\end{abstract}

Respondents: Village Headmen, Chairman of Village Development and Security Committee

\section{STRUCTURED INTERVIEW CHECKLIST}

\section{Profile:}

1. What is your role as a village headmen/chairman of village development and security committee? For how long?

2. Could you tell me about the village that you live in?

3. Could you tell me about the social structure in this village?

\section{Clarifying local communities:}

1. What is the formal boundary of the village?

2. Who lives there?

3. Are they originally from the village (where they born there)?

4. Does the villagers lived here primarily (or lived in a $2^{\text {nd }}$ home somewhere else)?

5. What are the compositions of ethnic groups of this village?

6. What are the compositions of nationalities of this village?

7. Is there any intermarriage with non-locals?

\section{Clarifying Ecotourism Sites:}

1. What is your understanding of ecotourism and its development?

2. When was ecotourism started in this area and how has it develop? 
3. What types of tourism and ecotourism activities are available around the village?

4. What types of tourism and ecotourism attractions are available around the village?

5. Do the ecotourism sites around the village employ any eco-practice ${ }^{16}$ ?

6. Is there any area around the village, which has a status of site protection?

7. Does the ecotourism industry in the village label itself as an ecotourism site?

8. What are success factors for an ecotourism industry?

9. Do you think the ecotourism industry is successful in this village? Why? or Why not?

\section{Clarifying Local Community Participation:}

1. How has the community become involved in the ecotourism industry (individuals, group of individuals, the whole community)?

2. What level and degree of participation do the villagers have in the ecotourism industry?

3. Who makes the decision in local community participation project/process?

4. What are the goals and objectives of local community participation project/process?

5. Could you tell me the process of local community participation in the ecotourism industry?

6. Is there any other form of local community participation in other industry, for e.g. agriculture?

7. Could you tell me the process of local community participation in the other industry?

8. What are the success factors of local community participation in ecotourism industry?

9. What are the success factors of local community participation in the other industry

10. Is the local community participation in the ecotourism industry successful?

11. How would you compare the process of local community participation in the ecotourism industry and in other industry?

\footnotetext{
${ }^{16}$ Eco-practice: Practices that based on ecotourism concept, generally environmentally friendly and contribute to the well being of the local community.
} 


\title{
APPENDIX 3- INTERVIEW STRUCTURES FOR VILLAGE LEADERS 2
}

\author{
VICTORIA UNIVERSITY OF WELLINGTON \\ Te Whare Wananga o te Upoko o te Ika a Maui
}

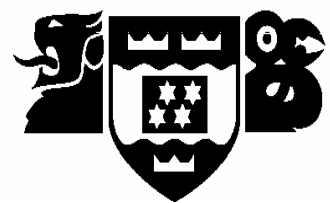

\section{ECOTOURISM AND LOCAL COMMUNITY PARTICIPATION}

The purpose of this interview is to find out the factors for ecotourism site and local community participation success in Sabah. The interview should take approximately 15 minutes. The information you provide will be used as part of a PhD research project being conducted by Hassanal Bagul and supervised by Prof. Doug Pearce, Professor of Tourism, Victoria Management School, Victoria University of Wellington, New Zealand. The information gathered will be used solely for academic purposes. Your cooperation would be greatly appreciated.

Respondents: Non-Formal Local Community Leaders (Headmaster/Principal of School, Imam)

\section{STRUCTURED INTERVIEW CHECKLIST}

\section{Profile:}

1. What is your role in the community?

2. How long have you been a Headmaster/Principal/Imam?

3. Are you actively involved in the development of this village? How?

\section{Clarifying Local Community Participation:}

1. How is the community involved in the ecotourism industry (individuals, group of individuals, the whole community)?

2. What level and degree of participation are the villagers involved in, in the ecotourism industry?

3. Who makes the decision in local community participation project/process?

4. What are the goals and objectives of local community participation project/process?

5. Could you tell me the process of local community participation in the ecotourism industry?

6. Is there any other form of local community participation in other industry, for e.g. agriculture?

7. Could you tell me the process of local community participation in the other industry? 
8. What are the success factors of local community participation in ecotourism industry?

9. What are the success factors of local community participation in the other industry

10. Is the local community participation in the ecotourism industry successful?

11. How would you compare the process of local community participation in the ecotourism industry and in other industry? 


\title{
APPENDIX 4 - INTERVIEW STRUCTURE FOR GOVERNMENT AND BUSINESS
}

\author{
VICTORIA UNIVERSITY OF WELLINGTON \\ Te Whare Wananga o te Upoko o te Ika a Maui
}

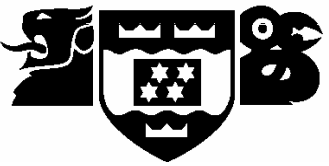

\section{ECOTOURISM AND LOCAL COMMUNITY PARTICIPATION}

\begin{abstract}
The purpose of this interview is to find out the factors for ecotourism site and local community participation success in Sabah. The interview should take approximately 30 minutes. The information you provide will be used as part of a PhD research project being conducted by Hassanal Bagul and supervised by Prof. Doug Pearce, Professor of Tourism, Victoria Management School, Victoria University of Wellington, New Zealand. The information gathered will be used solely for academic purposes. Your cooperation would be greatly appreciated.

Respondents: Sabah Tourism Promotion Corporation, Ministry of Tourism Development, Environment, Science and Technology of Sabah, Wildlife Department, Ecotourism Resort/Eco-Lodge Operators and Forestry Department
\end{abstract}

\section{STRUCTURED INTERVIEW CHECKLIST}

\section{Clarifying Ecotourism Sites:}

1. What is your understanding of ecotourism?

2. How did ecotourism start in village $\mathrm{X}$ (There are 13 villages in question)?

3. What types of tourism activities are available around village $\mathrm{X}$ ?

4. What types of tourism attractions are available around village $\mathrm{X}$ ?

5. Do the ecotourism sites around village $\mathrm{X}$ employ any eco-practice?

6. Is there any area around village $X$, which has a status of site protection?

7. Does the ecotourism site in village $\mathrm{X}$ label itself as ecotourism site?

8. Do you see any evidence of local community participation in the ecotourism industry in village $X$ ?

9. Are you involved in the process of local community participation?

10. How would you compare the local community participation in ecotourism at village $X$ with local community participation in other industry?

\section{Indicators for Local Community Participation Success:}

1. What is your understanding of success of local community particpation in ecotourism? 
2. What are the success/failure factors for the local community participation in ecotourism?

3. To what extent does the local community have control over the development process of ecotourism (Village 1-13)?

4. What is the monetary cost of local community participation and how important it is to the success of the local community participation process?

5. To what extent is the local community aware of the local community participation?

6. How important is time in terms of decision-making process?

7. What are the effects on the decision-making?

8. How independent are the local community in the development process of ecotourism?

9. How much dependency of the local community to the outsiders?

\section{Indicators for Ecotourism Site Success:}

1. What is your understanding on ecotourism site success?

2. What are the success/failure factors for an ecotourism site (Village 1-13)?

3. Has there been clear improvement in life and livelihood

4. Who is involved in the formulation of ecotourist venture?

5. Is there any 'Win-Win' situation where the locals and the tourist are satisfied?

6. Are there any positive experiences of the site?

7. Is there any positive image of the site?

8. Does the project promote conservation of natural resources?

9. Does the project provide financial gain for host country?

10. Does the project provide financial gain for local people? 


\title{
APPENDIX 5 - INTERVIEW STRUCTURE FOR NON GOVERNMENT ORGANIZATION
}

\author{
VICTORIA UNIVERSITY OF WELLINGTON \\ Te Whare Wananga o te Upoko o te Ika a Maui
}

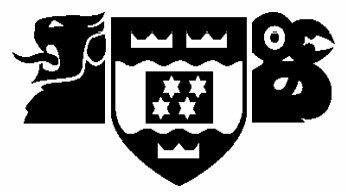

\section{ECOTOURISM AND LOCAL COMMUNITY PARTICIPATION}

\begin{abstract}
The purpose of this interview is to find out the factors for ecotourism site and local community participation success in Sabah. The interview should take approximately 30 minutes. The information you provide will be used as part of a PhD research project being conducted by Hassanal Bagul and supervised by Prof. Doug Pearce, Professor of Tourism, Victoria Management School, Victoria University of Wellington, New Zealand. The information gathered will be used solely for academic purposes. Your cooperation would be greatly appreciated.

Respondents: Local participation advocates (Government, the community, NGO's, business and individuals.
\end{abstract}

\section{STRUCTURED INTERVIEW CHECKLIST}

Profile:

1. Could you tell me about your organisation?

2. Why does your organisation advocates local community participation?

3. How does your organisation advocates local community participation?

4. What type of local community participation model does your organisation employed?

5. What are you current projects involved in local community participation in ecotourism?

\section{Clarifying Local Community Participation:}

1. How does the community involve in the ecotourism industry (individuals, group of individuals, the whole community)?

2. What level and degree of participation are the community involved in?

3. Who makes the decision?

4. What are the goals and objectives of local community participation project?

5. Could you tell me the process of local community participation in the ecotourism industry?

6. Is there any other form of local community participation in other industry, for e.g. agriculture? 
7. Could you tell me the process of local community participation in the other industry?

8. What are the success factors of local community participation in ecotourism industry?

9. What are the success factors of local community participation in the other industry?

10. Is the local community participation in the ecotourism industry successful?

11. How would you compare the process of local community participation in the ecotourism industry and in other industry? 


\title{
APPENDIX 6 - QUESTIONAIRE FOR TOURIST
}

\author{
VICTORIA UNIVERSITY OF WELLINGTON \\ Te Whare Wananga o te Upoko o te Ika a Maui
}

\section{Sor \\ ECOTOURISM AND LOCAL COMMUNITY PARTICIPATION}

The purpose of this survey is to find out the factors for ecotourism site and local community participation success in Sabah. The survey is designed to take approximately 10 minutes to complete. The information you provide will be used as part of a PhD research project being conducted by Hassanal Bagul and supervised by Prof. Doug Pearce, Professor of Tourism, Victoria Management School, Victoria University of Wellington, New Zealand. The information gathered will be used solely for academic purposes. Your participation in this survey implies consent for the information produced to be used in this way. Your cooperation would be greatly appreciated.

\section{YOUR PROFILE}

1. Sex

Please $\sqrt{ }$ where applicable

\begin{tabular}{|l|l|}
\hline Male & \\
\hline Female & \\
\hline
\end{tabular}

\section{Age}

Please $\sqrt{ }$ where applicable

\begin{tabular}{|l|l|}
\hline$<20$ Years Old & \\
\hline $21-30$ Years Old & \\
\hline $31-40$ Years Old & \\
\hline $41-50$ Years Old & \\
\hline$>50$ Years Old & \\
\hline
\end{tabular}

\section{Education}

Please $\sqrt{ }$ where applicable

\begin{tabular}{|l|l|}
\hline Primary School & \\
\hline High School & \\
\hline University/College & \\
\hline Graduate School & \\
\hline
\end{tabular}

\section{Where do you come from?}

5. How did you come to this site?

Please $\sqrt{ }$ where applicable

\begin{tabular}{|l|l|}
\hline Tour Packages & \\
\hline Independent & \\
\hline Others. Please specify? & \\
\hline
\end{tabular}

\section{ECOTOURISM SITE}

1. What are the attractions of this area?

\begin{tabular}{|l|l|}
\hline (i) & \\
\hline (iii) & (iv) \\
\hline (v) & (vi) \\
\hline
\end{tabular}

2. How would you rate the image of this area before you come here?

Please $\sqrt{ }$ where applicable

\begin{tabular}{|c|c|c|c|c|}
\hline Excellent & $\begin{array}{c}\text { Above } \\
\text { Average }\end{array}$ & Average & $\begin{array}{c}\text { Below } \\
\text { Average }\end{array}$ & Very Poor \\
\hline & & & & \\
\hline
\end{tabular}

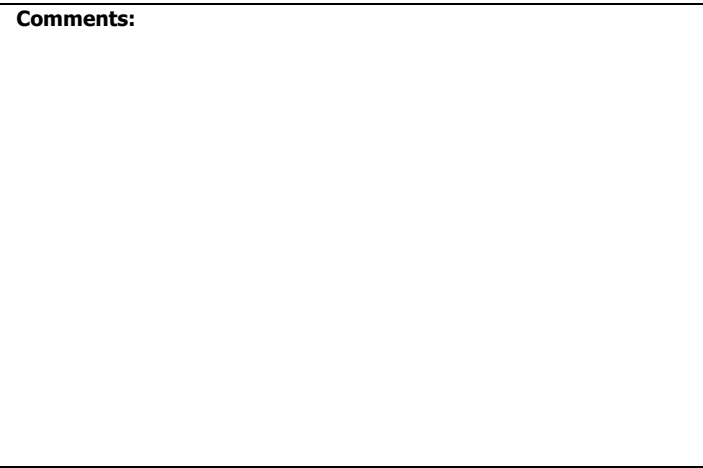

3. How would you rate the image of this area after now?

Please $\sqrt{ }$ where applicable

\begin{tabular}{|c|c|c|c|c|}
\hline Excellent & $\begin{array}{c}\text { Above } \\
\text { Average }\end{array}$ & Average & $\begin{array}{c}\text { Below } \\
\text { Average }\end{array}$ & Very Poor \\
\hline & & & & \\
\hline
\end{tabular}

Comments: 
4. How would you rate your experience in this area now?

Please $\sqrt{ }$ where applicable

\begin{tabular}{|c|c|c|c|c|}
\hline Excellent & $\begin{array}{c}\text { Above } \\
\text { Average }\end{array}$ & Average & $\begin{array}{c}\text { Below } \\
\text { Average }\end{array}$ & Very Poor \\
\hline & & & & \\
\hline
\end{tabular}

Comments:

\section{Do you think this site:}

Please $\sqrt{ }$ where applicable

\begin{tabular}{|l|l|l|}
\hline Item: & Yes & No \\
\hline $\begin{array}{l}\text { (i) Promote conservation of natural } \\
\text { resources? }\end{array}$ & & \\
\hline $\begin{array}{l}\text { (ii) Provide financial gain for the host } \\
\text { country? }\end{array}$ & & \\
\hline $\begin{array}{l}\text { (iii) Provide financial gain for the local } \\
\text { people? }\end{array}$ & & \\
\hline
\end{tabular}

Comments:

6. How important (i), (ii) and (iii) are to you in your experience?

Please $\sqrt{ }$ where applicable

\begin{tabular}{|l|c|l|l|c|c|}
\hline Item & $\begin{array}{c}\text { Very } \\
\text { Important }\end{array}$ & Important & $\begin{array}{c}\text { Moderately } \\
\text { Important }\end{array}$ & $\begin{array}{c}\text { Of Little } \\
\text { Importance }\end{array}$ & $\begin{array}{c}\text { Un- } \\
\text { important }\end{array}$ \\
\hline (i) & & & & & \\
\hline (ii) & & & & & \\
\hline (iii) & & & & & \\
\hline
\end{tabular}

Comments:
7. What elements do you think indicate the success of an ecotourism site and how would you rate them for this site?

Please $\sqrt{ }$ where applicable

\begin{tabular}{|l|l|l|l|l|l|}
\hline Item: & Excellent & Good & Undecided & Poor & $\begin{array}{c}\text { Very } \\
\text { Poor }\end{array}$ \\
\hline & & & & & \\
\hline & & & & & \\
\hline & & & & & \\
\hline & & & & & \\
\hline & & & & & \\
\hline & & & & & \\
\hline
\end{tabular}

Comments:

\section{COMMUNITY}

1. How do you rate the local community hospitality?

Please $\sqrt{ }$ where applicable

\begin{tabular}{|c|c|c|c|c|}
\hline Excellent & $\begin{array}{c}\text { Above } \\
\text { Average }\end{array}$ & Average & $\begin{array}{c}\text { Below } \\
\text { Average }\end{array}$ & Very Poor \\
\hline & & & & \\
\hline
\end{tabular}

\section{Comments:}

2. How do you think they benefit from ecotourism?

\begin{tabular}{|l|l|}
\hline (i) & \\
\hline (iii) & (iv) \\
\hline (v) & (vi) \\
\hline
\end{tabular}

3. Do you have a prior knowledge of the local community (own reading, briefing by tour operator etc.)?

4. Did you do any activity involving local community?

4.1 If yes, in what way/level/how long? 
4.2 If no, go to the next question

5. Do you see any evidence that local people are involved in ecotourism project?

5.1 If yes, in what way/level?

5.2 If no, go to the next question

6. Do you think it is important for local people to involve in ecotourism project?

\subsection{If yes, in what way/level?}

6.2 If no, go to the next question

7. Is your experience here enhanced knowing that the local people are involved in ecotourism project?

Please $\sqrt{ }$ where applicable

\begin{tabular}{|l|l|l|}
\hline Yes & & Why? \\
\hline No & & Why? \\
& & \\
\hline
\end{tabular}

8. Would you come again to visit this site?

Please $\sqrt{ }$ where applicable

\begin{tabular}{|l|l|l|}
\hline Yes & & Why? \\
\hline
\end{tabular}

\begin{tabular}{|l|l|l|}
\hline & & \\
\hline No & & Why? \\
& & \\
\hline
\end{tabular}

\section{SUCCESS AND FAILURE}

1. How do you define success for an ecotourism site? Comments:

2. Do you think this site is successful? Why?

Comments:

3. How do you define success in local community participation?

Comments: site is successful? Why?

Comments:

Thank you for your time and your valuable input! 


\section{APPENDIX 7 - INFORMATION SHEET}

VICTORIA UNIVERSITY OF WELLINGTON

Te Whare Wananga o te Upoko o te Ika a Maui

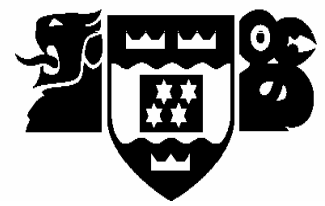

\section{ECOTOURISM AND LOCAL COMMUNITY PARTICIPATION}

\section{INFORMATION SHEET}

This research project seeks to find out the factors for ecotourism site and local community participation success in Sabah. The project is funded by Victoria Management School and Public Service Department of Malaysia. The investigator is Hassanal Bagul a PhD student at Victoria Management School and the supervisor is Prof. Doug Pearce, also from Victoria Management School. All information provided will be accessed only by members (investigator and supervisor) of the research project, stored securely and used only for the purposes of this project. The result of this research will be reported in academic publications and at academic workshops and conferences. While the confidentiality of individual i.e. name will be ensured, consent is sought to attribute information to the organisations they represent. All data collected will be destroyed two years from the completion of the project. For more information about this project contact Professor Doug Pearce at Victoria Management School, Victoria University of Wellington, P.O Box 600, Wellington, New Zealand; Tel: 00644 4635715; E-Mail: douglas.pearce@vuw.ac.nz 


\section{APPENDIX 8 - CONSENT FORM}

VICTORIA UNIVERSITY OF WELLINGTON

Te Whare Wananga o te Upoko o te Ika a Maui

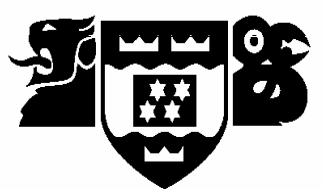

\section{ECOTOURISM AND LOCAL COMMUNITY PARTICIPATION}

\section{CONSENT FORM}

I agree to provide information under these conditions and allow/do not allow the attribution of information to my organisation in the reporting of this research. I understand that I may withdraw from participating in this project at any stage without any penalty nor requirement to provide any reason.

I would/would not like to receive a summary of the results of this project.

Name:

Position:

Organisation:

Signed:

Date: 


\title{
APPENDIX 9 - INFORMATION SHEET (MALAY VERSION)
}

\author{
VICTORIA UNIVERSITY OF WELLINGTON \\ Te Whare Wananga o te Upoko o te Ika a Maui
}

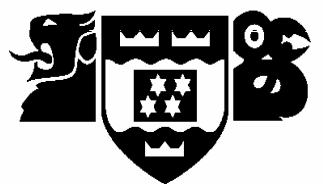

PROJEK PENYELIDIKAN

\section{PELANCONGAN EKO DAN PENGLIBATAN KOMUNITI TEMPATAN DI SABAH}

\begin{abstract}
MAKLUMAT AM
Projek penyelidikan ini bertujuan untuk mencari factor-faktor kejayaan dalam penglibatan komuniti tempatan dan projek pelancongan eko di Sabah. Projek ini dibiayai oleh Sekolah Pengurusan Victoria (Victoria Management School), Victoria University of Wellington, New Zealand dan Jabatan Perkhidmatan Awam Malaysia/Universiti Malaysia Sabah. Penyelidik untuk projek ini ialah Awangku Hassanal Bahar bin Pengiran Bagul, pelajar Doktor Falsafah (PhD) di Sekolah Pengurusan Victoria dan diselia oleh Prof. Doug Pearce, juga dari Sekolah Pengurusan Victoria. Segala maklumat yang dikutip dalam projek Penyelidikan ini hanya boleh diakses oleh ahli-ahli projek Penyelidikan (penyelidik dan penyelia) dan akan digunakan untuk projek penyelidikan ini sahaja. Data-data dan maklumat dari penyelidikan ini akan digunakan dalam penerbitan, bengkel dan konferen akademik. Identiti responden tidak akan dinyatakan dan kebenaran untuk menemubual akan diminta terlebih dahulu. Semua data yang dikutip dari penyelidikan ini akan dimusnahkan dalam masa dua tahun dari tarikh tamat projek penyelidikan ini. Untuk maklumat lebih lanjut lagi, sila hubungi Professor Doug Pearce di Victoria Management School, Victoria University of Wellington, P.O Box 600, Wellington, New Zealand; Tel: 00644 4635715; E-Mel: douglas.pearce@vuw.ac.nz
\end{abstract}




\title{
APPENDIX 10 - CONSENT FORM (MALAY VERSION)
}

\author{
VICTORIA UNIVERSITY OF WELLINGTON
}

Te Whare Wananga o te Upoko o te Ika a Maui

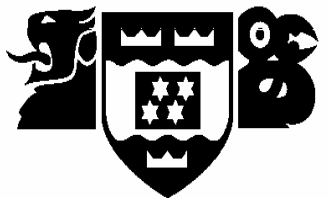

\section{PROJEK PENYELIDIKAN}

\section{PELANCONGAN EKO DAN PENGLIBATAN KOMUNITI TEMPATAN DI SABAH}

\author{
BORANG KEBENARAN UNTUK MENEMUBUAL
}

Saya bersetuju untuk memberi maklumat seperti yang ternyata di seksyen Maklumat Am dan mengizinkan/tidak mengizinkan* maklumat diimplikasikan kepada organisasi saya dalam laporan penyelidikan. Saya bebas untuk menarik diri dari temu bual ini pada bila-bila masa yang saya mahu tanpa penalti dan saya tidak perlu menyatakan sebab-sebab penarikan tersebut.

Saya mahu/tidak mahu* untuk menerima ringkasan penemuan projek ini.

Nama:

Jawatan:

Organisasi:

Tandatangan:

Tarikh:

*Sila potong yang tidak berkenaan 